DENNIS WILFREDO ROLDÁN SILVA

\title{
ANÁLISE DE FALHAS E SUAS CONSEQUÊNCIAS NA OPERAÇÃO DE NAVIOS TRANSPORTADORES DE GÁS NATURAL LIQUEFEITO (GNL)
}

Dissertação apresentada à Escola

Politécnica da Universidade de São Paulo como requisito para obtenção de Título de Mestre em Engenharia

São Paulo

2013 


\section{ANÁLISE DE FALHAS E SUAS CONSEQUÊNCIAS NA OPERAÇÃO DE NAVIOS TRANSPORTADORES DE GÁS NATURAL LIQUEFEITO (GNL)}

Dissertação apresentada à Escola

Politécnica da Universidade de São Paulo como requisito para obtenção do Título de Mestre em Engenharia.

Área de Concentração:

Engenharia Mecânica de Projetos e Fabricação

Orientador: Professor Dr.

Gilberto Francisco Martha de Souza

São Paulo 
Este exemplar foi revisado e alterado em relação à versão original, sob responsabilidade única do autor e com a anuência de seu orientador.

São Paulo, 25 de janeiro de 2013.

Assinatura do autor

Assinatura do orientador

FICHA CATALOGRÁFICA

Roldán Silva, Dennis Wilfredo

Análise de falhas e suas consequências na operação de navios transportadores de gás natural liquefeito / D.W. Roldán Silva. -- ed.rev. -- São Paulo, 2013.

206 p.

Dissertação (Mestrado) - Escola Politécnica da Universidade de São Paulo. Departamento de Engenharia Mecatrônica e de Sistemas Mecânicos.

1. Análise de risco 2. Gás natural 3. Navio tanque I. Universidade de São Paulo. Escola Politécnica. Departamento de Engenharia Mecatrônica e de Sistemas Mecânicos II. t. 


\section{DEDICATÓRIA}

A Deus, à minha família e especialmente aos meus sobrinhos Mauricio, Denisse e Bianca. 


\section{AGRADECIMENTOS}

Em primeiro lugar agradeço a Deus pela saúde, proteção e força durante todas as etapas percorridas da minha vida;

À minha família inteira, porque sempre estiveram comigo e espero de alguma maneira retribuir esse carinho com a realização deste trabalho;

Aos meus pais, Wilfredo e Tania, que sempre acreditaram em mim, agradeço pelo apoio, carinho e amor que me dedicam, e pela força que sempre me dão quando mais preciso;

À minha irmã, Yeliza, por estar sempre ao meu lado nos momentos bons e ruins;

À minha querida esposa, Solanch, pelo amor, e especialmente pelo entendimento e compreensão da decisão de ficarmos longe, certo que foi uma decisão muito difícil;

Aos meus avós, Andrés e Lelis, que sempre me confortaram mostrando que o tempo passaria e que brevemente estaria de volta à companhia deles, podendo ao voltar, dar-lhes um forte abraço;

Ao Prof. Dr. Gilberto Francisco Martha de Souza, pela oportunidade de ser seu orientando, e pela confiança depositada em mim;

Ao Programa de Pós-Graduação em Engenharia Mecânica pela oportunidade de integrar o grupo de mestrado. À CAPES pela bolsa de estudos concedida durante parte do desenvolvimento deste trabalho;

Aos meus amigos Erick Vargas Garcia e Erick Portugal Hidalgo, que me ajudaram em 2009 quando cheguei ao Brasil pela primeira vez, grandes amizades que perduram;

Aos meus colegas do Laboratório de Confiabilidade da Escola Politécnica, Erick Portugal Hidalgo, Érico Pessoa Felix, Camila Mancini, Fernando Guevara Carazas, Carmen Patiño Rodríguez e Marjorie Belinelli, que sempre se mostraram prestativos a me ajudar quando precisava, e pelos quais sinto apreço e gratidão;

E a todas as pessoas que de alguma maneira contribuíram para a realização e conclusão deste trabalho. 


\section{RESUMO}

No Brasil a geração de energia elétrica é predominantemente baseada no uso de fontes renováveis e obtida por meio de centrais hidroelétricas. Ainda assim é necessária a diversificação das fontes de suprimento de energia para a geração de eletricidade quando o recurso hídrico for escasso. Uma alternativa é utilizar gás natural como combustível para as usinas termoelétricas, como vem sendo introduzido na matriz energética de outros países, permitindo a diversificação das fontes energéticas dos mesmos.

A indústria do gás natural, assim como outras atividades industriais, não está isenta de acidentes que podem provocar graves consequências à integridade das pessoas e das propriedades. Por este motivo, é necessário desenvolver estudos para determinar quais são as possíveis causas que poderiam ocasionar estes acidentes, e quais são os possíveis cenários associados a estas falhas especificamente na área do transporte de GNL (Gás Natural Liquefeito). É neste contexto que este trabalho de pesquisa tem por objetivo desenvolver um método, baseado nas técnicas de análise de risco, que permita identificar os principais cenários de falha associados à ocorrência de um vazamento de GNL ou de boil-off durante as operações de carga e/ou descarga de navios. Neste cenário, considera-se a presença das barreiras de proteção destinadas a conter esse evento iniciador de perigo no sistema de carga e descarga do navio transportador de GNL, quando o navio está atracado no porto. Adicionalmente à apresentação do método, e como resultado do trabalho, são identificados quais os componentes que pertencem ao circuito de carga e descarga de GNL, e que tenham uma categoria de risco denominada como Crítica (C), Moderada (M) ou Não Crítica (NC).

Finalmente, a implantação do método propõe medidas que ajudam a diminuir o nível de risco associado aos componentes denominados críticos, a fim de garantir uma operação segura e livre de acidentes que ponham em risco a integridade dos operadores, dos equipamentos e do ambiente.

Palavras-chave: análise de risco, GNL (Gás Natural Liquefeito), sistema de carga e descarga, navio transportador de GNL. 


\begin{abstract}
Although the electricity generation in Brazil is predominantly based on renewable sources and obtained by means of hydroelectric power plants, it is still necessary to diversify sources of energy supply to generate electricity when the water resource is scarce. An alternative is the use natural gas as fuel for power plants, once it has been introduced in the energy matrix of other countries, allowing the diversification of their energy sources.

The natural gas industry, as well as other industrial activities, is not free from accidents, which can cause serious consequences to the integrity of people and properties. For this reason, it is necessary to develop studies to determine what are the possible causes that could lead to serious accidents and what are the possible scenarios of these faults specifically in the area of LNG (Liquefied Natural Gas) transportation. In this context, this research aims to develop a method based on risk analysis concepts which identifies the main failure scenarios given the occurrence of LNG or boil-off leakage during ship loading and unloading operations, considering the presence of containment barriers designed to hold this hazard initiator event in loading and unloading system of the LNG carrier when the ship is in harbor. In addition to the method presentation this research identifies which are the components of LNG loading and unloading circuit, which have a risk category classified as Critical (C), Moderate (M) and NonCritical (NC).
\end{abstract}

Finally, the method implementation allows the proposal of safety and maintenance measures to help reducing the risk level in order to ensure safe operation, free of accidents that endanger the integrity of the operators, the equipment and the environment.

Keywords: risk analysis, LNG (Liquefied Natural Gas), loading and unloading system, LNG carrier. 


\section{LISTA DE ILUSTRAÇÕES}

Figura 1.1 - Oferta Interna de Energia Elétrica por fonte para o ano 2009 (MME, 2010) 2

Figura 1.2 - Reservas provadas dos países da América do Sul em Trilhões de $\mathrm{m}^{3}$ (BP, 2010; PETROTECNIA, 2009)

Figura 2.1 - Limites mínimo e máximo de inflamabilidade para o metano (MICHOT, 2003; ANP, 2010).

Figura 2.2 - Nuvem de vapor de GNL criada controladamente para ver o seu comportamento (GIIGNL, 2008). 12

Figura 2.3 - Comportamento da nuvem de metano (RISKNOLOGY, 2006). 12

Figura 2.4 - Cadeia de valor completa do gás natural (ANP, 2010) 14

Figura 2.5 - Custos aproximados da cadeia de valor do gás natural (DOE, 2005;

EIA, 2003)

Figura 2.6 - Crescimento da frota de navios transportadores de GNL (VANEM et al., 2008)..... 16

Figura 2.7 - Tanque de tipo prismático (LAMB, 2004; JONES E TVEITNES, 2003) 20

Figura 2.8 - Tanque do tipo Moss (LAMB, 2004; MICHOT, 2003) 21

Figura 2.9 - Barreira parcial no tanque tipo Moss (WILSON, 1974) .......................... 22

Figura 2.10 - Tanque do tipo membrana GTT Mark III (LAMB, 2004; ABS, 2008) ... 24

Figura 2.11 - Detalhe da barreira secundária do tanque membrana GTT Mark III (ABS, 2008) 24

Figura 2.12 - Tanque do tipo membrana GTT No 96 (ABS, 2008; LAMB, 2004) ....... 25

Figura 2.13 - Detalhes do tanque de tipo membrana GTT No 96 (ABS, 2008;

LAMB, 2004) 26

Figura 2.14 - Comparação das mortalidades de acordo com o setor industrial (SOVACOOL, 2008)

Figura 2.15 - Comparação das fatalidades na indústria do gás natural (SOVACOOL, 2008)

Figura 2.16 - Comportamento do aço de baixa resistência (SHIGLEY, 2008)

Figura 2.17 - Bomba criogênica do tipo submersa (KARASSIK, 2001; WAVESPEC, 2006). 
Figura 2.18 - Válvulas criogênicas instaladas no navio transportador de GNL (SIGTTO, 2002)

Figura 2.19 - Braços criogênicos de carga/descarga de GNL e boil-off (ALVAREZ, 2009)

Figura 2.20 - O navio transportador de GNL do tipo Moss atracado no porto (MICHOT, 2003)

Figura 2.21 - Etapa de resfriamento dos braços criogênicos (CALIFORNIA SENATE OFFICE OF RESEARCH, 2008) 36

Figura 2.22 - Processo de carga do navio transportador de GNL (ICS, 1995)............. 37

Figura 2.23 - Esquema geralizado do sistema de carga de GNL e do boil-off .............. 38

Figura 2.24 - Processo de descarga do navio transportador de GNL (ENAGAS, 2006)

Figura 2.25 - Esquema geralizado do sistema de descarga de GNL e do boil-off ......... 40

Figura 3.1 - Tipos de consequências de ocorrência (CCPS-AIChE, 2008)................... 44

Figura 3.2 - Árvore de falhas da perda do sistema de propulsão de um navio (ABS, 2000) 50

Figura 3.3 - Árvore de falhas equivalente com os respectivos cortes mínimos ............ 51

Figura 3.4 - Diagrama causa-consequência (ERICSON, 2005; IEC, 2009)................. 52

Figura 4.1 - Representação do método de análise.........................................................56

Figura 4.2 - Representação de uma árvore funcional (SOUZA, 2010)..........................57

Figura 5.1 - Circuitos utilizados durante as operações de carga e descarga de GNL do navio transportador

Figura 5.2 - Circuito de GNL e boil-off no navio transportador durante a operação de carga do GNL 68

Figura 5.3 - Circuito de GNL e boil-off no navio transportador durante a operação de descarga do GNL

Figura 5.4 - Bomba criogênica submersa utilizada para efetuar a descarga do GNL.... 79 Figura 5.5 - a) Atuador do tipo pistão para as válvulas borboleta e b) Atuador do tipo palhetas para a válvula globo (PARKER, 2004) .............................................. 80

Figura 5.6 - Válvulas de alívio dos tanques de armazenagem de GNL ...................... 81

Figura 5.7 - Esquema geral do tanque de armazenamento .................................. 83

Figura 5.8 - Tanque de armazenamento tipo membrana GTT Mark III ..................... 83

Figura 5.9 - Compressor centrífugo de uma etapa de compressão (GE, 2010) ............. 85 
Figura 5.10 - Árvore funcional do sistema de carga e descarga durante a carga do GNL

Figura 5.11 - Árvore funcional do sistema de carga e descarga durante a descarga do GNL

Figura 5.12 - Árvore funcional para o circuito de boil-off durante a carga/descarga do GNL

Figura 5.13 - Diagrama Causa-Consequência para o vazamento de metano durante a operação de carga ou descarga de GNL 95

Figura 5.14 - Sala de Controle da Carga .96

Figura 5.15 - Esquema de uma UPS - Unidade de Alimentação Contínua (NASIRI, 2007)

Figura 5.16 - Unidades de geração e transformação de energia elétrica do navio sem as UPS (Unidade de Alimentação Contínua)

Figura 5.17 - Árvore de falhas para o evento topo "Falta de energia elétrica AC (230V) na Sala de Controle da Carga" 100

Figura 5.18 - Diagrama de blocos do sistema de alimentação de energia elétrica para a Sala de Controle da Carga com 230V AC 101

Figura 5.19 - Diagrama de blocos para a Linha 1 102

Figura 5.20 - Modelo de Markov para a Geração de energia elétrica na Linha 1 que corresponde ao sistema de abastecimento de energia principal. 102

Figura 5.21 - Diagrama de blocos para a Linha 2. 103

Figura 5.22 - Modelo de Markov para a Linha 1 e a Linha 2 que corresponde ao sistema de abastecimento de energia principal junto com o sistema de emergência.... 104 Figura 5.23 - Diagrama de blocos para a Linha 3. 104 Figura 5.24 - Curva da confiabilidade do fornecimento de energia elétrica na Sala de Controle da Carga 105

Figura 5.25 - Esquema geral dos componentes do sistema de amostragem de gás (CONSILIUM, 2012a)

Figura 5.26 - Detalhe do gabinete do sistema de amostragem de gás (CONSILIUM, 2012a)

Figura 5.27 - Detalhe dos pontos de amostragem no tanque de armazenamento e na praça de máquinas. 108

Figura 5.28 - Pontos de amostragem espalhados no navio para detectar a presença de gás metano 
Figura 5.29 - Unidade de detecção GS3000 (CONSILIUM, 2012b).

Figura 5.30 - Sistema de amostragem SW2020 junto com o sistema de detecção GS3000

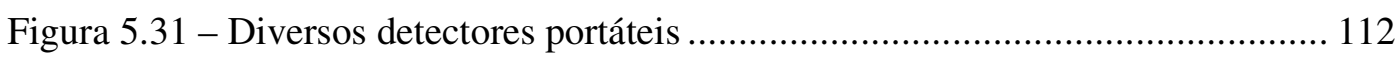

Figura 5.32 - Curva da confiabilidade do sistema de amostragem de gás ................. 113

Figura 5.33 - Gabinete das válvulas solenoides das unidades atuadoras (SCANA,

Figura 5.34 - Bomba manual de emergência......................................................... 116

Figura 5.35 - Sistema hidráulico de controle das válvulas ..................................... 117

Figura 5.36 - Árvore de falhas para o evento topo "Falha no fechamento das válvulas hidráulicas pela atuação do ESD (Paralisação de Emergência)”.

Figura 5.37 - Árvore de falhas renomeada para o evento topo "Falha no fechamento das válvulas hidráulicas pela atuação do ESD (Paralisação de Emergência)”. 120

Figura 5.38 - Árvore de falhas reduzida para a obtenção dos cortes mínimos

Figura 5.39 - Curva da confiabilidade do sistema hidráulico de controle das válvulas do ESD 125

Figura 5.40 - Diagrama Causa-Consequência com os valores da probabilidade de ocorrência para a avaliação quantitativa dos cenários de falha. 


\section{LISTA DE TABELAS}

Tabela 2.1 - Componentes do GNL (GASNET, 2011; MOKHATAB et al., 2006;

SPEIGHT, 2002)......

Tabela 2.2 - Propriedades do metano (GAMA GASES, 2011)

Tabela 2.3- Tipos de navios encarregados do transporte de substâncias químicas

líquidas (LAMB, 2004; IGC IMO, 2005)

Tabela 2.4 - Características dos navios que transportam GNL (LAMB, 2004)

Tabela 3.1 - Valores de frequência de ocorrência (IMO, 2002) .................................. 43

Tabela 3.2 - Valores de consequência de ocorrência (IMO, 2002).............................. 44

Tabela 3.3 - Matriz de risco de acordo com a IMO (IMO, 2002) ..............................45

Tabela 3.4 - Categoria de Risco (SMITH, 2001) .................................................... 45

Tabela 3.5 - Tabela para a aplicação da APP adaptada (ERICSON, 2005) ................. 47

Tabela 3.6 - Símbolos dos portões lógicos (KECECIOGLU, 1991) ........................... 49

Tabela 3.7 - Símbolos dos portões de eventos (KECECIOGLU, 1991) ....................... 50

Tabela 4.1 - Categoria de frequência de ocorrência (PETROBRAS, 2004) ................. 61

Tabela 4.2 - Categoria de frequência em termos da probabilidade de ocorrência......... 62

Tabela 4.3 - Categorias de severidade das consequências dos cenários (PETROBRAS, 2005).

Tabela 4.4 - Categorias de risco em função da frequência e da consequência de

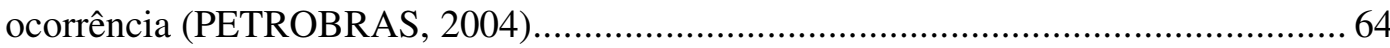

Tabela 5.1 - Principais características do navio transportador de GNL sob análise...... 66

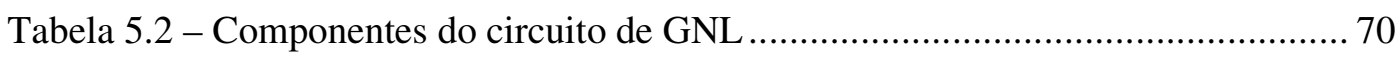

Tabela 5.3 - Componentes do circuito de boil-off ................................................ 70

Tabela 5.4 - Posições das válvulas de carga nos tanques durante a carga do GNL....... 72

Tabela 5.5 - Posições das válvulas no manifold de bombordo durante a carga do

GNL

Tabela 5.6 - Posições das válvulas durante a descarga do GNL .................................. 75

Tabela 5.7 - Posições das válvulas que permitem o fluxo do boil-off durante a carga

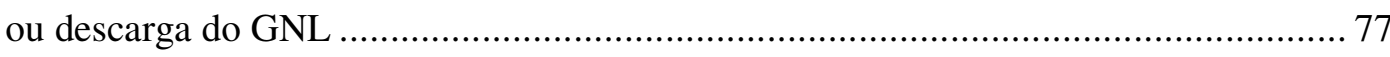

Tabela 5.8 - Principais características das bombas criogênicas................................ 79

Tabela 5.9 - Válvulas do sistema de carga e descarga do GNL e do boil-off de

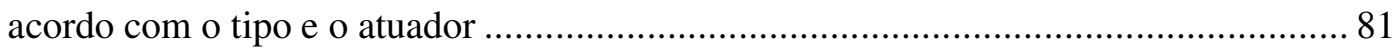

Tabela 5.10 - Válvulas que pertencem ao sistema ESD .......................................... 81 
Tabela 5.11 - Tipo de válvulas de alívio para os tanques de armazenamento de GNL

Tabela 5.12 - Válvulas de alívio na tubulação principal de GNL.............................. 82

Tabela 5.13 - Válvulas de alívio das tubulações secundárias nos tanques.................... 82

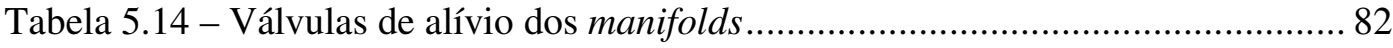

Tabela 5.15 - Principais características das tubulações de GNL e de boil-off................ 84

Tabela 5.16 - Características dos compressores de alta e baixa vazão ........................ 86

Tabela 5.17 - Identificação dos eventos de perigo numa frota de 12 navios transportadores de GNL (SKRAMSTAD et al., 2000)........................................... 91

Tabela 5.18 - Taxa de falha dos componentes do sistema de alimentação de energia elétrica do navio

Tabela 5.19 - Valores da confiabilidade e da probabilidade de falha do sistema de abastecimento de energia elétrica ao longo de cinco anos de operação ...................... 105

Tabela 5.20 - Taxa de falha do sistema de amostragem de gás

Tabela 5.21 - Valores da confiabilidade e da probabilidade de falha ao longo de cinco anos de operação

Tabela 5.22 - Taxa de falha para os componentes do sistema hidráulico de controle das válvulas

Tabela 5.23 - Valores da confiabilidade e da probabilidade de falha para o sistema hidráulico de controle das válvulas do ESD ao longo de cinco anos de operação ....... 125 Tabela 5.24 - Probabilidade de ocorrência e a sua consequência nos componentes do sistema de carga e descarga do GNL

Tabela 5.25 - Probabilidade de ocorrência e a sua consequência nos componentes do sistema de descarga do boil-off.

Tabela 5.26 - Matriz de risco para os componentes do sistema de carga e descarga do GNL

Tabela 5.27 - Matriz de risco para os componentes do sistema de descarga do boiloff 


\section{LISTA DE SIGLAS}

$\begin{array}{ll}\text { GNL } & \text { Gás Natural Liquefeito (Liquefied Natural Gas) } \\ \text { BOG } & \text { Boil-off gas } \\ \text { ANP } & \text { Agência Nacional do Petróleo } \\ \text { PPT } & \text { Programa Prioritário de Termoeletricidade } \\ \text { UTE } & \text { Usina Termoelétrica } \\ \text { APP } & \text { Análise Preliminar de Perigos (Preliminary Hazard Analysis) } \\ \text { DCC } & \text { Diagrama Causa-Consequência (Cause-Consequence Diagram) } \\ \text { FTA } & \text { Análise de Árvore de Falhas (Failure Tree Analysis) } \\ \text { FMEA } & \text { Análise de Modos e Efeitos de falhas (Failure Modes and Effect Analysis) } \\ \text { HAZOP } & \text { Estudo de Perigos de Operação (Hazard and Operability Studies) } \\ \text { DNV } & \text { Det Norske Veritas } \\ \text { ABS } & \text { American Bureau of Shipping } \\ \text { RPT } & \text { Transição Rápida de Fase (Rapid Phase Transition) } \\ \text { IMO } & \text { International Maritime Organization } \\ \text { ESD } & \text { Sistema de Paralisação de Emergência (Emergency Shut Down) } \\ \text { FSA } & \text { Formal Safety Assessment } \\ \text { DGS } & \text { Sala de Controle da Carga } \\ \text { DGidade de Alimentação Continua (Uninterrupted Power Supply) } \\ \text { Derador de Emergência }\end{array}$




\section{LISTA DE SÍMBOLOS}

$\begin{array}{ll}f_{i} & \text { Frequência de ocorrência do evento } i \\ c_{i} & \text { Consequência ou severidade de ocorrência do evento } i \\ p_{i} & \text { Probabilidade de ocorrência do evento } i \\ \lambda & \text { Taxa de falha constante no tempo } \\ n & \text { Número de ocorrências do evento em um determinado intervalo de tempo } \\ t & \text { Intervalo de tempo } \\ C & \text { Controlador eletrônico } \\ R & \text { Confiabilidade } \\ p f & \text { Probabilidade de falha }\end{array}$




\section{SUMÁRIO}

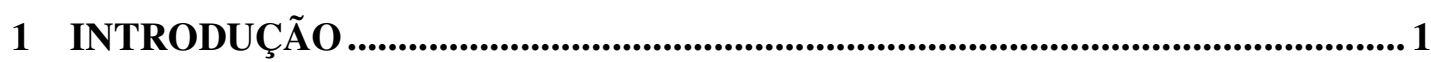

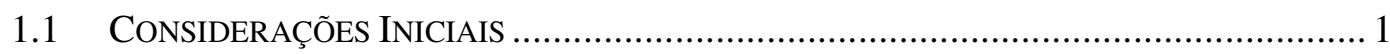

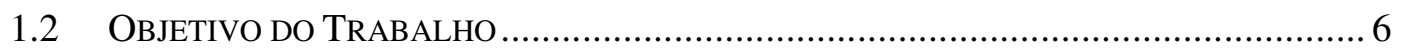

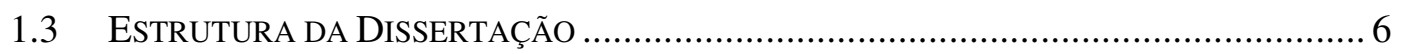

2 SISTEMA DE CARGA E DESCARGA DE GNL DO NAVIO TRANSPORTADOR DE GNL......................................................................................... 8

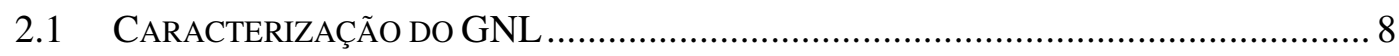

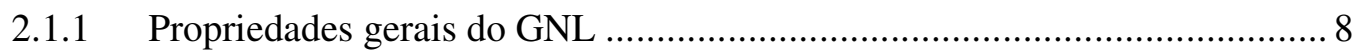

2.1.2 Propriedades de flamabilidade do GNL ................................................... 10

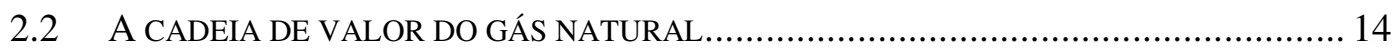

2.3 TIPOS DE NAVIOS UTILIZADOS NO TRANSPORTE DE GNL ..................................... 16

2.3.1 Navios do tipo prismático ..................................................................... 20

2.3.2 Navios do tipo Moss ou esféricos ............................................................. 21

2.3.3 Navios do tipo membrana GTT MARK III................................................ 22

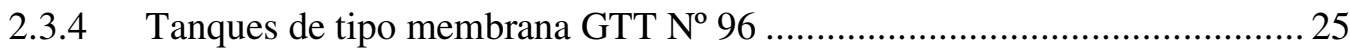

2.4 ACIDENTES ENVOLVENDO NAVIOS TRANSPORTADORES DE GNL OCORRIDOS QUANDO O NAVIO SE ENCONTRA ANCORADO NO TERMINAL ……………………………...... 26

2.5 Componentes DO Sistema DE CARGA E DESCARGa dos NAVIOS

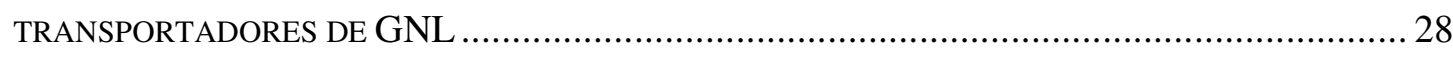

2.5.1 Tubulações do sistema de carga e descarga de GNL ................................... 30

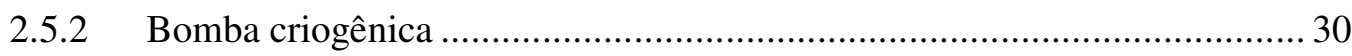

2.5.3 Sistema de paralisação de emergência ESD (Emergency Shut-Down)........ 31

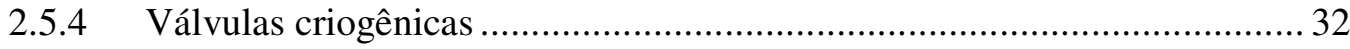

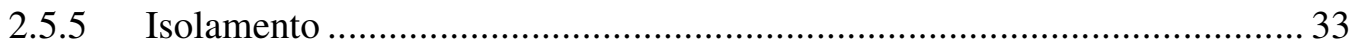

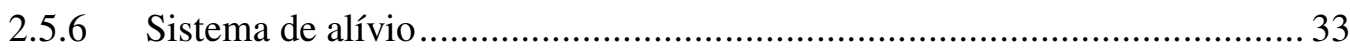

2.5.7 Braços criogênicos de conexão porto/navio .................................................. 34

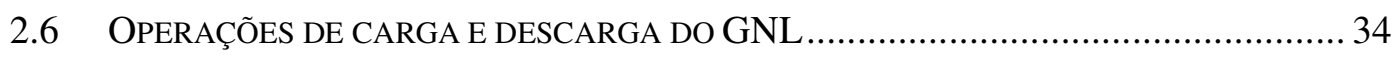

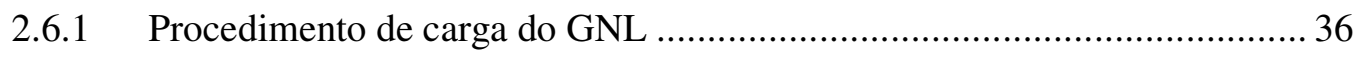

2.6.2 Procedimento de descarga do GNL …………........................................ 38

3 CONCEITOS DE RISCO ........................................................................................ 41 


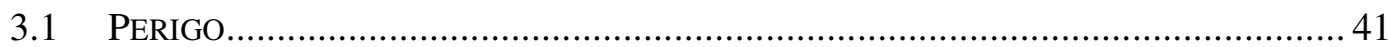

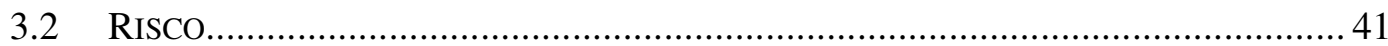

3.2.1 Frequência de Ocorrência......................................................................... 42

3.2.2 Consequência da Ocorrência ..................................................................... 43

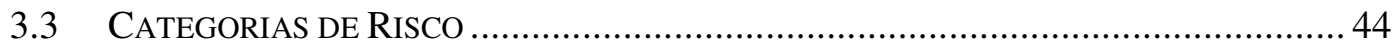

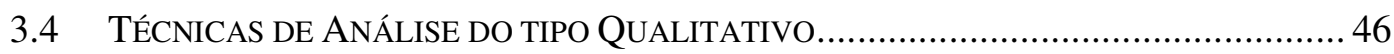

3.4.1 Análise Preliminar de Perigos (PHA - Preliminary Hazard Analysis) ....... 47

3.5 TÉCNICAS DE ANÁLISE DO TIPO QuANTITATIVO ……………………………...... 48

3.5.1 Análise de Árvore de Falhas (FTA - Failure Tree Analysis) ....................... 48

3.5.2 Diagrama Causa-Consequência DCC (CCA - Cause Consequence Analysis) 52

\section{PROPOSTA DO MÉTODO DE ANÁLISE DE RISCO PARA O SISTEMA} DE CARGA E DESCARGA DE GNL EM NAVIOS TRANSPORTADORES ...............54

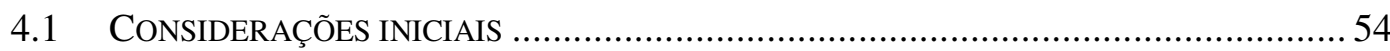

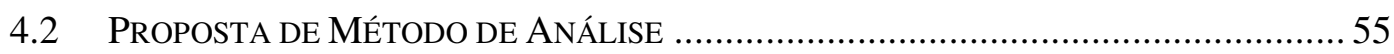

4.2.1 Passo 1: Etapa Preparatória ........................................................................ 56

4.2.2 Passo 2: Identificação dos Perigos............................................................ 58

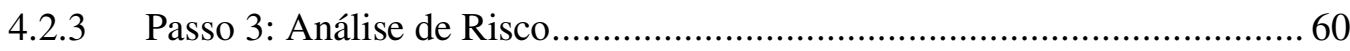

4.2.4 Passo 4: Recomendações e Conclusões Finais ................................................ 65

\section{ESTUdO DE CASO: SISTEMA DE CARGA E DESCARGA DE GNL DE} UM NAVIO TRANSPORTADOR DE GNL

\subsection{Passo 1 - Etapa Preparatória: Definição do Sistema de Carga e}

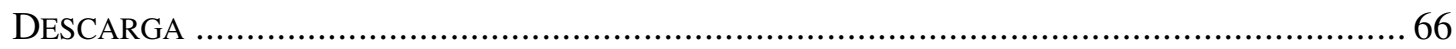

5.1.1 Procedimento de Carga e Descarga de GNL ............................................. 71

5.1.2 Componentes do sistema de carga e descarga do GNL ………………....... 78

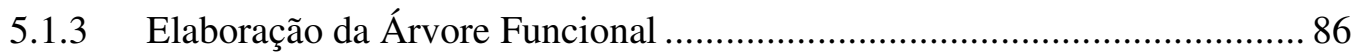

5.1.4 Descrição Funcional dos equipamentos .................................................... 90

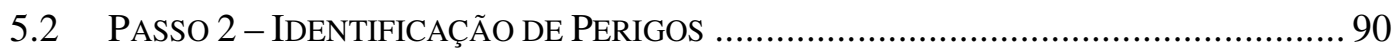

5.2.1 Definição dos Perigos: Aplicação da Análise Preliminar de Perigos (APP) 90

5.2.2 Definição do Cenário: Aplicação do Diagrama Causa-Consequência ........ 93

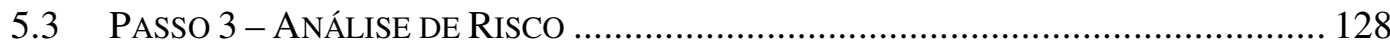


5.3.1 Determinação da probabilidade de ocorrência ....................................... 129

5.3.2 Determinação das consequências ou severidades................................... 130

5.3.3 Elaboração da Matriz de Risco........................................................... 134

5.4 PASSO 4 - RECOMENDAÇÕES E CONCLUSÕES FINAIS .................................... 135

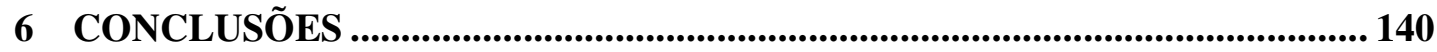

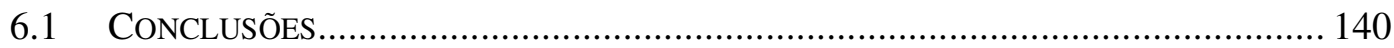

6.2 CONSIDERAÇÕES PARA TRABALHOS FUTUROS .................................................. 143

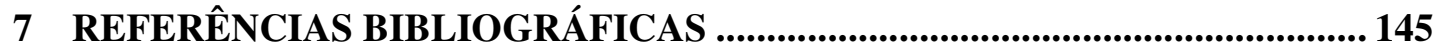




\section{INTRODUÇÃO}

\subsection{Considerações Iniciais}

O Brasil é o país da América Latina que tem a maior demanda por energia elétrica, a qual se deve principalmente à grande população e ao crescimento econômico do país. Para suprir a demanda de energia elétrica, o país deve adicionar fontes de energia as já existentes, permitindo, dessa maneira, uma maior disponibilidade na entrega da energia elétrica ao consumidor final. Nesse cenário, o gás natural se apresenta como forte alternativa para complementar a matriz energética brasileira.

Segundo a Energy Administration Information EIA (2011), o gás natural nos EUA, por exemplo, apresenta grande importância já que em 2010, 25\% da energia usada foi proveniente do gás natural, sendo $31 \%$ dessa porcentagem destinada para a geração de energia elétrica, representando o consumo de 209 bilhões de metros cúbicos.

De acordo com o MME (2010), no caso do Brasil, a geração de energia elétrica em centrais de serviço público e autoprodutores atingiu 466,2 TWh em 2009, sendo que a principal contribuição vem das centrais de serviço público, representando $87,8 \%$ da geração de energia total, e o restante corresponde à contribuição de centrais autoprodutoras. Um autoprodutor de energia elétrica é uma empresa, ou consórcio de empresas reunidas, que recebem concessão ou autorização para produzir energia elétrica destinada ao seu uso exclusivo.

A geração pública a partir de combustíveis fósseis caiu 35,1\%, com redução expressiva na geração a partir do uso do gás natural $(65,2 \%)$ e do óleo combustível $(33,3 \%)$, entretanto, a geração de autoprodutores em 2009 apresentou um crescimento de 11,5\%, ambos os casos são comparados ao ano de 2008. A Figura 1.1 apresenta a estrutura da oferta interna de eletricidade no Brasil em 2009. 


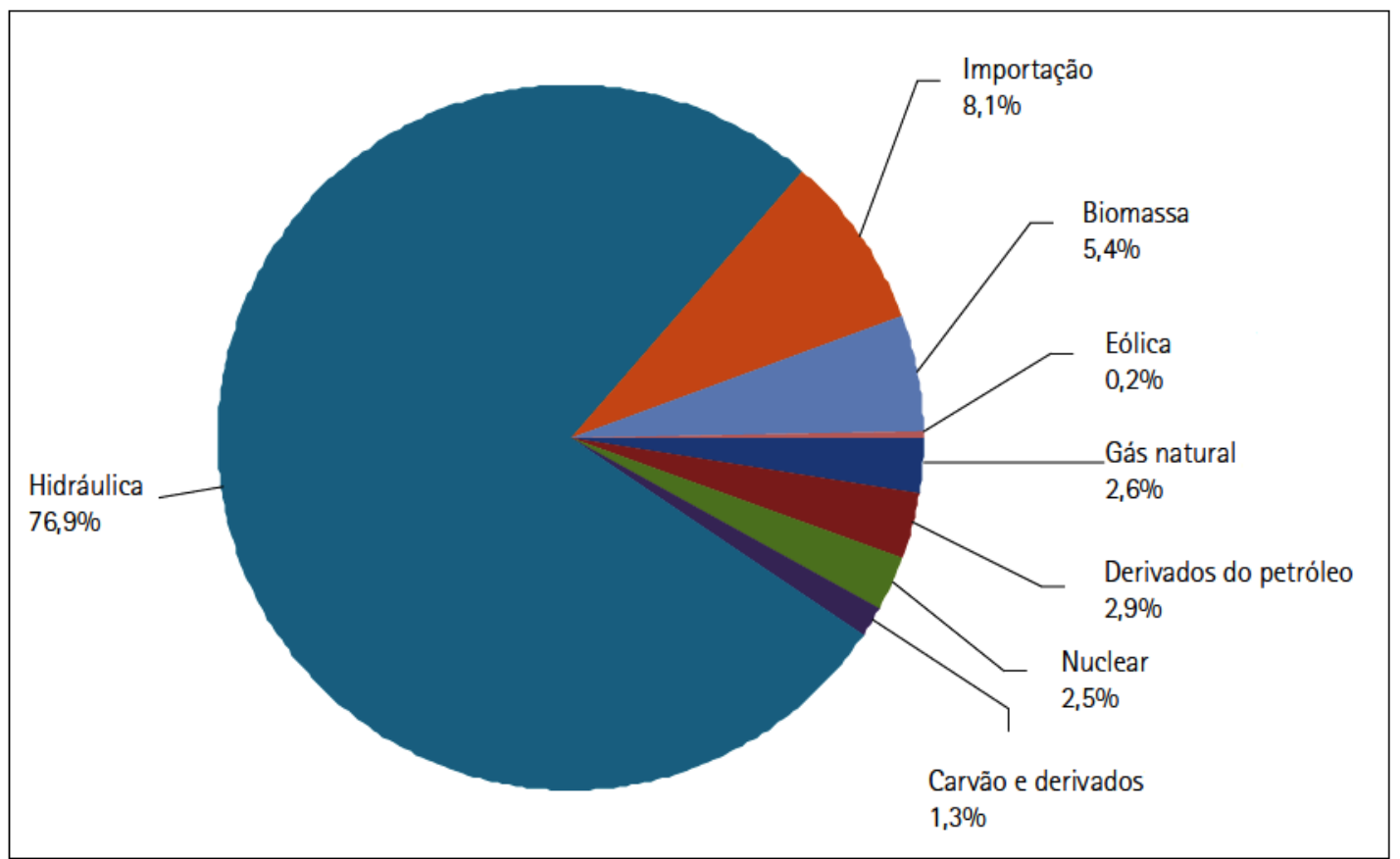

Figura 1.1 - Oferta Interna de Energia Elétrica por fonte para o ano 2009 (MME, 2010)

De acordo com o MME (2010) e Fernandes et al. (2005), o Brasil apresenta uma matriz de geração de energia elétrica de origem predominantemente renovável, sendo que a geração hidráulica responde por mais de $76 \%$ da oferta. Em função do elevado nível observado nos reservatórios das hidroelétricas, principalmente no segundo semestre de 2009, houve redução de 53,7\% na geração térmica a gás natural (incluindo autoprodutores e usinas de serviço público) em relação a 2008.

Muitos são os fatores que auxiliaram o gás natural tornar-se uma fonte de energia dentro da matriz energética de diversos países. Entre eles, é possível utilizar este combustível na geração de energia elétrica diminuindo a dependência dos combustíveis derivados do petróleo. De acordo com a Energy Administration Information aproximadamente 2/3 do consumo de gás natural mundial é destinado para a geração de energia elétrica (EIA, 2003).

O principal problema da dependência da energia hidroelétrica deve-se ao fato da necessidade da disponibilidade constante dos recursos hídricos. Para introduzir uma nova fonte de geração de energia é preciso dar incentivo à utilização do gás natural nas centrais termoelétricas. De acordo com a ANP - Agência Nacional do Petróleo, Gás Natural e Biocombustíveis, o Programa Prioritário de Termoeletricidade (PPT) teve por objetivo a construção de Usinas Termoelétricas (UTE's) para propiciar uma alternativa à geração 
hídrica, e uma das prerrogativas foi um preço diferenciado para a energia elétrica gerada pelas centrais térmicas incluídas no PPT (ANP, 2010). Com essas medidas de incentivo à operação das centrais termoelétricas, houve um aumento no consumo de gás natural destinado à geração de energia elétrica, fazendo com que fosse necessária a previsão de abastecimento de gás natural em maior volume, viabilizando projetos de terminais de recepção de GNL (Gás Natural Liquefeito).

Segundo The Economist (2012a) e The Economist (2012b), devido aos acontecimentos ocorridos no Japão em Março de 2011 com a grave falha da usina nuclear de Fukushima, provavelmente as políticas de investimento em projetos de geração de energia elétrica com usinas termonucleares serão revistos, e esta geração de energia elétrica passará a ser feita por meio da queima do gás natural, atribuindo maior importância à disponibilidade deste produto, aumentado o volume das importações por parte dos consumidores e exigindo maior disponibilidade de meios de transporte do produto.

De acordo com ANP (2010) e Golar LNG (2009), a primeira iniciativa para assegurar a implementação plena das atividades concernentes ao GNL e para superar possíveis problemas com sua execução foi a edição, pelo Conselho Nacional de Política Energética (CNPE), da Resolução $n^{\circ}$ 4, de 24/11/2006, que estabeleceu diretrizes para a implementação de projetos de importação de GNL, de modo a "Garantir suprimento confiável, seguro e diversificado de gás natural". Com base neste ato, a Petrobras apresentou dois projetos de terminais de importação de GNL, um em Pecém (CE) e outro na Baía de Guanabara (RJ), com capacidade para regaseificar, respectivamente, sete milhões de $\mathrm{m}^{3} /$ dia e 14 milhões de $\mathrm{m}^{3} / \mathrm{dia}$. Em novembro de 2008 a Petrobras iniciou a importação de GNL com a chegada do primeiro navio transportador de GNL no terminal de Pecém, proveniente da Trindade e Tobago, com um volume medido de $57.872 \mathrm{~m}^{3}$ de GNL.

Segundo a British Petroleum BP (2010) e Petrotecnia (2009), as reservas provadas de gás natural em âmbito mundial até o final do ano 2009, chegaram a 187,49 trilhões de metros cúbicos, sendo que a região do Oriente Médio tem as maiores reservas mundiais, com 76,18 trilhões de metros cúbicos. Para esse mesmo ano, na América do Sul, a Venezuela é o país que tem as maiores reservas da região, com 5,67 trilhões de metros cúbicos, seguido bem de longe pela Bolívia com 0,77 trilhões de metros cúbicos. Embora com poucas reservas de gás natural, Trindade e Tobago e o Peru, são países que se dedicam à exportação do GNL na 
atualidade. A Figura 1.2 apresenta o volume de reservas provadas de gás natural até o ano 2009 na América do Sul.

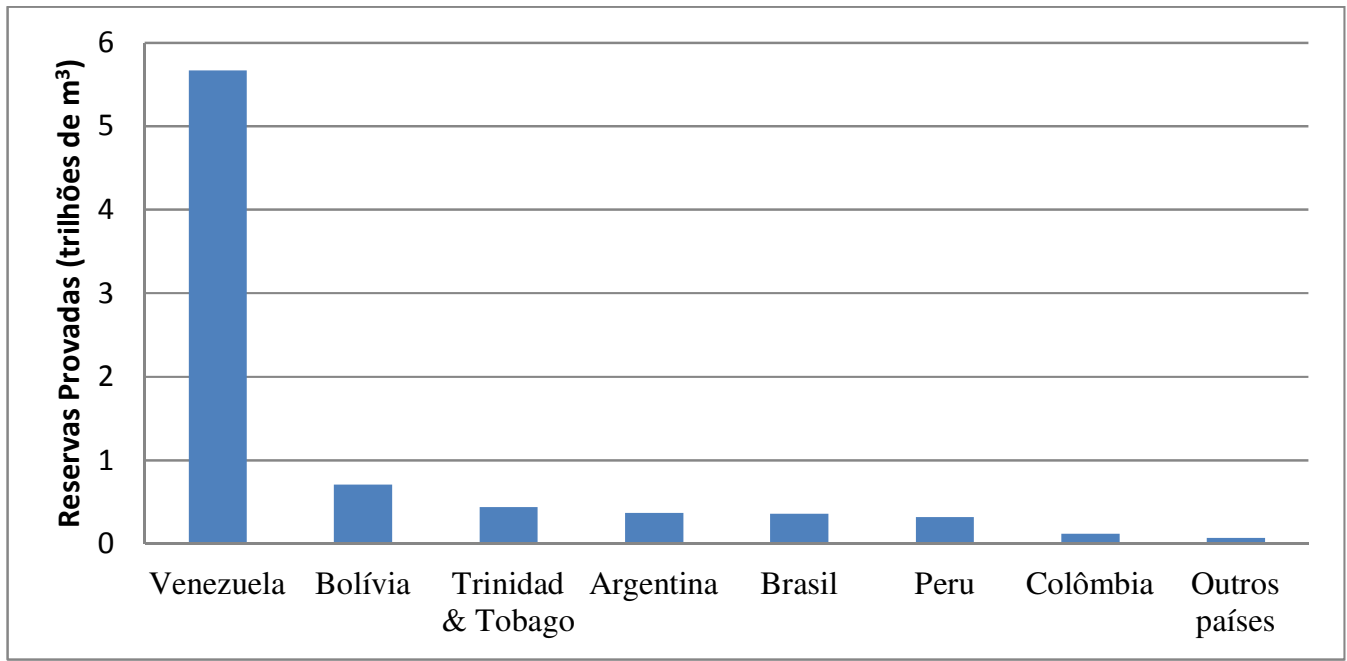

Figura 1.2 - Reservas provadas dos países da América do Sul em Trilhões de m³ (BP, 2010; PETROTECNIA, 2009)

O gás natural pode ser transportado em forma líquida, precisando para isto do uso de navios transportadores de GNL de grande porte que navegam entre as plantas de liquefação dos países exportadores (onde se faz a carga do GNL) até as plantas de regaseificação dos países importadores (onde se faz a descarga do GNL). De acordo com a Zeus Virtual Energy Library (2011a), Zeus Virtual Energy Library (2011b), e Global LNG Info (2011), atualmente estão em operação, em âmbito mundial, 30 terminais de liquefação, sendo Catar, Indonésia e Malásia os países que têm o maior número destes terminais. Entretanto existem 82 terminais de regaseificação, onde o Japão, EUA, Espanha e Coréia do Sul detêm aproximadamente $60 \%$ destas instalações em operação do mundo.

Os países que estão entre os maiores exportadores de GNL são: Catar, que é o maior exportador de GNL no mundo, Indonésia, Argélia, Malásia, Nigéria, Trindade e Tobago, Austrália e Egito. Países esses que, juntos, foram responsáveis, em 2008, por $83 \%$ das exportações mundiais. O Japão, EUA, Espanha e Coréia do Sul são os maiores importadores de GNL, importando mais da metade do GNL comercializado do mundo (DORIGONI et al., 2010). Na América do Sul, o Brasil, Chile e a Argentina já são considerados importadores de GNL, mas em quantidades pequenas em comparação com os países importadores de GNL citados acima. 
Dessa forma, no Brasil, é preciso que se realizem estudos na área de risco visando identificar os eventos de perigo e caracterizando-os de acordo com o risco que estão associados com as operações dos navios transportadores de GNL.

As operações de carga e descarga do GNL devem ser feitas de maneira confiável e segura, visando a ausência da ocorrência de incidentes e acidentes que possam provocar graves consequências à integridade das pessoas, da propriedade e do meio ambiente. Para isso é importante identificar as possíveis causas de falhas nos sistemas envolvidos na carga e descarga do GNL, e reduzir a sua possibilidade de ocorrência através de modificações de projeto, ou ações de manutenção, e da proposição de medidas de contingência em caso de ocorrência de acidentes, reduzindo a chance de eventos indesejáveis ocorrerem e minimizando suas consequências.

Basicamente os sistemas associados com ações de contingência que estão envolvidos na carga e descarga do GNL, são sistemas de proteção que devem atuar de maneira confiável caso seja ativado algum alarme, interrompendo as operações de carga e descarga do GNL, e evitando que o evento iniciador desenvolva-se de maneira descontrolada.

De acordo com Ditali e Fiore (2007) e Michot (2003), a maior preocupação com relação a ocorrência de um acidente durante as etapas de carga e descarga de GNL está relacionada, principalmente, ao grande volume de GNL que é transportado e armazenado nos navios. Esta grande quantidade representa um perigo potencial caso ocorra um incêndio, produto de um vazamento, que poderia prejudicar as pessoas, as propriedades e o meio ambiente, tanto do próprio terminal quanto das áreas vizinhas.

A utilização das técnicas de análise de risco disponíveis na literatura permite identificar as causas que poderão ocasionar os eventos de perigo e as consequências associadas à sua ocorrência, como vazamentos da substância transportada, levando-se em consideração que as causas desses vazamentos pode ser a falha em equipamentos como válvulas, tubulações, tanque de armazenagem, entre outras; e que as consequências podem ser dispersão dos gases, incêndio, entre outros. Para a avaliação do risco é necessário a determinação de duas variáveis: a frequência de ocorrência de falhas e a consequência da ocorrência das mesmas. 


\subsection{Objetivo do Trabalho}

O objetivo desta dissertação é desenvolver um método de análise baseado em risco, que permita identificar quais são os possíveis cenários de falha, dado que aconteceu o evento de perigo e como a sua propagação poderá ser contida por certas barreiras de proteção, que deverão evitar o desenvolvimento do cenário de falha associado a este evento indesejável, tentando bloqueá-lo e interrompê-lo, reduzindo graves consequências tanto no próprio navio como nas áreas circunvizinhas. Os eventos iniciadores de perigo estudados nesta dissertação serão o vazamento de GNL e de boil-off.

Este método também permite elaborar a Matriz de Risco para definir quais dos componentes, que pertencem ao circuito de carga e descarga de GNL e do boil-off, são considerados críticos e deverão ser foco de maior atenção dos projetistas e operadores do navio. O cálculo da probabilidade de ocorrência dos modos de falha dos componentes do sistema de carga e descarga de GNL é feito quantitativamente e as consequências da ocorrência dos mesmos é feita qualitativamente.

Na elaboração deste método está envolvida a aplicação de técnicas da análise de risco usualmente citadas em referências associadas ao estudo de risco em instalações industriais. Estas técnicas de análise são: a Análise Preliminar de Perigos (APP), que servirá para determinar quais são as causas que levam ao evento de perigo; o Diagrama CausaConsequência, que permitirá obter o valor quantitativo da probabilidade de ocorrência dos cenários de falha, considerando as barreiras de contenção; a análise de Árvore de Falhas (FTA) permitirá saber qual é a probabilidade de falha das barreiras de proteção com que estão equipados esses tipos de navios. A Matriz de Risco permite definir a criticidade dos componentes do sistema de carga e descarga de GNL.

\subsection{Estrutura da Dissertação}

Para uma melhor compreensão da estrutura deste trabalho, é necessário apresentar uma breve descrição dos seus capítulos.

O presente capítulo, Capítulo 1, trás uma introdução que expõe o contexto onde se iniciou a importação do GNL por meio dos navios. Adicionalmente neste capítulo apresenta-se os objetivos do trabalho e a estrutura do mesmo. 
No Capítulo 2 são expostos alguns aspectos importantes com respeito ao GNL transportado por meio de navios. São tratadas, de maneira resumida, as etapas da cadeia de valor do gás natural. Também são apresentados os tipos de navios metaneiros utilizados para este fim. Adicionalmente é feito um breve resumo dos acidentes mais importantes ocorridos em instalações que manuseiam o GNL. Finalmente, é feita uma apresentação dos principais componentes do sistema de carga e descarga de GNL de um navio.

No Capítulo 3, são tratadas as técnicas de análise utilizadas na área de risco e que são empregadas na elaboração do método de análise.

O Capítulo 4 apresenta a proposta do método de análise baseado em risco, que é utilizado no Capítulo 5, no estudo de caso.

No Capítulo 5, é feito o estudo de caso, aplicando o método proposto especificamente no sistema de carga e descarga do navio de transporte de GNL, quando o navio está atracado no porto.

O Capítulo 6 apresenta as conclusões desta dissertação e a proposta para trabalhos futuros.

E por fim, no Capítulo 7, serão citadas as referências bibliográficas utilizadas para a realização deste trabalho de pesquisa. 


\section{SISTEMA DE CARGA E DESCARGA DE GNL DO NAVIO TRANSPORTADOR DE GNL}

Este capítulo é dedicado a abordar as definições e os fundamentos técnicos que estão envolvidos na operação de carga e descarga do navio de transporte de GNL. Em primeiro lugar, é desenvolvida uma caracterização da substância transportada, em seguida são feitas as considerações sobre os navios utilizados no transporte deste combustível e dos componentes envolvidos nesta operação, e finalmente são indicadas as atividades que são necessárias para realizar a carga e descarga do GNL, tanto no terminal de liquefação, quanto no terminal de regaseificação.

\subsection{Caracterização do GNL}

\subsubsection{Propriedades gerais do GNL}

De acordo com Karassik et al. (2001) e a National Academy of Science (1995), os fluidos que têm o seu ponto de ebulição abaixo de $-73^{\circ} \mathrm{C}$ como o oxigênio, nitrogênio, hidrogênio, hélio, argônio, metano, etano, e outros são chamados fluidos criogênicos, e para fazer com que mudem do estado gasoso para o estado líquido eles precisam passar por um processo de liquefação.

Antes de fazer a caracterização do GNL é necessário mencionar que o produto é constituído majoritariamente por metano $\left(\mathrm{CH}_{4}\right)$ resfriado à $-162{ }^{\circ} \mathrm{C}$, temperatura na qual o gás natural torna-se líquido sob pressão atmosférica. O GNL ocupa um volume 600 vezes menor do que se estivesse em estado gasoso, por essa razão é liquefeito, facilitando assim o armazenamento e o transporte. O gás metano não é tóxico, mas pode causar asfixia, que se caracteriza como dificuldade respiratória, com possível perda de consciência devido à falta de oxigênio. A asfixia pode ocorrer se as pessoas estão perto do local de vazamentos ou se elas estão em espaços confinados, sem ventilação, onde elas ficam expostas a concentrações excessivamente altas de vapor de GNL. O gás metano é também incolor, inodoro e criogênico (RISKNOLOGY, 2006; ABS, 2004). A Tabela 2.1 apresenta os principais componentes do GNL. 
Tabela 2.1 - Componentes do GNL (GASNET, 2011; MOKHATAB et al., 2006; SPEIGHT, 2002)

\begin{tabular}{|c|c|c|c|c|c|c|}
\hline & $\begin{array}{c}\text { Metano } \\
\mathrm{CH}_{4}\end{array}$ & $\begin{array}{l}\text { Etano } \\
\mathrm{C}_{2} \mathrm{H}_{4}\end{array}$ & $\begin{array}{l}\text { Propano } \\
\mathbf{C}_{3} \mathbf{H}_{8}\end{array}$ & $\begin{array}{c}\text { Butano } \\
\mathrm{C}_{4} \mathrm{H}_{10}\end{array}$ & $\begin{array}{c}\text { Pentano } \\
\mathrm{C}_{5} \mathrm{H}_{12}\end{array}$ & $\begin{array}{l}\text { Nitrogênio } \\
\quad \mathrm{N}_{2}\end{array}$ \\
\hline Peso Molecular & 16,04 & 30,06 & 44,09 & 58,12 & 72,15 & 28,01 \\
\hline Ponto de ebulição a 1 bar $\left({ }^{\circ} \mathrm{C}\right)$ & $-161,5$ & -88 & -42 & -5 & -36 & -196 \\
\hline $\begin{array}{l}\text { Densidade do líquido no ponto de } \\
\text { ebulição }\left(\mathrm{kg} / \mathrm{m}^{3}\right)\end{array}$ & 426 & 544 & 580 & 601 & 610 & 0,8 \\
\hline $\begin{array}{l}\text { Relação do volume gás/líquido no } \\
\text { ponto de ebulição }\end{array}$ & 600 & 413 & 311 & 311 & 205 & 649 \\
\hline $\begin{array}{l}\text { Limite de inflamabilidade inferior e } \\
\text { superior ( } \% \text { por volume) }\end{array}$ & $5-15$ & $3-13$ & $2-10$ & $2-10$ & $3-13$ & $\begin{array}{l}\text { Não } \\
\text { inflamável }\end{array}$ \\
\hline Temperatura de auto-ignição $\left({ }^{\circ} \mathrm{C}\right)$ & 595 & 510 & 468 & $365 / 500$ & & \\
\hline $\begin{array}{l}\text { Porcentagem do produto na } \\
\text { composição do GNL }(\%)\end{array}$ & 89,3 & 6,8 & 2,6 & 1 & 0,1 & 0,2 \\
\hline
\end{tabular}

De acordo com NFPA59A (2001), ANP (2010) e SANDIA (2004), o GNL é um fluido composto predominantemente por metano, e que pode conter quantidades menores de etano, propano, butano, pentano, nitrogênio e outros componentes encontrados normalmente no gás natural. Segundo Speight (2002), a composição do gás natural depende da localização das jazidas de gás de onde ele foi extraído, e também do processo de liquefação, mas a composição típica do GNL é apresentada na Tabela 2.1. Os componentes do GNL que têm baixo ponto de ebulição são os que se vaporizarão primeiro devido à troca de calor da carga transportada com o meio ambiente.

Uma característica importante é a temperatura de ebulição, que para o metano é de $161,5^{\circ} \mathrm{C}$, o que significa que o GNL se tornará gás apenas quando superar essa temperatura, formando-se assim o que comumente se chama de BOG (boil off gas) ou simplesmente boiloff.

A densidade do GNL está na faixa de 400 a $500 \mathrm{~kg} / \mathrm{m}^{3}$, que significa dizer que sua densidade é aproximadamente a metade da densidade da água $\left(1000 \mathrm{~kg} / \mathrm{m}^{3}\right)$. É por isso que, quando acontece um vazamento de GNL sobre a água, ele permanece sobre esta até que todo o GNL se torne gás e se vaporize.

A Tabela 2.2 apresenta as propriedades típicas do GNL, considerando metano como seu principal componente. 
Tabela 2.2 - Propriedades do metano (GAMA GASES, 2011)

\begin{tabular}{|l|c|}
\hline \multicolumn{1}{|c|}{ Parâmetros } & Valor \\
\hline Ponto de ebulição a 1 bar absoluto $\left({ }^{\circ} \mathrm{C}\right)$ & $-161,5$ \\
\hline Densidade do líquido no ponto de ebulição $\left(\mathrm{kg} / \mathrm{m}^{3}\right)$ & 426 \\
\hline $\begin{array}{l}\text { Volume de gás/volume de líquido a }-161,5^{\circ} \mathrm{C} \text { e } 1 \text { bar } \\
\text { absoluto }\end{array}$ & 600 \\
\hline $\begin{array}{l}\text { Limites de inflamabilidade inferior e superior no ar por } \\
\text { volume na forma gasosa (\%) }\end{array}$ & $5-15$ \\
\hline Temperatura de autoignição na forma gasosa $\left({ }^{\circ} \mathrm{C}\right)$ & 595 \\
\hline Pressão crítica absoluta (bar) & 43 \\
\hline
\end{tabular}

A temperatura de autoignição é definida como a temperatura mínima em que ocorre a combustão, mesmo sem uma fonte de ignição, apenas quando o combustível entra em contato com o comburente, gerando-se a ignição da mistura. De acordo com Risknology (2006) o metano, etano e propano têm altas temperaturas de autoignição $595{ }^{\circ} \mathrm{C}, 515{ }^{\circ} \mathrm{C}$ e $480{ }^{\circ} \mathrm{C}$ respectivamente, quando comparada com a temperatura de autoignição de outros combustíveis, por exemplo, o GLP $\left(405^{\circ} \mathrm{C}\right)$, a gasolina $\left(367^{\circ} \mathrm{C}\right)$. Ao atingir altos valores de temperatura, os primeiros combustíveis estão menos propensos a um incêndio.

Não obstante, as substâncias criogênicas representam perigo à saúde porque podem acarretar congelamento que resulta do contato com o líquido ou o vapor, uma vez que baixas temperaturas podem causar severas queimaduras ao tecido humano (HADDAD, 2003).

As substâncias criogênicas também causam efeitos sobre outros materiais metálicos empregados nos equipamentos utilizados na manipulação do GNL. O contato com este tipo de fluido pode danificar os materiais, que basicamente podem tornar-se frágeis e quebradiços, podendo provocar vazamentos da substância transportada.

\subsubsection{Propriedades de flamabilidade do GNL}

O GNL não é inflamável. Para se tornar inflamável ele necessita tornar-se gás e estar dentro dos limites de inflamabilidade, além disso, para começar a queima necessita-se de uma fonte de ignição. O limite inferior de inflamabilidade é definido pela norma técnica da PETROBRAS N-2784 como a menor concentração de um vapor ou gás inflamável na mistura com o ar, abaixo da qual a mistura gás-ar é pobre, não permitindo a propagação da combustão. Já o limite superior de inflamabilidade é definido como a maior concentração de um vapor ou gás inflamável na mistura com o ar, acima da qual a mistura gás-ar é rica, não 
permitido a propagação da combustão (PETROBRAS, 2005). Fora desses limites de inflamabilidade não será possível a combustão por falta ou excesso de oxigênio na mistura de gás-ar. Os limites de inflamabilidade são expressos em porcentagens do volume, tomadas a $20^{\circ} \mathrm{C}$ e a uma atmosfera de pressão. Por exemplo, $1 \%$ por volume representa $10.000 \mathrm{ppm}$ (partes por milhão) nessa temperatura e pressão.

De acordo com ABS (2004), SANDIA (2004), GIIGNL (2008) e Luketa (2005), o metano é inflamável quando está misturado com ar na faixa dos 5 a $15 \%$ em termos do volume. Isso quer dizer que se a mistura gás-ar for inferior ou superior a faixa de 5 a $15 \%$ respectivamente, não ocorrerá a queima da mistura formada, mesmo que exista uma fonte de ignição. A Figura 2.1 apresenta esses limites, mínimo e máximo, de inflamabilidade para o metano.

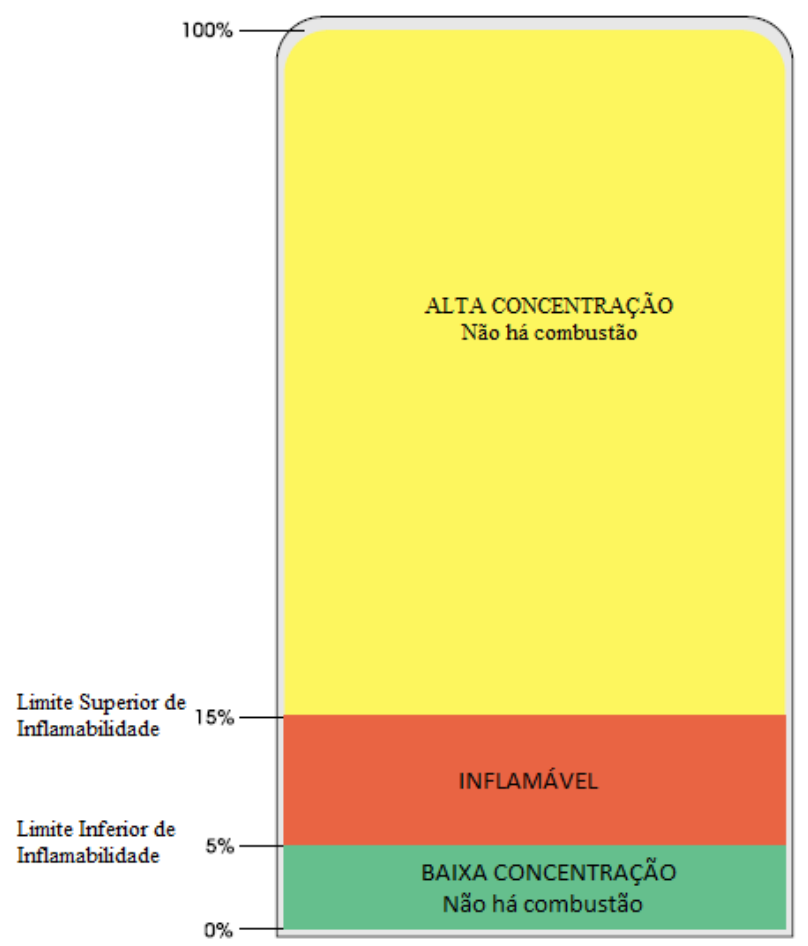

Figura 2.1 - Limites mínimo e máximo de inflamabilidade para o metano (MICHOT, 2003; ANP, 2010)

Por exemplo: de acordo com Haddad (2003), a concentração de oxigênio no meio ambiente normalmente é de $21 \%$ por volume.

Segundo a ABS (2004), Risknology (2006) e Lees (1996), quando o GNL é liberado para o ambiente, poderia formar uma poça, mas isso dependerá da quantidade de GNL vazado e 
das condições atmosféricas do local do vazamento. A poça de GNL se evaporaria formando vapor na forma de uma nuvem. Um pequeno vazamento de GNL não formará necessariamente uma poça de GNL havendo diretamente a vaporização do mesmo. A nuvem de vapor tende a permanecer perto da superfície onde ocorreu o vazamento do GNL (seja na terra ou na água), até que o vapor se misture e troque calor com o ar, aumentando sua temperatura. Sob essas condições ele torna-se menos denso que o ar e tende a subir e dispersar-se com maior rapidez no ambiente. Na Figura 2.2 pode-se ver o comportamento da nuvem de vapor gerada logo que se produz a troca de calor com o meio ambiente.

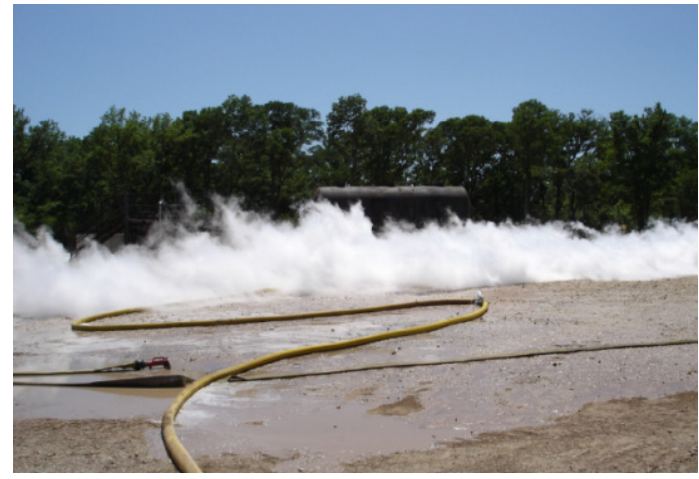

Figura 2.2 - Nuvem de vapor de GNL criada controladamente para ver o seu comportamento (GIIGNL, 2008)

De acordo com Lees (1996), dado que a superfície sobre a qual ocorreu o vazamento tenha uma temperatura maior do que a temperatura do GNL, durante o primeiro momento após o vazamento, a taxa de vaporização é alta, decaindo posteriormente. A Figura 2.3 apresenta como a nuvem de vapor é afetada pelo vento e pela troca de calor com o ar atmosférico.

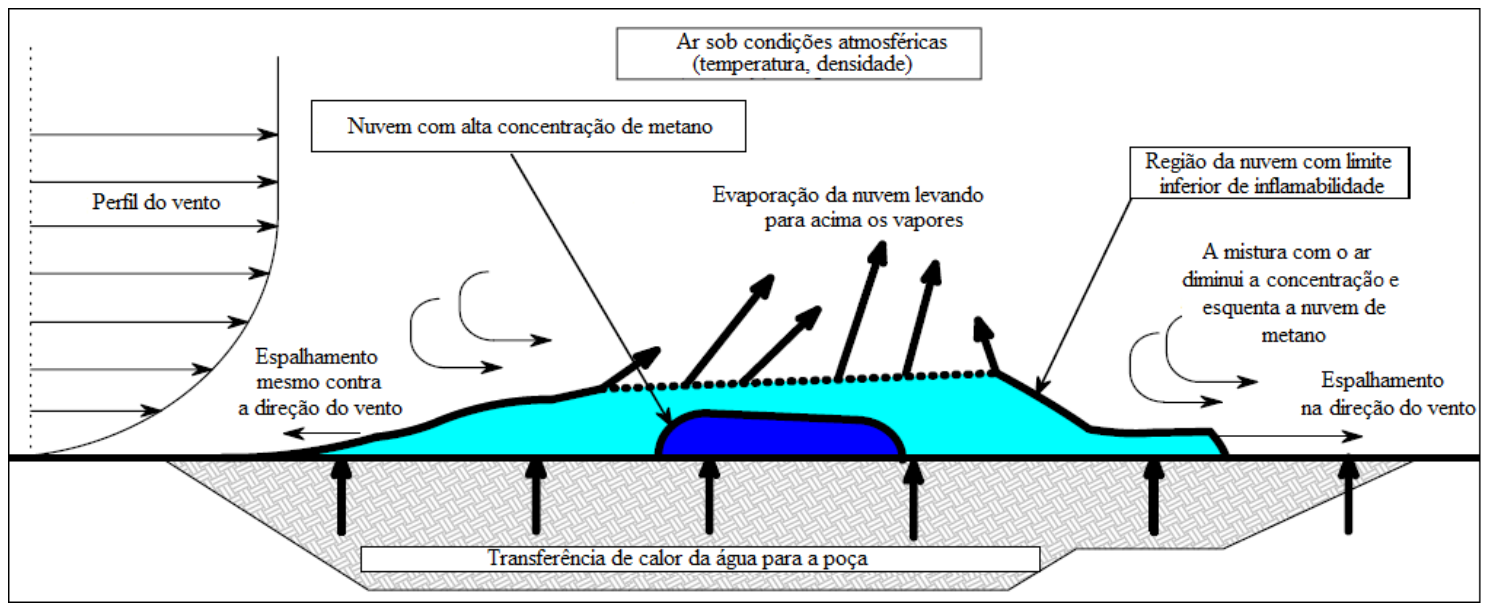

Figura 2.3 - Comportamento da nuvem de metano (RISKNOLOGY, 2006) 
ABS (2004), Risknology (2006), Ikeda et al. (2010), Michot (2003), SANDIA (2004) e Luketa (2005), apresentam os perigos próprios desta substância conforme descritos brevemente a seguir:

\section{$\checkmark$ Contato com o fluido criogênico}

Um dos perigos inerentes de qualquer fluido criogênico é que após o vazamento o fluido resfria o local onde ocorreu este vazamento. Isso causará queimaduras na pele caso pessoas entrem em contato com o fluido, ou trincas na estrutura devido à fragilização dos materiais, caso este não seja projetado para suportar as baixas temperaturas, por exemplo, o material do casco do próprio navio.

\section{$\checkmark$ Incêndio em poça (Pool Fire)}

Outro perigo associado ao GNL é o incêndio em poça que se dará quando o vazamento ocorrer perto de uma fonte de ignição, e se a mistura de vapor e ar estiver dentro dos limites de inflamabilidade. Esta mistura queimará sobre a poça de GNL. Este incêndio em poça não se extinguirá até que todo o GNL seja consumido. A radiação térmica produzida pelo incêndio em poça pode atingir às pessoas, à propriedade a uma distância considerável da fonte das chamas. Destaca-se que o incêndio é dos vapores e não do próprio GNL.

\section{$\checkmark$ Incêndio em nuvem (Flash Fire)}

O incêndio em nuvem se dá pela formação de nuvens de vapor. Caso não ocorra uma ignição imediata, o gás natural evaporado pode formar uma nuvem de vapor e percorrer certa distância se afastando do local de vazamento. Esta nuvem poderá entrar em ignição caso encontre uma fonte de ignição e esteja dentro da faixa de inflamabilidade, e queimará em seu caminho de volta até a fonte do derramamento, para continuar queimando na forma de um incêndio em poça desde que as condições de inflamabilidade do metano sejam atingidas.

$\checkmark$ Transição rápida de fase (RPT)

A transição rápida de fase (RPT - Rapid Phase Transition) é um perigo associado ao vazamento de GNL sobre a água, que ocorre devido ao fato do GNL vaporizar-se rapidamente, provocando uma rápida mudança de fase do estado líquido para o estado 
gasoso. Esta transição rápida de fase gera ondas de choque que tem o potencial de quebrar janelas e vidros em suas proximidades.

\section{$\checkmark$ Explosão}

No estado líquido o GNL não é explosivo, e o vapor de GNL somente explodirá caso esteja dentro da faixa de inflamabilidade e dentro de um espaço confinado, dada a existência de uma fonte de ignição.

Apesar dos vapores de GNL serem passíveis de explosão, isso somente ocorrerá caso o incêndio aconteça em um espaço fechado, como um edifício. Não existe evidência que o gás natural seja explosivo quando se inflama em espaços abertos.

\subsection{A cadeia de valor do gás natural}

A cadeia de valor do gás natural é formada por um conjunto de operações onde estão envolvidas uma série de atividades apresentadas na Figura 2.4.

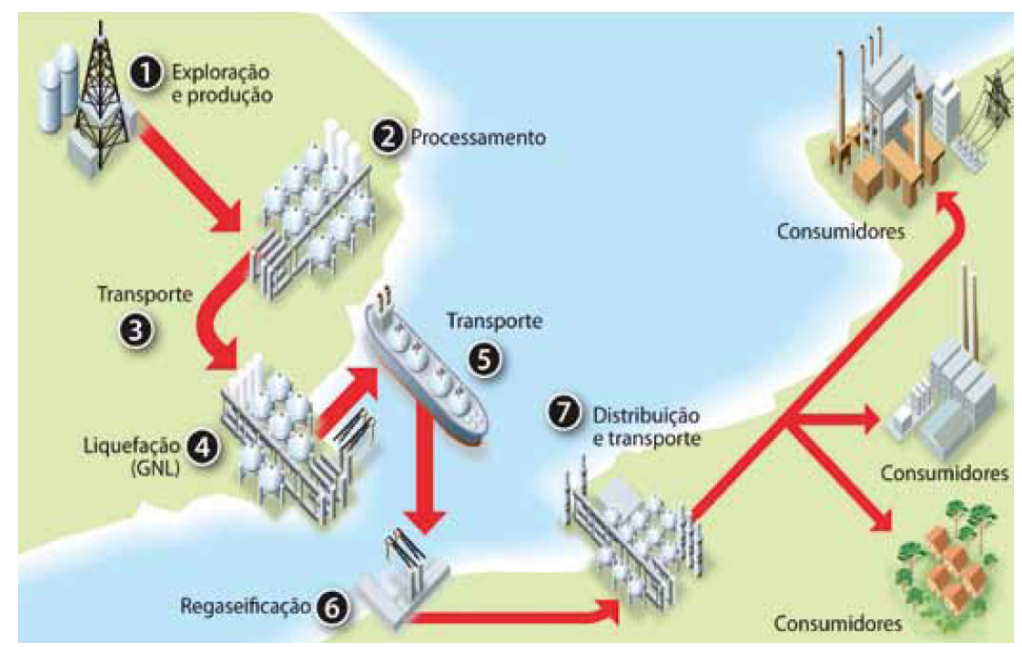

Figura 2.4 - Cadeia de valor completa do gás natural (ANP, 2010)

Segundo a EIA (2003), Maxwell e Zhu (2011) e DOE (2005), dentro desta cadeia de valor as quatro maiores atividades que representam os maiores custos são: a etapa de exploração e produção, que representa entre 15 a $20 \%$ do custo total; seguido pela etapa de liquefação, que representa entre 30 a $45 \%$ deste custo total; a etapa de transporte por meio de navios, que significa de 10 a $30 \%$ do custo total; e por último, a etapa de armazenagem e regaseificação, com 15 a $25 \%$ do total do custo. O processo de liquefação é a etapa mais custosa da cadeia 
produtiva do GNL. A Figura 2.5 apresenta os custos aproximados da cadeia de valor do gás natural.

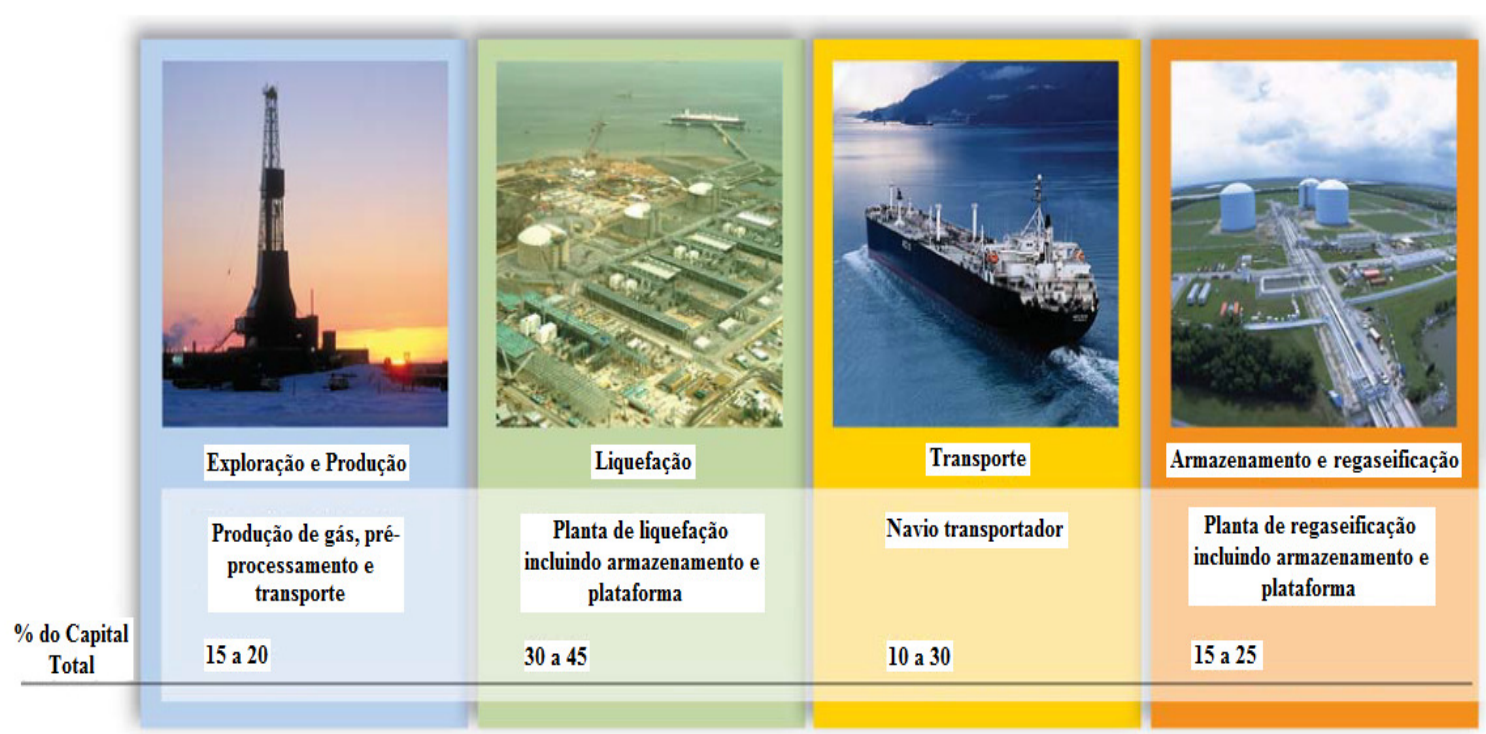

Figura 2.5 - Custos aproximados da cadeia de valor do gás natural (DOE, 2005; EIA, 2003)

De acordo com Naturalgas (2010), na etapa de exploração e produção (E \& P), as empresas pesquisam prováveis reservas de gás natural, e de acordo com o volume destas, as exploram. No processamento o gás é encaminhado para unidades onde são extraídas as impurezas como a água e o dióxido de carbono, e onde, principalmente, se faz a separação de todos os gases que foram extraídos, como metano, etano, propano, e outros. Logo em seguida, o gás natural tratado é liquefeito em plantas de liquefação para que ele possa ser transportado por meio dos navios transportadores de GNL, chegando finalmente aos terminais de regaseificação, onde voltará ser gás natural para ser injetado nas tubulações de transporte de gás natural, denominadas de gasodutos.

O GNL pode ser regaseificado diretamente em plantas de regaseificação ou armazenado para a sua posterior regaseificação. Também existem plantas de regaseificação a bordo do próprio navio, onde o GNL é armazenado nos tanques para que posteriormente, e de acordo com a demanda, ele possa ser regaseificado. Esses tipos de navios são os FSRU (Floating Storage and Regasification Unit). Em países em que existam grandes picos de consumo de gás, em determinadas épocas do ano, o GNL é armazenado nos períodos de baixa demanda de gás para sua posterior regaseificação e utilização nos períodos de grande demanda. Estas 
instalações recebem a denominação de peak shaving e assumem destaque em diversos países, constituindo a maior parte das instalações de GNL nos EUA (ANP, 2010).

\subsection{Tipos de navios utilizados no transporte de GNL}

O uso dos navios no transporte de GNL constitui uma alternativa economicamente viável desde que a distância entre o ponto de produção e de utilização seja grande, e/ou envolva a transposição de um oceano.

O número de navios transportadores de GNL tem aumentado desde a construção do Methane Pioneer, que foi o primeiro navio construído para este fim. Ao longo das décadas passadas, com a construção de novas plantas de liquefação e de regaseificação de GNL, a frota desses navios cresceu. Esta tendência é mostrada na Figura 2.6. De acordo com o Shipbuilding History (2011) e o LNG Journal (2010), até o ano 2010 o número de navios transportadores de GNL era de 355 navios. De acordo com a EIA (2003), no ano 2003, o número de navios transportadores de GNL era de 151, onde 31 deles tinham uma capacidade menor que $120000 \mathrm{~m}^{3}$, enquanto os restantes tinham uma capacidade maior do que esse volume.

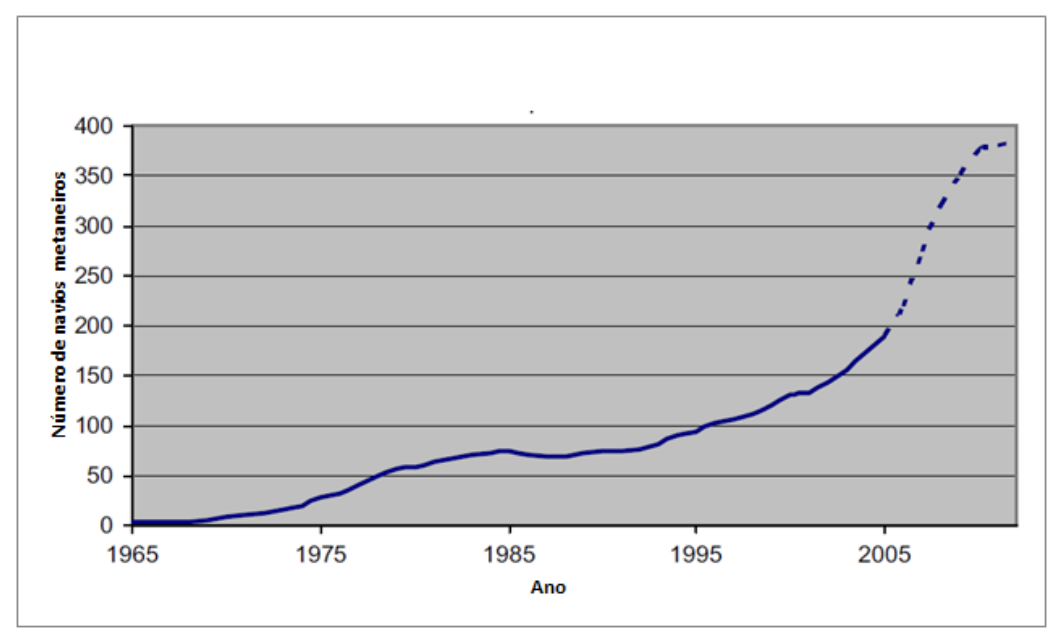

Figura 2.6 - Crescimento da frota de navios transportadores de GNL (VANEM et al., 2008)

Todos os navios que carregam metano liquefeito têm normas específicas de projeto e operação. De acordo com Harris (1993) a IMO (International Maritime Organization) publicou o Code for the Construction and Equipment of Ships Carryiend Liquefied Gases in Bulk em 1976 para fornecer os padrões internacionais para o transporte seguro de gás liquefeito a granel por via marítima. 
Segundo a DNV (2011), Lamb (2004) e IGC IMO (2005), existem diferentes tipos de navios dedicados ao carregamento de gases liquefeitos em geral, incluídos entre eles os navios transportadores de GNL. A Tabela 2.3 mostra alguns dos parâmetros e os tipos de navios utilizados durante o transporte de diferentes gases liquefeitos. Os navios que transportam o GLP (Gás Liquefeito de Petróleo) também estão incluídos entre os navios transportadores de gases liquefeitos, já que carregam propano $\left(\mathrm{C}_{3} \mathrm{H}_{8}\right)$ e butano $\left(\mathrm{C}_{4} \mathrm{H}_{10}\right)$, mas estes produtos não são considerados como fluidos criogênicos.

Tabela 2.3- Tipos de navios encarregados do transporte de substâncias químicas líquidas (LAMB, 2004; IGC

IMO, 2005)

\begin{tabular}{|c|c|c|c|}
\hline $\begin{array}{c}\text { Nome do } \\
\text { produto }\end{array}$ & $\begin{array}{c}\text { Temperatura } \\
\text { no ponto de } \\
\text { ebulição }\left({ }^{\circ} \mathbf{C}\right)\end{array}$ & $\begin{array}{c}\text { Densidade do líquido } \\
\text { no ponto de ebulição } \\
\left(\mathbf{k g} / \mathbf{m}^{\mathbf{3}}\right)\end{array}$ & $\begin{array}{c}\text { Tipo de navio de } \\
\text { acordo ao código da } \\
\text { IMO }\end{array}$ \\
\hline Amônia & $-33,4$ & 681 & $2 \mathrm{G} / 2 \mathrm{PG}$ \\
\hline Butadieno & -5 & 650 & $2 \mathrm{G} / 2 \mathrm{PG}$ \\
\hline \multirow{2}{*}{ Butano (n-, i-) } & $-0,5(\mathrm{n}-)$ & $601(\mathrm{n}-)$ & $2 \mathrm{G}$ \\
\cline { 2 - 4 } & $-11,7(\mathrm{i}-)$ & $595(\mathrm{i}-)$ & $2 \mathrm{PG}$ \\
\hline Cloro & $-34,6$ & 1157 & $1 \mathrm{G}$ \\
\hline Etano & -89 & 546,7 & $2 \mathrm{G}$ \\
\hline Etileno & $-103,7$ & 570 & $2 \mathrm{G}$ \\
\hline Metano & $-161,5$ & 425 & $2 \mathrm{G} / 2 \mathrm{PG}$ \\
\hline Propano & $-42,1$ & 583 & $2 \mathrm{G} / 2 \mathrm{PG}$ \\
\hline Propileno & -47 & 606 & $2 \mathrm{G} / 2 \mathrm{PG}$ \\
\hline Cloreto de vinilo & $-13,7$ & 965 & $3 \mathrm{G}$ \\
\hline Nitrogênio & -196 & 0,8 & \\
\hline
\end{tabular}

Segundo IGC IMO (2005) dentro da classificação da IMO os navios que transportam GNL são considerados como navios do tipo $2 \mathrm{G}$. A IMO define quatro níveis de perigo (1G, $2 \mathrm{G}, 2 \mathrm{PG}, 3 \mathrm{G})$ associados à periculosidade da carga transportada. $\mathrm{O}$ navio com denominação $1 \mathrm{G}$ requer as máximas medidas de prevenção para impedir o vazamento da carga. O navio do tipo $2 \mathrm{G}$ exige significativas medidas preventivas para impedir o vazamento da carga. $\mathrm{O}$ tipo 2PG é um navio de 150 metros de comprimento ou menor que requer medidas preventivas significativas para impedir o vazamento da carga. E por último, o navio tipo $3 \mathrm{G}$ é o navio que requer medidas preventivas moderadas para impedir o vazamento da carga. Assim, o navio tipo $1 \mathrm{G}$ é um navio transportador destinado ao transporte de produtos considerados de maior perigo, e os tipos $2 \mathrm{G} / 2 \mathrm{PG}$ e $3 \mathrm{G}$ são navios que transportam cargas que tem um perigo menor. 
Lamb (2004) e IGC IMO (2005) apresentam características específicas para os navios que transportam GNL. Essas características são apresentadas na Tabela 2.4 onde, dependendo da característica do tanque principal de carga, é que será instalada uma barreira secundária do tipo parcial ou total. Para navios transportadores do tipo B (navio tipo esférico ou Moss) não será necessária a instalação de uma barreira secundária completa. Por outro lado, nos navios tipo membrana é obrigatória a instalação desta barreira. Em todos os navios de transporte de GNL o isolamento é indispensável.

O IGC IMO (2005) e Wilson (1974) definem a barreira primária como o elemento interior projetado para conter a carga quando o sistema de contenção de carga inclui duas barreiras. A barreira secundária é o elemento externo à barreira primária, projetada para proporcionar contenção temporária ante qualquer vazamento da carga através da barreira primária e para impedir a redução da temperatura da estrutura do navio para um nível inseguro. Esta barreira secundária é um requisito obrigatório para substâncias transportadas em temperaturas inferiores a $-10^{\circ} \mathrm{C}$ e à pressão atmosférica.

A barreira secundária é projetada para:

Ser capaz de conter qualquer vazamento da carga líquida por um período de 15 dias.

$\checkmark$ Impedir a redução da temperatura da estrutura do navio a um nível de perigo no caso de vazamento da barreira primária.

As barreiras secundárias devem ser inspecionadas periodicamente para comprovar o seu bom estado, devendo ser executados testes de pressão/vácuo e inspeções visuais (IGC IMO, 2005).

É importante que o GNL não entre em contato com a estrutura do navio, já que o material de fabricação do casco é aço carbono e ele não é capaz de suportar as baixas temperaturas dos fluidos criogênicos sem apresentar fragilização (WILSON, 1974).

Os navios que são utilizados para transportar grandes quantidades de GNL são os navios com tanques independentes tipo B e os navios tipo membrana. Os navios independentes tipo A são utilizados para o transporte do GLP. Os navios independentes tipo C são utilizados para transportar pequenas quantidades de GNL e GLP sob certas condições de pressão e 
temperatura. Na Tabela 2.4 apresentam-se as características dos navios de acordo com a IMO segundo o tipo de tanque utilizado.

Tabela 2.4 - Características dos navios que transportam GNL (LAMB, 2004)

\begin{tabular}{|c|c|c|c|l|}
\hline $\begin{array}{c}\text { Tipo de tanque de } \\
\text { acordo ao código da } \\
\text { IMO }\end{array}$ & Configuração & Isolamento & $\begin{array}{c}\text { Barreira } \\
\text { secundária }\end{array}$ & Exemplo do navio \\
\hline Independente tipo C & Esférico & Sim & Não & $\begin{array}{l}\text { Navios pequenos de transporte de } \\
\text { GLP }\end{array}$ \\
\cline { 2 - 5 } & Esférico & Sim & Não & $\begin{array}{l}\text { Navios de transporte multi-propósito } \\
\text { GNL }\end{array}$ \\
\cline { 2 - 5 } Independente tipo B de transporte de \\
\hline $\begin{array}{c}\text { Independente tipo A } \\
\text { prismático }\end{array}$ & $\begin{array}{c}\text { Esférico ou } \\
\text { prismático }\end{array}$ & Sim & Parcial & $\begin{array}{l}\text { Navios transportadores de } \\
\text { grandes quantidades de GNL e } \\
\text { GLP }\end{array}$ \\
\hline Integrados tipo \\
Membrana & Prismático & Sim & Completa & $\begin{array}{l}\text { Navios transportadores de GLP } \\
\text { grandes quantidades de GNL }\end{array}$ \\
\hline
\end{tabular}

Segundo DNV (2011), Wilson (1974) e Harris (1993), os navios transportadores de GNL podem ser divididos em dois grandes grupos de acordo com o tipo de apoio do tanque de carga, os quais são:

$>$ Tanques independentes ou auto-apoiados

$>$ Tanques integrados

$\mathrm{Na}$ categoria dos tanques independentes se encontram os navios que tem tanques do tipo prismático ou esférico. Neste tipo de configuração o tanque de carga deve resistir a todas as cargas geradas pelo fluido durante a sua operação de maneira independente da estrutura do casco da embarcação. Uma característica deste tipo de tanques é que, como ele deve suportar de maneira independente as cargas internas e externas associadas ao transporte do fluido, esses tanques são fabricados com uma espessura de parede maior, mas os materiais utilizados para a sua fabricação devem suportar também as baixas temperaturas.

Por outro lado, na categoria dos tanques integrados, têm-se tanques que dependem intimamente da estrutura do navio para manter a sua forma geométrica e a integridade estrutural. Esses são conhecidos como tanques do tipo membrana. Embora geralmente requeiram um sistema de isolamento mais complexo, assim como a instalação completa de 
uma barreira secundária que proteja todo o tanque de carga, a vantagem é que exigem uma menor quantidade de materiais para a construção dos tanques de carga em comparação com o primeiro grupo, determinado pela menor espessura da camada de material utilizada na fabricação das barreiras, reduzindo o tempo de resfriamento do tanque de carga. Por outro lado, tem-se que o espaço entre a estrutura do navio e a do tanque de armazenamento é reduzido, fato que reduz a quantidade de gás inerte requerido para a inertização dos espaços que estão em torno destes tanques de carga (ICS, 1995).

Dentre os grupos de classificação dos tanques de armazenamento identificam-se quatro tipos de navios de acordo com a forma do tanque de armazenamento e do material utilizado para a sua fabricação. A seguir são apresentados estes quatro tipos de navios de maneira resumida.

\subsubsection{Navios do tipo prismático}

Segundo Harris (1993), Wang (2005) e Lamb (2004) a companhia japonesa IshikawajimaHarima Heavy Industries Co. Ltd foi quem desenvolveu este projeto baseado no uso de tanques independentes feitos de liga de alumínio. Este conceito foi chamado de sistema IHI SPB (Self-supporting Prismatic-shape IMO type B SPB) onde os tanques de carga são posicionados com o uso de apoios e calços que impedem o movimento do corpo rígido do tanque sob ação das cargas estáticas e dinâmicas, permitindo a contração e expansão dos tanques sob as variações de temperatura e deformações do casco. Na Figura 2.7 é apresentada a configuração deste tipo de navio.

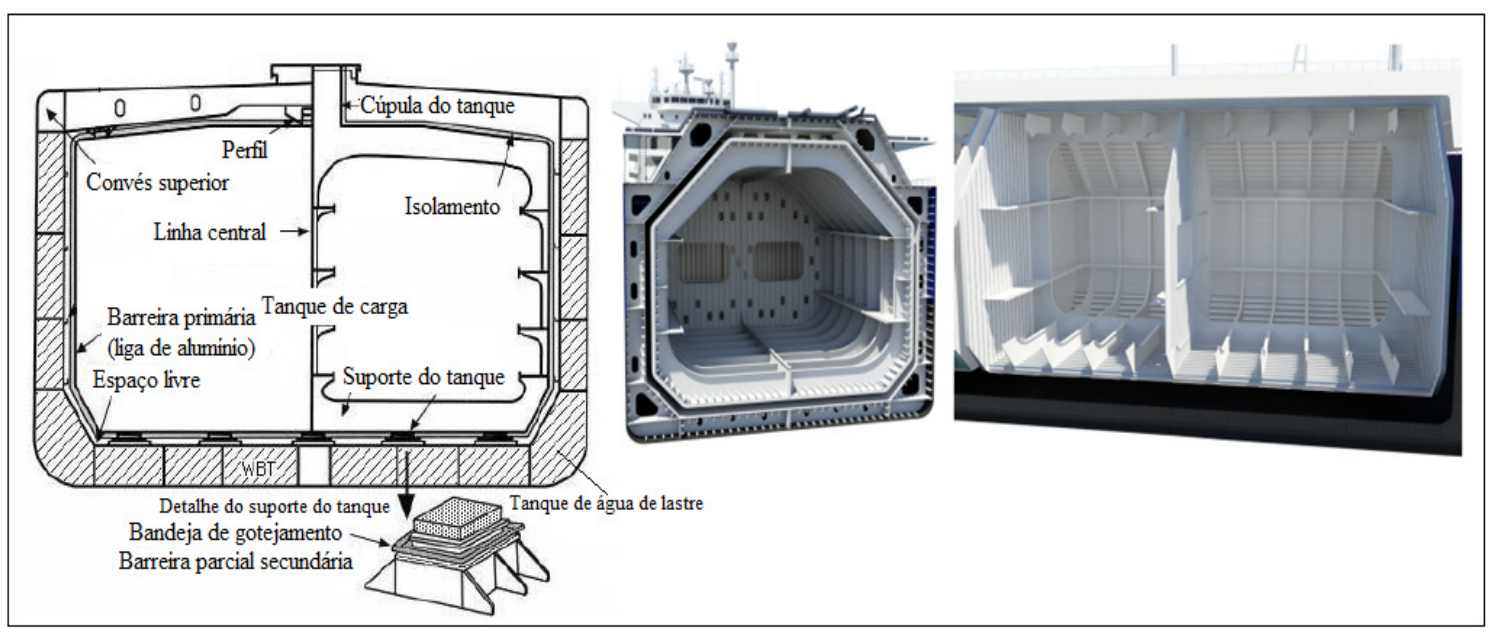

Figura 2.7 - Tanque de tipo prismático (LAMB, 2004; JONES E TVEITNES, 2003) 
A barreira secundária deste tanque é uma barreira parcial constituída por bandejas de gotejamento. De acordo com a IGC IMO (2005) os tanques de carga do tipo B só requerem uma barreira secundária do tipo parcial.

De acordo com Jones e Tveitnes (2003), a frota total de navios com este tipo de configuração é pequena. A maioria dos navios transportadores de metano existentes são do tipo Moss-Rosenberg (esfera) e do tipo Technigas (membrana), analisados na sequência deste texto.

\subsubsection{Navios do tipo Moss ou esféricos}

Estes navios são do tipo de tanques independentes que suportam integralmente o peso da carga. Também são conhecidos como esféricos, ou Moss tipo B. De acordo com Wilson (1974) este tanque conta com um cilindro vertical cuja base está soldada à estrutura do navio, como pode ser visto na Figura 2.8.

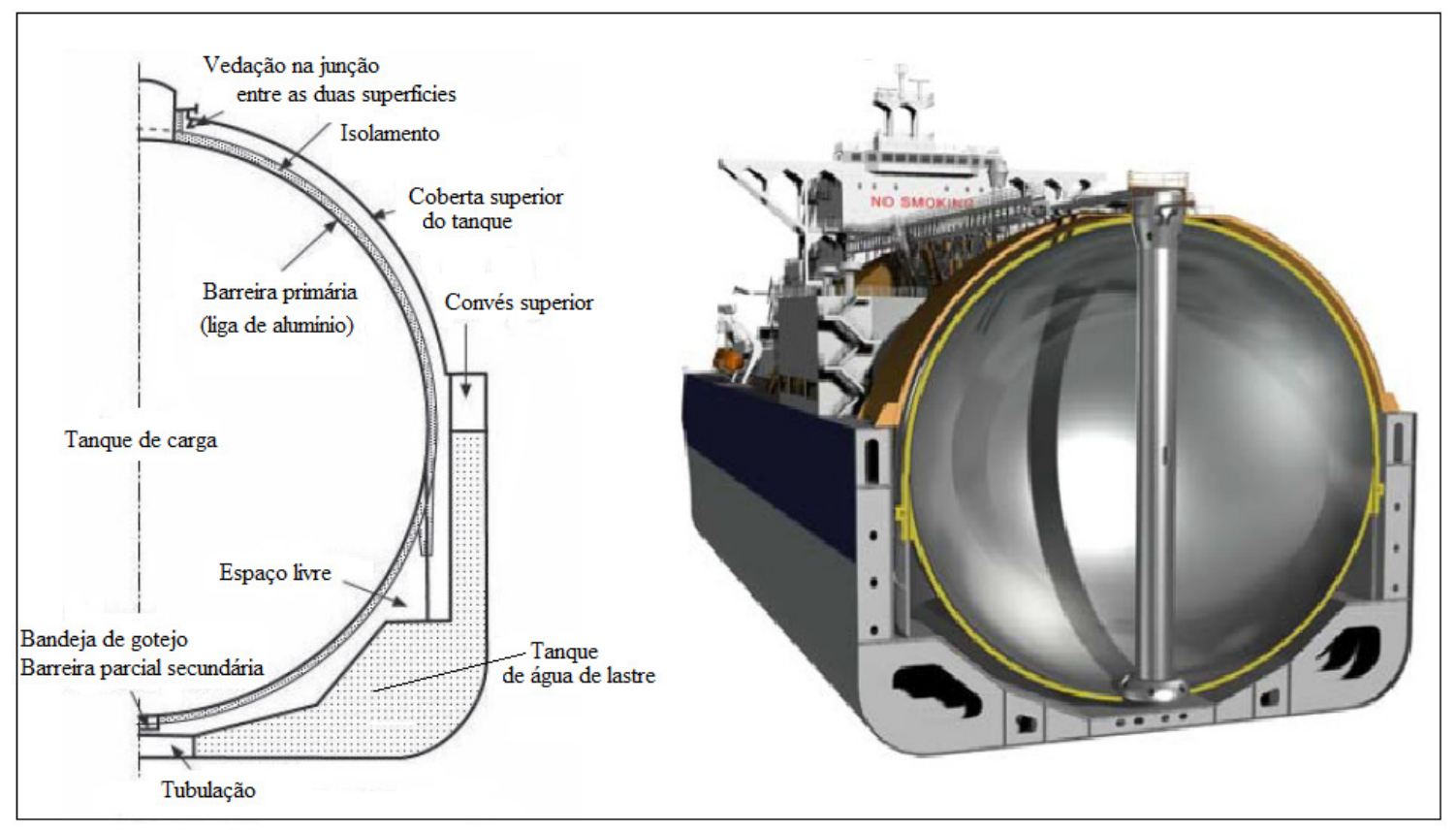

Figura 2.8 - Tanque do tipo Moss (LAMB, 2004; MICHOT, 2003)

De acordo com Wang (2005) e Lamb (2004), as esferas são construídas de liga de alumínio com espessuras de $25 \mathrm{~mm}$ até $100 \mathrm{~mm}$ e são suportadas em seu equador pela estrutura do navio. Os tanques são isolados com espuma de resina de fenol e espuma de 
poliuretano. A parte superior da esfera do tanque de carga deve estar protegida contra os efeitos ambientais, já que essa parte é a que tem contato com ao ambiente externo marinho.

Segundo Wilson (1974) e ICS (1995), todos os espaços em torno dos tanques de carga são preenchidos com gás inerte. Um sistema de monitoração é montado nesses espaços para indicar o possível local do vazamento do GNL. O grau de contaminação do gás inerte dependerá da gravidade do problema que produz o vazamento do GNL.

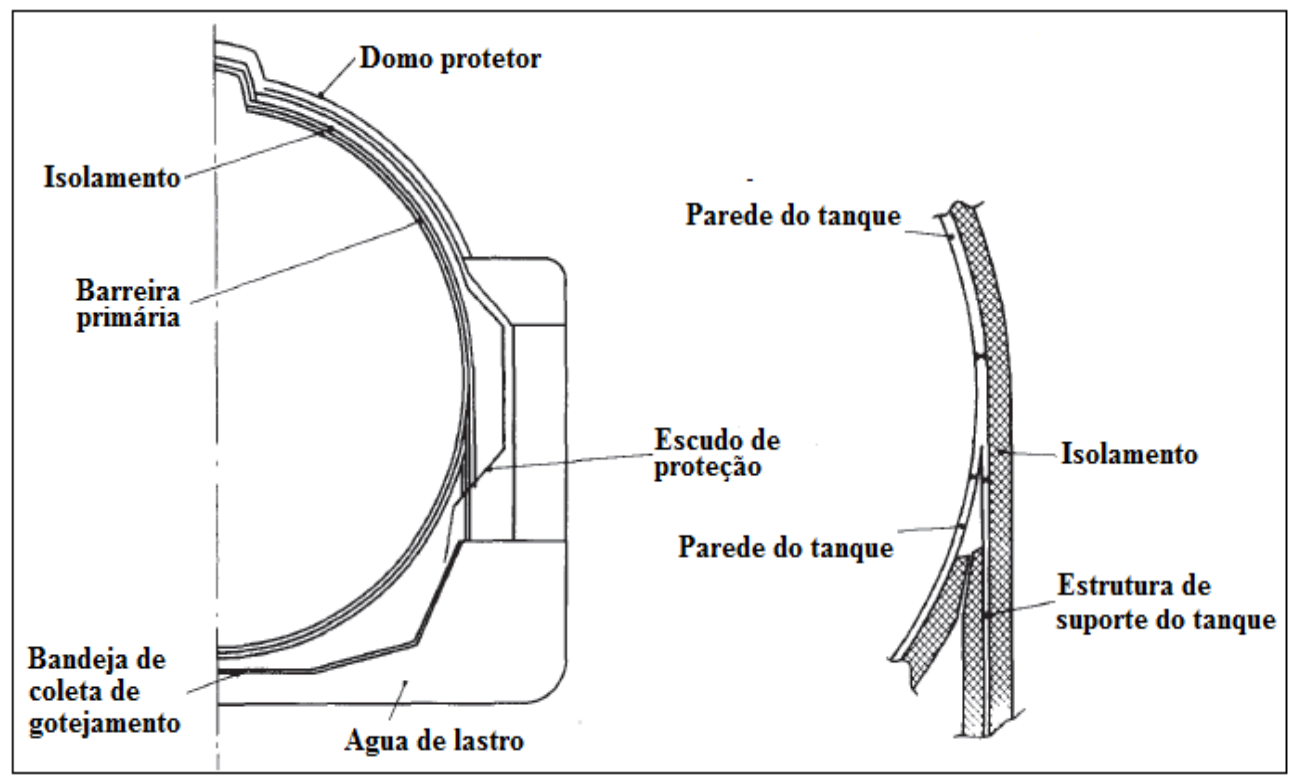

Figura 2.9 - Barreira parcial no tanque tipo Moss (WILSON, 1974)

A instalação de uma barreira secundária completa não é necessária, e no seu lugar o tanque conta com uma barreira parcial que serve como proteção contra vazamentos e evitando a redução da temperatura do casco pelo contato com o GNL. A barreira parcial é uma bandeja de coleta de gotejamento que fica na parte inferior do tanque principal de carga. Na Figura 2.9 é apresentada a barreira parcial nos navios tipo Moss.

\subsubsection{Navios do tipo membrana GTT MARK III}

Estes tipos de tanques são conhecidos como Technigaz Membrane ou simplesmente membrana. Eles são fabricados utilizando a tecnologia Francesa chamada Technigaz Mark III onde a primeira camada de contato com o produto é fabricada de aço inoxidável (HARRIS, 1993). 
Segundo o IGC IMO (2005), os tanques tipo membrana são do tipo integrados, que consistem numa camada fina chamada membrana que é suportada através do isolamento pela estrutura do casco adjacente. Esta membrana é projetada de tal forma que a expansão e contração térmica são compensadas sem gerar esforços adicionais sobre a membrana. $\mathrm{O}$ valor da pressão interna do tanque não deve exceder 0,7 bar, mas a pressão durante um funcionamento normal é da ordem de 0,25 bar.

De acordo com Wilson (1974) e Wang (2005) a pequena espessura formando a primeira camada do tanque (de $0,7 \mathrm{~mm}$ até $1,5 \mathrm{~mm}$ ) requer um período de tempo menor para o processo de resfriamento do tanque, conforme o protocolo de carga/descarga. A inspeção para este tipo de tanque é mais complexa quando comparada com navios de tanques independentes devido à acessibilidade, porém um bom controle de qualidade nos processos de soldagem nas placas do tanque é uma tarefa de prevenção recomendada.

A membrana é montada e soldada em forma de tiras de aço inoxidável montadas sobre os painéis de isolamento. Os painéis de isolamento são feitos de três camadas coladas no casco do navio e que servem para apoiar a primeira camada do tanque (ABS, 2008; LAMB, 2004). Essas três camadas são:

$160 \mathrm{~mm}$ de espessura de espuma de poliuretano reforçado com fibra de vidro.

$>$ Uma camada Triplex que atua como barreira secundária.

$>80 \mathrm{~mm}$ de espessura de placa de poliuretano.

A membrana é um forro flexível com uma série de ondulações perpendiculares entre si que resistem às mudanças térmicas e deformações na estrutura do navio por flexão. Esta tecnologia inclui uma folha de alumínio com fibra de vidro que forma a barreira secundária chamada de Triplex e um sistema de isolamento como um sanduíche entre as duas camadas que, basicamente, são madeira compensada e fibra de vidro reforçado com espuma rígida de poliuretano (HARRIS, 1993). Na Figura 2.10 e Figura 2.11 visualiza-se a configuração deste tipo de navio. 

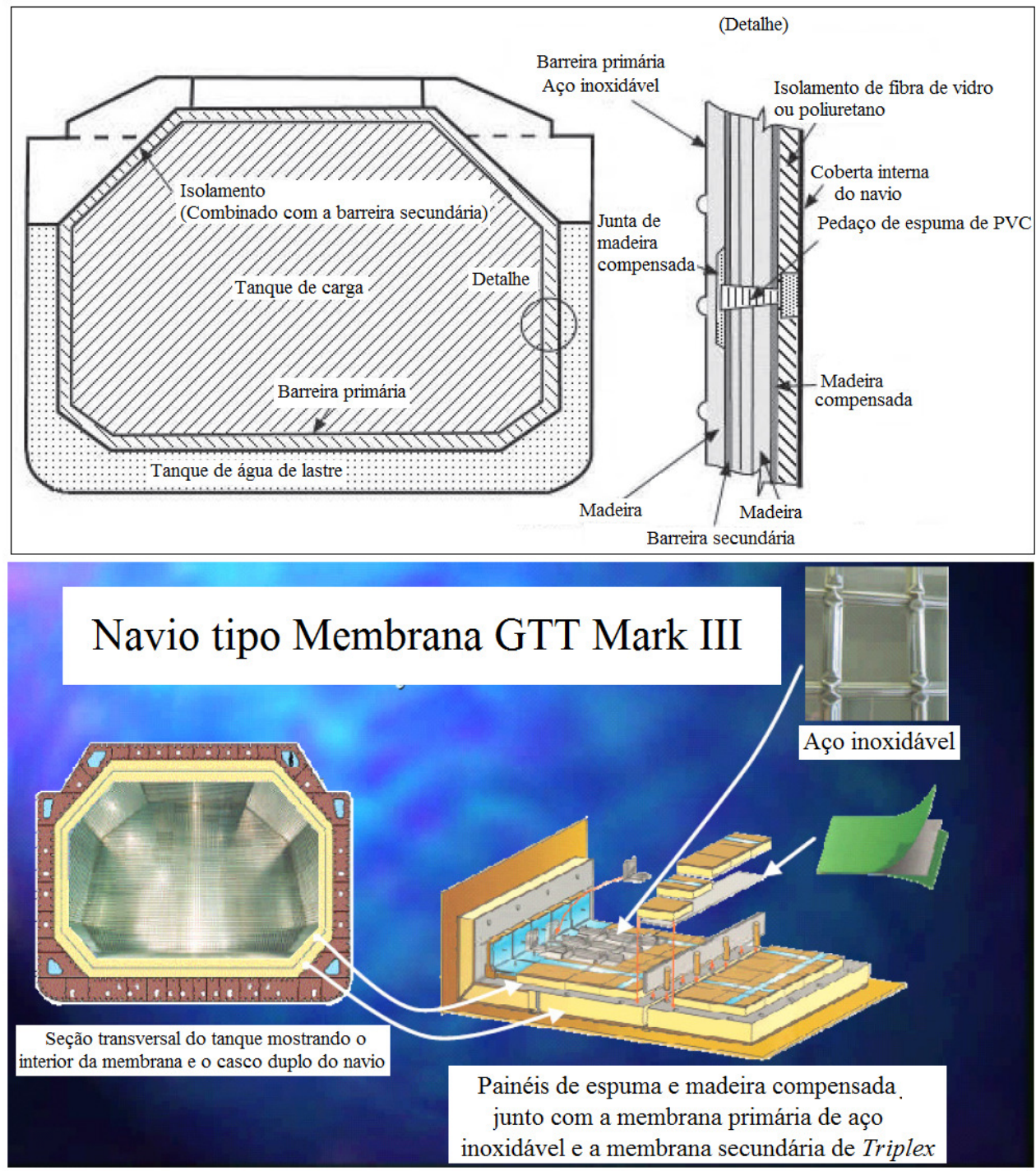

Figura 2.10 - Tanque do tipo membrana GTT Mark III (LAMB, 2004; ABS, 2008)

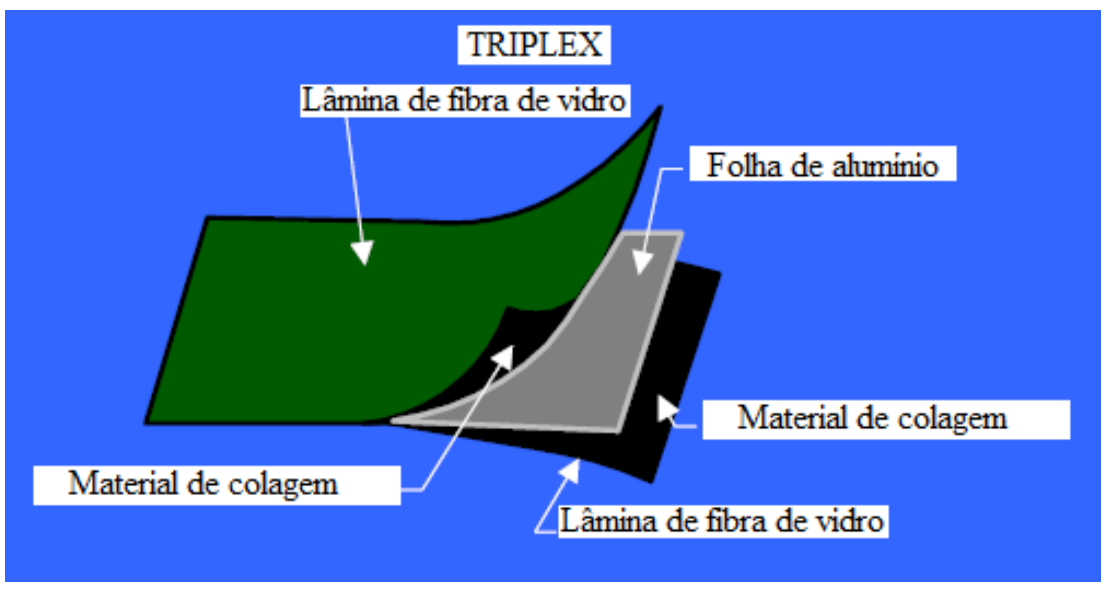

Figura 2.11 - Detalhe da barreira secundária do tanque membrana GTT Mark III (ABS, 2008) 


\subsubsection{Tanques de tipo membrana GTT $\mathbf{N}^{\circ} 96$}

De acordo com a ABS (2008) o ponto importante do projeto Francês chamado sistema Gas Transport (GT096) é o uso de invar para a fabricação da membrana. O invar é um aço inoxidável com alto teor de níquel (36\%) que tem um coeficiente muito baixo de dilatação térmica (da ordem $10 \%$ do observado em um aço comum) com quase nenhuma contração na faixa das temperaturas criogênicas, como a utilizada na operação com GNL. As membranas dos navios construídos com esta tecnologia estão dispostas com superfícies planas internas semelhantes à tecnologia Technigaz. A Figura 2.12 e Figura 2.13 apresentam este tipo de tanque de armazenamento.

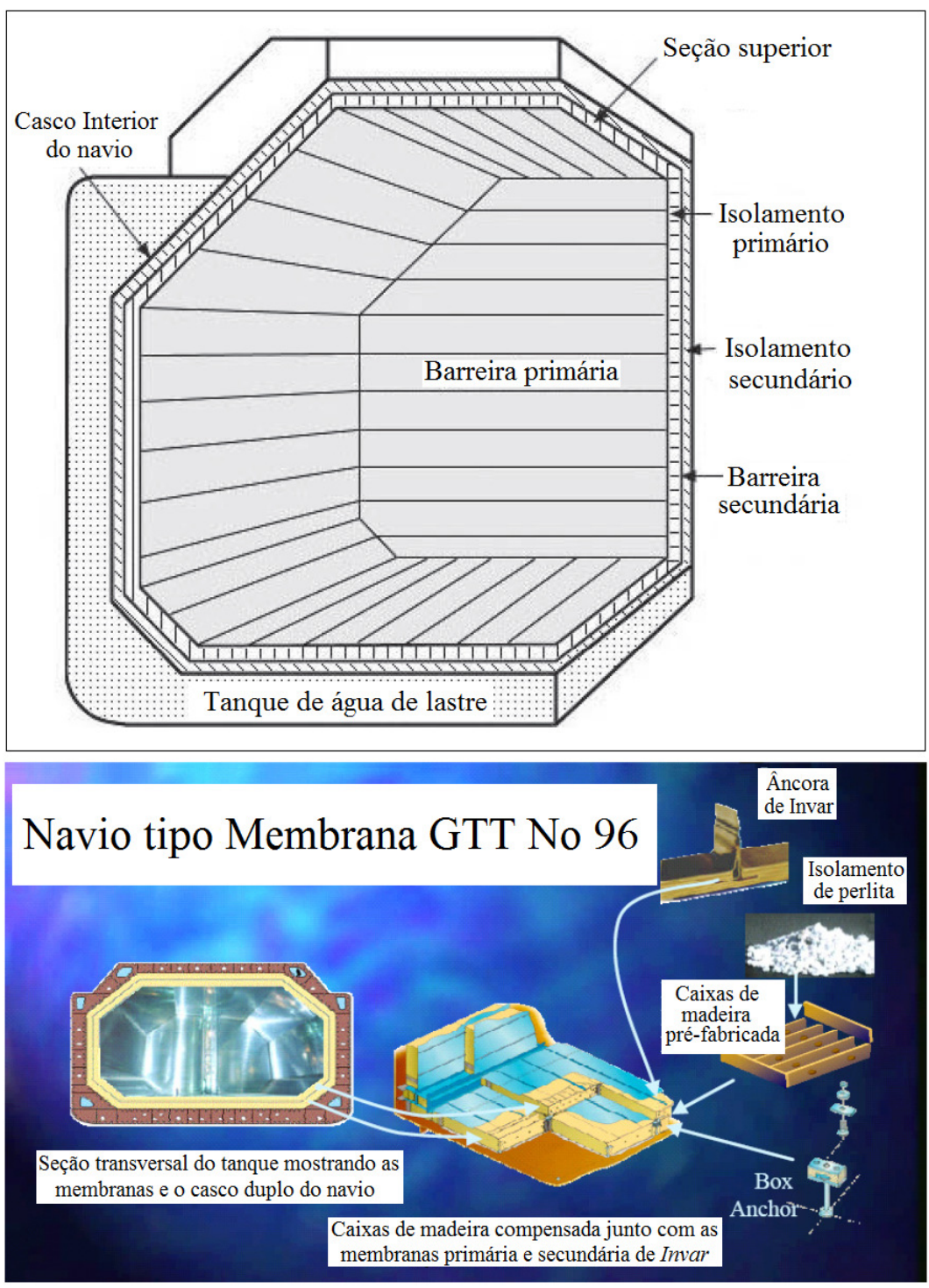

Figura 2.12 - Tanque do tipo membrana GTT No 96 (ABS, 2008; LAMB, 2004) 


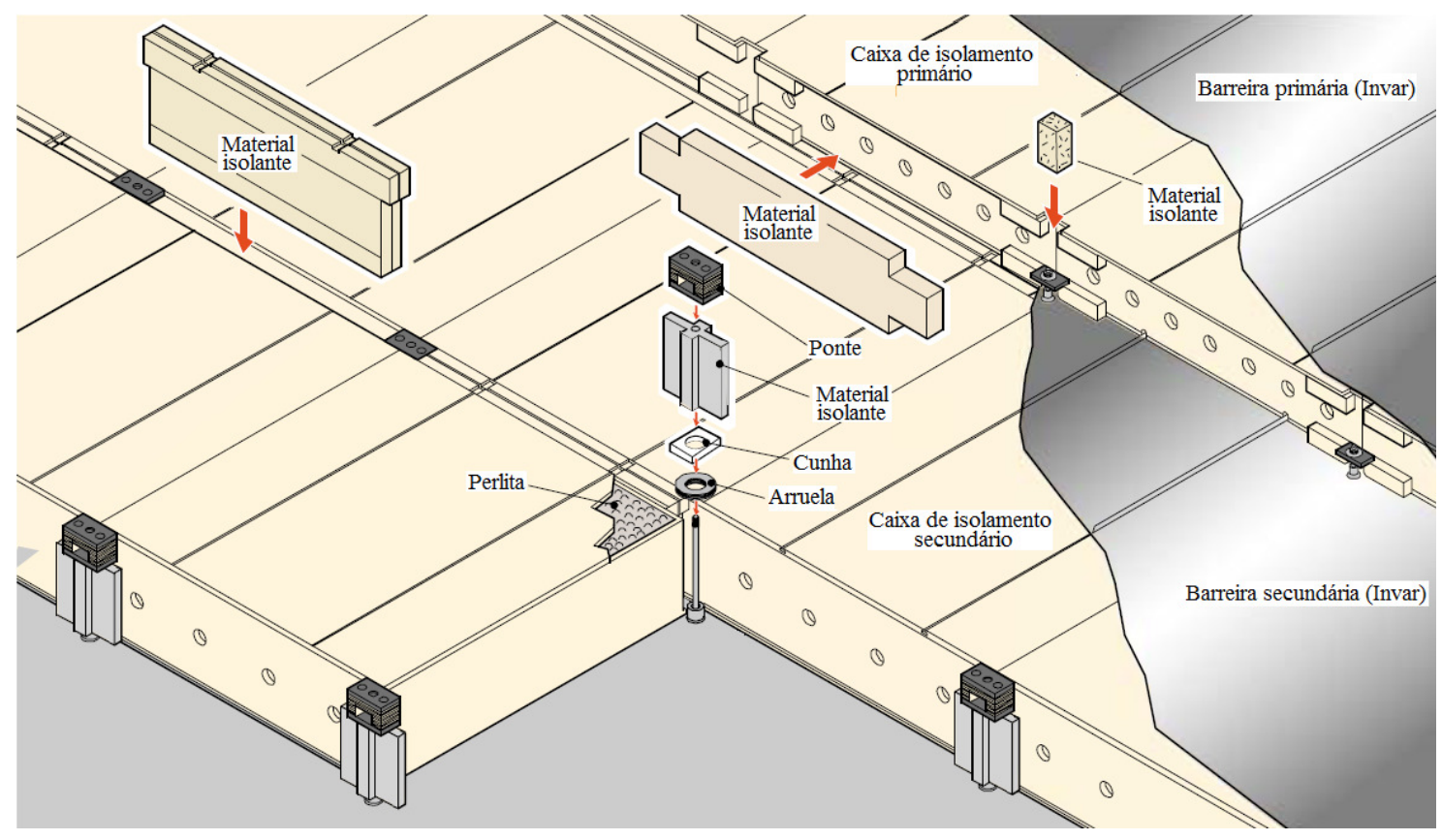

Figura 2.13 - Detalhes do tanque de tipo membrana GTT No 96 (ABS, 2008; LAMB, 2004)

Este tipo de navio está equipado com membranas idênticas feitas de Invar (barreira primária e barreira secundária). Os elementos isolantes, tanto primário quanto secundário, são caixas de madeira cheias de perlita expandida como mostrado em detalhe na Figura 2.13. A perlita expandida é um material de isolamento à base de sílica expandida. As caixas são parafusadas ao casco interno e fornecem a superfície de apoio ao tanque de carga primário.

Este tipo de tanque de carga tem uma barreira secundária que envolve toda a barreira primária (IGC IMO, 2005; ABS, 2008).

\subsection{Acidentes envolvendo navios transportadores de GNL ocorridos quando o navio se encontra ancorado no terminal}

Segundo a Rausand (2011), acidente é definido como um evento imprevisto, indesejável, instantâneo ou não, que resulta em danos às pessoas, ao patrimônio (próprio ou de terceiros), ou impacto ao meio ambiente. Entretanto, incidente é definido como um evento imprevisto, indesejável, instantâneo ou não, que poderia resultar em danos às pessoas, ao patrimônio ou ao meio ambiente, as quais não ocorrem em função da ação das barreiras de proteção existentes no sistema. De acordo com esta definição um acidente é um caso especial de um incidente, ou seja, é um incidente que resulta em danos. 
Sovacool (2008) afirma que, ao longo da história foram registrados 279 acidentes com graves consequências dentro das indústrias de geração hidroelétrica, nuclear, do petróleo, carvão e gás natural no período compreendido entre os anos de 1907 e de 2007. O mais lamentável é que todos esses acidentes custaram a vida de mais de 182,156 pessoas. $\mathrm{Na}$ Figura 2.14 há uma comparação entre os maiores acidentes ocorridos nas diferentes indústrias anteriormente mencionadas, de acordo com o número de mortes para esse período.

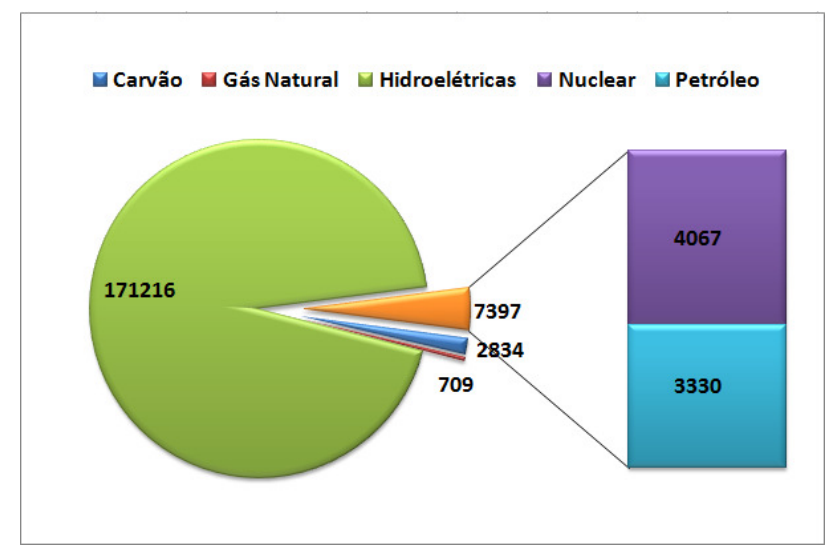

Figura 2.14 - Comparação das mortalidades de acordo com o setor industrial (SOVACOOL, 2008)

Pode-se observar que a indústria de geração hidroelétrica foi o setor em que os acidentes causaram o maior número de mortes entre os anos 1907-2007, onde um único acidente foi o responsável por mais da metade das mortes. Esse grande acidente ocorreu na represa de Shimantan, província de Henan, na China, em 1975, onde 171.000 foram a óbito. O setor de gás natural é o setor que teve o menor número de fatalidades, com 709 mortes.

Dos acidentes ocorridos na área do gás natural deve-se mencionar que a maioria foi em instalações associadas ao transporte do gás natural como gasodutos, estações de compressão, entre outras. A maioria restante ocorreu em terminais de liquefação ou de regaseificação. A Figura 2.15 mostra o número de fatalidades dentro do setor que manuseia o gás natural.

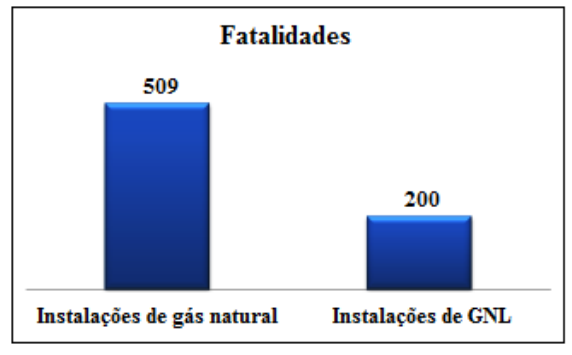

Figura 2.15 - Comparação das fatalidades na indústria do gás natural (SOVACOOL, 2008) 
Como se pode ver na Figura 2.15 somente 200 das mortes aconteceram em instalações relacionadas com a manipulação do GNL, sendo estas instalações tipo onshore.

Ditali e Fiore (2007), Sovacool (2008), CH IV International (2010) e Michot (2003), mostram que dentro os mais conhecidos acidentes envolvendo GNL tem-se o acontecido em Cleveland nos Estados Unidos da América em 1944 (instalação do tipo peak shaving), que é o acidente mais documentado e que trouxe como consequência o maior número de mortes no setor do GNL, tem-se também o acidente em Arzew na Argélia em 1977 (terminal de exportação), em Cove Point nos Estados Unidos da América em 1979 (terminal de importação), em Bontang na Indonésia em 1983 (terminal de exportação), e por último em Skikda na Argélia em 2004 (terminal de exportação), todos eles em instalações fixas localizadas em terra.

Segundo Ditali e Fiore (2007), Vanem et al. (2008) e IMO (2007), durante a história do transporte do GNL por meio de navios não houve perda de carga transportada. É assim que, de todos os acidentes mais significativos que ocorreram com estes navios, nenhum deles teve um resultado catastrófico como poderia ser o naufrágio do navio transportador de GNL.

No Anexo I se apresentam alguns dos acidentes ocorridos durante a permanência de navios transportadores de GNL nos terminais, seja fazendo o carregamento ou o descarregamento da carga transportada.

\subsection{Componentes do sistema de carga e descarga dos navios transportadores de GNL}

A praça de máquinas destinada a conter os equipamentos utilizados para carga ou descarga do GNL está localizada em um espaço aberto e diferente do espaço onde fica a praça de máquinas do próprio navio.

Os equipamentos estão submetidos a diferentes condições de operação, e a característica principal neste tipo de navio, em particular, é que a substância a ser carregada, transportada e descarregada é uma substância que tem temperatura criogênica. Essa temperatura provoca alterações nas propriedades mecânicas dos materiais, e os requisitos do projeto visam atender essas condições operacionais. Alguns metais podem apresentar trincas, ou até romper-se, como, por exemplo, o aço carbono do casco do navio, como consequência das baixas temperaturas características do GNL. É por essa razão, que os materiais usados neste tipo de 
sistemas devem suportar as baixas temperaturas sem significativa alteração de suas propriedades mecânicas.

De acordo com Shigley (2008) os aços estruturais podem sofrer fratura frágil a baixas temperaturas requerendo uma reduzida energia para propagar a sua fratura, ao contrário dos materiais resistentes à fratura como o alumínio ou os aços inoxidáveis austeníticos que precisam de uma maior energia para propagar a trinca. Os aços estruturais têm uma região de transição entre a zona frágil e dúctil que está na faixa de temperatura de $-50{ }^{\circ} \mathrm{C}$ a $0{ }^{\circ} \mathrm{C}$. A curva característica de um aço de baixa resistência à fratura é mostrada na Figura 2.16.

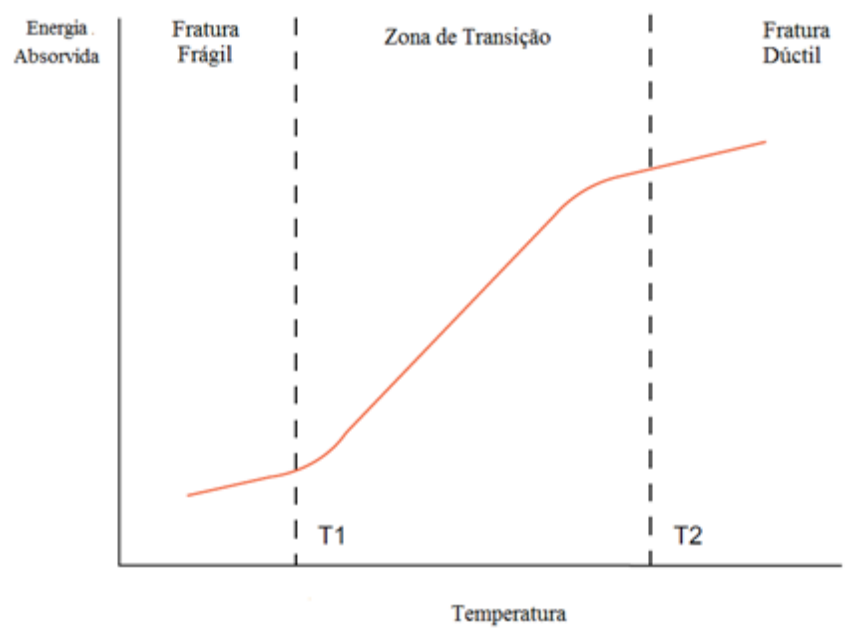

Figura 2.16 - Comportamento do aço de baixa resistência (SHIGLEY, 2008)

Os materiais apresentam uma variação de tenacidade ou de ductilidade com a variação da temperatura. Metais com estrutura cristalina cúbica de faces centradas, por exemplo, cobre, alumínio, níquel e aço inoxidável austenítico, apresentam uma queda suave de tenacidade com a diminuição da temperatura. Por sua vez, metais com estrutura cristalina cúbica de corpo centrado, por exemplo, aço ferrítico, apresentam sensível queda em tenacidade em certa faixa de temperatura (FORTES, 2003).

Para conseguir um controle do fluxo da substância transportada durante a carga e descarga de GNL, necessita-se de uma série de equipamentos e de sistemas que permitam controlar e monitorar o fluxo do produto. Alguns destes componentes serão apresentados na sequência deste texto. 


\subsubsection{Tubulações do sistema de carga e descarga de GNL}

De acordo com IGC IMO (2005), as tubulações que carregam o líquido criogênico devem estar termicamente isoladas para evitar a troca de calor com o meio ambiente. Nos lugares onde as tubulações ou conexões são regularmente desmontadas ou desconectadas, como no caso do manifold, deve existir uma proteção no casco do navio para evitar o contato direto do líquido com o casco quando produzido um vazamento. Essa proteção é feita por meio de bandejas de gotejamento e por uma cortina de água.

Segundo Harris (1993) e ABS (2008), o sistema de tubulações é composto por três tipos de tubulações que estão localizadas acima da coberta do navio e são as seguintes: 1) tubulações destinadas ao carregamento ou descarregamento de GNL, 2) tubulações destinadas ao deslocamento de boil-off durante a carga e descarga do GNL e 3) tubulações que fazem parte do sistema de alívio. Estas tubulações são projetadas para contraírem e expandirem, dependendo das condições internas e externas de temperatura, dos movimentos dos tanques de armazenamento ou pelas deformações da estrutura do navio, e para isso estão equipadas com juntas de dilatação mecânica. Todas as tubulações ou componentes que manuseiam o GNL devem ser providos de válvulas de alívio.

\subsubsection{Bomba criogênica}

Vários tipos de bombas estão disponíveis no mercado para bombear fluidos criogênicos, mas a tendência para o bombeamento do GNL a partir do interior dos tanques criogênicos é o uso da bomba do tipo submersa (do inglês - submerged pump) fixas ou removíveis. Estas últimas, em caso de necessidade, podem ser retiradas do tanque mesmo quando o tanque contiver a carga (ICS, 1995).

De acordo com Karassik (2001) a aplicação da bomba submersa foi introduzida em 1959. Dado que estes fluidos são excelentes dielétricos, parte do fluxo de fluido bombeado pode ser direcionado através do motor para resfriá-lo e lubrificar os rolamentos. Não há necessidade de proteger os enrolamentos do motor da bomba, mas como uma proteção adicional, é necessário o uso de vernizes especialmente selecionados para evitar a reação química devido ao contato direto com o fluido criogênico. Este tipo de bomba criogênica apresenta as seguintes vantagens:

Não necessitam de um sistema de resfriamento. 
$\checkmark$ Alta confiabilidade inerente devido à proteção contra a corrosão e umidade e eliminação de vedação do eixo.

$\checkmark$ Problemas mínimos de contração do material.

$\checkmark$ Capacidade de rejeitar o calor evitando a formação de um ponto quente.

Este tipo de bomba é pequeno, já que não tem um sistema de refrigeração que está presente em bombas normais que trabalham abertas ao meio ambiente. Na Figura 2.17 podese ver a bomba criogênica do tipo submersa.

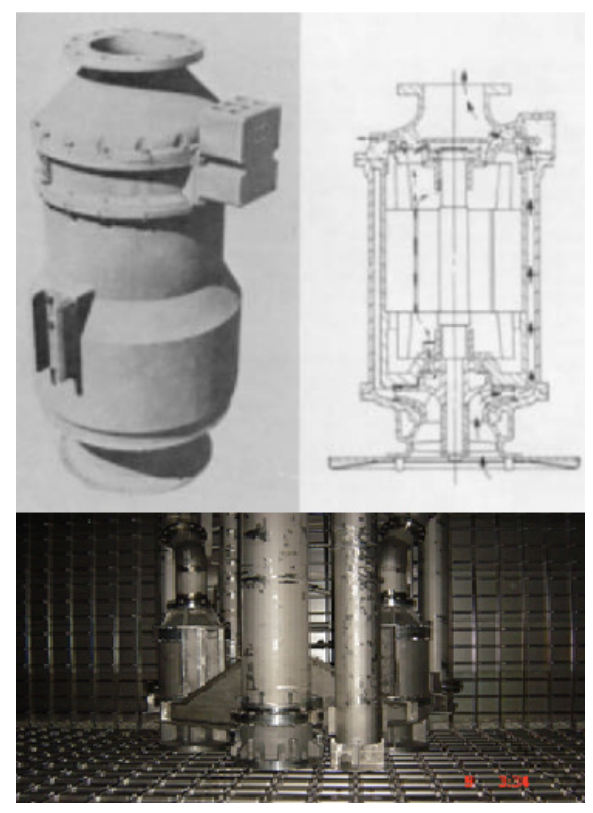

Figura 2.17 - Bomba criogênica do tipo submersa (KARASSIK, 2001; WAVESPEC, 2006)

Wilson (1974) afirma que as bombas são normalmente projetadas com pouca folga e quando o GNL é carregado contendo impurezas ou até água, esses cristais de gelo (gerados devido à presença de água no GNL) podem ser a causa da falha da bomba. Daí a importância da etapa de processamento, que retira as principais impurezas do gás natural.

\subsubsection{Sistema de paralisação de emergência ESD (Emergency Shut-Down)}

Cada instalação portuária, onde se carrega ou descarrega o GNL, deve contar com um sistema ESD, que quando ativado isola ou desliga as fontes de abastecimento de GNL, como, bombas de GNL, ou fecha válvulas impedindo a vazão do fluido e paralisando as operações de carga e descarga de GNL (NPFA59A, 2001; ABS, 2008). 
Segundo Harris (1993), o sistema de fechamento de emergência operará automaticamente devido à perda de energia elétrica ou de energia de controle, à perda de energia no atuador da válvula e ao incêndio nas cúpulas dos tanques ou no manifold de bombordo ou estibordo. Além disso, em vários lugares ao redor do navio, pontos de controle para a ativação do ESD são instalados para fechar as válvulas que funcionam com o ESD e parar as bombas de carga e compressores, se necessário, evitando vazamentos de grandes magnitudes.

De acordo com BS (2007) a função do ESD é minimizar o vazamento do hidrocarboneto e a geração de qualquer evento de perigo em áreas adjacentes.

\subsubsection{Válvulas criogênicas}

Todas as tubulações que carregam o GNL ou o boil-off com exceção do sistema de alívio e os sistemas de medição do nível dentro dos tanques, têm válvulas que servem para o controle do fluxo, as quais são ativadas durante o processo de carga e descarga do navio (HARRIS, 1993). Na Figura 2.18 observa-se as válvulas criogênicas instaladas no navio transportador de GNL.

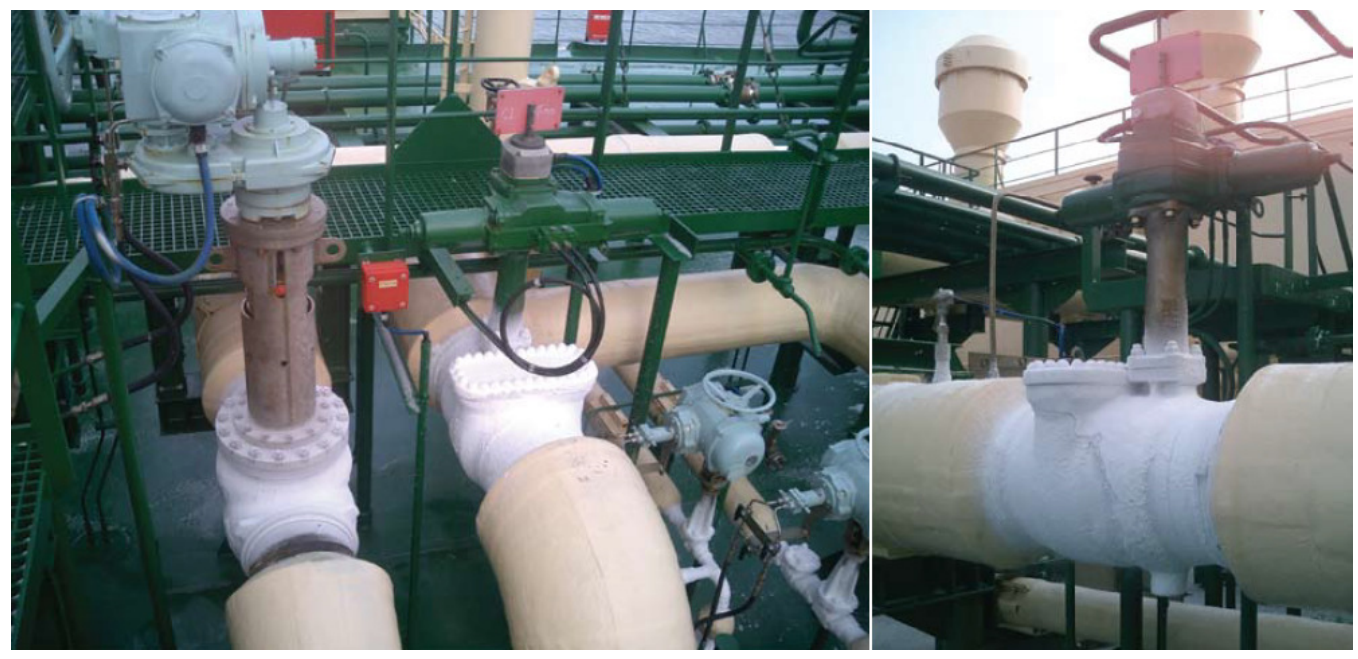

Figura 2.18 - Válvulas criogênicas instaladas no navio transportador de GNL (SIGTTO, 2002)

Segundo com SIGTTO (2002) as válvulas criogênicas que trabalharão com substâncias a temperaturas inferiores a $-55^{\circ} \mathrm{C}$ são submetidas a testes de vedação. Este teste é feito da seguinte maneira:

$\checkmark$ A válvula é submersa em $\mathrm{N}_{2}$ a $-196{ }^{\circ} \mathrm{C}$ resfriando-a. Esta temperatura é inferior à temperatura usual com que a válvula opera $\left(-162^{\circ} \mathrm{C}\right)$. 
$\checkmark$ Logo em seguida é injetado Hélio na válvula para verificar a presença de vazamentos na vedação das juntas.

$\checkmark$ Nestes testes é utilizado o Hélio já que este tem um baixo peso molecular permitindo detectar facilmente os vazamentos, que não aconteceria com fluidos com maior peso molecular.

\subsubsection{Isolamento}

De acordo com IGC IMO (2005) quando o produto que está sendo transportado tem uma temperatura abaixo de $-10^{\circ} \mathrm{C}$ o isolamento deve assegurar que a temperatura do casco do navio não caia abaixo da temperatura para o qual ele foi projetado. Os materiais do isolamento devem resistir ao fogo e a propagação de chamas.

$\mathrm{O}$ isolamento executa a função de reduzir a troca de calor para dentro do tanque ou das tubulações, função importante quando se trata da armazenagem de fluidos criogênicos, a fim de evitar o aquecimento dos mesmos. O aumento da temperatura dentro do tanque ou das tubulações produzirá o boil-off, mas a geração destes gases não será um problema grave desde que o navio conte com sistemas que possam utilizá-los ou eliminá-los para a atmosfera por meio do sistema de alívio (WILSON, 1974).

\subsubsection{Sistema de alívio}

Dado que as tubulações, válvulas e tanques do sistema não estão projetados para suportar pressões excessivas, o GNL não pode permanecer na tubulação, já que este vaporizará devido à troca de calor com o meio ambiente e gerará um acréscimo de pressão. Para evitar esta situação estes navios possuem um sistema de alívio que permite transferir o GNL para dentro dos tanques de armazenamento, evitando um incremento da pressão no interior das tubulações. O boil-off, por sua vez, será descarregado ao meio ambiente por meio dos risers ou utilizado no próprio navio.

De acordo com IGC IMO (2005) e ABS (2008), os tanques de armazenamento que tenham uma capacidade maior do que $20 \mathrm{~m}^{3}$ devem estar equipados com pelo menos duas válvulas de alívio de características semelhantes. Estas duas válvulas devem estar instaladas na parte superior do tanque de armazenamento e devem estar conectadas aos risers por onde os gases sairão livremente para a atmosfera. A altura destes risers (um por tanque) é de três a seis metros. 
Os líquidos criogênicos tendem a se expandir gerando volumes gasosos muito superiores ao volume de líquido inicial. Isso quer dizer que os recipientes contendo este tipo de líquido não podem ser aquecidos porque pode ocorrer uma sobrepressurização do tanque, e como consequência os sistemas de alívio não suportarão a geração excessiva de vapores, causando a ruptura do tanque.

\subsubsection{Braços criogênicos de conexão porto/navio}

Segundo Wilson (1974) e ABS (2008), as bandejas de gotejamento são utilizadas nas seções onde se produz a desconexão dos braços criogênicos com o navio. Em uma instalação de carga ou descarga de GNL existem geralmente três braços criogênicos que escoarão o GNL e um braço criogênico que transportará o boil-off. A Figura 2.19 apresenta os braços criogênicos de carga/descarga estando conectados ao navio.

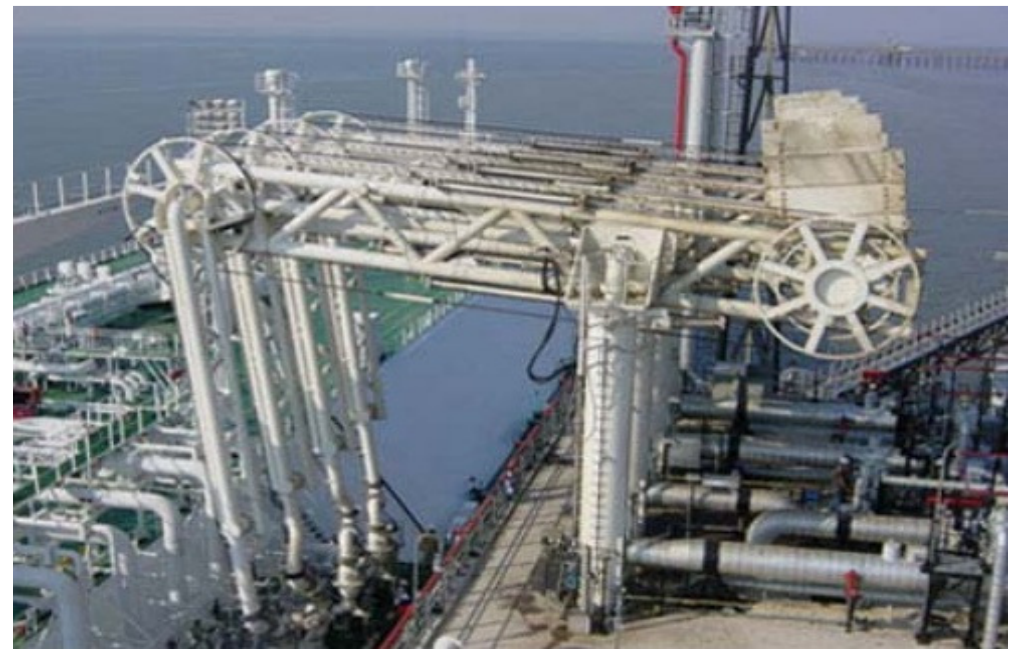

Figura 2.19 - Braços criogênicos de carga/descarga de GNL e boil-off (ALVAREZ, 2009)

\subsection{Operações de carga e descarga do GNL}

O processo de carga e descarga é uma das atividades de um longo procedimento que começa com a chegada do navio ao terminal de liquefação ou regaseificação e acaba quando o navio abandona esses terminais.

Após a chegada do navio ao terminal, ele deve realizar a atracação e a amarração nos cabos com o intuito de fixá-lo de maneira segura ao terminal, evitando a movimentação excessiva durante as operações de carga e descarga. Logo depois é feita a conexão do manifold de bombordo ou de estibordo. A Figura 2.20 mostra o navio atracado e amarrado ao 
terminal com os braços conectados prontos para começar o processo de carga ou descarga do GNL.

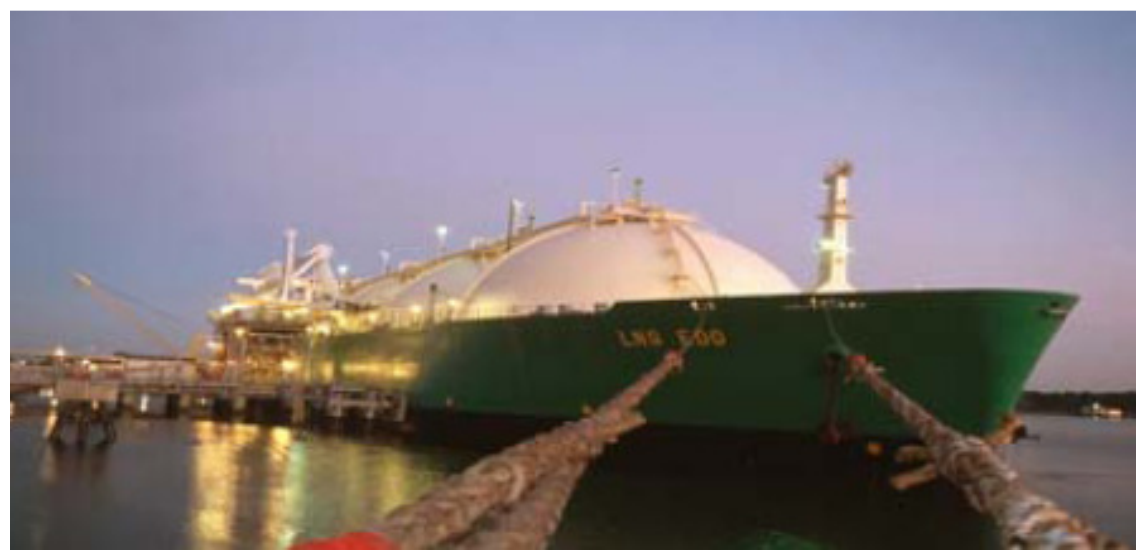

Figura 2.20 - O navio transportador de GNL do tipo Moss atracado no porto (MICHOT, 2003)

Antes da realização da operação de carga, os tanques são cheios com gás inerte, utilizando-se comumente o nitrogênio. $\mathrm{O}$ monitoramento da etapa de inertização é feita por meio dos alarmes instalados dentro dos espaços inertizados para indicar um possível vazamento da carga que provenha dos tanques, permitindo a ativação dos sistemas de emergência dependendo do grau de severidade e da contaminação do gás inerte.

A inertização refere-se ao processo de proporcionar um ambiente não combustível através da adição de gases inertes, que podem ser transportados em recipientes de armazenamento a bordo do navio ou fornecidos a partir do terminal. Estes gases inertes devem ser compatíveis quimicamente com os materiais dos componentes por onde circulam (IGC IMO, 2005; ICS, 1995; ABS, 2008).

Após o processo de inertização vem o resfriamento das tubulações e dos tanques de armazenamento. Em torno de 5\% da carga total de GNL deve permanecer em cada tanque de armazenagem depois da descarga do GNL visando manter a temperatura interna dos tanques durante a viagem do navio vazio. De acordo com Wilson (1974) devido ao súbito ingresso do GNL dentro dos tanques, tendo estes uma temperatura muito maior do que o GNL, haveria um gradiente de temperatura severo no interior dos tanques se não se fizesse o processo de resfriamento. A Figura 2.21 apresenta o aspecto externo dos braços criogênicos durante o processo de resfriamento, que é monitorado continuamente para detectar algum vazamento do GNL nas tubulações. O resfriamento é feito utilizando o sistema spray do navio, usando para 
isso uma bomba chamada bomba stripping/spray, que fica dentro de cada um dos tanques de carga, fazendo com que o GNL percorra os braços criogênicos e os tanques de carga até que a temperatura alcance os $-130^{\circ} \mathrm{C}$. O GNL utilizado para fazer o resfriamento pode vir do terminal ou do próprio tanque de carga do navio (ICS, 1995).

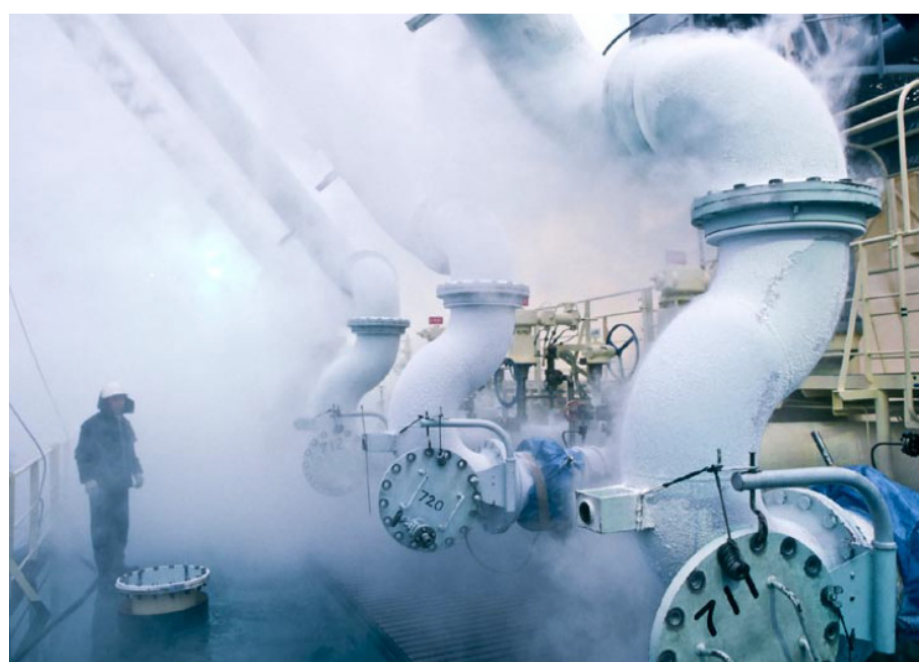

Figura 2.21 - Etapa de resfriamento dos braços criogênicos (CALIFORNIA SENATE OFFICE OF RESEARCH, 2008)

Devido à baixa temperatura dos líquidos criogênicos eles podem condensar outros fluidos como a água, presente na umidade atmosférica, formando como consequência uma camada de gelo que fica na parte externa das tubulações, como pode ser visto nos braços criogênicos que aparecem na Figura 2.21.

Na sequência começa o processo de carga ou descarga paralelamente com os processos de controle de lastro. Para este fim os navios de transporte de GNL têm tanques independentes que servem exclusivamente para conter água de lastro. Estes tipos de navios não podem ter seus espaços de carga cheios com água de lastro porque a água contaminaria os tanques e romperia o processo de inertização.

Levando em consideração todas estas atividades prévias, será realizada a carga e descarga do GNL, que será finalizada com a saída do navio do terminal.

\subsubsection{Procedimento de carga do GNL}

De acordo com ICS (1995), ABS (2008) e Alvarez (2009), o processo de carga é feito seguindo o fluxograma da Figura 2.22. 


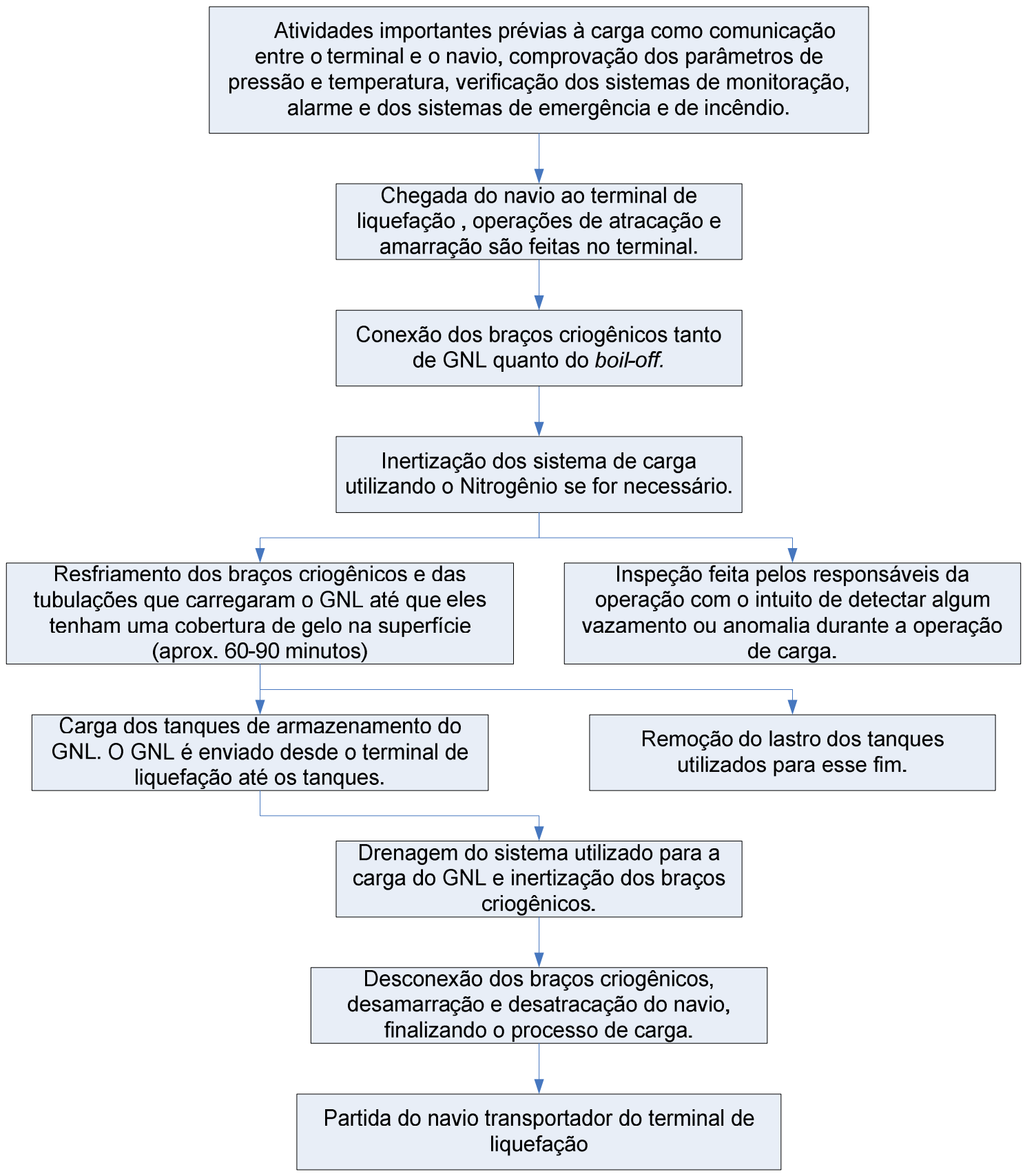

Figura 2.22 - Processo de carga do navio transportador de GNL (ICS, 1995)

Paralelamente ao processo de carga de GNL é feito o controle do lastro do navio, que é a atividade que visa manter o trim da embarcação, as tensões no casco do navio em magnitude inferior as admissíveis em projeto, a estabilidade, entre outras características. Na Figura 2.23 tem-se um esquema simplificado do processo de movimentação do GNL e do boil-off durante o processo de carga. 


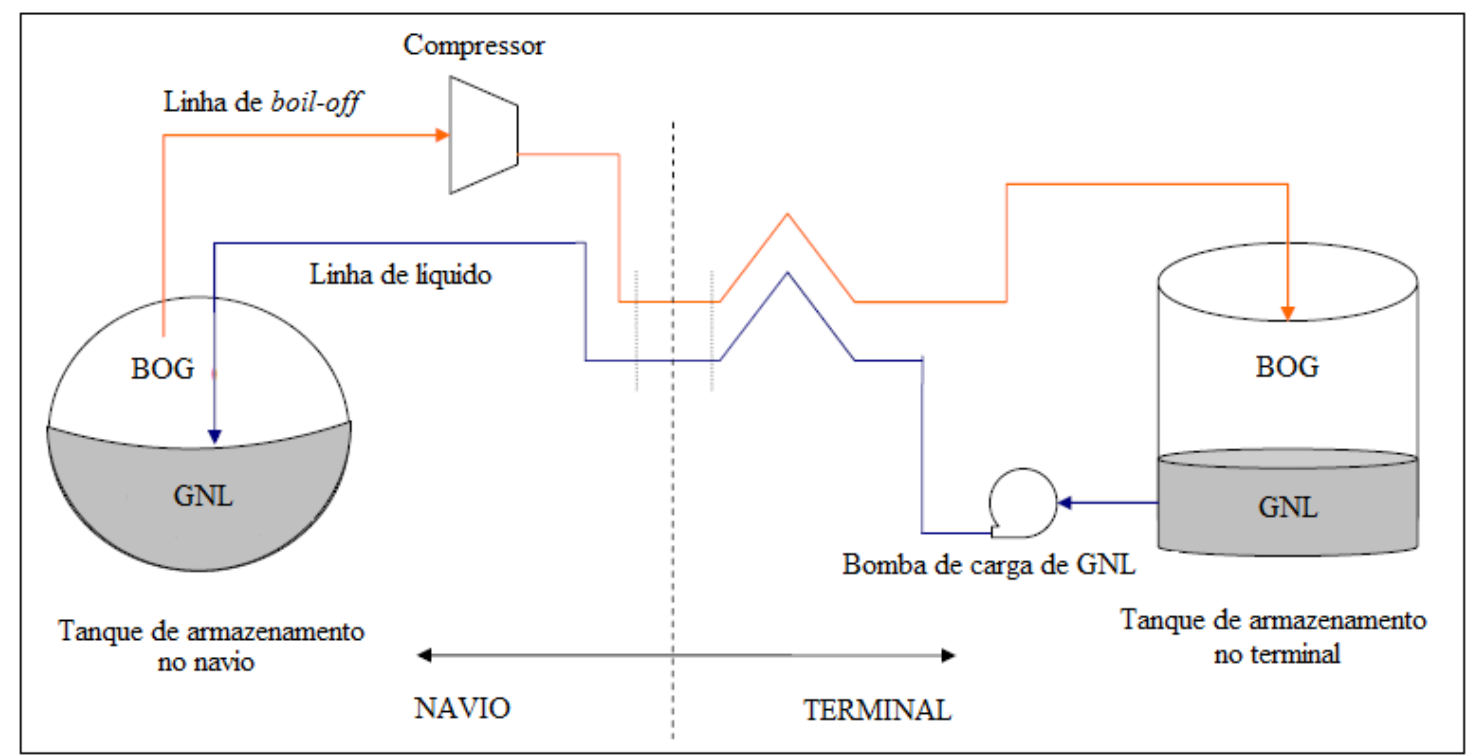

Figura 2.23 - Esquema geralizado do sistema de carga de GNL e do boil-off

\subsubsection{Procedimento de descarga do GNL}

De acordo com ICS (1995), Alvarez (2009), ABS (2008) e ENAGAS (2006), o processo de descarga é feito seguindo o fluxograma da Figura 2.24 apresentada a seguir. 


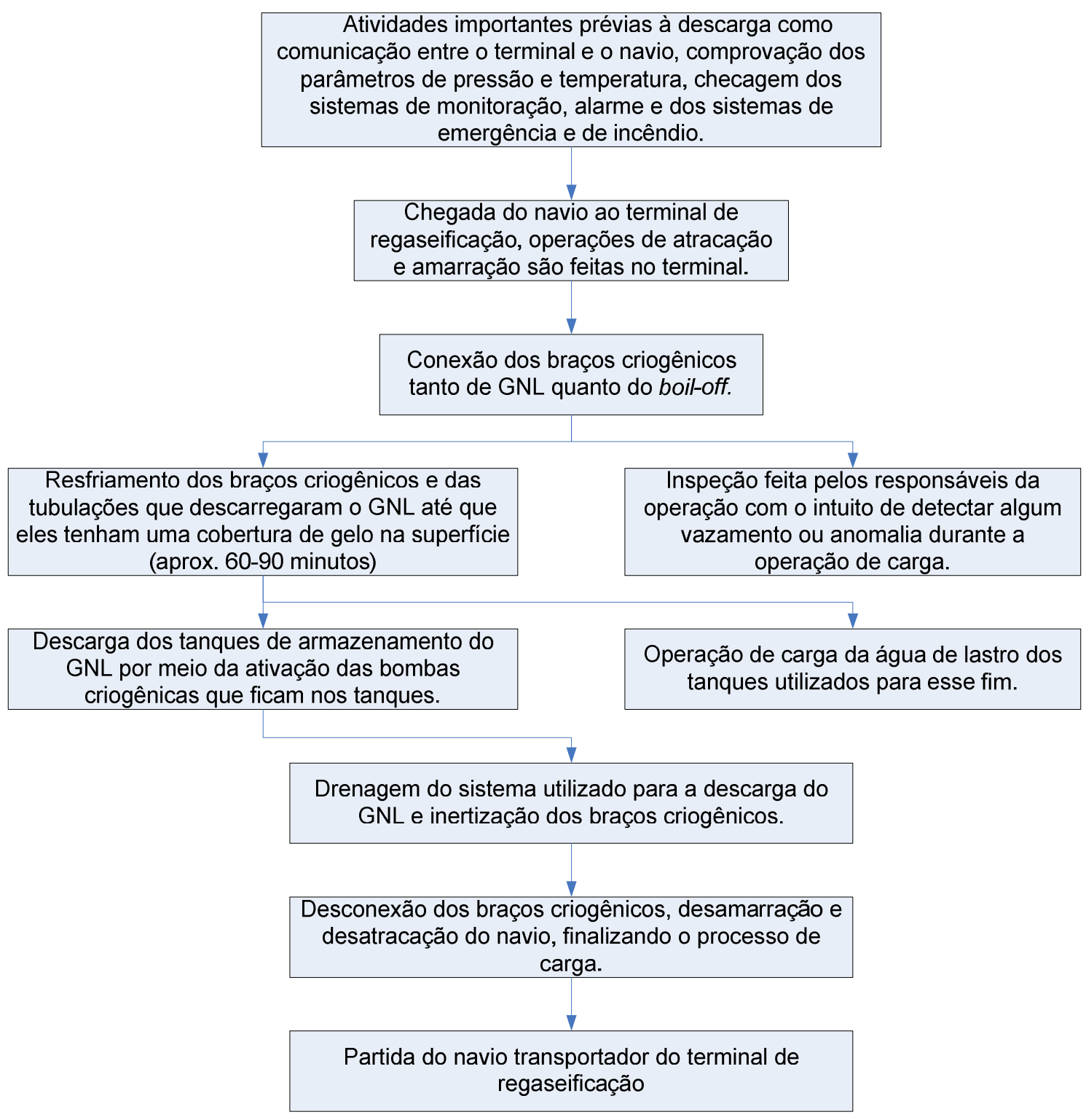

Figura 2.24 - Processo de descarga do navio transportador de GNL (ENAGAS, 2006)

A operação de lastro é realizada ao mesmo tempo em que se realiza a operação de descarregamento do GNL. O lastro é utilizado para manter o navio dentro dos limites requeridos de trim da embarcação, das tensões no casco do navio admissíveis em projeto, da estabilidade, entre outras características. 


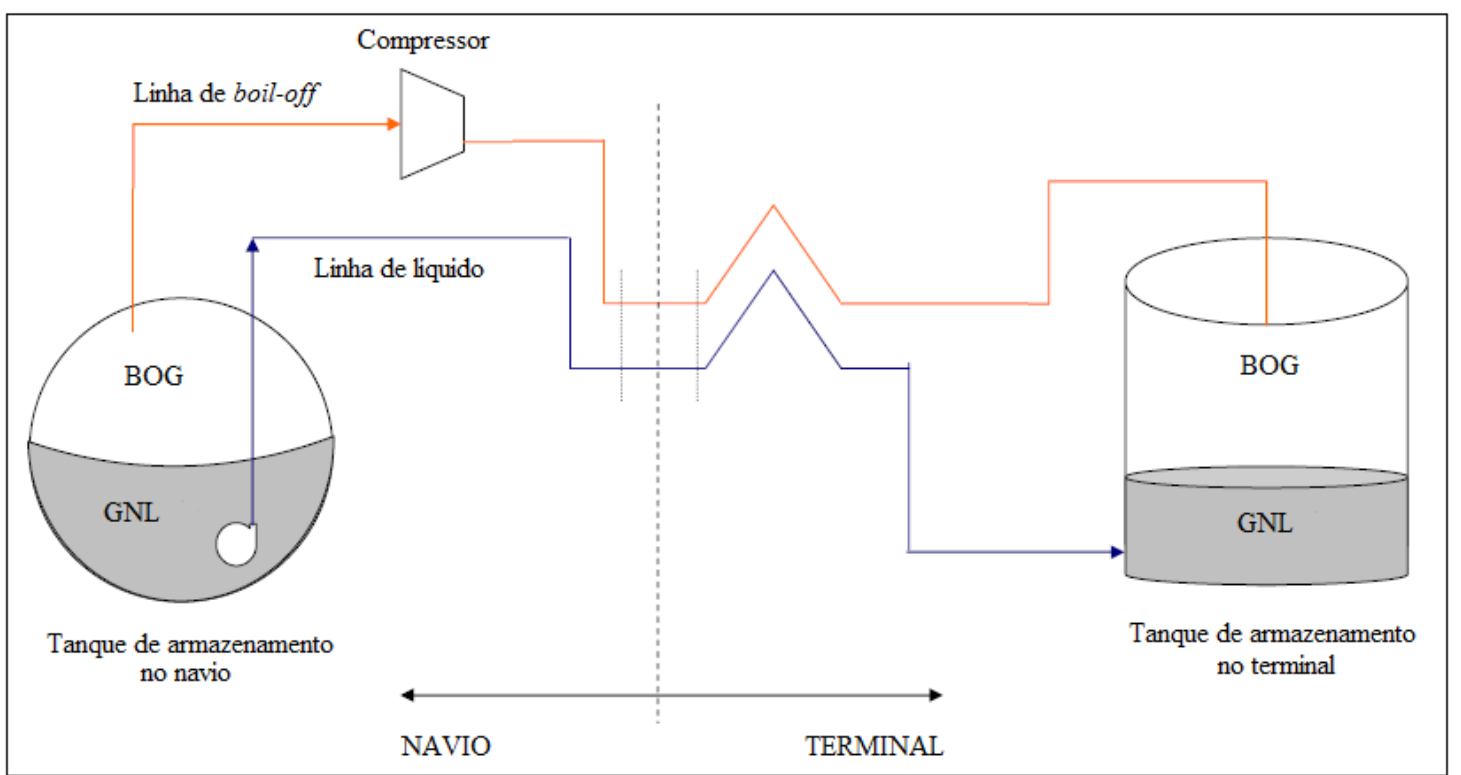

Figura 2.25 - Esquema geralizado do sistema de descarga de GNL e do boil-off

As mesmas considerações de refrigeração e de inertização (se for o caso) dos tanques é realizada durante o processo de descarga. A Figura 2.25 apresenta o esquema simplificado do sistema de movimentação do GNL e do boil-off durante o processo de descarga. 


\section{CONCEITOS DE RISCO}

Este capítulo tem por objetivo apresentar os conceitos de risco e as técnicas de análise que serão utilizadas no Capítulo 4, no qual apresenta-se a proposta do método de análise.

Para esclarecer a diferença entre perigo e risco são apresentados ambos os conceitos para entender melhor o significado de cada um dos mesmos.

\subsection{Perigo}

Segundo a norma técnica da PETROBRAS N-2784, o perigo é definido como o potencial de qualquer estado da matéria, evento ou circunstância que possa causar danos às pessoas e/ou propriedades e/ou meio ambiente (PETROBRAS, 2005).

$\mathrm{Na}$ área química o conceito de perigo não tem variações muito significativas com respeito ao conceito apresentado pela norma N-2784. Segundo o CCPS-AIChE (Center for Chemical Process Safety of the American Institute of Chemical Engineers), o perigo é uma característica física ou química inerente de um material, sistema, processo ou planta que tem o potencial de causar dano às pessoas, à propriedade e ao meio ambiente (CCPS-AIChE, 2008).

Já na área marítima, de acordo com a IMO (International Maritime Organization), o perigo é definido como o potencial de ameaçar a vida humana, a saúde, a propriedade e o meio ambiente (IMO, 2002).

Segundo os autores Kristiansen (2005), Ericson (2005) e Alencar (2005), o perigo é definido como todo evento acidental com potencial para causar danos às pessoas, às instalações ou ao meio ambiente.

\subsection{Risco}

O risco costuma ser confundido com o termo perigo, mas o risco surge por causa de um perigo e envolve outras variáveis (ERICSON, 2005). O risco combina a frequência de ocorrência de um evento e as consequências de sua ocorrência, como é expresso na Equação 3.1. 


$$
\text { Risco }=f_{i} * c_{i}
$$

onde:

$f_{i}$ : Frequência de ocorrência do evento $i$

$c_{i}$ : Consequência ou severidade associada à ocorrência do evento $i$

Segundo a norma técnica da PETROBRAS N-2784, o risco é definido como a medida de perdas econômicas, danos ambientais ou lesões à vida humana em termos da probabilidade de ocorrência de um acidente (frequência) e magnitude das perdas, dano ao meio ambiente e/ou de lesões (consequências) (PETROBRAS, 2005).

No setor marítimo, a IMO define ao risco como a combinação da frequência e da severidade da consequência (IMO, 2002).

Smith (2001), afirma que para fazer uma análise ou avaliação de risco é necessário caracterizar as duas variáveis, a frequência e a consequência. Tendo os valores qualitativos ou quantitativos destas duas variáveis é possível definir quais são os eventos que tem maior risco classificando-os em categorias de risco. A seguir são apresentados os dois termos utilizados para definir o risco.

\subsubsection{Frequência de Ocorrência}

No setor marítimo, segundo a IMO, a frequência é definida como o número de ocorrências por unidade de tempo, por exemplo, por anos. Cada área da indústria avalia a frequência de acordo com o que ela considera apropriada. Por exemplo, os dados da frequência de ocorrência de eventos na área marítima, são classificados como indicado na Tabela 3.1 (IMO, 2002). 
Tabela 3.1 - Valores de frequência de ocorrência (IMO, 2002)

\begin{tabular}{|c|c|c|l|}
\hline Categoria & Frequência & F (por navio por ano) & \multicolumn{1}{|c|}{ Descrição } \\
\hline 7 & Frequente & 12 & $\begin{array}{l}\text { Possível de ocorrer uma vez por mês em um } \\
\text { navio. }\end{array}$ \\
\hline 5 & $\begin{array}{c}\text { Razoavelmente } \\
\text { provável }\end{array}$ & $10^{-1}$ & $\begin{array}{l}\text { Possível de ocorrer uma vez por ano em uma frota } \\
\text { de } 10 \text { navios, ou seja, possível de ocorrer algumas } \\
\text { vezes durante a vida operacional do navio. }\end{array}$ \\
\hline 3 & Remota & $10^{-3}$ & $\begin{array}{l}\text { Possível de ocorrer uma vez por ano em uma frota } \\
\text { de 1000 navios, ou seja, possível de ocorrer } \\
\text { durante a vida útil de vários navios similares. }\end{array}$ \\
\hline 1 & $\begin{array}{c}\text { Extremadamente } \\
\text { remota }\end{array}$ & $10^{-5}$ & $\begin{array}{l}\text { Possível de ocorrer uma vez durante a vida } \\
\text { operacional (20 anos) de uma frota de 5000 } \\
\text { navios. }\end{array}$ \\
\hline
\end{tabular}

Já na norma técnica N-2784, a frequência de falhas é definida como o número de eventos de falha ocorridos, dividido pelo tempo "calendárico" ou tempo de operação no qual ocorrem tais eventos, ou pelo número total de demandas (PETROBRAS, 2005).

Smith (2001) coloca um exemplo para definir a frequência de ocorrência: levando em consideração a operação de uma planta industrial que manuseia materiais tóxicos e inflamáveis, e dado que aconteceria um evento de perigo em um período de 10000 anos, o resultado da frequência de ocorrência seria de $10^{-4}$ em dita instalação industrial. $\mathrm{O}$ valor da frequência de ocorrência de um evento pode ser muito baixo, mas as consequências desse mesmo evento podem ter elevada magnitude.

\subsubsection{Consequência da Ocorrência}

Segundo a norma técnica N-2784, a consequência é a manifestação de como os efeitos físicos impactam sobre os recursos humanos, ambientais e/ou materiais, ocasionados por incêndio, explosões ou vazamentos de produtos tóxicos ou perigosos, expressa sob forma de danos à saúde, perda econômica e impactos ao meio ambiente (PETROBRAS, 2005).

A IMO (2002), define a consequência como o resultado de um acidente, envolvendo fatalidades, lesões, perda ou dano do navio; perda ou dano de propriedades ou danos ambientais classificando-a conforme a sua severidade. Na Tabela 3.2 pode-se ver as categorias de severidade de acordo com a IMO. 
Tabela 3.2 - Valores de consequência de ocorrência (IMO, 2002)

\begin{tabular}{|c|c|c|c|}
\hline Categoria & Severidade & $\begin{array}{c}\text { Efeitos na segurança das } \\
\text { pessoas }\end{array}$ & Efeitos no navio \\
\hline 1 & Menor & Lesões menores & $\begin{array}{c}\text { Danos aos equipamentos } \\
\text { locais }\end{array}$ \\
\hline 2 & Significativo & $\begin{array}{c}\text { Ferimentos múltiplos ou } \\
\text { severos }\end{array}$ & $\begin{array}{c}\text { Danos não severos sobre } \\
\text { o navio }\end{array}$ \\
\hline 3 & Severo & $\begin{array}{c}\text { Uma fatalidade ou } \\
\text { múltiplas lesões graves }\end{array}$ & Danos severos \\
\hline 4 & Catastrófico & Múltiplas fatalidades & Perda total do navio \\
\hline
\end{tabular}

O CCPS-AIChE define as consequências indesejáveis em três grandes categorias como mostrados na Figura 3.1. Cada uma das três categorias pode ser subdividida pelo tipo de impacto que os eventos de perigo podem trazer. São elas: impacto à vida humana, impactos ambientais e impactos econômicos tanto na própria instalação quanto nas áreas circunvizinhas (CCPS-AIChE, 2008).

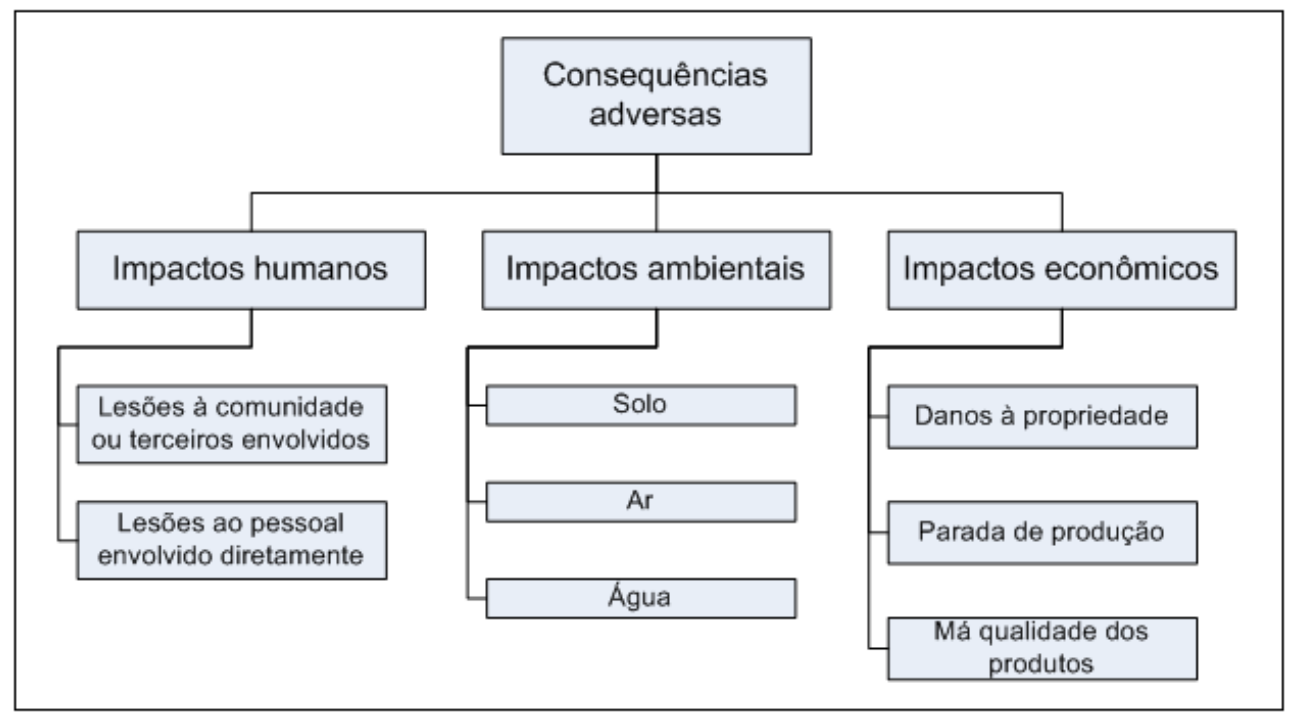

Figura 3.1 - Tipos de consequências de ocorrência (CCPS-AIChE, 2008)

\subsection{Categorias de Risco}

A matriz de risco é utilizada para classificar o risco de acordo com a sua significância. Segundo Kontovas e Psaraftis (2009) e Alencar (2005), a matriz de risco está dividida em categorias de acordo com os valores da frequência e da consequência, onde cada evento de perigo é colocado na matriz de risco. Da matriz de risco se obtém uma classificação do risco em categorias. 
Dependendo da literatura utilizada para a elaboração da matriz de risco, ela pode ser apresentada de diferentes maneiras, já que podem ser utilizados valores de frequência e de consequência, em alguns casos, diferentes em comparação com outras áreas industriais.

$\mathrm{Na}$ indústria marítima, por exemplo, a frequência e a consequência são introduzidas de maneira ordenada dentro da matriz de risco, que é apresentada na Tabela 3.3 (IMO, 2002).

Tabela 3.3 - Matriz de risco de acordo com a IMO (IMO, 2002)

\begin{tabular}{|c|c|c|c|c|c|}
\hline & \multicolumn{4}{|c|}{ Severidade } \\
\hline & & 1 & 2 & 3 & 4 \\
\hline Categoria & Frequência & Menor & Significativo & Severo & Catastrófico \\
\hline \multirow{2}{*}{7} & \multirow{2}{*}{ Frequente } & 8 & 9 & 10 & 11 \\
\hline & & 7 & 8 & 9 & 10 \\
\hline \multirow{2}{*}{5} & \multirow{2}{*}{ Razoavelmente provável } & 6 & 7 & 8 & 9 \\
\hline & & 5 & 6 & 7 & 8 \\
\hline \multirow{2}{*}{3} & \multirow{2}{*}{ Remota } & 4 & 5 & 6 & 7 \\
\hline & & 3 & 4 & 5 & 6 \\
\hline 1 & Extremadamente remota & 2 & 3 & 4 & 5 \\
\hline
\end{tabular}

A IMO define a sua matriz de risco por meio de valores numéricos, os quais começam com o valor menos crítico (2) e vão até o valor que representa o valor mais crítico (11). Para os eventos de perigo que geram um maior índice de risco é necessário e obrigatório a implementação de todas as medidas de controle possíveis com o intuito de diminuir esse elevado índice de risco.

É preciso estabelecer quais são as categorias de risco e definir que significa cada uma delas. De acordo com Smith (2001) e IEC (2009) as categorias de risco são definidas como "tolerável”, "aceitável” e "inaceitável”. Na Tabela 3.4 apresentam-se as categorias de risco com as suas respectivas definições.

Tabela 3.4 - Categoria de Risco (SMITH, 2001)

\begin{tabular}{|c|l|}
\hline Categoria de Risco & \multicolumn{1}{|c|}{ Descrição } \\
\hline Tolerável & $\begin{array}{l}\text { Pode-se aceitar o nível de risco como razoável não sendo necessário implementar } \\
\text { medidas adicionais para o seu controle. }\end{array}$ \\
\hline Aceitável & $\begin{array}{l}\text { Embora o sistema esteja preparado para operar com um risco particular, deve-se } \\
\text { continuar analisando suas causas e as defesas que se aplicarão, tendo em vista uma } \\
\text { redução adicional do nível de risco. }\end{array}$ \\
\hline Inaceitável & $\begin{array}{l}\text { Este nível de risco não é tolerável e deverão ser tomadas medidas corretivas no } \\
\text { projeto e operação para reduzir a probabilidade de ocorrência e as consequências } \\
\text { dos perigos. }\end{array}$ \\
\hline
\end{tabular}


O termo "tolerável" significa que aceita-se o nível de risco de um evento de perigo como razoável, não sendo necessário investir mais esforços, e recursos em reduzir este nível de risco. O termo "aceitável" denota que embora o sistema esteja preparado para operar com um risco particular, deve-se continuar trabalhando na procura da redução deste nível de risco. Isto pode-se obter mediante a análise das causas do evento de perigo ou por meio da instalação de defesas ou barreiras para reduzir seu impacto em caso da ocorrência do evento. Finalmente, o termo "inaceitável" significa que tal categoria de risco não é tolerável, de maneira que deverão necessariamente ser tomadas medidas de alteração do projeto como: instalação de redundâncias, instalação de barreiras de proteção, entre outras, para evitar a exposição dos eventos de perigo que geram esta categoria de risco. Dessa forma evita-se a operação nessas condições.

Cada área da indústria têm as suas próprias métricas, assim o que para algumas é considerado como tolerável para outras áreas este mesmo evento de perigo pode ser considerado como inaceitável.

A matriz de risco serve para fazer a avaliação dos riscos associados aos eventos de perigo identificados em qualquer instalação industrial. Talvez esta seja a maneira mais simples de avaliação de riscos para ser empregada na análise de risco, pois a interpretação é mais rápida e fácil, para depois recomendar e implementar as medidas de proteção, mesmo na etapa de projeto ou durante a vida operacional da instalação industrial.

Segundo a IMO (2002), o risco pode ser analisado qualitativamente ou quantitativamente, sendo que com a análise quantitativa obtém-se um número de risco, enquanto que com a análise qualitativa encontra-se um nível de risco que será baixo, médio, ou alto, como definido na matriz de risco da IMO.

\subsection{Técnicas de Análise do tipo Qualitativo}

Como mencionado na seção anterior, para fazer a análise qualitativa podem ser empregadas ferramentas como a APP, FMEA, HAZOP, Check Lists, What if...?, entre outras (ABS, 2000). Nesta seção será apresentada a técnica do tipo qualitativo denominada de APP, que será empregada no método de estudo proposto neste trabalho.

De acordo com Ericson (2005), a análise qualitativa envolve o uso de critérios qualitativos. Normalmente esta abordagem usa definições qualitativas como, por exemplo, 
pouco frequente, frequente, provável, alto, baixo, entre outros; sem utilizar valores para quantificar estas categorias, mas o maior problema é que esta análise tem uma abordagem subjetiva, e dependerá da percepção da pessoa que faz a análise.

\subsubsection{Análise Preliminar de Perigos (PHA - Preliminary Hazard Analysis)}

A APP ou Análise Preliminar de Perigos é uma técnica que se originou no programa de segurança militar do Departamento de Defesa dos EUA e que foi formalmente instituída pela norma MIL-STD-882 (ERICSON, 2005).

Segundo Smith (2001) e Lees (1996), esta é uma técnica basicamente qualitativa que pode ser aplicada tanto na fase do projeto quanto na fase da operação de um sistema. Esta técnica não requer a utilização de muitos documentos detalhados, fato que justifica a sua frequente aplicação em estudos de análise de risco.

Na Tabela 3.5 há um exemplo da tabela que deve ser preenchida para aplicar a técnica da APP. Nesta tabela devem ser colocados os perigos que serão analisados, junto com as suas causas, consequências, barreiras de proteção e as recomendações.

Tabela 3.5 - Tabela para a aplicação da APP adaptada (ERICSON, 2005)

\begin{tabular}{|c|c|c|c|c|c|}
\hline \multicolumn{4}{|c|}{ Sistema: } & \multirow{2}{*}{$\begin{array}{l}\text { ANÁLISE } \\
\text { PRELIMINAR DE } \\
\text { PERIGOS }\end{array}$} & Analista: \\
\hline \multicolumn{4}{|c|}{ Sub-sistemas: } & & \\
\hline $\mathrm{N}^{\circ}$ & Perigo & Causas & Consequências & Barreiras de proteção & Recomendações \\
\hline & & & & & \\
\hline
\end{tabular}

Ericson (2005) define as causas dos perigos como as responsáveis pela ocorrência do perigo, podendo ser falhas nos equipamentos ou falhas humanas. A análise das causas que ocasionam esses eventos de perigo devem ser as mais abrangentes possíveis, a fim de evitar o esquecimento de possíveis eventos que levam ao perigo ou evento iniciador.

A técnica APP examina as maneiras pelas quais um material perigoso pode ser liberado de forma descontrolada, fazendo o levantamento para cada um dos perigos identificados, as respectivas causas e as suas consequências. Todos os eventos de perigo identificados com a APP englobam as falhas dos componentes do sistema (ALENCAR, 2005). 


\subsection{Técnicas de Análise do tipo Quantitativo}

A análise quantitativa envolve o uso de base de dados com valores numéricos. Deve-se notar, no entanto, que resultados quantitativos podem ser influenciados pela validade e precisão dos dados de entrada. Por esta razão, os resultados quantitativos não devem ser vistos como números exatos, mas sim como um valor de referência para poder obter conclusões importantes, desde que se tenha uma boa qualidade dos dados de entrada (ERICSON, 2005). A seguir são apresentadas as técnicas de análise quantitativa que serão empregadas na proposta do método de análise neste trabalho de pesquisa.

\subsubsection{Análise de Árvore de Falhas (FTA - Failure Tree Analysis)}

A FTA é amplamente usada no campo aeroespacial, eletrônico, e nuclear. Esta técnica foi originalmente desenvolvida em 1961 por H. A. Watson nos laboratórios da empresa de telefonia Norte Americana Bell Telephone para avaliar o sistema de controle de lançamento dos mísseis Minuteman, a fim de evitar um lançamento não autorizado (acidental) (NIST, 2008).

De acordo com Kececioglu (1991), a análise de árvore de falhas é uma técnica de análise de confiabilidade e segurança aplicada a sistemas, e visa determinar as causas de um evento indesejado chamado de "evento topo". A árvore de falhas utiliza uma estrutura lógica em forma de ramificações com símbolos de álgebra booleana que precisam ser desenvolvidos para obter os cut-sets mínimos (cortes mínimos) que permitam avaliar a probabilidade de falha do evento topo. Esta ferramenta está baseada em uma análise dedutiva, onde o sucesso da aplicação dependerá muito do conhecimento do sistema por parte do analista. Cada nível inferior na árvore lista os eventos básicos que são necessários e suficientes para causar um problema no nível superior.

Segundo Hidalgo (2010) e O' Connor (1985), o corte mínimo de uma árvore de falhas é o evento ou conjunto de eventos básicos que causam a ocorrência do evento topo. Desta forma se pode definir que um corte é a combinação de eventos básicos que ao ocorrerem levam necessariamente à falha do sistema. Um corte é definido como corte mínimo quando é constituído pelo menor número possível de eventos básicos, cuja ocorrência causa a ocorrência do evento topo, não podendo ser reduzido sem perder a sua condição de corte. Para identificar os cortes mínimos pode-se aplicar as principais leis de álgebra booleana. 
A análise da árvore de falhas é, sobretudo, um meio para analisar as causas de perigo e não para identificar os perigos. O evento topo, ou evento indesejável, deve ser identificado por outras técnicas, já que a elaboração da árvore de falha dependerá da escolha do mesmo (LEVESON, 1995). O referido autor afirma que a análise da árvore de falha é composta de quatro passos listados a seguir:

\section{a. Escopo da análise}

Esta é a etapa mais difícil na elaboração da árvore de falha, requer a determinação do evento topo, as condições iniciais, eventos existentes e eventos inadmissíveis, assim como a determinação de todos os elementos que vão estar compreendidos dentro da análise. A seleção do evento topo é crucial, pois a avaliação dos eventos de perigo no sistema não será compreendida a menos que dentro da árvore de falhas estejam considerados todos os eventos significativos sob o ponto de vista da degradação do sistema ou da segurança da operação do mesmo.

b. Construção da árvore de falha

Uma vez que o sistema e o evento topo foram definidos, o próximo passo é a construção da árvore de falha. $\mathrm{O}$ analista agora escreve o evento topo e detalha os eventos que causam esse evento não desejado, para depois determinar qual é a relação lógica entre eles, usando os símbolos lógicos para descrever essa relação.

$\mathrm{Na}$ Tabela 3.6, são apresentados os portões lógicos mais utilizados durante a construção da árvore de falha, os portões E e OU. O portão E fornecerá um valor de saída se todos os eventos ocorrerem simultaneamente. Por sua vez, o portão OU fornecerá um valor de saída se pelo menos um dos eventos acontecerem na entrada.

Tabela 3.6 - Símbolos dos portões lógicos (KECECIOGLU, 1991)

\begin{tabular}{|c|c|l|}
\hline $\begin{array}{c}\text { Nome do } \\
\text { portão }\end{array}$ & Símbolo do portão & \multicolumn{1}{c|}{ Descrição } \\
\hline Portão E & & $\begin{array}{l}\text { O evento de saída ocorrerá se todos os eventos de } \\
\text { entrada ocorrerem. }\end{array}$ \\
\hline Portão OU & $\begin{array}{l}\text { O evento de saída ocorrerá se pelo menos um dos } \\
\text { eventos de entrada ocorrerem. }\end{array}$ \\
\hline
\end{tabular}


Na Tabela 3.7 pode-se ver os símbolos dos eventos que serão utilizados durante a construção da árvore de falha.

Tabela 3.7 - Símbolos dos portões de eventos (KECECIOGLU, 1991)

\begin{tabular}{|c|c|l|}
\hline Nome do portão & $\begin{array}{c}\text { Símbolo do } \\
\text { portão }\end{array}$ & \multicolumn{1}{|c|}{ Descrição } \\
\hline Evento Básico & & $\begin{array}{l}\text { Representa a falha do equipamento. } \\
\text { Representa o nível mais baixo da árvore }\end{array}$ \\
\hline Evento resultante & $\left\langle\begin{array}{l}\text { É o resultado da combinação dos eventos de } \\
\text { falha. }\end{array}\right.$ \\
\hline $\begin{array}{c}\text { Evento não desenvolvido } \\
\text { Evento de transferência para } \\
\text { dentro e para fora }\end{array}$ & $\begin{array}{l}\text { Evento que não foi desenvolvido por falta } \\
\text { de interesse ou informação. }\end{array}$ \\
\hline
\end{tabular}

Na Figura 3.2 visualiza-se um exemplo da elaboração da árvore de falhas onde o evento topo é a perda do sistema de propulsão de um navio.

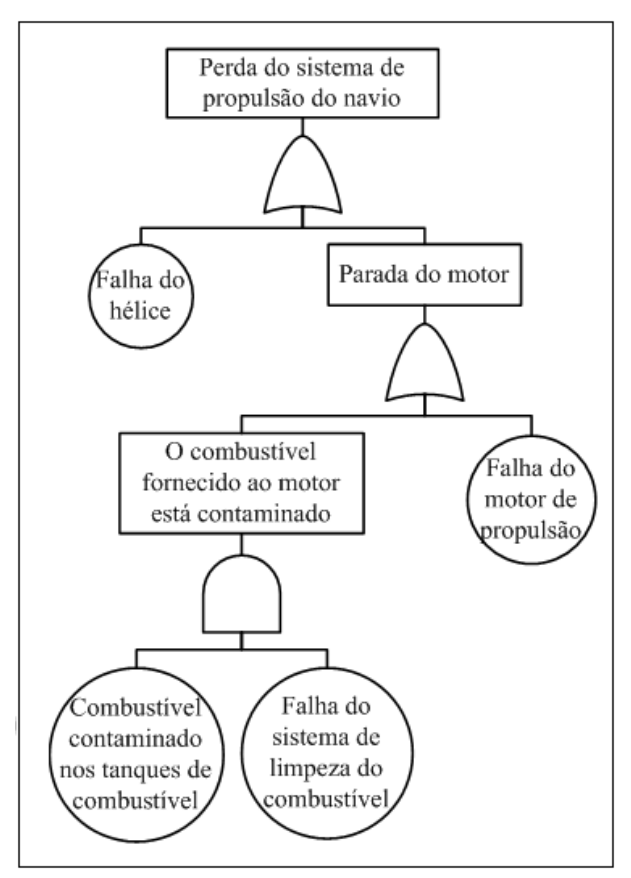

Figura 3.2 - Árvore de falhas da perda do sistema de propulsão de um navio (ABS, 2000)

c. Análise qualitativa da árvore de falhas

Logo da construção da árvore, a análise qualitativa pode ser iniciada. O propósito é reduzir a árvore de falhas para levá-la a sua forma equivalente, mostrando as combinações 
especificas (intersecções) dos eventos básicos que são suficientes para causar a ocorrência do evento topo. Em essência, os eventos entre o evento topo e os eventos básicos são removidos e só as relações entre o evento topo e os eventos básicos são descritas. O objetivo da análise é encontrar todos os cut-sets, para depois classificá-los em cortes mínimos de primeira, segunda, n-ésima ordem. O número mínimo de cut-sets fornece a informação que ajuda identificar os pontos fracos do sistema sob o ponto de vista do risco associado à sua operação, (LEVESON, 1995). Os cut-sets de primeira ordem causam a ocorrência do evento topo, não dependendo de algum outro evento básico.

A árvore de falhas pode ser convertida a partir daquela que se pode ver na Figura 3.2, para a árvore na forma reduzida, conforme a Figura 3.3, visando identificar os cortes mínimos.

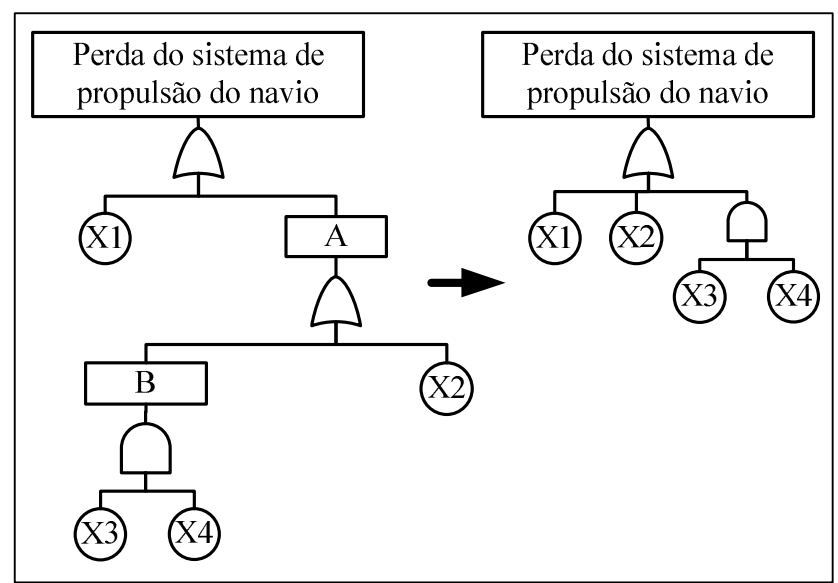

Figura 3.3 - Árvore de falhas equivalente com os respectivos cortes mínimos

Na Figura 3.3 observa-se dois cortes mínimos de um evento básico X1 e X2, também chamados como cortes mínimos de primeira ordem, que fazem com que apenas a ocorrência de qualquer um destes eventos básicos cause a ocorrência do evento topo. Os cortes mínimos de dois eventos básicos são conhecidos como cortes mínimos de segunda ordem (X3X4). Para que estes eventos de segunda ordem causem a ocorrência do evento topo, eles precisam ocorrer simultaneamente.

d. Análise quantitativa da árvore de falhas

A análise quantitativa da árvore de falha usa os cortes mínimos para calcular a probabilidade de ocorrência do evento topo a partir da probabilidade de ocorrência dos eventos base que compõem os cortes mínimos. A probabilidade de cada corte é determinada 
combinando a probabilidade de todos os eventos básicos que formam o corte (LEVESON, 1995; ERICSON, 2005).

\subsubsection{Diagrama Causa-Consequência DCC (CCA - Cause Consequence Analysis)}

Segundo Ericson (2005) e IEC (2009), este método foi desenvolvido pelo RISO National Laboratories, Denmark, na década de 70, com o interesse de ajudar na análise de confiabilidade e de risco de plantas nucleares nos países escandinavos.

De acordo com CCPS-AIChE, a análise de causa-consequência é uma combinação das análises por árvore de falhas e árvore de eventos (CCPS-AIChE, 2008).

Autores como Ericson (2005), Andrews e Ridley (2002) e Modarres (1993), indicam que esta ferramenta de análise serve para identificar e avaliar a sequência de eventos que acontecem dada a ocorrência de um evento iniciador, e o objetivo é determinar se esse evento iniciador poderá desencadear um acidente ou se ele é suficientemente controlado pelas barreiras de proteção implementadas na fase de projeto. Entre o evento iniciador e as consequências finais, existem eventos intermediários que interromperão a sequência do evento iniciador, e tais elementos de bloqueio são as chamadas barreiras de proteção. Na Figura 3.4 apresenta-se um esquema de como deve ser estruturada a análise de causaconsequência.

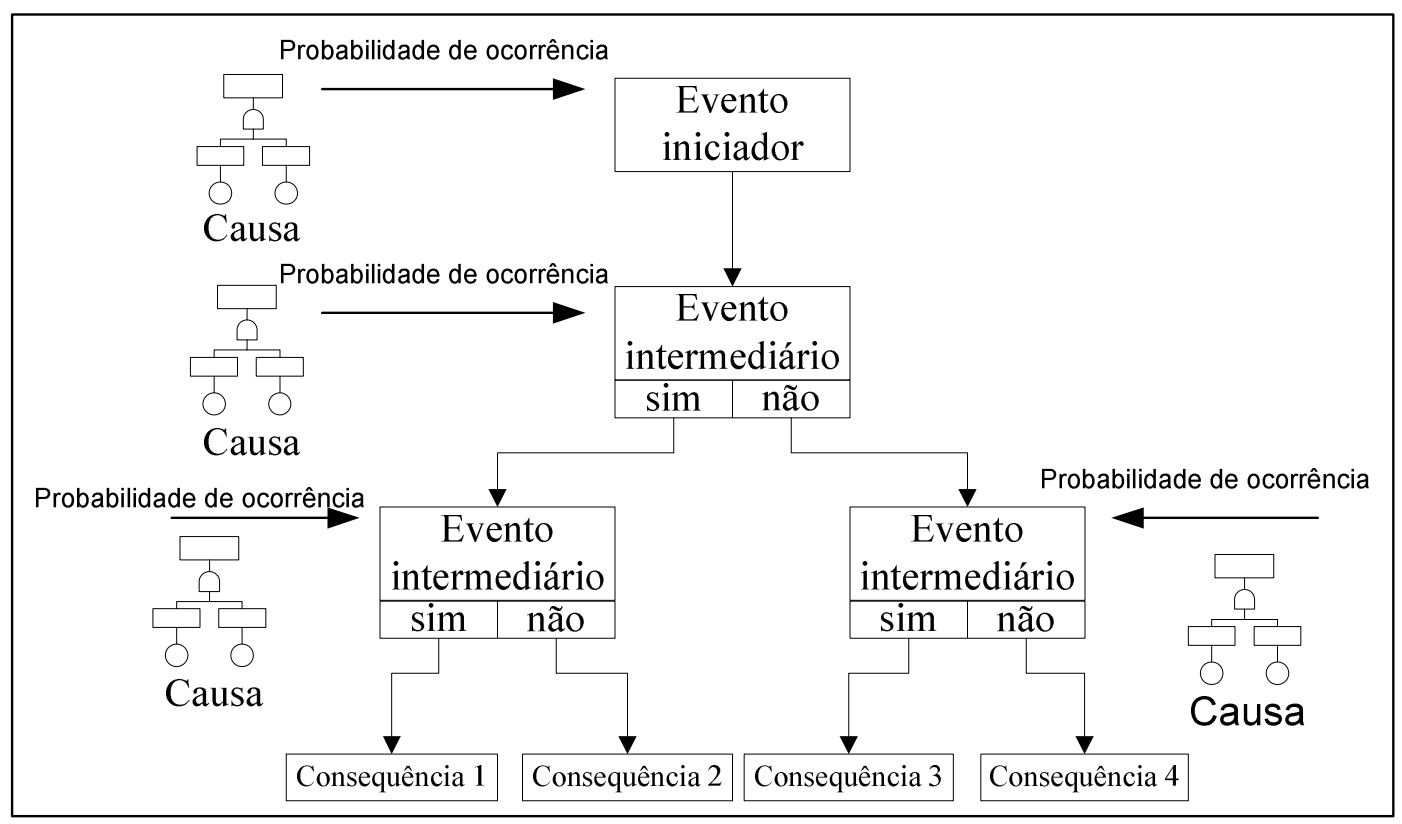

Figura 3.4 - Diagrama causa-consequência (ERICSON, 2005; IEC, 2009) 
Esta técnica de análise também pode ser utilizada nas etapas inicias do projeto, quando ela é usada para determinar quais deveriam ser as barreiras de proteção para tentar evitar a propagação de um dado evento iniciador. Desta forma evita-se utilizar medidas corretivas quando o projeto já esta em operação, ou mesmo custos associados à ocorrência de um acidente.

Essas barreiras são sistemas de monitoração e controle que funcionam automaticamente no caso de acontecer um desvio do desempenho previamente estabelecido que corresponda ao evento iniciador. Também podem ser sistemas de alarme que alertam aos operadores sobre a ocorrência de um evento iniciador, devendo haver uma reação de acordo com um procedimento previamente definido (RAUSAND, 2004; LEVESON, 1995).

O diagrama é construído com uma série de caixas com a estrutura de respostas do tipo Sim/Não. Essas caixas representam as condições que podem ocorrer caso as barreiras de proteção não funcionem. No diagrama se delineiam as combinações dos eventos até chegar aos possíveis resultados que serão os cenários de falha e as respectivas consequências associadas aos mesmos (IEC, 2009). 


\section{PROPOSTA DO MÉTODO DE ANÁliSE DE RISCO PARA O SISTEMA DE CARGA E DESCARGA DE GNL EM NAVIOS TRANSPORTADORES}

\subsection{Considerações iniciais}

As sociedades classificadoras como a DNV (Det Norske Veritas), a ABS (American Bureau of Shipping), e o LR (Lloyd's Register of Shipping) entre outras, permanentemente trabalham no desenvolvimento de técnicas de análise de risco, e devem cumprir com as normas estabelecidas pela IMO (NATACCI e MARTINS, 2009). Esta organização é encarregada de lidar com todos os aspectos de segurança marítima e com a proteção do ambiente marinho. Os estudos realizados pelas sociedades classificadoras demonstraram preocupação com a ocorrência de incêndios, explosões, dispersão de gases, e outros acidentes que podem causar graves consequências e tornarem-se catastróficos.

A IMO estabeleceu uma guia para a avaliação dos riscos chamado FSA (Formal Safety Assessment) que têm os mesmos princípios de análise de riscos de outras áreas industriais, e mostra os passos que devem ser feitos para sua aplicação na área marítima (IMO, 2002). Este guia foi introduzido como um processo racional e sistemático para avaliar o risco e também para calcular os custos e os benefícios das opções adotadas com o intuito de reduzir os respectivos riscos de uma operação marítima (KRISTIANSEN, 2005; SOARES e TEIXEIRA, 2001; KONTOVAS e PSARAFTIS, 2009).

Esta guia não difere muito da metodologia apresentada pela norma técnica da PETROBRAS, a N-2782. A diferença é que a norma sugere a aplicação de algumas técnicas de análise que podem ser utilizadas em cada uma das etapas da análise de risco (PETROBRAS, 2004). Outra metodologia é a apresentada na CSChE (Canadian Society for Chemical Engineering) que também não varia muito em relação às anteriores (CSChE, 2004).

Para desenvolver o método utilizado nesta dissertação, decidiu-se utilizar técnicas de análise de risco com o objetivo de estabelecer os cenários de falha, dada a atuação ou não das barreiras de proteção, e determinar quais são os componentes cujos modos de falha provocam maior risco. Do ponto de vista do risco, deve-se tomar todas as medidas preventivas a fim de evitar que, principalmente os riscos considerados como Críticos (C), aconteçam durante o tempo operacional. Os componentes cujas falhas provocam esta elevada categoria de risco 
podem ser considerados como componentes críticos, e sobre os quais devem ser focados todos os estudos de alteração de projeto ou de rotinas de manutenção.

\subsection{Proposta de Método de Análise}

Ao falar de riscos operacionais é preciso determinar quais são as categorias de risco e se elas são aceitáveis ou não para a empresa ou organização. Para responder essa questão é necessário quantificá-los, e em função disso tomar a decisão de eliminá-los ou mitigá-los. Esta atividade é denominada como a análise de risco. Por isso, é necessário seguir uma série de passos que visam entender e analisar todos os aspectos econômicos e ambientais associados a uma determinada atividade industrial. A abordagem de análise baseada em risco adotada para este trabalho é apresentada na Figura 4.1. Este método de análise foi baseado em informações obtidas em referências bibliográficas associadas ao estudo de análise de risco. Entre as referências bibliográficas tem-se IMO (2002), PETROBRAS (2004), Vanem et al. (2008), Kontovas e Psaraftis (2009), Bai et al. (2010), Rausand (2011), ABS (2000), Risknology (2006), CSCHE (2004), IEC (2009), entre outras. No fluxograma da Figura 4.1 são apresentados os passos da implementação do método para a obtenção dos resultados de uma análise de risco de um sistema instalado em um navio. 


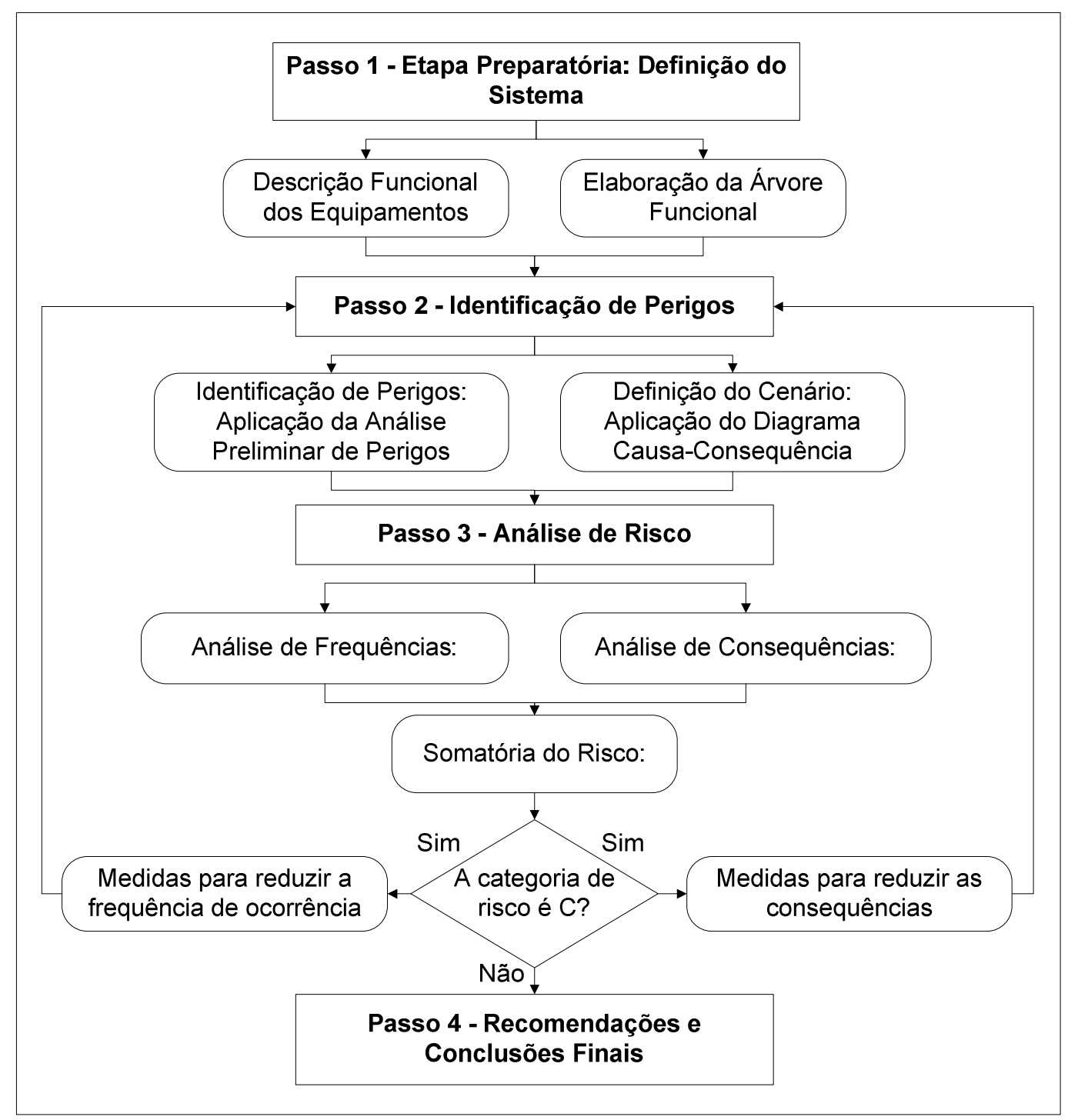

Figura 4.1 - Representação do método de análise

O método apresentado é composto pelos seguintes passos: Etapa Preparatória, Identificação de Perigos, Análise de Risco e por último as Recomendações e Conclusões Finais. Em cada uma destas etapas são aplicadas técnicas de análise para obter resultados qualitativos ou quantitativos e dar conclusões no final da aplicação do método. As etapas do método de análise serão descritas na sequência deste texto.

\subsubsection{Passo 1: Etapa Preparatória}

Para o desenvolvimento desta etapa será necessário contar com os planos do sistema, catálogos e informações técnicas que permitam entender como funciona o sistema a ser estudado. Esta etapa é a mais importante, já que o entendimento e a caracterização do sistema 
permitirá um bom andamento dos outros passos que, finalmente, nos levarão a um bom resultado da aplicação do método de análise proposto, ou seja, a determinação do perfil de risco associado com uma operação de um navio.

Esta etapa é dividida em dois passos: 1) a elaboração da Árvore Funcional e 2) a Descrição Funcional dos equipamentos do sistema. Na sequência serão apresentadas as subetapas mencionadas.

\subsubsection{Elaboração da Árvore Funcional}

Rausand (2004), Hidalgo et al. (2011) e Fujiyama et al. (2004), afirmam que a elaboração da árvore funcional é uma ferramenta que facilita a compreensão do sistema, fundamental para uma boa análise do mesmo. Desta maneira, com a aplicação da árvore funcional é possível entender de maneira mais profunda a composição do sistema, assim como a lógica operacional e como os eventos associados à falha de componentes se propagam pelo sistema. Como resultado da elaboração da árvore funcional, obtém-se uma representação gráfica do sistema que mostra, de forma estruturada, os principais componentes e a sequência lógica das informações em cada um dos subsistemas principais, que compõem o sistema sob análise.

Segundo Hidalgo (2010) e Carazas (2011), para a elaboração da árvore funcional é preciso seguir uma lógica baseada em perguntas: Como é executada (cumprida) uma determinada função? A resposta desta pergunta permitirá definir quais componentes devem ser utilizados para a execução desta função, as suas ligações e a sua localização em relação aos outros subsistemas. Logo, para comprovar se a resposta da primeira pergunta foi bem respondida, faz-se a segunda pergunta que é: Por que uma determinada função deve ser executada? A lógica desta sequência de perguntas pode ser entendida com melhor clareza mediante a observação da Figura 4.2.

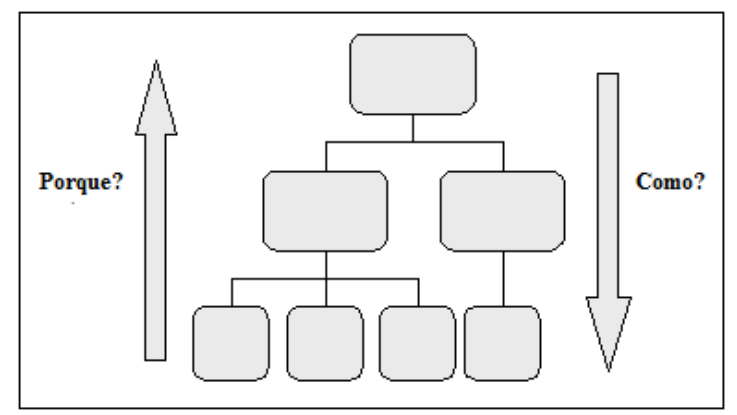

Figura 4.2 - Representação de uma árvore funcional (SOUZA, 2010) 


\subsubsection{Descrição Funcional dos Equipamentos}

A descrição funcional é a descrição das funções de cada um dos componentes identificados nos diferentes níveis da árvore funcional. Os componentes devem cumprir funções primárias, secundárias ou terciárias para completar a função global do sistema. Dessa forma se conhecerá as funções mais importantes de cada um dos subsistemas e dos seus respectivos componentes. O desenvolvimento destas duas ferramentas torna-se importante já que ela permitirá entender a magnitude do sistema, permitindo a delimitação da análise (RAUSAND, 2004; SOUZA, 2010).

\subsubsection{Passo 2: Identificação dos Perigos}

Uma vez descrito o sistema a ser estudado pode-se iniciar a etapa de identificação dos perigos. Deve-se ter em consideração que cada sistema em geral está exposto a um número finito de perigos que podem ser identificados com a realização de estudos e a aplicação de técnicas da área de risco.

Este passo envolve duas sub-etapas que são: 1) a identificação de perigos mediante a aplicação da Análise Preliminar de Perigos e 2) a determinação do cenário de falha por meio do Diagrama Causa-Consequência que permitirá estabelecer o que pode acontecer após o evento iniciador ter acontecido.

\subsubsection{Identificação de Perigos: Aplicação da Análise Preliminar de Perigos (APP)}

Para a análise dos perigos foi selecionada a análise APP, pois esta permite colocar de maneira ordenada quais são as prováveis causas, bem como quais são as consequências, de um evento de perigo estudado. Essa informação é preenchida numa tabela estruturada, possibilitando uma boa organização dos dados introduzidos. Além disso, a técnica APP pode ser aplicada também na fase de operação do sistema a ser estudado. A sua aplicação é relativamente simples em comparação a outras técnicas utilizadas para este mesmo fim (SMITH, 2001; LEES, 1996).

Para a execução da Análise Preliminar de Perigos utilizou-se a Tabela 3.5 apresentada no Capítulo 3. 
A coluna intitulada como perigo servirá para colocar o evento de perigo que vai ser postulado e avaliado. Este evento de perigo pode ser, por exemplo, explosão, vazamento, incêndio, entre outros.

As causas identificam-se como os eventos ou falhas de equipamentos ou sistemas que possam desencadear ou provocar o evento de perigo. Por sua vez, a coluna das consequências é utilizada para definir quais serão os efeitos ou consequências, caso aconteça o evento de perigo.

As barreiras de proteção são aquelas que estão projetadas para evitar o desenvolvimento de um cenário de falha associado com o evento de perigo, impedindo que ele possa gerar um acidente com graves consequências.

E por fim, a coluna das recomendações é destinada para sugerir ações para eliminar ou mitigar cada um dos eventos de perigo identificados.

Como resultado da aplicação da APP, são identificadas as causas e consequências da ocorrência das falhas nos componentes do sistema, e também é possível identificar quais são as barreiras de proteção cuja falha deixa desprotegido o sistema que vai ser estudado.

\subsubsection{Definição do Cenário: Aplicação do Diagrama Causa-Consequência (DCC)}

Paralelamente à aplicação da APP deverá desenvolver-se a aplicação do Diagrama CausaConsequência, partindo das informações fornecidas pela aplicação do APP.

Deve-se levar em conta que a sequência de eventos começa com um evento iniciador (evento de perigo), que será o mesmo evento postulado na Análise Preliminar de Perigos. Silva e Souza (2012) e Souza et al. (2012), começam a elaboração do DCC selecionando o evento iniciador de perigo.

De acordo com Rausand (2004) e Andrews e Ridley (2002), o intuito da aplicação desta técnica é determinar se esse evento iniciador será capaz de gerar um acidente, considerando que existem barreiras de proteção projetadas para bloquear e evitar a sequência de eventos intermediários. Para isso são desenvolvidas, na etapa do projeto, medidas de proteção que visam evitar o desenvolvimento de um cenário de falha específico. 
Realizado o DCC, pode-se identificar quais são as barreiras de proteção com que cada instalação está equipada, para posteriormente estudá-las do ponto de vista da probabilidade de falha e da confiabilidade com a elaboração de Árvore de Falhas. Hidalgo et al. (2011) indica que uma das técnicas que podem ser utilizadas para a determinação da probabilidade de falhas é a análise de Árvore de Falhas, que permite obter um valor quantitativo para a probabilidade de ocorrência de um evento topo. Segundo a CSChE (2004) e IEC (2009), quando não se tem os dados históricos da taxa de falha de um determinado evento é possível estimá-la usando o método de análise FTA que utiliza a probabilidade de falha de cada um dos eventos básicos que causam a ocorrência de um evento topo. A elaboração da Árvore de Falhas é baseada em manuais, livros, catálogos e artigos científicos.

Como resultado da aplicação do DCC são obtidos os possíveis cenários ou caminhos que o evento iniciador pode tomar até chegar ao estado final ou consequência (VANEM et al., 2008).

\subsubsection{Passo 3: Análise de Risco}

O propósito deste passo é determinar as frequências de ocorrência de um dado evento de perigo e determinar as consequências de ocorrência do mesmo, mas desta vez detalhando cada um dos cenários de falha associados ao sistema em estudo, ou seja, determinando a probabilidade de ocorrência dos mesmos. Com o valor destas duas variáveis (probabilidade de ocorrência do cenário de falha e suas consequências) é possível montar a matriz de risco, permitindo classificar cada modo de falha dos componentes (considerados os eventos iniciadores do cenário de falha) em categorias de risco.

Para a avaliação de risco são utilizadas as tabelas de frequência, de consequência e a matriz de risco de acordo com a norma técnica da PETROBRAS N-2782 (PETROBRAS, 2004).

\subsubsection{Análise das Frequências de Ocorrência}

Segundo a norma técnica PETROBRAS N-2782, a frequência de falhas é o número de eventos de falhas ocorridos, dividido pelo tempo "calendárico" ou tempo de operação no qual ocorrem tais eventos, ou pelo número total de demandas, segundo sua aplicação. Na Tabela 4.1 apresentam-se as faixas de em termos da frequência junto com as respectivas descrições e denominação, conforme a norma técnica anteriormente citada. 
Tabela 4.1 - Categoria de frequência de ocorrência (PETROBRAS, 2004)

\begin{tabular}{|c|c|c|l|}
\hline Categoria & Denominação & Faixa (Ocorrência/ano) & \multicolumn{1}{|c|}{ Descrição } \\
\hline A & $\begin{array}{c}\text { Extremamente } \\
\text { Remota }\end{array}$ & Inferior a 1 em $10^{6}$ anos & $\begin{array}{l}\text { Conceitualmente possível, mas extremamente } \\
\text { improvável de ocorrer durante a vida útil da } \\
\text { instalação. Não há referencias históricas de } \\
\text { ocorrência. }\end{array}$ \\
\hline B & Remota & $\begin{array}{c}\text { Entre } 1 \text { em } 10^{4} \text { anos e } 1 \\
\text { em } 10^{6} \text { anos }\end{array}$ & $\begin{array}{l}\text { Não esperado ocorrer durante a vida útil da } \\
\text { instalação, apesar de já poder ter ocorrido em algum } \\
\text { lugar no mundo. }\end{array}$ \\
\hline C & Pouco Provável & $\begin{array}{c}\text { Entre } 1 \text { em } 10^{2} \text { anos e } 1 \\
\text { em } 10^{4} \text { anos }\end{array}$ & $\begin{array}{l}\text { Possível de ocorrer até uma vez durante a vida útil } \\
\text { da instalação. }\end{array}$ \\
\hline D & Provável & $\begin{array}{c}\text { Entre } 1 \text { por ano e } 1 \text { em } \\
10^{2} \text { anos }\end{array}$ & $\begin{array}{l}\text { Esperado ocorrer poucas vezes durante a vida útil da } \\
\text { instalação. }\end{array}$ \\
\hline E & Frequente & Superior a 1 por ano & $\begin{array}{l}\text { Esperado ocorrer muitas vezes durante a vida útil da } \\
\text { instalação. }\end{array}$ \\
\hline
\end{tabular}

Em caso de não ter disponíveis os valores em termos da frequência, autores como Modarres (1993), Haimes (1998), Nilson (2003) e Tien et al. (2007), afirmam que sob o ponto de vista da análise de risco, o risco pode ser definido como a medida da probabilidade de ocorrência de um efeito indesejado e a severidade dos seus efeitos sobre um sistema. É assim que, para cada um dos componentes que compõem um determinado sistema, torna-se necessário conhecer as probabilidades das principais falhas que estes podem apresentar.

Para o cálculo da probabilidade de ocorrência pode-se utilizar bases de dados existentes na literatura ou bases de dados da própria empresa, sendo que essa última permitirá obter valores mais reais da probabilidade de ocorrência do evento. Estas bases de dados devem fornecer valores da taxa de falha em termos de falha/unidade de tempo para os diferentes componentes do sistema analisado, com a qual é possível calcular a probabilidade de um evento acontecer.

A distribuição que será utilizada para calcular a probabilidade de ocorrência de um evento acontecer ao longo de uma campanha operacional é a distribuição de Poisson a qual é definida na Equação 4.1. Esta distribuição define o valor da probabilidade $(P)$ de um número de eventos $(n)$ ocorrerem em um determinado tempo de análise $(t)$, considerando a taxa de ocorrência do evento $(\lambda)$ constante. Nesta distribuição, quanto maior for o número de eventos, menor será a probabilidade de ocorrência para um mesmo período de tempo (MODARRES, 1993; MELCHERS, 1999). 


$$
P(\text { ocorrência de } n \text { eventos })=\frac{(\lambda t)^{n} \cdot e^{-\lambda t}}{n !}
$$

onde:

$P(n)$ : Probabilidade de um evento ocorra um número " $n$ " de vezes num intervalo de tempo $(t)$.

n: Valor da variável aleatória ou número de ocorrências do evento em um determinado intervalo de tempo $(t)$.

$\lambda$ : Taxa de ocorrência do evento.

$t$ : Tempo de análise.

Introduzido o valor de " $n$ " número de eventos e estabelecido o tempo de análise, se obterá a probabilidade de acontecer esse número de eventos nesse determinado tempo sob análise. Garvey e Landsdowne (1998) e Bezerra (2004) relacionam para cada faixa do valor da probabilidade, uma categoria de frequência. $\mathrm{O}$ valor da probabilidade obtido será introduzido dentro das faixas de probabilidade de ocorrência que se encontram na Tabela 4.2, onde se utilizaram as denominações e descrições da frequência de acordo com a norma técnica PETROBRAS N-2782 apresentadas na Tabela 4.1.

Na Tabela 4.2 é apresentada a tabela em termos da probabilidade de ocorrência de um evento considerando as categorias de frequência, a denominação e a descrição da norma N2782.

Tabela 4.2 - Categoria de frequência em termos da probabilidade de ocorrência

\begin{tabular}{|c|c|c|l|}
\hline $\begin{array}{c}\text { Categoria de } \\
\text { frequência }\end{array}$ & Denominação & $\begin{array}{c}\text { Faixas da probabilidade } \\
\text { de ocorrência }\end{array}$ & \multicolumn{1}{c|}{ Descrição } \\
\hline $\mathrm{A}$ & $\begin{array}{c}\text { Extremamente } \\
\text { Remota }\end{array}$ & $<0,001 \%$ & $\begin{array}{l}\text { Conceitualmente possível, mas extremamente } \\
\text { improvável de ocorrer durante a vida útil da } \\
\text { instalação. Não há referências históricas de } \\
\text { ocorrência. }\end{array}$ \\
\hline $\mathrm{B}$ & Remota & $0,001 \%-0,01 \%$ & $\begin{array}{l}\text { Não esperado ocorrer durante a vida útil da } \\
\text { instalação, apesar de já poder ter ocorrido em } \\
\text { algum lugar no mundo. }\end{array}$ \\
\hline $\mathrm{C}$ & $\begin{array}{c}\text { Pouco } \\
\text { Provável }\end{array}$ & $0,01 \%-1 \%$ & $\begin{array}{l}\text { Possível de ocorrer até uma vez durante a vida } \\
\text { útil da instalação. }\end{array}$ \\
\hline $\mathrm{D}$ & Provável & $1 \%-40 \%$ & $\begin{array}{l}\text { Esperado ocorrer poucas vezes durante a vida útil } \\
\text { da instalação. }\end{array}$ \\
\hline $\mathrm{E}$ & Frequente & $40 \%-100 \%$ & $\begin{array}{l}\text { Esperado ocorrer muitas vezes durante a vida útil } \\
\text { da instalação. }\end{array}$ \\
\hline
\end{tabular}




\subsubsection{Análise das Consequências de Ocorrência}

Como descrito anteriormente, cada um dos componentes de um sistema pode ter diferentes modos de falha, cuja consequência pode variar dependendo da localização do componente e da gravidade da falha (BAI et al., 2010). As consequências podem ser determinadas qualitativamente ou quantitativamente dependendo da disponibilidade de dados.

Na Tabela 4.3 visualiza-se as categorias de consequências de acordo com a norma técnica PETROBRAS N-2782. Nesta tabela foi retirada a coluna das consequências relacionadas ao meio ambiente.

Tabela 4.3 - Categorias de severidade das consequências dos cenários (PETROBRAS, 2005)

\begin{tabular}{|c|c|c|c|}
\hline \multirow{2}{*}{\multicolumn{2}{|c|}{$\begin{array}{l}\text { Categorias de } \\
\text { Severidade }\end{array}$}} & \multicolumn{2}{|c|}{ Descrição/Característica } \\
\hline & & Segurança Pessoal & Segurança das Instalações \\
\hline I & Desprezível & $\begin{array}{c}\text { Não ocorrem lesões/mortes de } \\
\text { funcionários ou de terceiros (não } \\
\text { funcionários); e/ou de pessoas extra- } \\
\text { muros (indústrias e comunidade); o } \\
\text { máximo que pode ocorrer são casos de } \\
\text { primeiros socorros ou tratamento médico } \\
\text { menor }\end{array}$ & $\begin{array}{l}\text { Sem danos ou danos insignificantes aos } \\
\text { equipamentos ou instalações }\end{array}$ \\
\hline II & Marginal & Lesões leves em funcionários e terceiros & $\begin{array}{c}\text { Danos leves aos equipamentos ou } \\
\text { instalações (os danos são controláveis } \\
\text { e/ou de baixo custo de reparo) }\end{array}$ \\
\hline III & Crítica & $\begin{array}{l}\text { Lesões leves em pessoas extra-muros. } \\
\text { Lesões de gravidade moderada em } \\
\text { funcionários, terceiros e/ou em pessoas } \\
\text { extra-muros (probabilidade remota de } \\
\text { morte de funcionários e/ou de terceiros) }\end{array}$ & $\begin{array}{l}\text { Danos severos a equipamentos ou } \\
\text { instalações }\end{array}$ \\
\hline IV & Catastrófica & $\begin{array}{l}\text { Provoca morte ou lesões graves em uma } \\
\text { ou mais pessoas (em funcionários, } \\
\text { terceiros e/ou em pessoas extra-muros) }\end{array}$ & $\begin{array}{c}\text { Danos irreparáveis a equipamentos ou } \\
\text { instalações (reparação lenta ou } \\
\text { impossível) }\end{array}$ \\
\hline
\end{tabular}

De acordo com Rausand (2011) os modos de falha podem ser definidos como a maneira na qual o defeito se apresenta ou a maneira como o item falha ou deixa de apresentar o resultado desejado ou esperado. Deve-se associar uma categoria de consequência para cada modo de falha encontrado para os componentes que pertencem ao sistema em estudo. 


\subsubsection{Elaboração da Matriz de Risco}

A associação das duas variáveis, frequências e consequências, pode ser feita de maneira lógica em uma matriz de risco a partir da classificação dos modos de falha, relacionando os mesmos com os seus respectivos valores de frequência e consequência, obtendo a correspondente categoria de risco, e finalmente com esses resultados monta-se a matriz de risco. Com isso, os analistas, em conjunto com os projetistas, podem direcionar suas decisões na melhoria da segurança da instalação, permitindo visualizar quais são os eventos de perigo que tem maior categoria de risco em caso de acontecimento (NATACCI e MARTINS, 2009).

A matriz de risco, segundo a norma técnica da PETROBRAS N-2782 é apresentada na Tabela 4.4 a seguir.

Tabela 4.4 - Categorias de risco em função da frequência e da consequência de ocorrência (PETROBRAS, 2004)

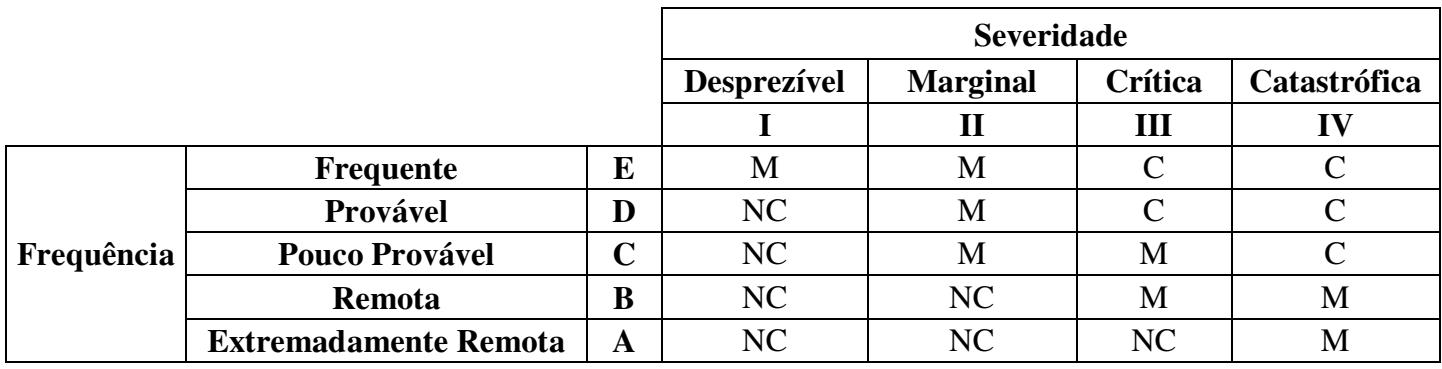

Nesta última tabela a sigla NC (Não Crítico) indica que o risco é considerado tolerável quando não há necessidade de medidas adicionais para evitar a ocorrência do evento de perigo. A sigla M (Moderado) representa o risco que é considerado tolerável quando mantido sob controle. Controles adicionais devem ser avaliados e implementados, aplicando-se uma análise para avaliar as alternativas disponíveis, de forma a se obter uma redução adicional dos riscos; e por último o pior dos casos é C (Crítico), onde o risco é considerado não tolerável com os controles existentes e devem ser consideradas modificações no projeto para evitar a operação em tal nível de risco, reduzindo a probabilidade de ocorrência e/ou as consequências.

Como resultado da elaboração da matriz de risco, é possível classificar cada evento de perigo associados aos modos de falha dos componentes em três categorias de risco $\mathrm{C}$ (Crítico), M (Moderado) e Não Crítico (NC) (SILVA e SOUZA, 2012). 
O método proposto indica que no caso do risco ser considerado como crítico, deve-se propor medidas que reduzam essa categoria de risco, e depois voltar para o Passo 2 para verificar se essas medidas surtiram efeito controlador. Se o risco foi reduzido e já não é mais considerado como Crítico passa-se ao último passo do método proposto, que serve para fazer as recomendações e fornecer as conclusões finais do estudo de risco.

\subsubsection{Passo 4: Recomendações e Conclusões Finais}

De acordo com os resultados obtidos após a aplicação do método de análise, devem ser fornecidas as recomendações e conclusões finais.

Este passo tem por finalidade propor as recomendações, baseado nos resultados obtidos na análise de risco com o intuito de reduzir o nível do risco nas áreas onde o risco for elevado, seja diminuindo a frequência ou a consequência. Nas conclusões é possível determinar se houveram erros de projeto, ou propor a instalação de novos sistemas de proteção que visem reduzir o risco da operação em estudo. 


\section{ESTUDO DE CASO: SISTEMA DE CARGA E DESCARGA DE GNL DE UM NAVIO TRANSPORTADOR DE GNL}

Este capítulo apresenta a aplicação do método proposto no Capítulo 4. Para a aplicação do método foi selecionado um navio transportador de GNL do tipo membrana, cujas principais características são apresentadas na Tabela 5.1.

Tabela 5.1 - Principais características do navio transportador de GNL sob análise

\begin{tabular}{|l|c|}
\hline \multicolumn{1}{|c|}{ Descrição } & Características \\
\hline Tipo de navio de transporte & Membrana \\
\hline Tecnologia utilizada & GTT Mark III \\
\hline Número de tanques de armazenamento & 4 \\
\hline Comprimento total $(\mathrm{m})$ & 280 \\
\hline Comprimento entre perpendiculares $(\mathrm{m})$ & 265 \\
\hline Capacidade total de armazenamento $\left(\mathrm{m}^{3}\right)$ & 138.000 \\
\hline Gás inerte utilizado & $\mathrm{N}_{2}$ \\
\hline
\end{tabular}

\subsection{Passo 1 - Etapa Preparatória: Definição do Sistema de Carga e Descarga}

O sistema em estudo é o sistema de carga e descarga do GNL que envolve os circuitos de GNL e o circuito de boil-off. Esse sistema foi escolhido dado que ele possui características e componentes particulares por manipular uma substância criogênica e inflamável.

Os componentes que estão envolvidos no sistema de carga e descarga são apresentados, assim como as funções que cada um deles deve executar.

O boil-off é o metano em estado gasoso que se origina devido à troca de calor entre o GNL e o meio circundante ao sistema de carga e descarga no navio. Todo esse gás (boil-off) deve ser deslocado e encaminhado pelas suas respectivas tubulações para dentro do circuito de boil-off. Durante a operação de carga ou descarga do GNL, o boil-off deve ser encaminhado para a instalação portuária. Por sua vez, durante a operação de transporte, o boil-off pode ser utilizado como combustível no navio, ou também pode passar por um novo processo de liquefação sendo injetado novamente dentro dos tanques de armazenamento ou simplesmente jogado para a atmosfera, caso o navio não tenha os equipamentos necessários 
para realizar alguma das duas atividades anteriormente mencionadas (CHANG et al., 2008; ICS, 1995).

O processo de descarga de boil-off foi projetado com o intuito de impedir que a pressão dentro do sistema de carga ou descarga do GNL se eleve e cause problemas severos nos componentes que não foram projetados para operar sob a ação da pressão, permitindo que a pressão no interior do circuito de GNL seja mantida na faixa de 70 a 100 mbar.

Para a carga do GNL são utilizados dois circuitos: 1) o circuito que transportará o GNL do ponto de conexão navio/terminal até os tanques de armazenagem e 2) o circuito que deslocará o boil-off gerado durante a operação de carga.

Para a descarga do GNL são utilizados: 1) o circuito que transportará o GNL dos tanques de armazenagem até o ponto de conexão navio/terminal e 2) o circuito que deslocará o boil-off que é o mesmo utilizado durante a carga. Na Figura 5.1 indicam-se os circuitos utilizados na operação em referência.

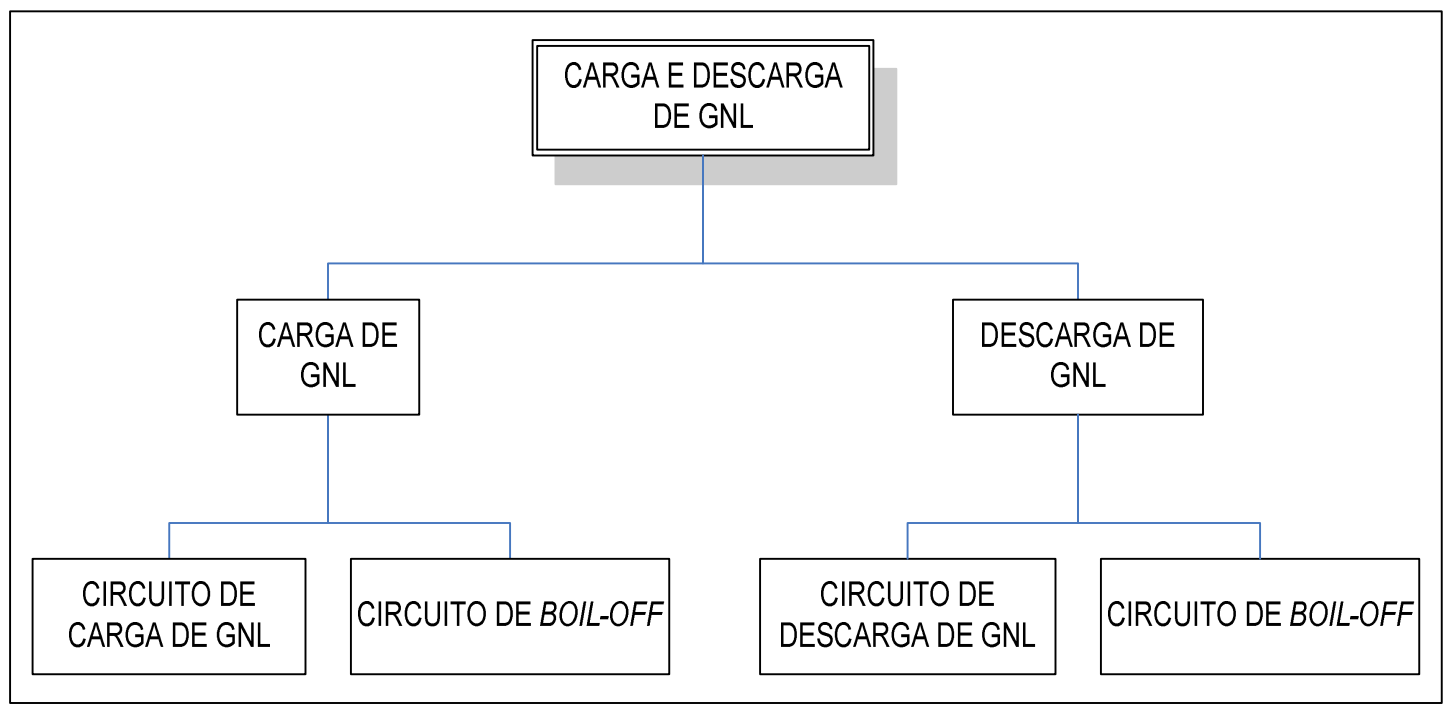

Figura 5.1 - Circuitos utilizados durante as operações de carga e descarga de GNL do navio transportador

Na Figura 5.2 e na Figura 5.3 são apresentados os circuitos que manuseiam o GNL e o boil-off durante a carga e descarga do GNL respectivamente. 


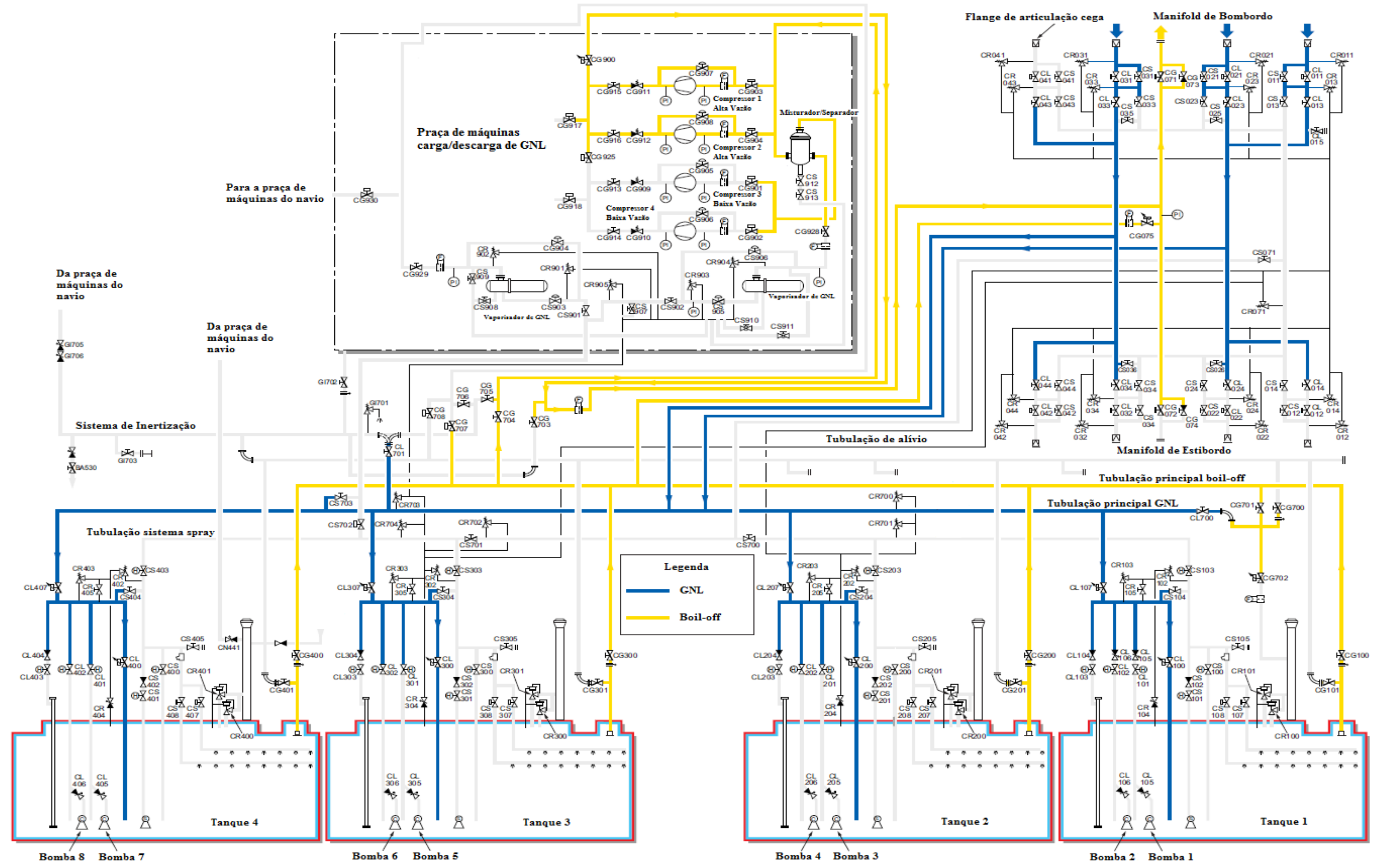

Figura 5.2 - Circuito de GNL e boil-off no navio transportador durante a operação de carga do GNL 


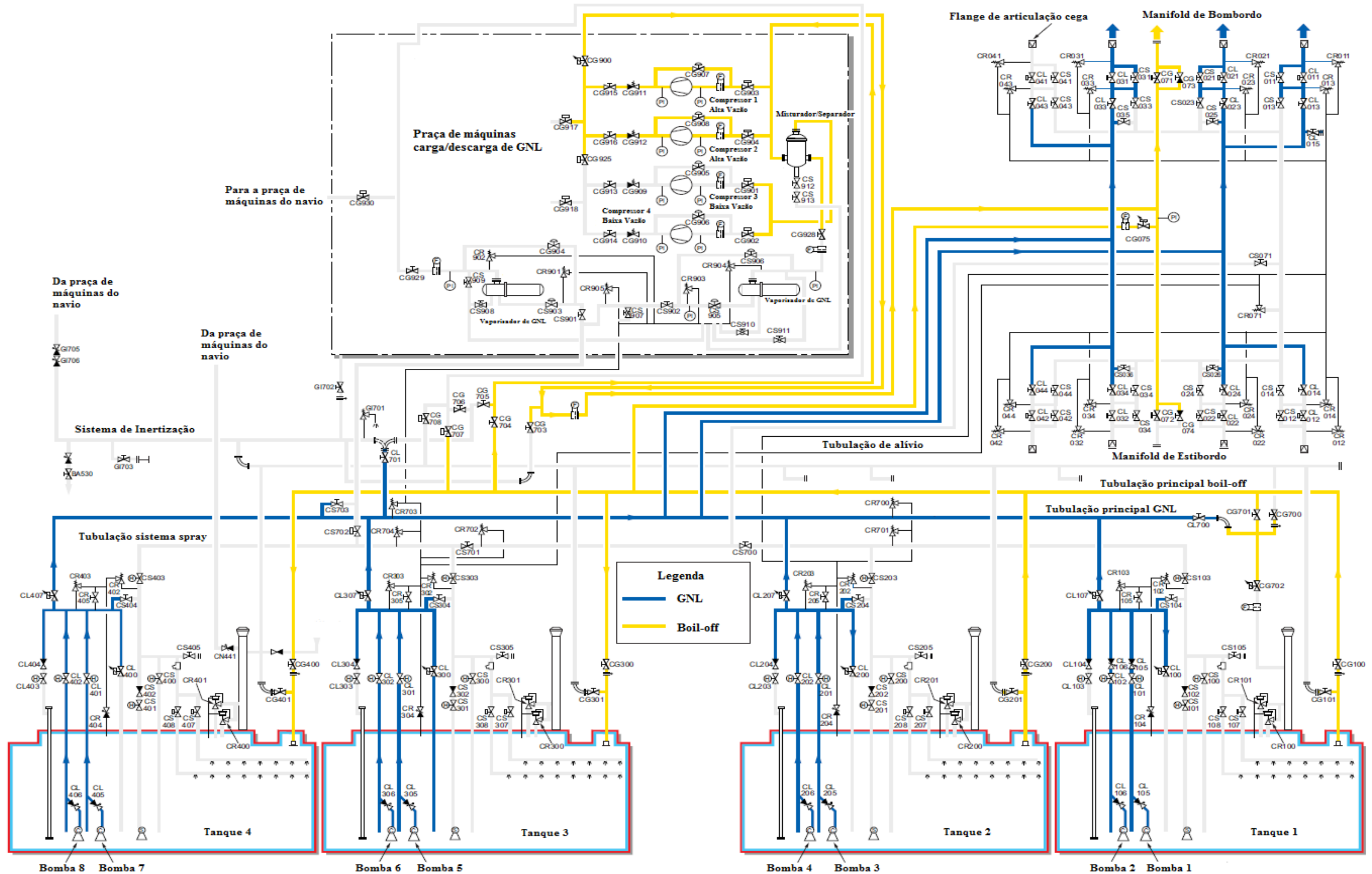

Figura 5.3 - Circuito de GNL e boil-off no navio transportador durante a operação de descarga do GNL 
Na Tabela 5.2 e Tabela 5.3 são apresentadas as legendas dos componentes dos circuitos de GNL e de boil-off respectivamente.

Tabela 5.2 - Componentes do circuito de GNL

\begin{tabular}{|c|c|}
\hline Símbolo & Componente \\
\hline 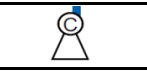 & Bomba de GNL \\
\hline 准 & Válvula de retenção anti-retorno \\
\hline$\stackrel{\mathbb{A}}{4}$ & Válvulas de globo com atuador hidráulico tipo palheta \\
\hline 象 & Válvulas borboleta com atuador tipo pistão com regulação variável \\
\hline 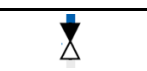 & Válvula anti-retorno sem mola \\
\hline$\Rightarrow$ & Válvula de globo com atuador hidráulico tipo palheta \\
\hline & Tanque de armazenamento \\
\hline & Tubulação secundária \\
\hline & Tubulação principal \\
\hline 䒜 & Válvulas borboleta com atuador hidráulico tipo pistão ativadas pelo ESD \\
\hline 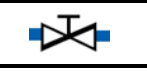 & Válvulas borboleta com atuador hidráulico tipo pistão sem regulação \\
\hline 新 & Válvula de alívio do tipo mola \\
\hline - & Tubulação de alívio \\
\hline
\end{tabular}

Tabela 5.3 - Componentes do circuito de boil-off

\begin{tabular}{|c|c|}
\hline Símbolo & Componente \\
\hline D & Válvula borboleta com atuador hidráulico tipo pistão sem regulação \\
\hline 只 & Válvulas borboleta com atuador hidráulico tipo pistão ativadas pelo ESD \\
\hline 邑 & Válvula borboleta com atuador hidráulico tipo pistão com regulação variável \\
\hline 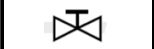 & Válvula de globo com atuador hidráulico tipo palheta sem regulação \\
\hline П & Riser de saída do boil-off \\
\hline$\$$ & Válvula borboleta com atuador pneumático tipo diafragma \\
\hline , & Misturador/Separador \\
\hline$=$ & Tubulações secundárias \\
\hline 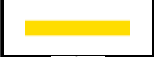 & Tubulação principal \\
\hline 员 & Válvulas de alívio tipo mola \\
\hline 8 & Compressor de alta e baixa vazão \\
\hline 药 & Válvula anti-retorno com mola \\
\hline 死 & Válvula borboleta com atuador hidráulico tipo pistão sem regulação \\
\hline 丈 & Válvula anti-retorno de haste roscada \\
\hline
\end{tabular}


Na sequência é explicado como se executa o processo de carga e descarga de GNL no navio transportador e também o processo de descarga de boil-off durante a carga ou descarga do GNL. Neste estudo de caso o processo de carga e descarga do GNL é realizado do lado do manifold de bombordo, mas esta operação também pode ser executada pelo lado do manifold do estibordo.

\subsubsection{Procedimento de Carga e Descarga de GNL}

\subsubsection{Procedimento de Carga do GNL no terminal de liquefação}

São importantes as atividades prévias ao carregamento do GNL como a inertização e o resfriamento dos tanques de armazenamento e das linhas do circuito de GNL. A atividade de resfriamento impede a variação brusca da temperatura dentro do sistema de carga do GNL e impede a geração descontrolada de boil-off, principalmente durante o começo do processo de carregamento do GNL. A atividade de resfriamento demora aproximadamente 90 minutos, dependendo da quantidade de produto que é injetado, com o objetivo de alcançar uma temperatura de $-130^{\circ} \mathrm{C}$. Utiliza-se para tal fim gás natural proveniente do próprio terminal, sendo que, após o resfriamento, o produto é reencaminhado para o terminal com o auxilio de compressores do circuito de boil-off.

No início da operação de carregamento, a taxa de vazão do GNL é inferior à vazão durante a operação normal de carga ou descarga, permitindo inspecionar os parâmetros de operação no início do processo e os locais que poderiam apresentar vazamentos. É importante destacar que todos os vazamentos, inclusive os de pequeno volume, deverão ser corrigidos imediatamente, pois a ocorrência de vazamento causa a redução da vazão do GNL para o navio, e a paralisação do processo de transferência. Se não for detectado qualquer problema, pode-se aumentar o volume da carga do GNL para dentro dos tanques criogênicos.

O processo de carregamento será completado quando todos os tanques alcançarem $98,5 \%$ do volume total. Nesse instante o terminal de liquefação não fornecerá mais GNL para dentro dos tanques de armazenamento e as válvulas do manifold devem permanecer fechadas. Paralelamente ao processo de carga de GNL é feito o controle do lastro do navio, que consiste em manter o trim da embarcação, as tensões no casco do navio em magnitude inferior admitidas no projeto, a estabilidade, entre outras características. 
No começo da operação de carga as válvulas do sistema deverão estar fechadas e o processo de carga deve ser realizado da seguinte maneira:

a) O GNL é carregado por meio do sistema de conexão manifold. O GNL ingressa no navio e segue por duas tubulações secundárias até a tubulação principal, onde se distribui para cada um dos quatro tanques de armazenamento.

b) As posições das válvulas de carga nos seus respectivos tanques devem estar tal como apresentada na Tabela 5.4.

Tabela 5.4 - Posições das válvulas de carga nos tanques durante a carga do GNL

\begin{tabular}{|c|c|c|}
\hline Indicação & Descrição & Válvula \\
\hline Abrir & Válvula de controle de fluxo de GNL do tanque 1 & CL100 \\
\hline Abrir & Válvula de controle de fluxo de GNL do tanque 2 & CL200 \\
\hline Abrir & Válvula de controle de fluxo de GNL do tanque 3 & CL300 \\
\hline Abrir & Válvula de controle de fluxo de GNL do tanque 4 & CL400 \\
\hline Abrir & Válvula de controle de fluxo de GNL do tanque 1 & CL107 \\
\hline Abrir & Válvula de controle de fluxo de GNL do tanque 2 & CL207 \\
\hline Abrir & Válvula de controle de fluxo de GNL do tanque 3 & CL307 \\
\hline Abrir & Válvula de controle de fluxo de GNL do tanque 4 & CL407 \\
\hline Abrir & Válvula de controle de fluxo de boil-off do tanque 1 & CG100 \\
\hline Abrir & Válvula de controle de fluxo de boil-off do tanque 2 & CG200 \\
\hline Abrir & Válvula de controle de fluxo de boil-off do tanque 3 & CG300 \\
\hline Abrir & Válvula de controle de fluxo de boil-off do tanque 4 & CG400 \\
\hline
\end{tabular}

c) Durante a carga do GNL as válvulas no manifold devem estar colocadas como apresentada na Tabela 5.5.

Tabela 5.5 - Posições das válvulas no manifold de bombordo durante a carga do GNL

\begin{tabular}{|c|c|c|}
\hline Indicação & Descrição & Válvula \\
\hline Abrir & Válvula de ESD do manifold (braço 1) & CL011 \\
\hline Abrir & Válvula de ESD do manifold (braço 2) & CL021 \\
\hline Abrir & Válvula de ESD do manifold (braço 3) & CL031 \\
\hline Abrir & Válvula do manifold (braço 1) & CL013 \\
\hline Abrir & Válvula do manifold (braço 2) & CL023 \\
\hline Abrir & Válvula do manifold (braço 3) & CL033 \\
\hline
\end{tabular}

d) Seguidamente, libera-se o abastecimento de GNL (por parte do terminal) com uma vazão reduzida através dos três braços criogênicos, começando assim o processo de carga do GNL. Durante o tempo em que a vazão da carga de GNL é reduzida é importante inspecionar as tubulações e válvulas localizadas no convés para monitorar e verificar todos os potenciais lugares para ocorrência de vazamentos.

e) Pelo menos um dos compressores de alta vazão deverá estar ligado para permitir o deslocamento do boil-off gerado durante o processo de carga de GNL para a instalação portuária. 
f) Posteriormente aumenta-se a vazão de carga de GNL em etapas, conforme acordado com o terminal de liquefação.

g) Deve-se ajustar a abertura das válvulas de enchimento dos tanques para manter-se uma distribuição uniforme de volume por tanque (CL100, CL200, CL300, CL 400).

O sistema de carga de GNL possui alarmes que permitem monitorar o nível do GNL dentro dos tanques de armazenamento que podem ser observados da sala de controle da carga:

$\checkmark \quad$ Um alarme de nível de GNL ativa-se quando o tanque atinge uma capacidade de $95 \%$ e $98 \%$ da sua capacidade total.

$\checkmark$ Outro alarme ativa-se antes que o nível de GNL alcance os 98,5\% de capacidade nos tanques.

$\checkmark \quad$ Um alarme de alto nível sonoro ativa-se com 98,5\% da capacidade dos tanques, e as válvulas de controle de fluxo dos tanques (CL100, CL200, CL300, CL400) se fecharão automaticamente.

$\checkmark \quad$ O último alarme de nível alto operará aos $99 \%$ da capacidade dos tanques e ativará o fechamento de emergência, caso as válvulas de enchimento não tenham sido fechadas.

É importante destacar que, o último alarme de nível alto dentro dos tanques e a ativação do sistema de emergência, não constituem parte de um procedimento de carga normal do navio, ao contrário, são eles os meios de proteção caso aconteça alguma falha no sistema de controle da carga de GNL.

h) Antes de finalizar o preenchimento dos tanques de armazenamento, deve-se solicitar ao terminal a redução da vazão do GNL, que é continuamente reduzida em função do volume da carga nos tanques. Quando um tanque está no nível requerido deve se fechar a correspondente válvula de controle de fluxo (CL100, CL200, CL300, CL400) para permitir a drenagens das linhas de carga.

i) Deve-se parar o compressor de alta vazão quando a pressão no interior do tanque estiver baixa. Quando o compressor estiver parado, o fluxo livre do boil-off para o terminal será por meio da válvula CG075. Fechar a válvula CG900, a qual pertence à saída do sistema de alta pressão na praça de máquinas.

j) O procedimento de carga do navio acabará quando todos os tanques alcançam $98,5 \%$ da sua capacidade. O GNL residual que ficou nas tubulações será descarregado no tanque 4. Por isso é importante deixar a válvula de carga CL400 (do tanque 4) aberta 
até o final do processo de carga de GNL. O alarme aos 98,5\% é bloqueado pelo sistema de controle de carga para prevenir que a válvula de enchimento do último tanque seja automaticamente bloqueada, já que o nível alcançou 98,5\% da sua capacidade. Isso acontece somente no caso do tanque 4 e quando as demais válvulas de controle de fluxo dos tanques de GNL já estão fechadas. Neste momento ocorre a monitoração não automatizada do volume abastecido no tanque 4 .

O GNL que ainda permanece nas partes inclinadas do manifold é carregado para o tanque 4, usando-se para isto o nitrogênio.

Quando o processo de carga do GNL estiver completo, todas as válvulas no manifold devem ser fechadas de acordo com o procedimento do próprio navio. O manifold deve estar bloqueado quando os braços criogênicos forem desconectados.

\subsubsection{Procedimento de Descarga do GNL no terminal de regaseificação}

Antes do processo de descarregamento do GNL é necessário purgar as linhas de descarregamento usando nitrogênio a uma pressão de pelo menos 3 bar. Isto é feito para assegurar a drenagem das conexões do manifold. Este sistema é controlado pelo próprio navio.

A operação de controle de lastro é realizada ao mesmo tempo que a operação de descarregamento do GNL. O controle de lastro é programado para manter o navio dentro dos limites requeridos de trim da embarcação, das tensões no casco do navio admitidas no projeto, da estabilidade, entre outras características.

Durante o processo normal de descarga do GNL, uma bomba principal de descarga será usada, mas dependendo da necessidade (aumento da vazão de GNL para o terminal de regaseificação), poderá ser ativada a bomba secundária de descarga, que têm as mesmas características operacionais da bomba principal. Tanto a bomba principal quanto a bomba secundária funcionarão até que a pressão de descarga caia na saída das bombas, indicando que será finalizado o processo.

Quando as duas bombas estão ligadas, como recomendação do processo de descarga de GNL, uma das bombas é desligada quando o nível de GNL no interior dos tanques alcança uma altura de aproximadamente $0,6 \mathrm{~m}$, evitando turbulência excessiva no fundo do tanque 
que criará agitação e perturbação na sucção de ambas as bombas. Cada tanque é descarregado até que o nível alcance $0,1 \mathrm{~m}$ normalmente.

Deve-se prever que uma quantidade do GNL ficará no interior dos tanques para manter a baixa temperatura no seu interior. Essa quantidade a ser mantida dentro dos tanques dependerá do tempo de duração da viagem até o local de carga de GNL. Para extrair o GNL residual no tanque de armazenamento é necessária a ativação das bombas do tipo spray/stripping ligadas uma a cada um dos tanques.

É importante que os compressores de alta vazão, e se for o caso, os compressores de baixa vazão, estejam prontos para operar, permitindo o deslocamento do boil-off para a instalação portuária. O processo de descarga do GNL deve ser executado da seguinte maneira:

a) As bombas criogênicas descarregam o GNL, que primeiro circula pelas tubulações secundárias e vão para a tubulação principal, seguindo para a instalação portuária por meio de duas tubulações secundárias, que vão da tubulação principal até os três braços criogênicos que se conectam com o manifold de bombordo.

b) A Tabela 5.6 apresenta as posições das válvulas, para iniciar o processo de descarga do GNL:

Tabela 5.6 - Posições das válvulas durante a descarga do GNL

\begin{tabular}{|c|c|c|}
\hline Indicação & Descrição & Válvula \\
\hline Fechar & Válvulas de bloqueio & CS013, CS023, CS033 \\
\hline Abrir & Válvula de ESD do manifold (braço 1, 2, 3) & CL011, CL021, CL031 \\
\hline Abrir & Válvula do manifold (braço 1, 2, 3) & CL013, CL023, CL033 \\
\hline Abrir & Válvula de ESD do manifold (braço único boil-off) & CG071 \\
\hline Fechar & Válvula de bloqueio & CG075 \\
\hline Auto & Válvula de controle de fluxo de GNL (tanque 1, 2, 3, 4) & CL107, CL207, CL307, CL407 \\
\hline Auto & Válvula de controle de fluxo de GNL (tanque 1, 2, 3, 4) & CL100, CL200, CL300, CL400 \\
\hline Abrir & Válvulas de retorno do circuito spray & CS100, CS200, CS300, CS400 \\
\hline
\end{tabular}

O processo de descarga começará pelo tanque 2, continuando com o tanque 3 , seguido pelo 4 e por último o tanque 1.

c) Selecionada a sequência de descarregamento dos tanques, deverá ser ligada a bomba 3 do tanque 2. Na sequência automática, serão executadas as seguintes ações:

Fechar a válvula CL207. 
$\checkmark$ Abertura parcial da válvula de controle de fluxo do tanque 2, CL201 até $18 \%$ do total.

$\checkmark$ A bomba 3 é ligada, e fará com que o GNL circule para dentro desse mesmo tanque via válvula CL200. Isso permitirá saber se existe um problema com o funcionamento da bomba em questão. Posteriormente será feita a mesma ação, mas desta vez para a bomba 4 , no mesmo tanque, com a abertura da válvula de controle de fluxo respectiva, a válvula CL202.

d) Seguidamente serão executadas as seguintes ações:

$\checkmark$ A válvula CL207 começa a abrir-se para $100 \%$.

$\checkmark$ A válvula CL200 começa a fechar-se.

$\checkmark$ Os passos anteriormente apontados continuarão até que a válvula CL207 esteja totalmente aberta e a válvula CL200 esteja totalmente fechada, respectivamente.

e) Realizar os mesmos procedimento (c) e (d) para os tanques restantes 3, 4 e 1, com as respectivas válvulas equivalentes.

Para completar o processo de descarga do GNL, os braços de carga e as tubulações são purgados e drenados para o tanque 4 , logo esses componentes são inertizados e finalmente desconectados.

Quando o processo de descarga estiver completo, todas as válvulas no manifold devem ser fechadas de acordo com o procedimento próprio do navio. O manifold deve estar bloqueado quando os braços criogênicos forem desconectados.

\subsubsection{Procedimento de descarga do boil-off durante a carga ou descarga de GNL}

Durante o processo de carga ou descarga do GNL, o boil-off é encaminhado para as instalações portuárias. Para isso é necessário o uso dos compressores de alta vazão (dois compressores), e em caso de haver maior quantidade de boil-off, o navio conta com compressores de baixa vazão (dois compressores) que complementarão o funcionamento dos compressores de alta vazão. Esse deslocamento do boil-off permitirá que a pressão no interior dos circuitos seja mantida constante entre 70 a 100 mbar manométricos. 
O boil-off pode fluir livremente para a instalação portuária através da abertura da válvula CG075, mas usualmente um compressor de alta vazão é utilizado para este fim. Dessa forma o boil-off é deslocado para o terminal com pressão e vazão controladas. Caso a pressão do tanque aumente, outro compressor de alta vazão entra em operação com o objetivo de aumentar o fluxo de gás para o porto e limitar a pressão no circuito de boil-off, e portanto a pressão dentro dos tanques.

A temperatura média com que o boil-off ingressa nos compressores é aproximadamente $130^{\circ} \mathrm{C}$ negativos, e um compressor de alta vazão trabalhando com $50 \%$ da sua capacidade é suficiente para deslocar o boil-off gerado. Antes de começar os processos de carga e descarga do GNL deve-se verificar se os compressores estão disponíveis para entrar em operação quando eles forem requisitados. Baseado na descrição anterior, normalmente um só compressor de alta vazão seria usado e os outros compressores ficarão em standby.

O processo de descarga do boil-off durante o processo de carga ou descarga do GNL deve ser feito da seguinte maneira:

a) O boil-off deve ser deslocado do tanque de armazenamento através de suas respectivas cúpulas, sendo transportado por meio de tubulações secundárias para a tubulação principal onde é coletado. Logo após, o gás entra na praça de máquinas, passa pelo processo de elevação de pressão e finalmente vai para a instalação portuária. Na praça de máquinas, onde ficam os compressores de alta e baixa vazão, executa-se o procedimento apresentado na Tabela 5.7 que mostra a posição das válvulas para realizar a descarga do boil-off durante o processo de carga ou descarga do GNL.

Tabela 5.7 - Posições das válvulas que permitem o fluxo do boil-off durante a carga ou descarga do GNL

\begin{tabular}{|c|c|c|}
\hline Indicação & Descrição & Válvula \\
\hline Abrir & Válvula de controle de fluxo de boil-off (tanque 1, 2, 3, 4) & $\begin{array}{c}\text { CG100, CG200, } \\
\text { CG300, CG400 }\end{array}$ \\
\hline Abrir & Válvula no ingresso ao sistema de baixa pressão & CG704 \\
\hline Abrir & Válvula no ingresso ao compressor 1 de alta vazão & CG903 \\
\hline Abrir & Válvula no ingresso ao compressor 2 de alta vazão & CG904 \\
\hline Abrir & Válvula na saída do compressor 1 de alta vazão & CG915 \\
\hline Abrir & Válvula na saída do compressor 2 de alta vazão & CG916 \\
\hline Abrir & Válvula no sistema de alta pressão & CG900 \\
\hline Fechar & Válvula de bloqueio & CG075 \\
\hline Fechar & Válvula no sistema de alta pressão & CG703 \\
\hline Fechar & Válvulas no manifold de estibordo & CG072, CG074 \\
\hline Abrir & Válvulas no sistema de alta pressão no manifold de bombordo & CG071, CG073 \\
\hline
\end{tabular}


A válvula CG075 deverá estar fechada quando um dos compressores estiverem ligados, caso contrário o gás circulará no próprio circuito de boil-off ao invés de ser descarregado para o terminal.

b) A abertura da válvula de saída de boil-off CG071 no manifold permitirá o livre fluxo de gás para a instalação portuária.

c) O compressor de alta vazão deve ser parado quando a pressão no interior do tanque for baixa. Quando ele estiver parado, o fluxo livre do boil-off para o terminal portuário será por meio da válvula CG075. A válvula CG900 deverá estar fechada, a qual está localizada na saída do sistema de alta pressão na praça de máquinas.

\subsubsection{Componentes do sistema de carga e descarga do GNL}

\subsubsection{Bombas criogênicas submersas}

De acordo com Karassik (2001) e ABS (2008) a característica operacional deste tipo de bomba é a baixa temperatura em que os fluidos são bombeados. Os projetistas devem considerar o efeito da temperatura nas propriedades dos materiais, incluindo a contração e a dilatação do corpo dos componentes, implicando em variação nas tolerâncias de montagem dos mesmos. O problema é ainda complexo pelo fato de que os fluidos criogênicos são armazenados à pressão atmosférica e devem ser bombeados perto do seu ponto de ebulição, exigindo cuidado no projeto da instalação. As bombas são instaladas perto do motor elétrico, eliminando a necessidade de um eixo longo e reduzindo os problemas associados com a variação dimensional dos mesmos. A Figura 5.4 apresenta a bomba submersa instalada dentro dos tanques de armazenamento, que é fabricada em alumínio fundido tanto na estrutura da bomba como no rotor da mesma. O eixo e os rolamentos de esferas são fabricados em aço inoxidável. 


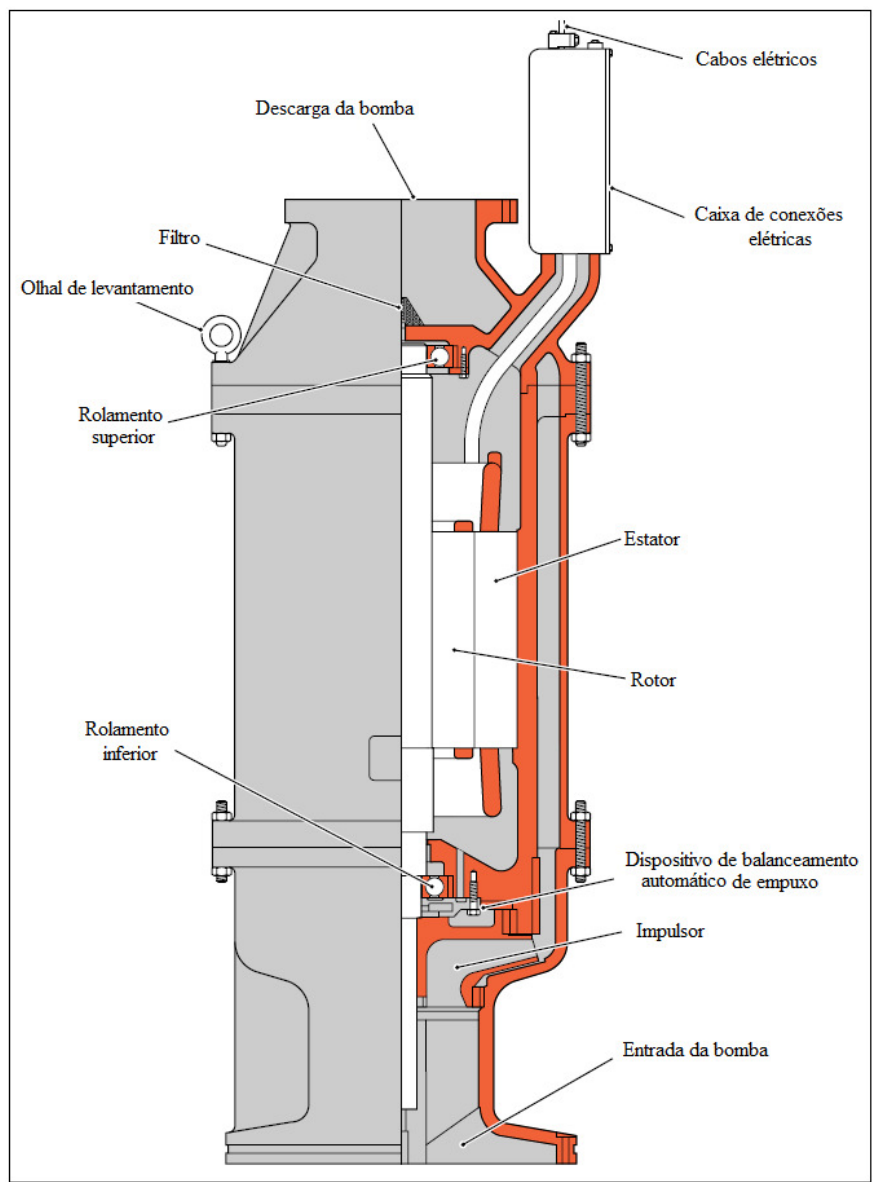

Figura 5.4 - Bomba criogênica submersa utilizada para efetuar a descarga do GNL

\section{A lubrificação e o resfriamento das bombas e seus respectivos motores é feito pelo próprio}

GNL. Na Tabela 5.8 observam-se as principais características das bombas criogênicas instaladas dentro dos tanques de armazenamento de GNL do navio.

Tabela 5.8 - Principais características das bombas criogênicas

\begin{tabular}{|l|c|}
\cline { 2 - 2 } \multicolumn{1}{c|}{} & Características \\
\hline Tipo de bomba & Bomba centrífuga submersa \\
\hline Material de fabricação & Alumínio \\
\hline Vazão & $1,700 \mathrm{~m}^{3} / \mathrm{h}$ \\
\hline Potência do motor & $465.1 \mathrm{~kW}$ \\
\hline Velocidade de rotação do motor elétrico & $1,780 \mathrm{rpm}$ \\
\hline Temperatura de operação & $-163^{\circ} \mathrm{C}$ \\
\hline Número de estágios & 1 \\
\hline Número total de bombas & $8(2$ por cada tanque $)$ \\
\hline
\end{tabular}




\subsubsection{Válvulas criogênicas}

Este tipo de válvulas tem uma distância considerável entre o assento da válvula e a prensa gaxeta. Esta extensão permite que o prensa gaxeta fique afastado do corpo da válvula e que o fluido hidráulico com que trabalha o atuador não seja congelado pelas baixas temperaturas do fluido criogênico (KUTZ, 2006).

De acordo com SIGTTO (2002), a operação destas válvulas deve prever a dilatação e a contração térmica e ainda fornecer um fechamento hermético sem vazamento através do assento. Um problema particular é o bloqueio do líquido (do inglês - liquid lock) no corpo da válvula. O bloqueio do líquido no corpo da válvula é um problema que ocorre pela ação de fechamento da válvula, onde um pouco do líquido fica preso na cavidade dentro do corpo da válvula. Isto é um perigo potencial, porque o líquido pode regaseificar-se e gerar pressão suficiente para causar a deformação dos componentes ou causar a fratura do corpo da válvula.

Todas as válvulas utilizadas na operação de carga ou descarga do GNL são acionadas hidraulicamente. Com a utilização dos atuadores hidráulicos consegue-se alcançar os torques necessários para abrir ou fechar as mesmas. Os atuadores destas válvulas são do tipo pistão e palhetas, utilizando a energia hidráulica para movimentar o eixo das válvulas. Os atuadores apresentados na Figura 5.5 correspondem aos atuadores das válvulas borboleta e globo respectivamente. Estas válvulas são comandadas pelo sistema de controle da carga.

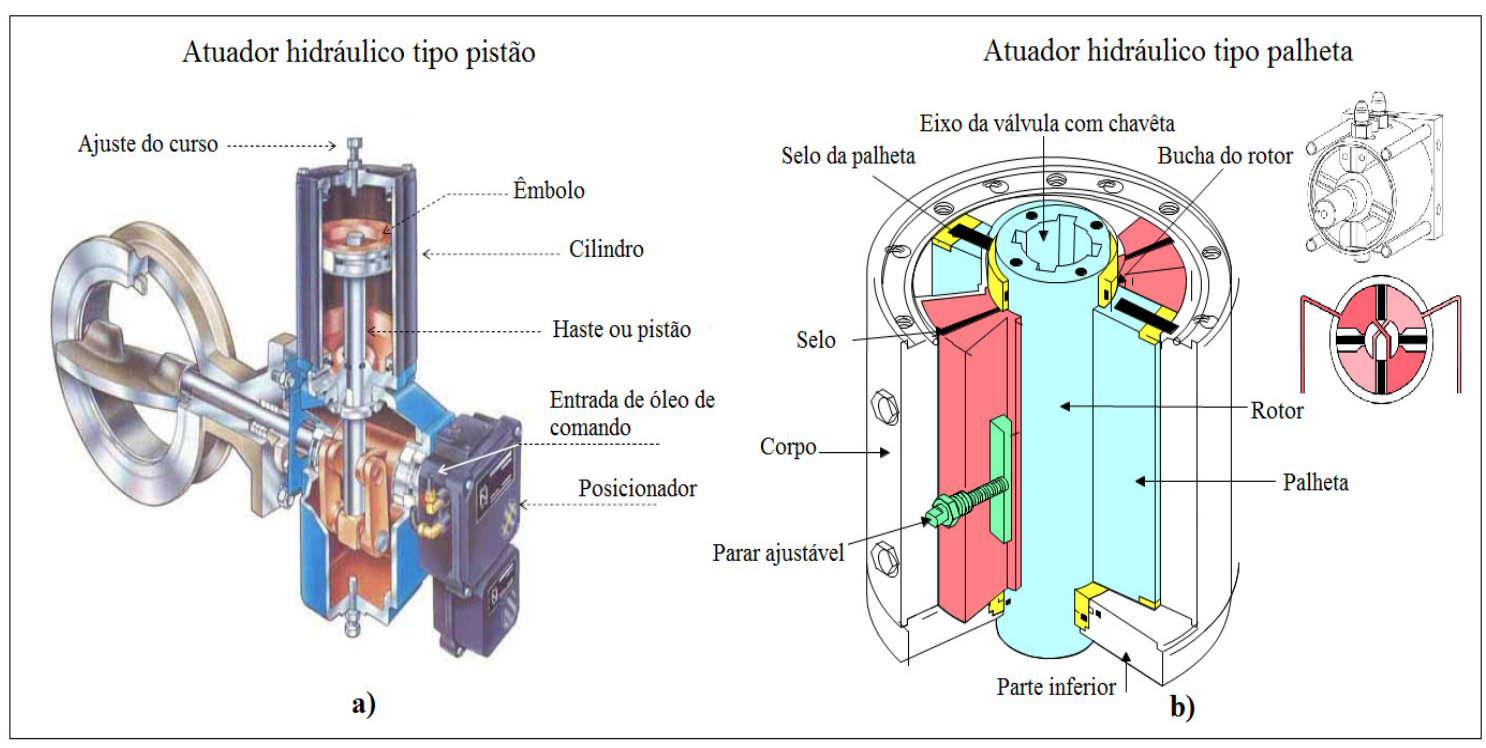

Figura 5.5 - a) Atuador do tipo pistão para as válvulas borboleta e b) Atuador do tipo palhetas para a válvula globo (PARKER, 2004) 
Na Tabela 5.9 observa-se as válvulas que são acionadas hidraulicamente e que pertencem ao sistema de carga e descarga do GNL e do boil-off.

Tabela 5.9 - Válvulas do sistema de carga e descarga do GNL e do boil-off de acordo com o tipo e o atuador

\begin{tabular}{|c|c|c|}
\hline & Válvula Borboleta & Válvula de globo \\
\hline Válvulas & $\begin{array}{l}\text { CL100, CL107, CG702; CL200, CL207; } \\
\text { CG075; CL300, CL301, CL302, CL303, } \\
\text { CL307; CG900, CG901, CG902, CG903, } \\
\text { CG904, CG925; CL400, CL407, CG708 }\end{array}$ & $\begin{array}{lll}\text { CL101, } & \text { CL102, } & \text { CL103; } \\
\text { CL201, } & \text { CL202, } & \text { CL203; } \\
\text { CL401, CL402, CL403 } & \end{array}$ \\
\hline Tipo de atuador & Pistão & Palheta \\
\hline
\end{tabular}

A Tabela 5.10 apresenta as válvulas ativadas pelo sistema de paralisação de emergência (ESD), que são ativadas caso o sistema detecte algum problema que precise fechar as válvulas como medida de contingência.

Tabela 5.10 - Válvulas que pertencem ao sistema ESD

\begin{tabular}{|c|c|}
\cline { 2 - 2 } \multicolumn{1}{c|}{} & Válvula Borboleta \\
\hline \multirow{2}{*}{ Válvulas } & CG071, CL011, CL021, CL031, CL041; \\
\hline Tipo de atuador & CL012, CL022, CL032, CL042, CG072; CG930 \\
\hline
\end{tabular}

As válvulas de alívio dos tanques de armazenamento servem para aliviar a pressão dentro deles, e estão configuradas a uma pressão de alívio de 0,25 bares. As características das válvulas deste tipo são apresentadas na Tabela 5.11. Cada tanque do navio conta com duas válvulas de alívio com a mesma capacidade (IGC IMO, 2005). A Figura 5.6 apresenta as duas válvulas de alívio de um tanque de armazenagem de GNL.

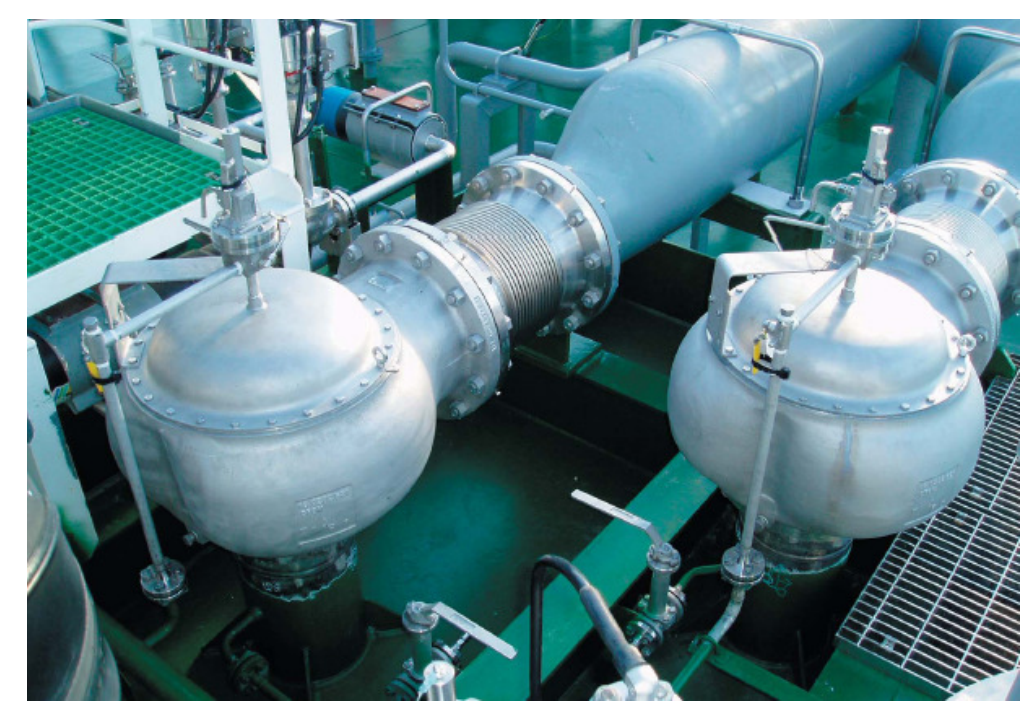

Figura 5.6 - Válvulas de alívio dos tanques de armazenagem de GNL 
As válvulas de alívio dos tanques de armazenamento estão conectadas a uma tubulação chamada de riser, que serve para encaminhar os gases liberados pelas válvulas de alívio para o ambiente. A expulsão dos gases acontece de forma segura e a uma altura de 3 metros, que não permitirá a formação de nuvens inflamáveis próximas à coberta do navio.

Tabela 5.11 - Tipo de válvulas de alívio para os tanques de armazenamento de GNL

\begin{tabular}{|l|l|}
\hline \multicolumn{1}{|c|}{ Válvulas } & $\begin{array}{l}\text { CR100, CR101, CR200, CR201, CR300, CR301, } \\
\text { CR400, CR401 }\end{array}$ \\
\hline Tipo & Mola \\
\hline Ajuste da pressão & $250 \mathrm{mbar}$ \\
\hline Taxa de vazão por válvula & $27,630 \mathrm{Nm}^{3} / \mathrm{h}$ \\
\hline Localização & Parte superior dos tanques de armazenamento \\
\hline
\end{tabular}

O sistema de tubulações do circuito de carga ou de descarga do GNL está equipado também com válvulas de alívio. As válvulas de alívio das conexões dos manifolds descarregam no tanque dois, enquanto que as válvulas de alívio das tubulações da praça de máquinas descarregam para o tanque três. As características das válvulas de alívio da tubulação principal de GNL, das tubulações secundárias nos tanques e de alívio dos manifolds são apresentadas nas Tabela 5.12, Tabela 5.13 e Tabela 5.14, respectivamente.

Tabela 5.12 - Válvulas de alívio na tubulação principal de GNL

\begin{tabular}{|l|l|}
\hline \multicolumn{1}{|c|}{ Válvulas } & $\begin{array}{l}\text { CR700, CR703, CR071, CR701, CR702, } \\
\text { CR704 }\end{array}$ \\
\hline Ajuste da pressão & 10 bar \\
\hline Pressão de fechamento & 9,5 bar \\
\hline Localização & Tubulação de GNL \\
\hline
\end{tabular}

Tabela 5.13 - Válvulas de alívio das tubulações secundárias nos tanques

\begin{tabular}{|l|l|}
\hline \multicolumn{1}{|c|}{ Válvulas } & $\begin{array}{l}\text { CR103, CR203, CR303, CR403, CR102, } \\
\text { CR202, CR302, CR402 }\end{array}$ \\
\hline Ajuste da pressão & 10 bar \\
\hline Pressão de fechamento & 9,5 bar \\
\hline Localização & Tubulação secundária nos tanques \\
\hline
\end{tabular}

Tabela 5.14 - Válvulas de alívio dos manifolds

\begin{tabular}{|l|l|}
\hline & CR013, CR014, CR023, CR024, CR033, \\
& CR034, CR043, CR044, CR011, CR012, \\
& CR021, CR022, CR031, CR032, CR041, \\
& CR042 \\
\hline Ajuste da pressão & 10 bar \\
\hline Pressão de fechamento & 9,5 bar \\
\hline Localização & Manifold \\
\hline
\end{tabular}




\subsubsection{Tanque de armazenamento}

O tanque primário é feito de uma membrana fina e flexível, chamada de barreira primária, que está apoiada contra a estrutura do isolamento. O navio conta com uma barreira secundária com seu respectivo isolamento apoiada no casco interno do próprio navio, como pode-se observar na Figura 5.7.

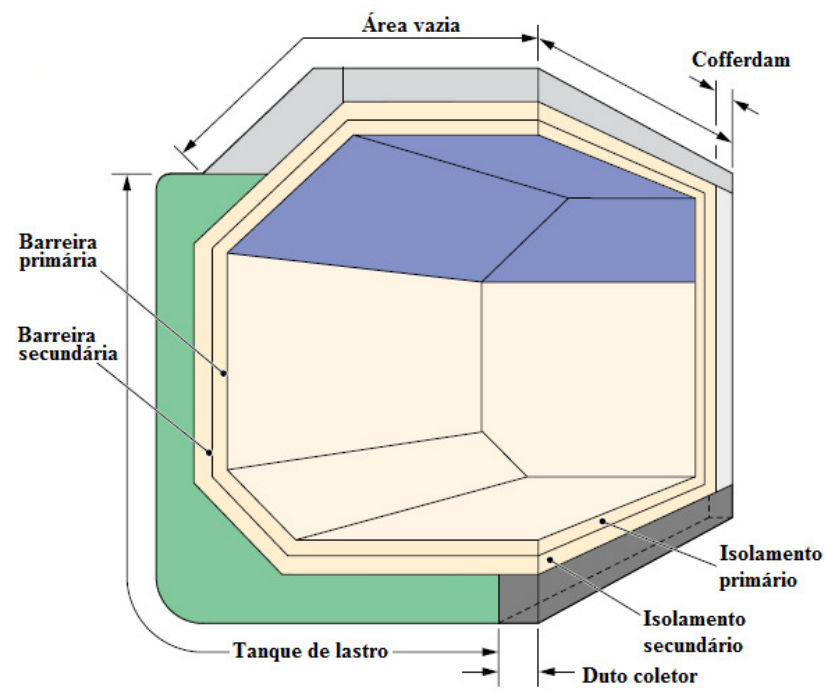

Figura 5.7 - Esquema geral do tanque de armazenamento

O tanque de armazenamento para o navio estudado é do tipo membrana GTT Mark III e é apresentado na Figura 5.8.

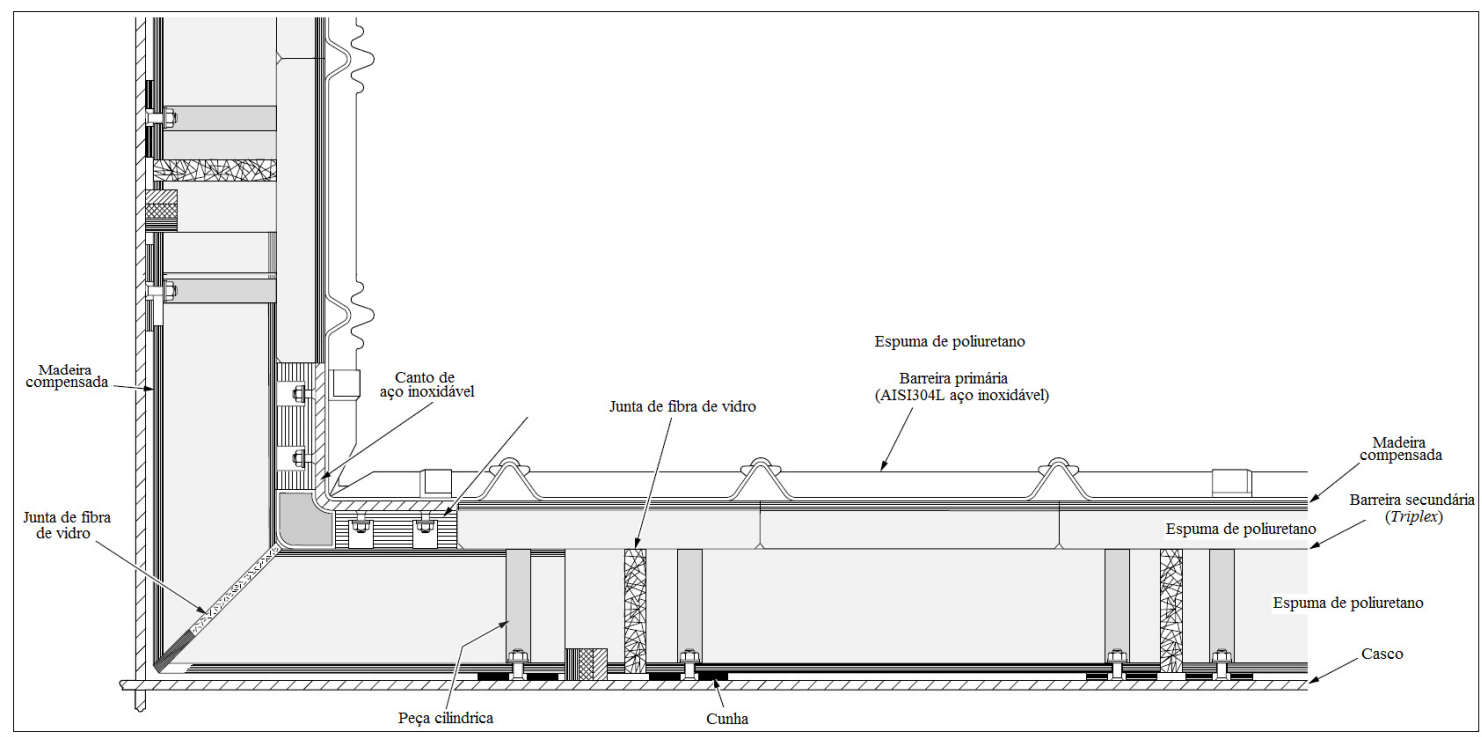

Figura 5.8 - Tanque de armazenamento tipo membrana GTT Mark III 
A barreira primária é uma montagem de chapas corrugadas de 1,2 $\mathrm{mm}$ de espessura, feitas de aço inoxidável AISI 304L. Sob a madeira compensada que aparece na Figura 5.8 é instalada a barreira primária, na sequência são instaladas duas camadas de espuma de poliuretano, entre as quais é instalada a barreira secundária feita de Triplex.

\subsubsection{Tubulações}

Todas as tubulações são soldadas para reduzir a possibilidade de vazamento nas uniões entre elas. As tubulações que transportam o GNL e o boil-off são projetadas de tal forma que possam suportar a contração e expansão por meio dos loops de expansão e dos foles, respectivamente. Suportes fixos e deslizantes são instalados nas tubulações para garantir que os limites de esforço sejam mantidos em níveis aceitáveis.

As tubulações secundárias que saem dos tanques, que se ligam à tubulação principal e que saem desta, são soldadas de topo, tanto as tubulações que transportam o GNL quanto as de boil-off. As principais características da tubulação principal e das tubulações secundárias são apresentadas na Tabela 5.15.

Tabela 5.15 - Principais características das tubulações de GNL e de boil-off

\begin{tabular}{|l|c|c|c|}
\hline \multicolumn{1}{|c|}{ Item } & \multicolumn{3}{c|}{ Descrição } \\
\hline Tubulação & Principal & Secundária & Riser \\
\hline Diâmetro (mm) & 600 & 400 & 400 \\
\hline Pressão máx. de operação (bar) & 10 & 10 & 1 \\
\hline Material & \multicolumn{3}{|c|}{ Aço inoxidável 304L } \\
\hline Temperatura de operação $\left({ }^{\circ} \mathrm{C}\right)$ & \multicolumn{3}{|c|}{-162} \\
\hline
\end{tabular}

Tanto as tubulações que carregam o GNL quanto as que deslocam o boil-off estão protegidas por isolamento de espuma de poliuretano e por uma coberta que protege contra os efeitos do meio ambiente.

\subsubsection{Compressores Centrífugos}

Dois compressores de alta vazão e dois compressores de baixa vazão, da mesma capacidade, são instalados na praça de máquinas para comprimir o boil-off e encaminhá-lo ao terminal de liquefação ou de regaseificação (ABS, 2008). Estes compressores são acionados por motores elétricos instalados em outro ambiente. $\mathrm{O}$ eixo do motor atravessa o anteparo que 
divide ambos ambientes e aciona o compressor. Na Figura 5.9 observa-se o compressor centrífugo de uma etapa de compressão.

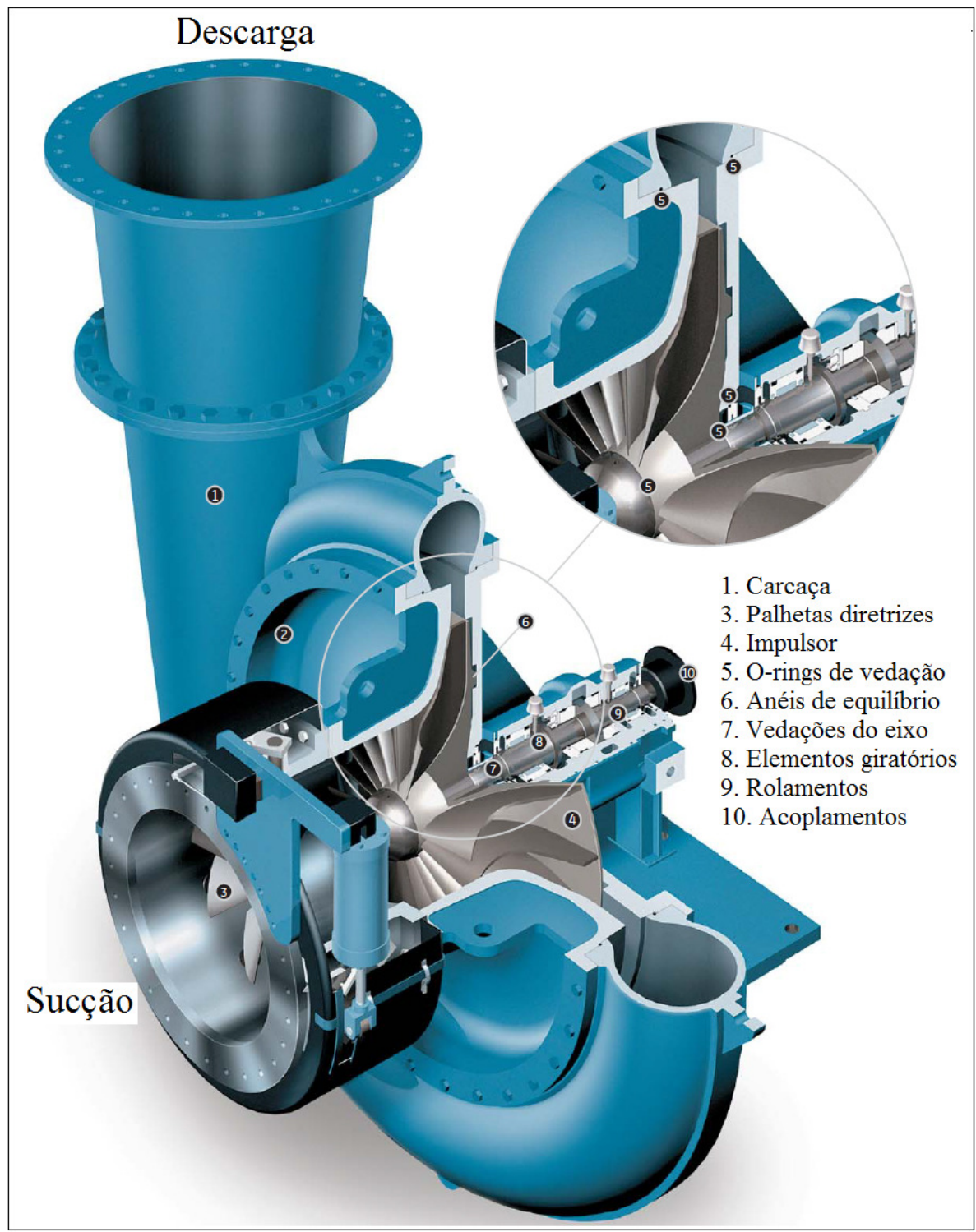

Figura 5.9 - Compressor centrífugo de uma etapa de compressão (GE, 2010)

Os compressores são desativados de forma emergencial quando o ESD é acionado e também por baixa pressão na linha de sucção do compressor, pela perda de energia elétrica, entre outras causas. Os compressores são operados localmente na praça de máquinas ou pelo sistema de controle de carga.

As principais características dos compressores de alta vazão e baixa vazão são apresentadas na Tabela 5.16. 
Tabela 5.16 - Características dos compressores de alta e baixa vazão

\begin{tabular}{|l|c|c|}
\hline \multicolumn{1}{|c|}{ Características } & Compressor de alta vazão & Compressor de baixa vazão \\
\hline Tipo & Centrifugo & Centrifugo \\
\hline $\mathrm{N}^{\mathbf{o}}$ de Etapas & 1 & 1 \\
\hline Velocidade & Fixa & Variável \\
\hline Fluxo de volume & $26,000 \mathrm{~m}^{3} / \mathrm{h}$ & $8,000 \mathrm{~m}^{3} / \mathrm{h}$ \\
\hline Pressão na entrada & $1,03 \mathrm{bar}$ & $1,06 \mathrm{bar}$ \\
\hline Pressão de descarga & $2,0 \mathrm{bar}$ & $2,0 \mathrm{bar}$ \\
\hline Temperatura na entrada & $-140{ }^{\circ} \mathrm{C}$ & $-140^{\circ} \mathrm{C}$ \\
\hline Temperatura na descarga & $-112^{\circ} \mathrm{C}$ & $-106^{\circ} \mathrm{C}$ \\
\hline
\end{tabular}

\subsubsection{Elaboração da Árvore Funcional}

A árvore funcional para a operação da carga do GNL é representada na Figura 5.10, onde o GNL é encaminhado para o interior do navio a partir da planta de liquefação. A Figura 5.11 apresenta a árvore funcional referente à operação de descarga do GNL, onde o bombeio do GNL é feito do interior dos tanques do navio, por meio das bombas criogênicas, até o terminal de regaseificação, que pode ser instalado em terra ou flutuante, neste caso denominado de FSRU (Floating Storage and Regasification Unit).

Verifica-se que o sistema de conexão manifold, o sistema de distribuição, o sistema de armazenagem, o sistema de controle da carga, o sistema de amostragem e detecção de gás e o sistema hidráulico de controle das válvulas são os mesmos tanto para o processo de carga quanto para o processo de descarga.

Tanto o sistema de controle da carga, o sistema de amostragem e detecção de gás e o sistema de controle das válvulas são sistemas complexos e que contam com uma série de equipamentos e configurações que tem influência sobre as operações de carga e descarga de GNL. Estes sistemas são estudados posteriormente para determinar a confiabilidade dos mesmos.

A árvore funcional para o circuito de boil-off apresentada na Figura 5.12, é a mesma tanto durante a carga quanto durante a descarga do GNL. Esses gases são encaminhados por meio do circuito de boil-off e pressurizados na praça de máquinas, para depois serem encaminhados para o terminal de liquefação ou de regaseificação. 


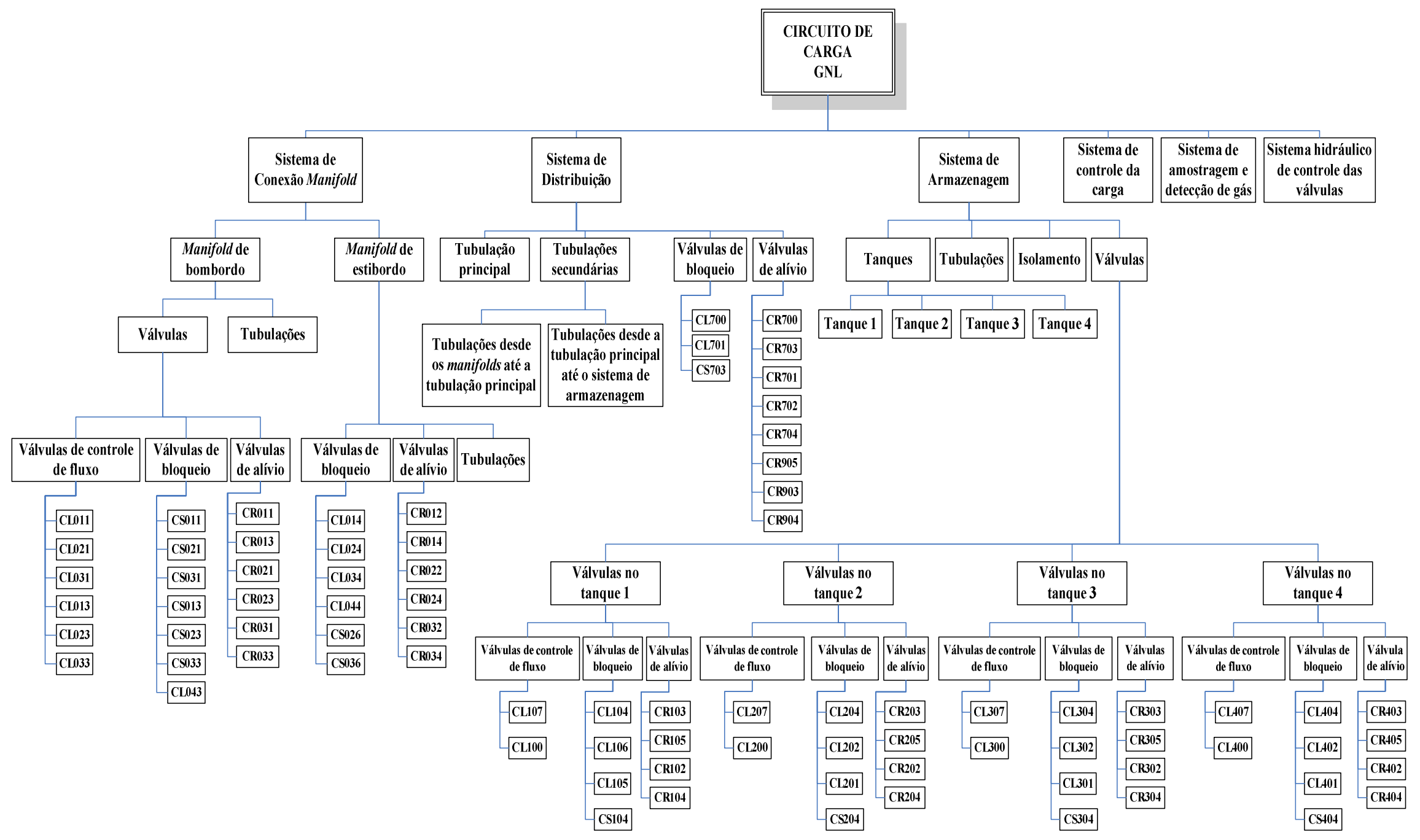

Figura 5.10 - Árvore funcional do sistema de carga e descarga durante a carga do GNL 


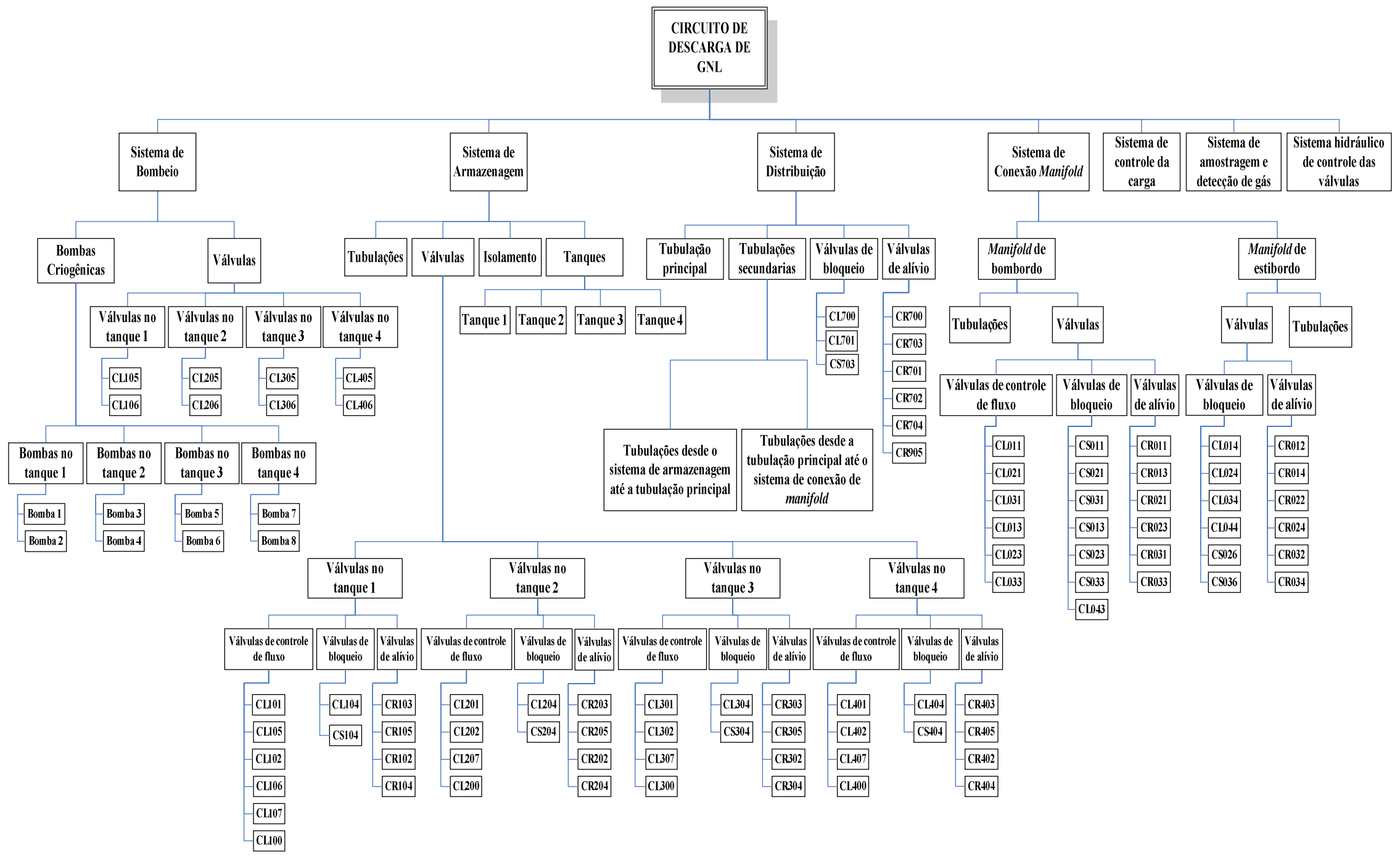

Figura 5.11 - Árvore funcional do sistema de carga e descarga durante a descarga do GNL 


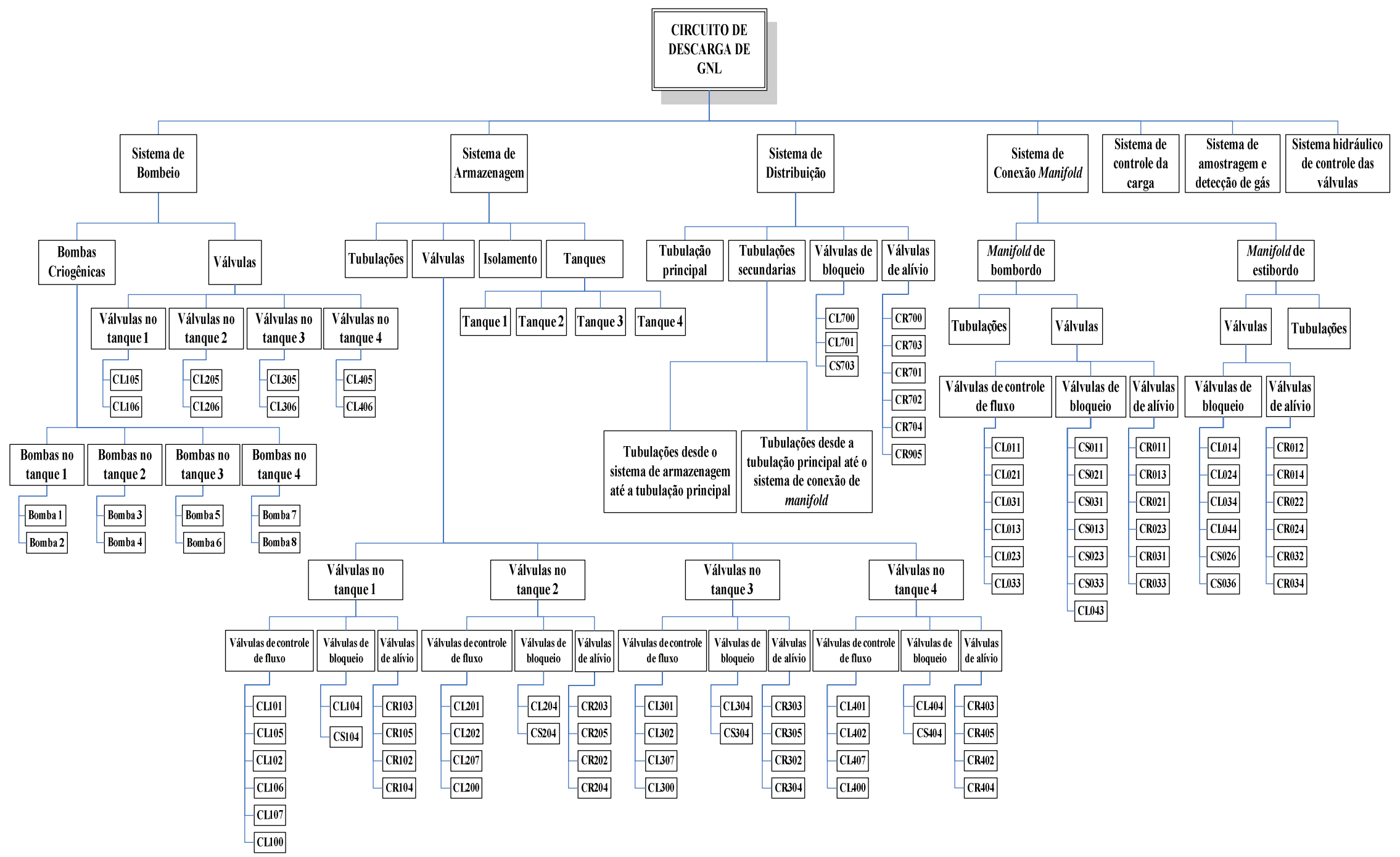

Figura 5.12 - Árvore funcional para o circuito de boil-off durante a carga/descarga do GNL 


\subsubsection{Descrição Funcional dos equipamentos}

Concomitantemente com a elaboração da árvore funcional, deve ser feita a descrição funcional que indicará claramente quais são as funções de cada um dos subsistemas e dos seus respectivos componentes. A descrição funcional é apresentada no Apêndice A desta dissertação.

\subsection{Passo 2 - Identificação de Perigos}

\subsubsection{Definição dos Perigos: Aplicação da Análise Preliminar de Perigos (APP)}

Segundo Skramstad et al. (2000), existem mais de 50 eventos de perigo na operação de navios transportadores de GNL, onde o vazamento de metano está relacionado direta ou indiretamente com a maioria desses eventos de perigo. Alguns deles estão associados com a ocorrência de falhas durante as manobras dos navios, tais como colisão e encalhe, e não propriamente associadas com sistemas de transferência e armazenamento de GNL. Na Tabela 5.17 observa-se a lista dos eventos de perigo que foram levantados pela sociedade classificadora DNV, baseados em uma frota de 12 navios de transporte de GNL operados pela Osprey Maritime da Noruega. 
Tabela 5.17 - Identificação dos eventos de perigo numa frota de 12 navios transportadores de GNL

(SKRAMSTAD et al., 2000)

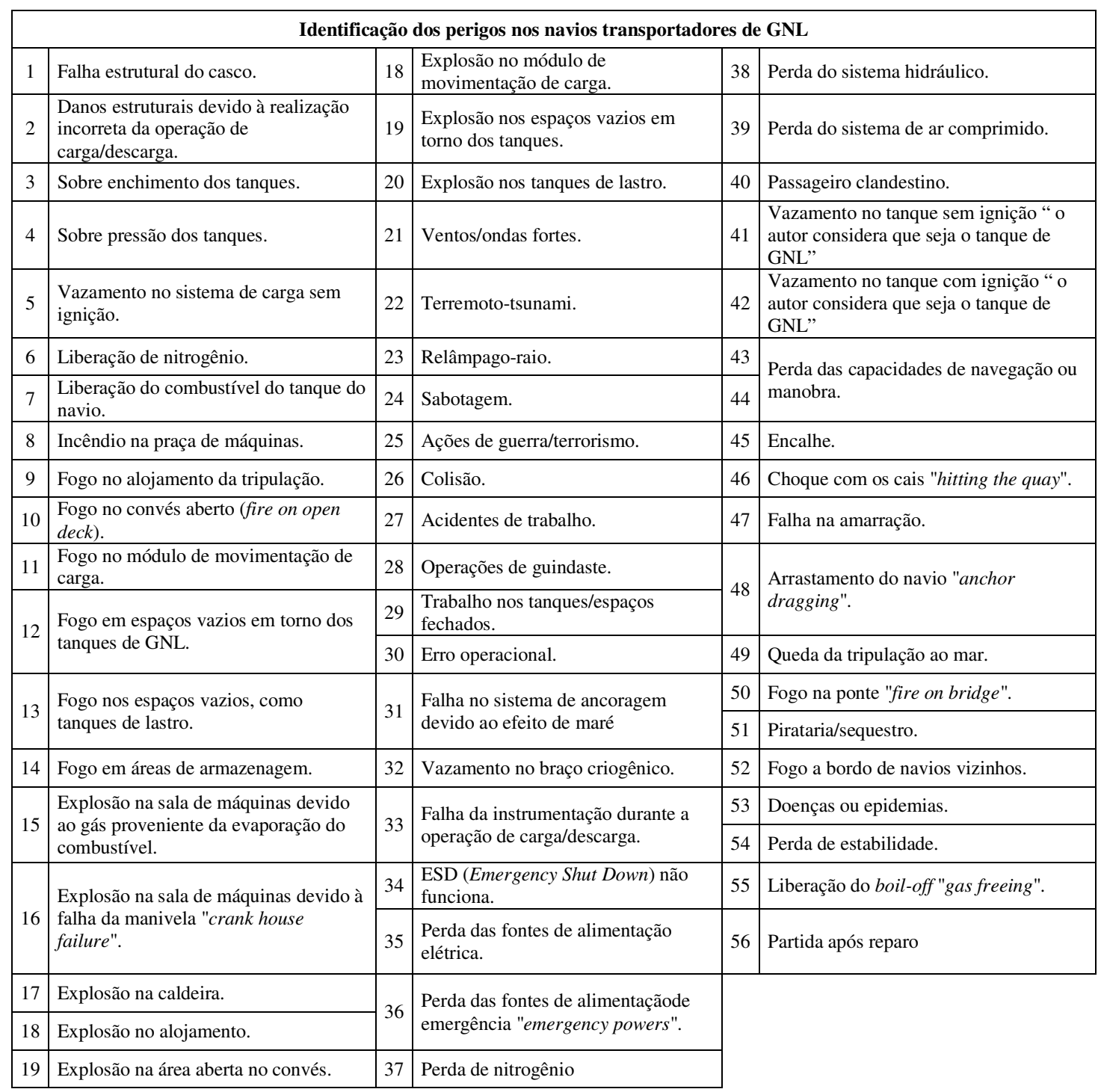

De acordo com IMO (2007), dos 158 incidentes ocorridos nos navios de transporte de GNL ao longo da história, em dezoito deles ocorreu vazamento de GNL ou de boil-off durante as operações de carga ou descarga do GNL. A grande maioria dos incidentes (47 incidentes) encontrados ocorreram devido à falha dos equipamentos próprios do navio, incluindo também aqueles componentes que formam parte do circuito de carga e descarga de GNL, por exemplo, falha nas bombas criogênicas de descarga, falha das válvulas, falha do compressor, entre outros. Embora esses vazamentos tenham sido de pequeno porte e sem perda considerável do GNL, um grande vazamento, produto da falha dos componentes do sistema de carga e descarga de GNL durante as operações de carga e descarga no terminal, poderia provocar 
graves consequências não só no próprio navio, mas também no terminal e nas áreas circunvizinhas.

É por essa razão que o foco desta dissertação são os eventos de perigo associados a pequenos e grandes vazamentos de GNL e de boil-off dentro do navio transportador de GNL, durante as operações de carga e descarga, quando o navio está atracado no terminal. Como mencionado anteriormente, para este fim se aplicará a Análise Preliminar de Perigos para determinar as causas e consequências relacionadas com esse evento de perigo, partindo do fato que o vazamento pode ser provocado pela falha dos componentes dos circuitos de GNL e de boil-off. Nos parágrafos seguintes são indicadas algumas considerações assumidas para elaboração das tabelas da APP.

De acordo com Kutz (2006), os ciclos de temperatura a que estão expostos os materiais em contato com o GNL ao longo da sua vida operacional, implicam em possibilidade de dano devido à expansão e contração do material. Essa mudança de temperatura é o principal problema dos sistemas que transportam ou armazenam os fluidos criogênicos.

Componentes como as válvulas de controle de fluxo não estão isolados, possibilitando a troca permanente de calor com o meio ambiente. Esse problema é agravado quando as operações são feitas em regiões com climas tropicais como o Brasil. Essas válvulas, por um lado tem contato com o GNL e quando impedem a passagem de fluxo, pelo lado oposto tem contato com o gás (o próprio GNL vaporizado ou o gás inerte), a maior temperatura do que o GNL. Esta diferença de temperatura poderá provocar no momento da abertura da válvula, para liberação de fluxo, uma mudança brusca da temperatura que poderá trincar os componentes internos provocando como consequência o vazamento do fluido transportado. $\mathrm{Na}$ aplicação da APP considerou-se o problema descrito anteriormente quando utiliza-se o termo perda da integridade estrutural da válvula. Também pelo desgaste mecânico dos selos e do assento, o fluido pode não ser bloqueado, provocando a perda de estanqueidade e, como consequência disso, tem-se a passagem de GNL para as tubulações de outros circuitos.

Os metais e ligas podem ter altos valores de resistência mecânica, mas serem frágeis a baixas temperaturas. Materiais como o aço inoxidável austenítico e o alumínio embora possuam resistência mecânica inferior à aços utilizados para fabricação de estruturas, não são frágeis à temperatura de liquefação do gás natural, sendo utilizados na fabricação de equipamentos em contato com o GNL (ICS, 1995). 
As Tabelas B.1 e B.2 do Apêndice B apresentam a aplicação da APP para um pequeno e grande vazamento de GNL, respectivamente. As Tabelas B.3 e B.4 do Apêndice B apresentam a aplicação da APP para um pequeno e grande vazamento do boil-off, respectivamente.

\subsubsection{Definição do Cenário: Aplicação do Diagrama Causa-Consequência}

Como definido no método apresentado no Capítulo 4, a elaboração do Diagrama CausaConsequência se inicia selecionando o evento iniciador de perigo. Logo depois são definidas as barreiras de proteção com que está equipado o navio transportador de GNL, definindo a sequência de propagação do acidente considerando a falha (ou não) das mesmas.

Das tabelas da APP utilizou-se a coluna das Consequências e a coluna das barreiras de proteção para montar o diagrama Causa-Consequência. A seguir são apresentadas as considerações tomadas para a elaboração desse diagrama.

Qualquer anomalia durante a operação de carga e descarga do GNL é monitorada pela Sala de Controle da Carga (SCC), que indica se os parâmetros da operação (pressão, temperatura, vazão, nível) estão de acordo com os estabelecidos nos protocolos de carga e descarga do navio. A informação correta fornecida pela Sala de Controle da Carga constituise na primeira barreira de proteção com a qual o navio está projetado, já que, caso algum dos parâmetros esteja com valores fora do normal, deve-se ativar o ESD que isolará a parte afetada e paralisará a operação de carga ou descarga de GNL.

Como segunda barreira de proteção, o navio transportador de GNL conta com um sistema de amostragem de gás, com pontos de amostragem espalhados por todo o navio, e cuja função é a detecção de qualquer vazamento de gás. Ante a ocorrência de um vazamento de gás este sistema também ativará o ESD, paralisando a operação de carga e descarga de GNL.

O próprio ESD é a terceira barreira de proteção. Este sistema tem por objetivo fechar certas válvulas e desligar alguns equipamentos, conseguindo interromper o processo de carga e descarga do GNL, e dessa forma evitar o desenvolvimento do evento iniciador (ICS, 1995).

Depois de detectado o vazamento, o pessoal responsável pela operação tomará as medidas corretivas para interromper o processo de carga ou descarga do GNL, devendo isolar o setor onde ocorre o vazamento. Este se constitui no Cenário 1 do diagrama Causa Consequência 
indicado na Figura 5.13. De acordo com a gravidade do vazamento, após a paralisação da operação poderá ser executado o plano de emergência que inclui a desconexão rápida do navio dos cabos de amarração e dos braços criogênicos para depois efetuar o afastamento do navio do terminal, utilizando para esse fim os navios rebocadores.

Dependendo das condições de vento, da quantidade de vapor gerado após o vazamento do gás metano e dado que as três barreiras de detecção não funcionaram, o gás poderá percorrer certa distância na forma de nuvem. Caso a mistura gás-ar esteja dentro da faixa de inflamabilidade e haja uma fonte de ignição, a consequência será a ocorrência de ignição da nuvem em espaços abertos (Cenário 2) ou a ignição e explosão da nuvem metano-ar em espaços fechados (Cenário 3). A chama gerada produzirá o incêndio em nuvem (flash fire) que tem efeito na região interna da nuvem. A nuvem incendiará em direção à fonte que gerou o vazamento do gás metano (MARTINS et al., 2011).

Vanem et al. (2008) e Souza et al. (2012), indicam que as fontes de ignição podem vir do próprio navio transportador, de outros navios que ficam perto do terminal ou mesmo da instalação portuária. A presença de uma fonte de ignição nas áreas de alojamento da tripulação é considerada altamente provável. Existe uma chance de existir uma fonte de ignição na sala de máquinas do próprio navio ou na praça de máquinas onde estão localizados os compressores.

Se a nuvem de vapor não for atingida por uma fonte de ignição e não estiver dentro dos limites de inflamabilidade, a nuvem se espalhará na atmosfera sem causar maiores consequências, constituindo-se no Cenário 4.

Se o vazamento não tem possibilidades de formar uma nuvem porque ele é muito pequeno, haverá a formação de uma camada de gelo na superfície externa, o qual se constitui no Cenário 5.

Se o vazamento de gás aconteceu em outro componente que manuseia o gás e que não pertence ao sistema destinado para o processo de carga e descarga de GNL, por exemplo, os vaporizadores de GNL ou os aquecedores de gás, este último cenário será chamado como o Cenário 6. Na Figura 5.13 é apresentado o Diagrama Causa-Consequência para o evento iniciador do vazamento de GNL. 


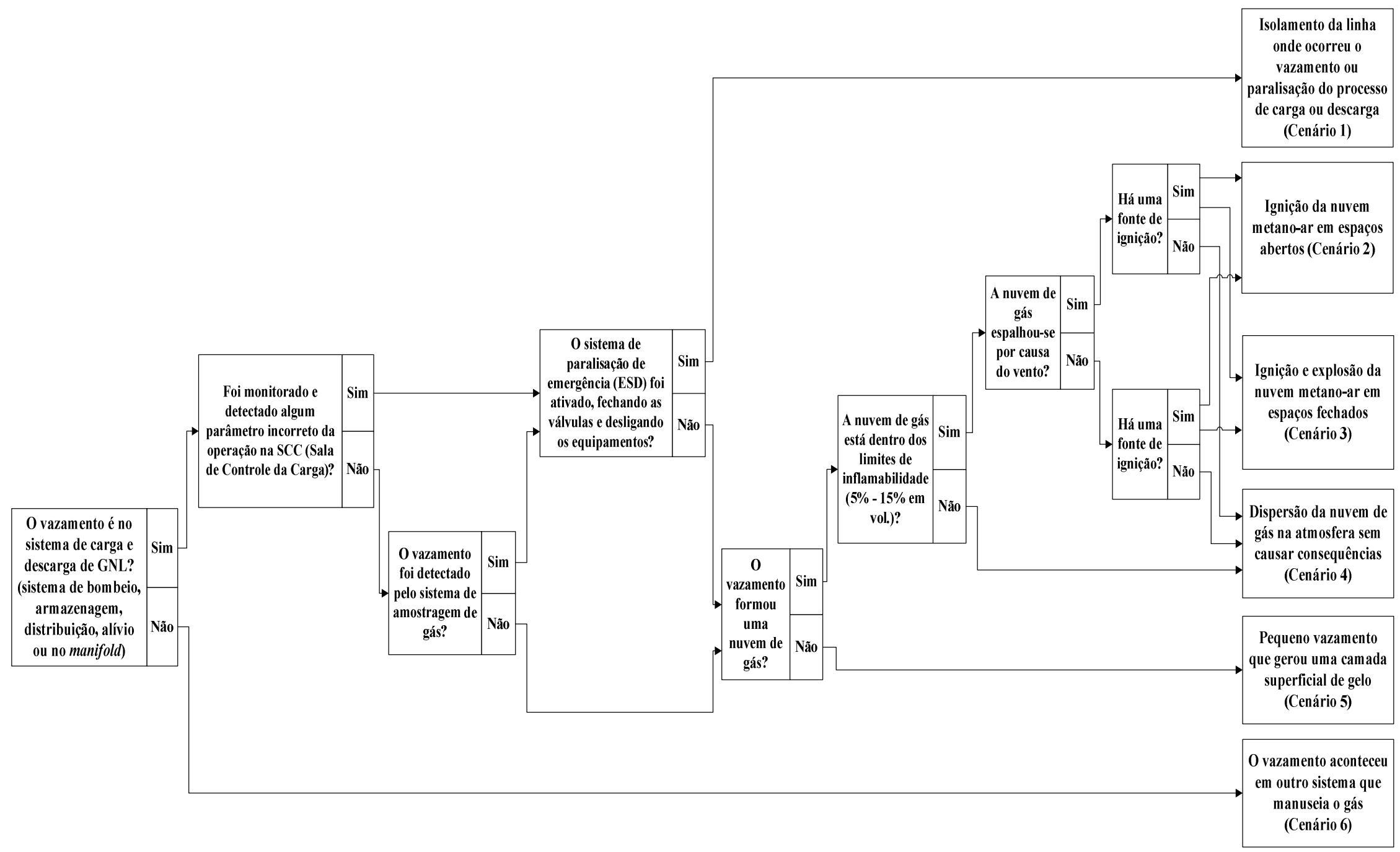

Figura 5.13 - Diagrama Causa-Consequência para o vazamento de metano durante a operação de carga ou descarga de GNL 
Na sequência é feita uma descrição mais aprofundada das barreiras de proteção instaladas no navio transportador de GNL. É feita a análise de confiabilidade para o Sistema de Controle da Carga, o sistema de amostragem de gás e o sistema hidráulico de controle das válvulas que correspondem às três barreiras de proteção no diagrama Causa-Consequência. Este análise permitirá quantificar as probabilidades de ocorrência dos cenários indicados.

\subsubsection{Sala de Controle da Carga (SCC)}

Tudo o processo de carga e descarga é remotamente controlado e monitorado pela Sala de Controle da Carga, permitindo comandar e visualizar todos os parâmetros de operação durante esse período e também durante o tempo de navegação do navio. Portanto, deve existir um abastecimento de energia elétrica que garanta o funcionamento normal do mesmo.

Nos monitores da SCC aparecem os símbolos gráficos que representam os componentes do sistema de carga e descarga do GNL, e também são mostrados os alarmes e mensagens que podem surgir durante o processo de carga e descarga de GNL. Na Figura 5.14 é apresentada a Sala de Controle da Carga onde são mostradas as unidades de alimentação elétrica contínua e os painéis de controle do processo que trabalha com $230 \mathrm{~V}$ AC.

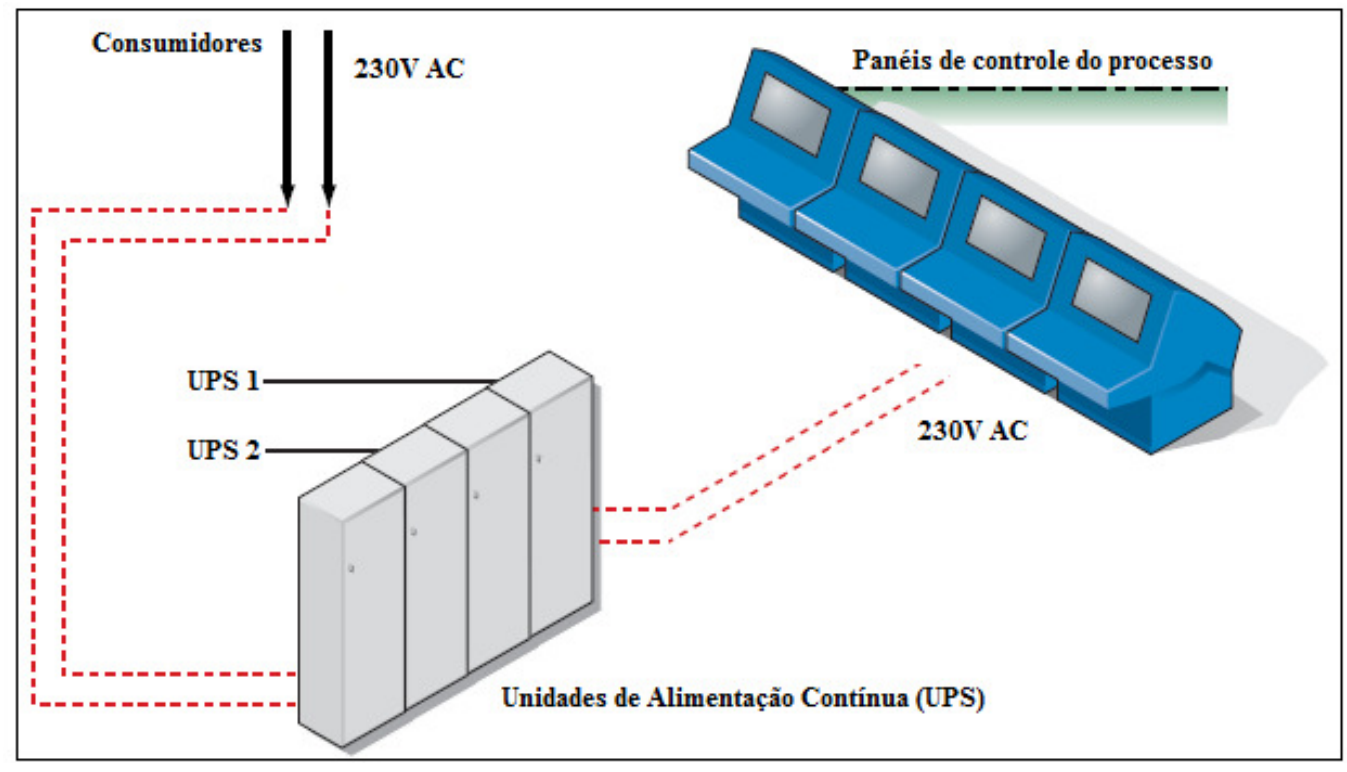

Figura 5.14 - Sala de Controle da Carga

A SCC está alimentada por $230 \mathrm{~V}$ AC, que tem que ser fornecida pelos geradores elétricos, e em casos da falha de todos eles, pelas Unidades de Alimentação Contínua - UPS (do inglês - Uninterrupted Power Supply) para que não fique por nenhum instante sem energia elétrica. 
Segundo Nasiri (2007), a Unidade de Alimentação Contínua é um equipamento elétrico que é instalado em linha com a carga para manter uma alimentação de energia elétrica contínua. No caso da falta de energia, a UPS supre a carga durante um tempo determinado que dependerá da capacidade do banco de baterias interno. Na Figura 5.15 é apresentado o esquema de uma UPS dando destaque aos componentes que formam parte da mesma.

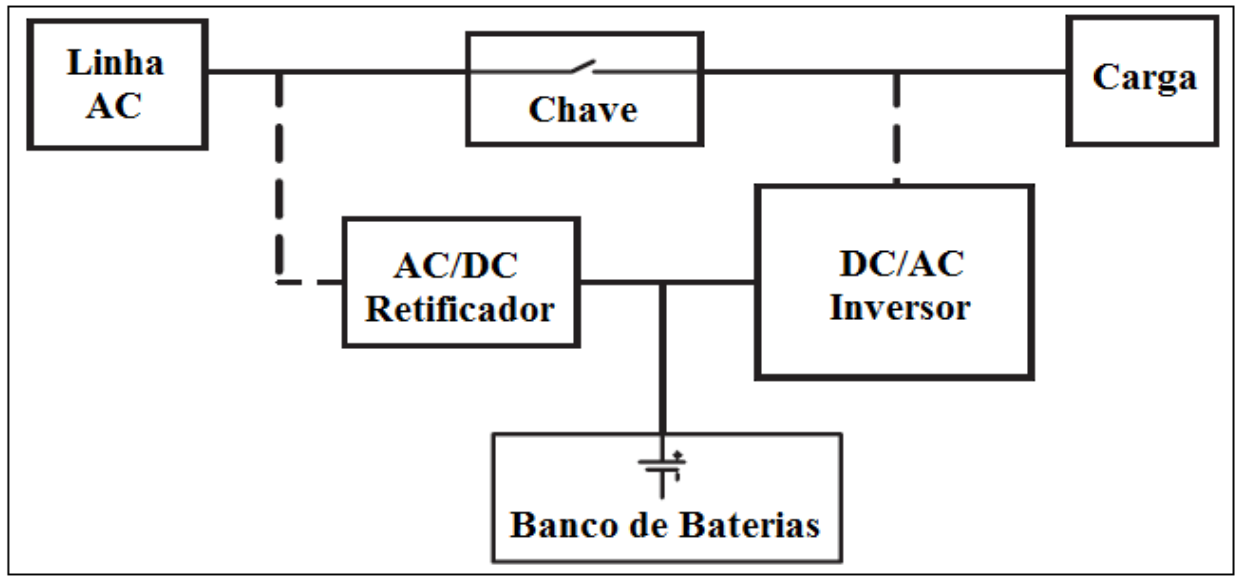

Figura 5.15 - Esquema de uma UPS - Unidade de Alimentação Contínua (NASIRI, 2007)

A UPS tem uma linha $\mathrm{AC}$ que alimenta o retificador com tensão alternada $\mathrm{AC}$, que é convertida em tensão continua. Essa tensão CC é usada para suprir o inversor e também prover carga ao banco de baterias. $\mathrm{O}$ inversor converte a tensão $\mathrm{CC}$ em tensão $\mathrm{AC}$ regulada. $\mathrm{O}$ banco de baterias funciona quando a alimentação da linha AC principal falha, nesse momento ele fornece tensão CC para alimentar o inversor, e assim suprir a alimentação elétrica da carga. As UPS's devem assumir a carga quando acontece alguma falta de energia elétrica por falha no sistema de geração de energia do navio.

O navio está equipado com três geradores principais (dois Turbogeradores e um Diesel gerador) da mesma potência, como indicado na Figura 5.16. A energia elétrica gerada por estes geradores precisa ser transformada de $6600 \mathrm{~V}$ para $440 \mathrm{~V}$ nos transformadores 1,4 e 2, para depois ser transformada novamente de $440 \mathrm{~V}$ para $230 \mathrm{~V}$ nos transformadores 5 e 6 que é o valor da tensão de alimentação dos equipamentos da SCC. O fornecimento de energia elétrica pode vir de qualquer um dos geradores principais, portanto quando um deles estiver operando os demais devem estar desligados, correspondendo a um sistema em paralelo passivo. Para controlar a partida de todos os geradores o sistema conta com uma unidade de controle que funciona automaticamente. 
O navio também conta com um sistema de geração de emergência composto por um Diesel gerador de emergência e dois transformadores que servem para alimentar a SCC. Para isso a tensão gerada pelo Diesel gerador de emergência deve ser transformada de $440 \mathrm{~V}$ para 230V nos transformadores de emergência 7 e 8 conectados em paralelo. Este sistema funciona quando todos os três geradores principais falharam.

Como último recurso para o abastecimento de energia do SCC se tem a energia que vem das duas UPS's. Estes equipamentos devem funcionar o tempo todo já que eles estão instalados com uma configuração de paralelo ativo com as unidades geradoras e começam assumir a carga quando todas elas falham. Na Figura 5.16 são apresentadas as unidades de geração de energia elétrica principal e de emergência assim como os transformadores do navio.

De acordo com Rausand (2004) e Ericson (2005), para o cálculo da confiabilidade de sistemas em paralelo passivo utiliza-se as cadeias de Markov, enquanto que para sistemas em paralelo ativo utiliza-se a ferramenta FTA. Na sequência é calculada a confiabilidade utilizando as cadeias de Markov.

Também elaborou-se a árvore de falhas considerando o evento topo chamado "Falta de energia elétrica AC (230V) na Sala de Controle da Carga". A Figura 5.17 ilustra a árvore de falhas elaborada para esse evento. 


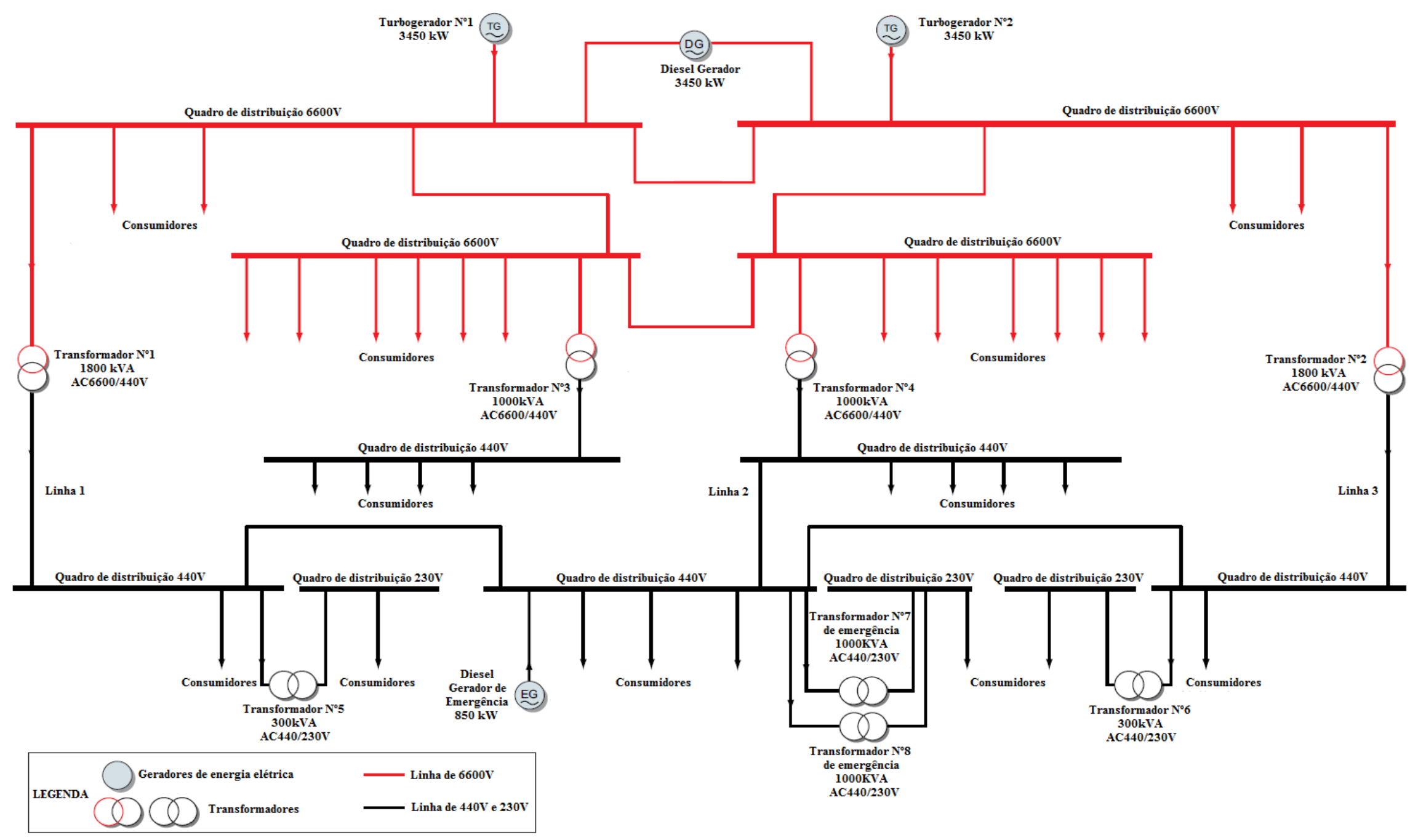

Figura 5.16 - Unidades de geração e transformação de energia elétrica do navio sem as UPS (Unidade de Alimentação Contínua) 


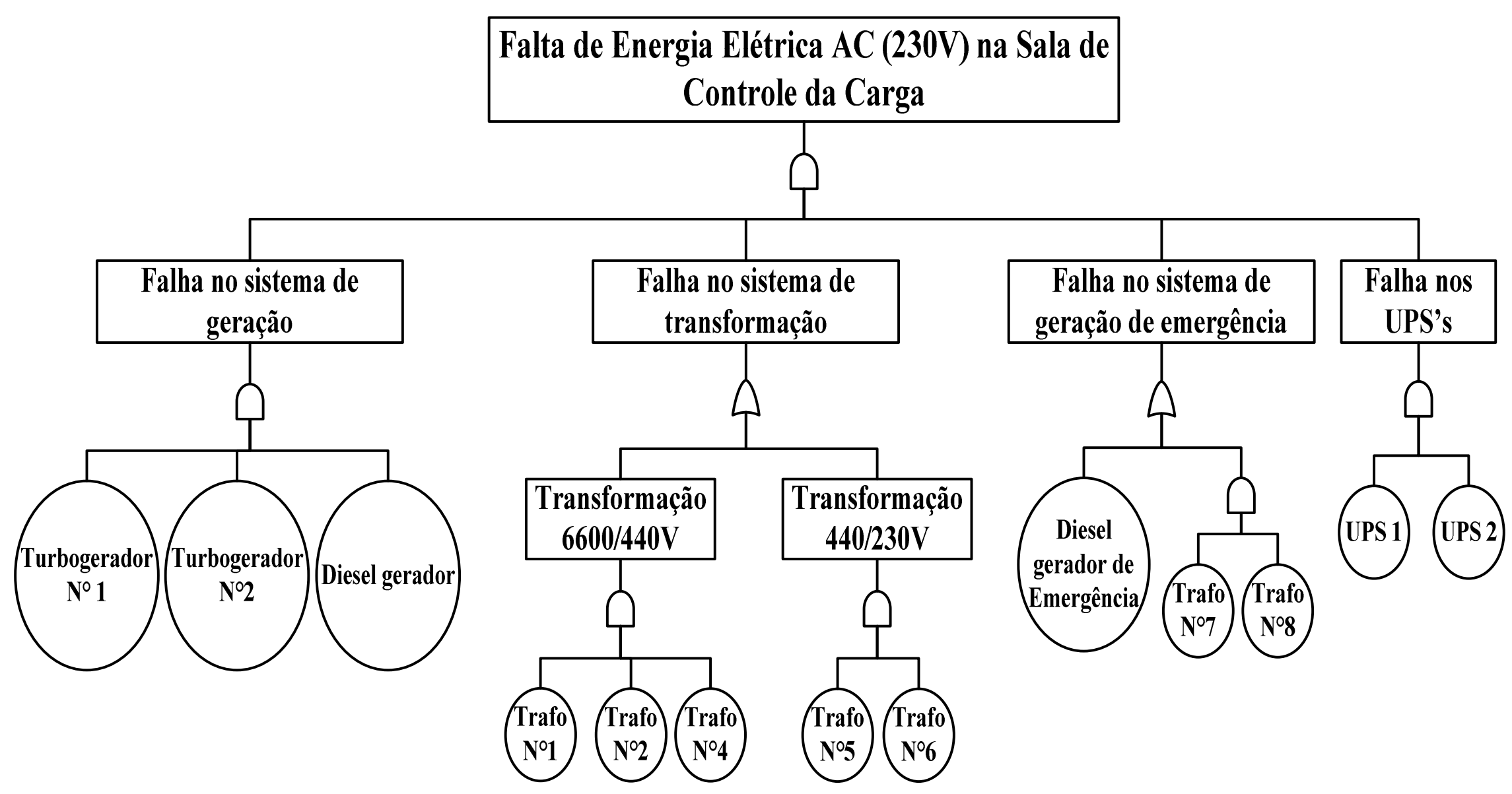

Figura 5.17 - Árvore de falhas para o evento topo "Falta de energia elétrica AC (230V) na Sala de Controle da Carga" 
Conforme a Figura 5.17, a ocorrência do evento topo é causada pela falha de todos os geradores principais de energia elétrica e seus respectivos transformadores, pela falha no sistema de geração de emergência e pela falha nas duas UPS's.

Por meio da utilização das cadeias de Markov é possível fazer a avaliação quantitativa para determinar a confiabilidade da primeira barreira de proteção. Todos os transformadores e os UPS's possuem uma configuração paralelo ativa. Na Figura 5.18 é apresentado o diagrama de blocos do sistema de abastecimento de energia elétrica e na sequência é feito o esclarecimento para realização do cálculo da confiabilidade das Linhas 1,2 e 3. Existe um controlador eletrônico que tem a função de dar sequência ao funcionamento dos geradores elétricos, para este componente é assumida uma confiabilidade de $99 \%$, ou seja $\mathrm{C}=99 \%$.

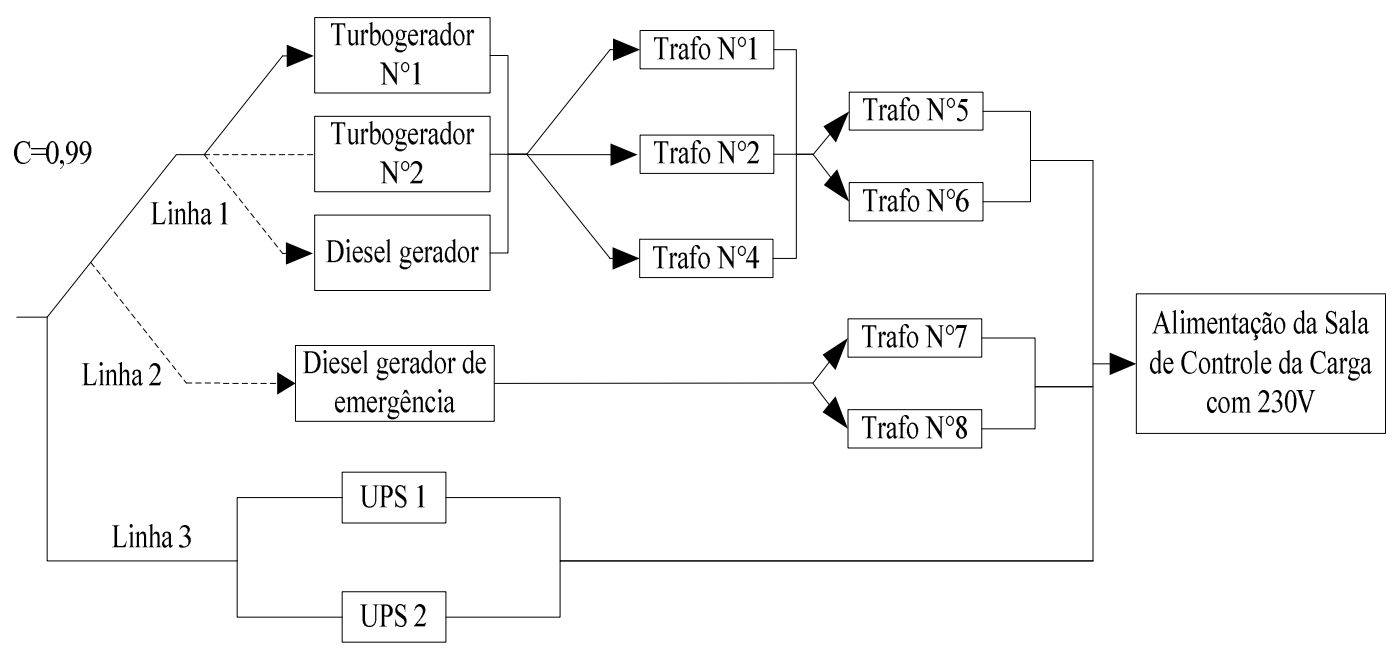

Figura 5.18 - Diagrama de blocos do sistema de alimentação de energia elétrica para a Sala de Controle da Carga com 230V AC

Para determinar a confiabilidade dos componentes que têm a configuração em paralelo ativo (transformadores e UPS's) é utilizada a Equação 5.1.

$$
R_{\text {sistema }}=1-\Pi\left[\left(1-R_{\text {componentes }}\right)\right]
$$

Para a determinação da confiabilidade dos componentes $\left(R_{\text {componentes }}\right)$ da equação anteriormente citada, se utilizará a Equação 5.2. As taxas de falha de cada um dos componentes $\left(\lambda_{\text {componentes }}\right)$ da primeira barreira de proteção são apresentadas na Tabela 5.18.

$$
R=e^{-\lambda_{\text {componente }}^{* t}}
$$


A seguir é apresentada a Figura 5.19, onde se dá destaque aos componentes da Linha 1.

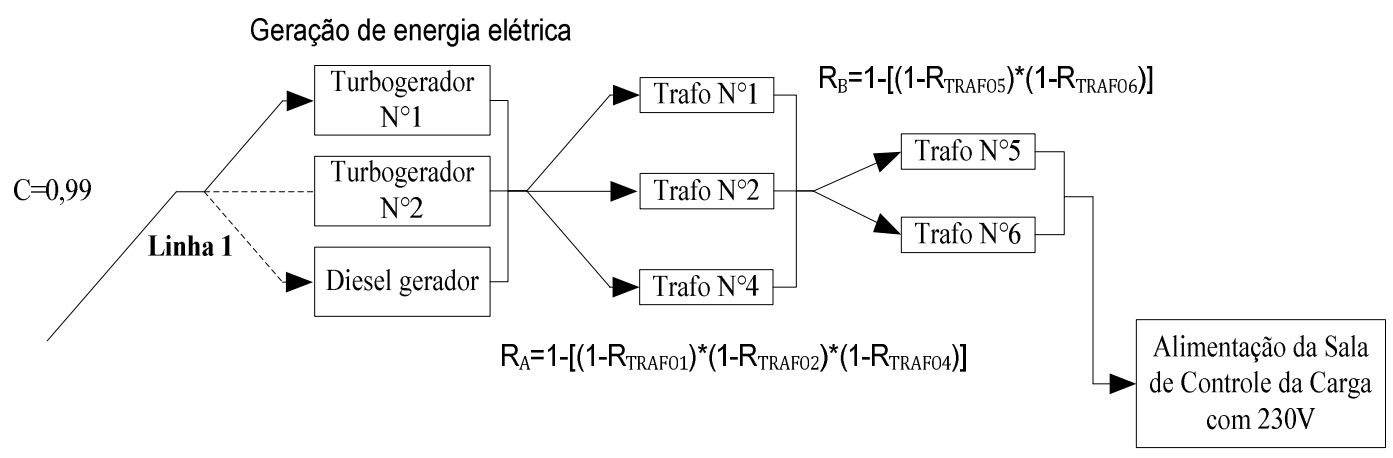

Bloco G

Bloco A

Bloco B

Figura 5.19 - Diagrama de blocos para a Linha 1

Na Linha 1 identificada na Figura 5.18 e Figura 5.19, na parte denominada Geração de energia elétrica é utilizado o modelo de Markov apresentado na Figura 5.20.

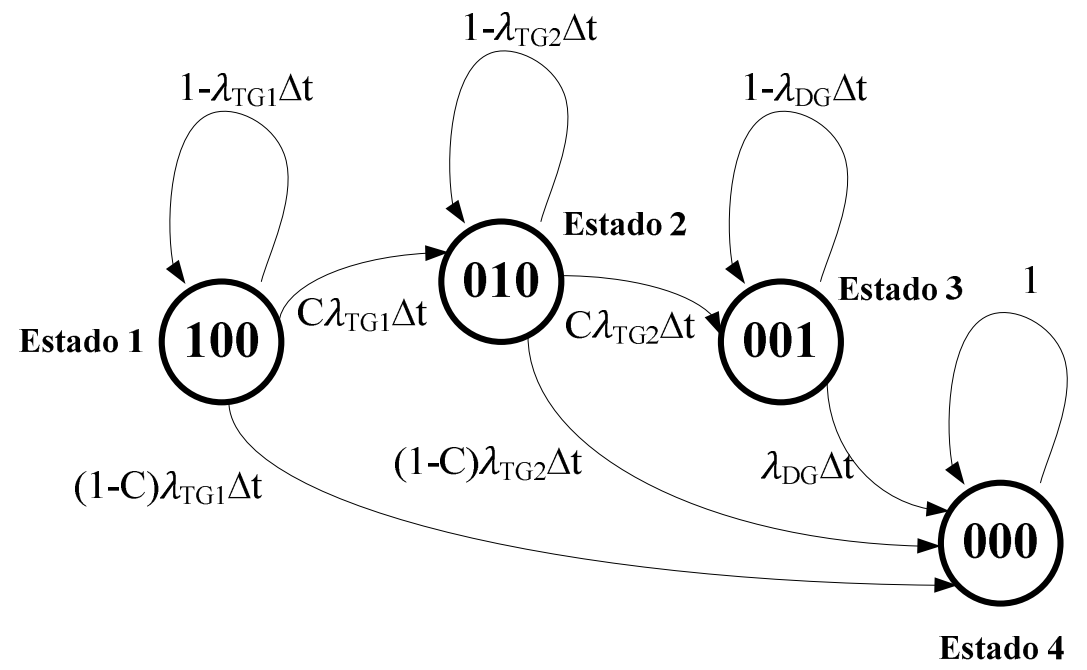

Figura 5.20 - Modelo de Markov para a Geração de energia elétrica na Linha 1 que corresponde ao sistema de abastecimento de energia principal.

Na Figura 5.20 o Estado 1 representa a operação do Turbogerador 1 (TG1), enquanto o Turbogerador 2 (TG2) e o Diesel Gerador (DG) estão desligados. O Estado 2 significa que deixou de funcionar o Turbogerador 1, por causa de uma falha, e começou a funcionar o Turbogerador 2, mantendo-se inativo o Diesel Gerador. No Estado 3 leva-se em consideração a falha dos dois Turbogeradores 1 e 2 e o funcionamento do Diesel Gerador. Por último, o Estado 4 representa a falha de todos os geradores de energia elétrica. 
Para cada estado também existe a chance que a falha não seja detectada pelo controlador eletrônico (expressa pela relação: $(1-C) \lambda \Delta t$ ) e que passe diretamente para o Estado 4 (estado de falha total da geração de energia elétrica na Linha 1). Também existe uma probabilidade de permanecer no mesmo estado $(1-\lambda \Delta t)$.

Tendo a confiabilidade de cada um dos blocos (Bloco G, A, B) é possível calcular a confiabilidade da Linha 1 pela multiplicação das mesmas e utilizando a Equação 5.3.

$$
R_{\text {Linha1 }}=R_{\text {Geraçãoenergiaelétrica }} * R_{A} * R_{B}
$$

A seguir é apresentada a Figura 5.21, onde se dá destaque aos componentes da Linha 2.

$\mathrm{R}_{\text {CONTROLADOR }}=0.99$

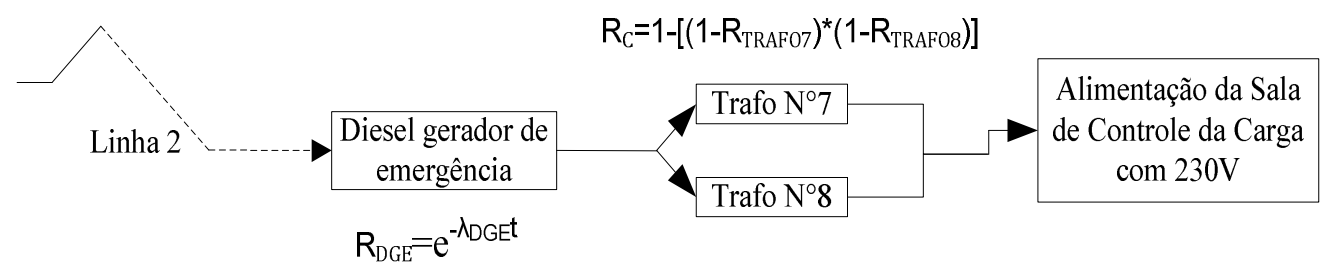

Bloco DGE Bloco C

Figura 5.21 - Diagrama de blocos para a Linha 2

Quando à Linha 2, ilustrada na Figura 5.18 e Figura 5.21, para determinar a confiabilidade do Diesel Gerador de Emergência $\left(R_{D G E}\right)$ é utilizada a Equação 5.4, e no caso dos transformadores a Equação 5.1.

$$
R_{D G E}=e^{-\lambda_{D G E^{*} t}}
$$

Sabendo a confiabilidade de cada um dos blocos DGE e C, calcula-se a confiabilidade da Linha 2 utilizando a Equação 5.5.

$$
R_{\text {Linha2 }}=R_{D G E} * R_{C}
$$

Para a Linha 1 junto com a Linha 2 da Figura 5.18 utilizou-se o modelo de Markov apresentado na Figura 5.22 que corresponde ao sistema de abastecimento de energia principal (Linha 1) e ao sistema de emergência (Linha 2), que é modelado como um sistema em paralelo passivo. 


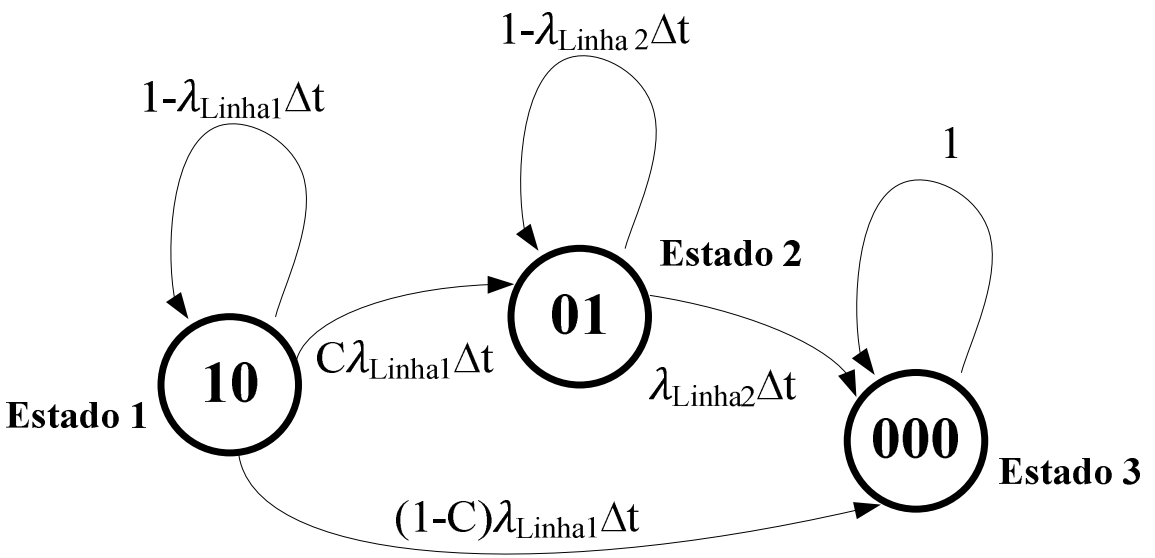

Figura 5.22 - Modelo de Markov para a Linha 1 e a Linha 2 que corresponde ao sistema de abastecimento de energia principal junto com o sistema de emergência.

Na Figura 5.22 o Estado 1 representa que a alimentação de energia é realizada pela Linha 1, estando a Linha 2 permanece inativa. $\mathrm{O}$ estado 2 significa que falhou a Linha 1 e começou operar a Linha 2, e por último o Estado 3 representa a falha das duas Linhas 1 e 2. Nesse momento passa a operar a Linha 3, que permanece em paralelo ativo o tempo todo, representando o conjunto de UPS's.

Por último, é apresentada a Figura 2.23, onde se dá destaque aos componentes da Linha 3.

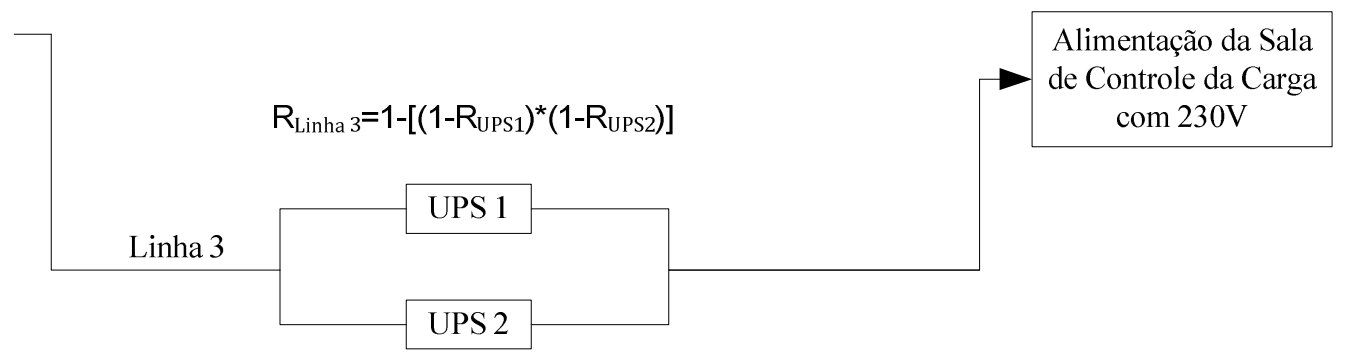

Figura 5.23 - Diagrama de blocos para a Linha 3

Para o cálculo da confiabilidade da Linha 3 utiliza-se a Equação 5.6.

$$
R_{\text {Linha } 3}=1-\left[\left(1-R_{U P S 1}\right) *\left(1-R_{U P S 2}\right)\right]
$$

Tendo-se a confiabilidade das Linhas é possível realizar o cálculo da confiabilidade do sistema de abastecimento de energia para o SCC. Utilizou-se o software Matlab considerando as taxas de falha mostradas na Tabela 5.18. 
Tabela 5.18 - Taxa de falha dos componentes do sistema de alimentação de energia elétrica do navio

\begin{tabular}{|l|c|c|}
\hline \multicolumn{1}{|c|}{ Componente } & Taxa de falha (falha/hora) & Referência \\
\hline Turbogerador & $1,84 \mathrm{E}-03\left(\lambda_{T G 1}, \lambda_{T G 2}\right)$ & OREDA (2002) \\
\hline Diesel gerador & $1,70 \mathrm{E}-03\left(\lambda_{D G}\right)$ & Zubair e Zhijian (2011) \\
\hline Diesel gerador de Emergência & $1,70 \mathrm{E}-03\left(\lambda_{D G E}\right)$ & Zubair e Zhijian (2011) \\
\hline UPS (Uninterruptable Power Supply) & $2,11 \mathrm{E}-06\left(\lambda_{U P S}\right)$ & NPRD (1995) \\
\hline Transformador & $6,74 \mathrm{E}-07\left(\lambda_{T R A F O}\right)$ & Abdelfatah et al. $(2011)$ \\
\hline
\end{tabular}

Na Figura 5.24 é apresentada a curva da confiabilidade do sistema de abastecimento de energia elétrica da Sala de Controle da Carga para cinco anos de operação. Para o cálculo da confiabilidade não foi considerada ações de manutenção de nenhum tipo, já que o intuito foi enxergar o comportamento da confiabilidade sem estas ações.

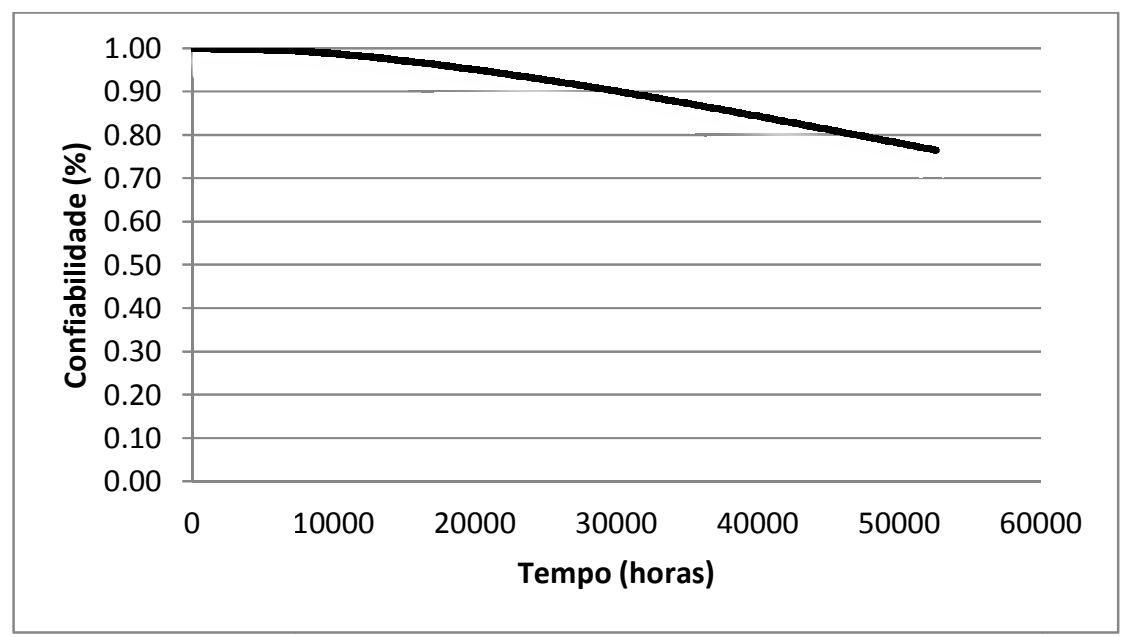

Figura 5.24 - Curva da confiabilidade do fornecimento de energia elétrica na Sala de Controle da Carga

$\mathrm{Na}$ Tabela 5.19 são apresentados os valores da confiabilidade e da probabilidade de falha do sistema de fornecimento de energia elétrica da Sala de Controle da Carga, calculados para cinco anos de operação.

Tabela 5.19 - Valores da confiabilidade e da probabilidade de falha do sistema de abastecimento de energia elétrica ao longo de cinco anos de operação

\begin{tabular}{|l|c|c|}
\cline { 2 - 3 } \multicolumn{1}{c|}{} & Confiabilidade $(R)$ & Probabilidade de falha $(p f)$ \\
\hline Primeiro ano (8760 horas) & 0,9904 & 0,0096 \\
\hline Segundo ano (17520 horas) & 0,9609 & 0,0391 \\
\hline Terceiro ano (26280 horas) & 0,9202 & 0,0798 \\
\hline Quarto ano (35040 horas) & 0,8719 & 0,1281 \\
\hline Quinto ano (43800 horas) & 0,8192 & 0,1808 \\
\hline
\end{tabular}


Nos componentes do sistema de geração de energia elétrica do navio é possível implementar ações de manutenção preventiva e preditiva que, visem diminuir a taxa de falha dos mesmo, e portanto, aumentado a sua confiabilidade.

\subsubsection{Sistema de amostragem e sistema de detecção de gás}

No navio existem dois sistemas completamente independentes: 1) Um sistema de amostragem que monitora a presença de gás a partir dos pontos de amostragem, localizados em zonas de influência direta de gás e 2) Um sistema de detecção de gás que monitora as zonas que não tem influência direta de gás como o alojamento da tripulação, sala de máquinas do próprio navio, entre outras. Adicionalmente o navio conta com aparelhos portáteis de detecção de gás.

Caso o gás seja detectado, alarmes são ativados simultaneamente em diferentes pontos do navio nas unidades repetidoras e na SCC, que mandará os sinais para fechar as válvulas ativadas pelo ESD, desligar equipamentos e paralisar o processo de carga ou descarga de GNL, dependendo da gravidade do problema. Estes alarmes são do tipo sonoro e luminoso.

O sistema de amostragem de gás consiste de duas bombas de sucção em paralelo que aspiram a amostra de cada um dos pontos de amostragem de maneira individual, através de um filtro, e depois a amostra é descarregada no analisador de gases para, finalmente, ser descarregada para a atmosfera. Esta configuração das bombas de sucção permite obter uma maior vazão reduzindo o tempo de amostragem e, caso ocorra uma falha em uma das bombas, o sistema de amostragem continuará operando. Na Figura 5.25 é apresentado o esquema geral dos componentes do sistema de amostragem de gás, dando destaque para a unidade analisadora SW2020 deste sistema que é do tipo infravermelho (CONSILIUM, 2010a). 


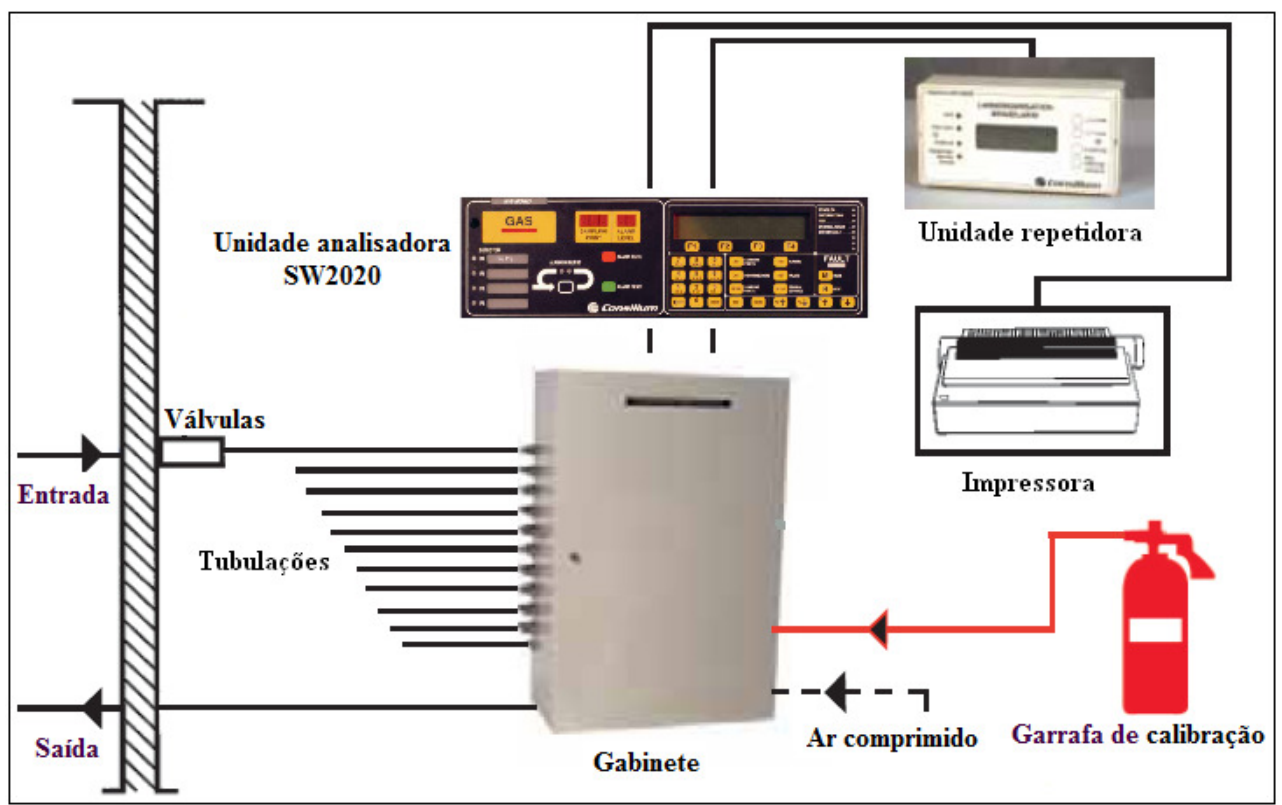

Figura 5.25 - Esquema geral dos componentes do sistema de amostragem de gás (CONSILIUM, 2012a)

Na Figura 5.26 observa-se em detalhe o gabinete mostrado na Figura 5.25 onde estão instaladas as duas bombas de sucção anteriormente citadas.

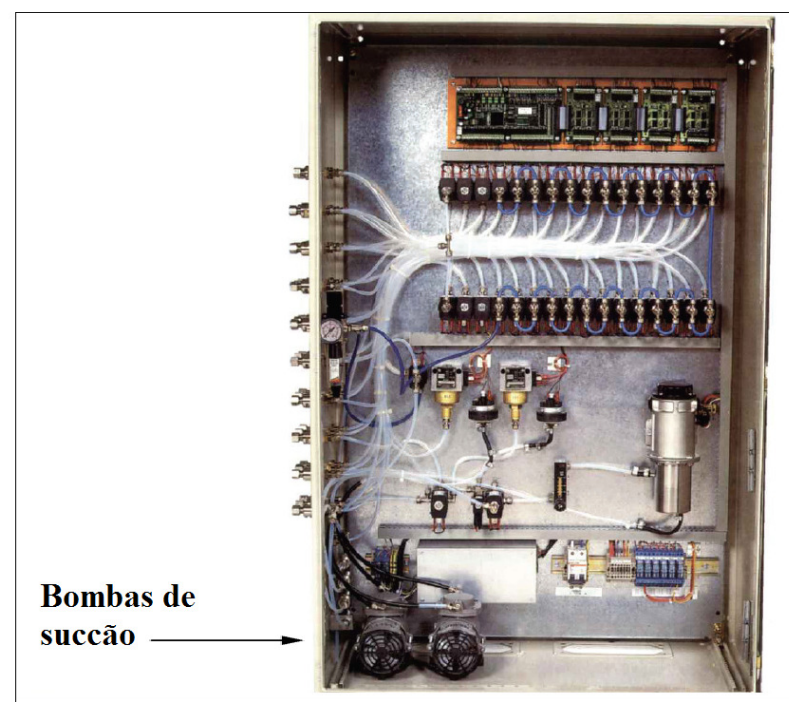

Figura 5.26 - Detalhe do gabinete do sistema de amostragem de gás (CONSILIUM, 2012a)

Existem 34 pontos de amostragem de gás localizados na parte externa do gabinete e um ponto no interior do gabinete. Este último serve para detectar a presença de gás dada a ocorrência de um vazamento no interior do gabinete. Na sequência é apresentada a Figura 
5.27 , onde se podem ver os detalhes de alguns dos pontos de amostragem localizados no tanque de armazenamento e na praça de máquinas.

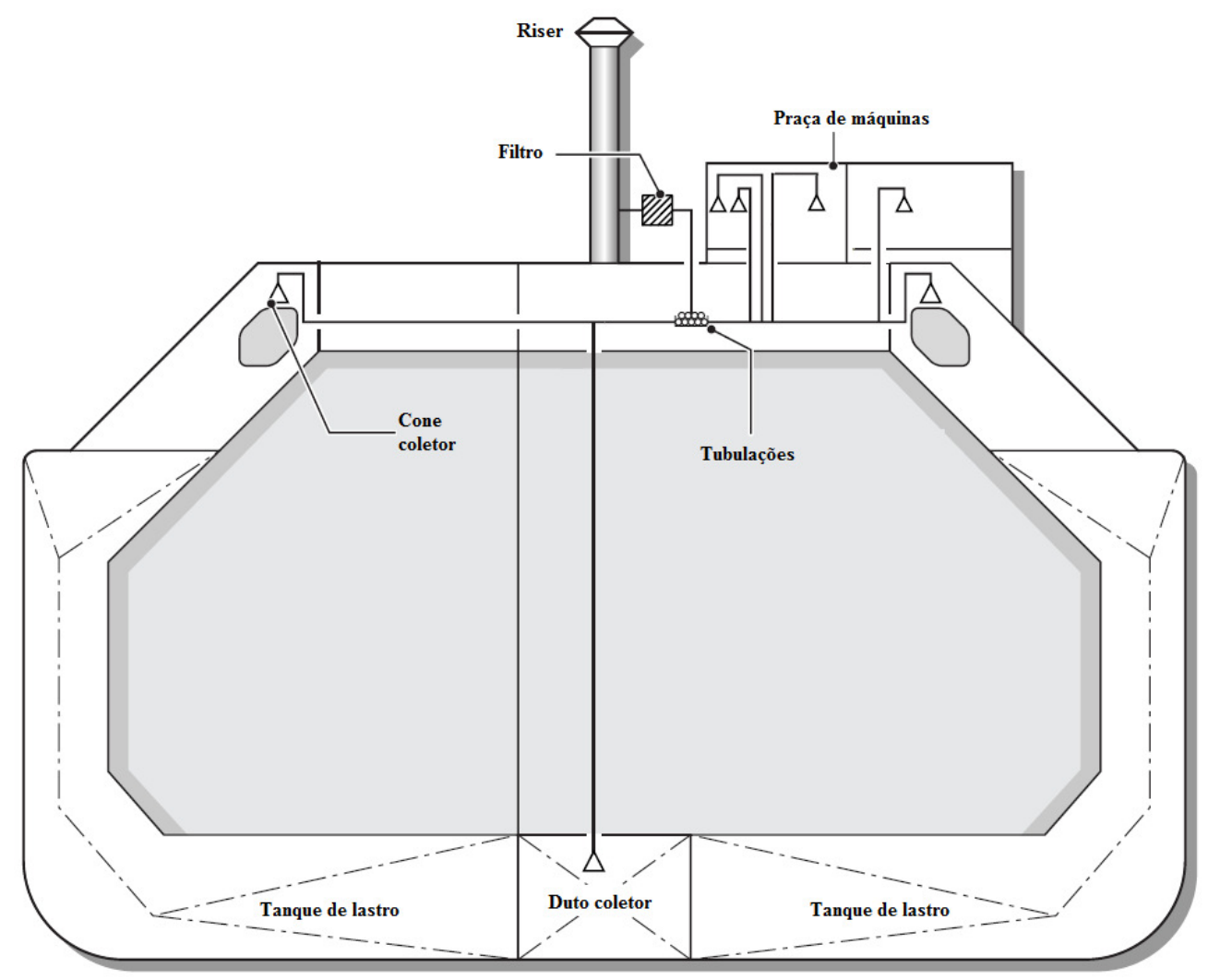

Figura 5.27 - Detalhe dos pontos de amostragem no tanque de armazenamento e na praça de máquinas

Se qualquer um dos 35 pontos de amostragem detecta a presença do metano, este sistema ativará um alarme de presença de gás natural no SCC e nas unidades repetidoras. Nesse caso começa ser feita uma verificação da concentração dos pontos de amostragem manualmente, selecionando o ponto que se deseja testar para acompanhar o desenvolvimento do problema ao longo do tempo com o intuito de tomar as medidas correspondentes. Um ciclo completo de amostragem para todos os pontos leva aproximadamente 15 minutos.

Cabe mencionar que o sistema de amostragem de gás deve funcionar o tempo inteiro, ou seja, durante a carga e descarga do GNL e durante o tempo de navegação do navio. A Figura 5.28 apresenta os pontos de amostragem de gás para verificar a presença do metano. 

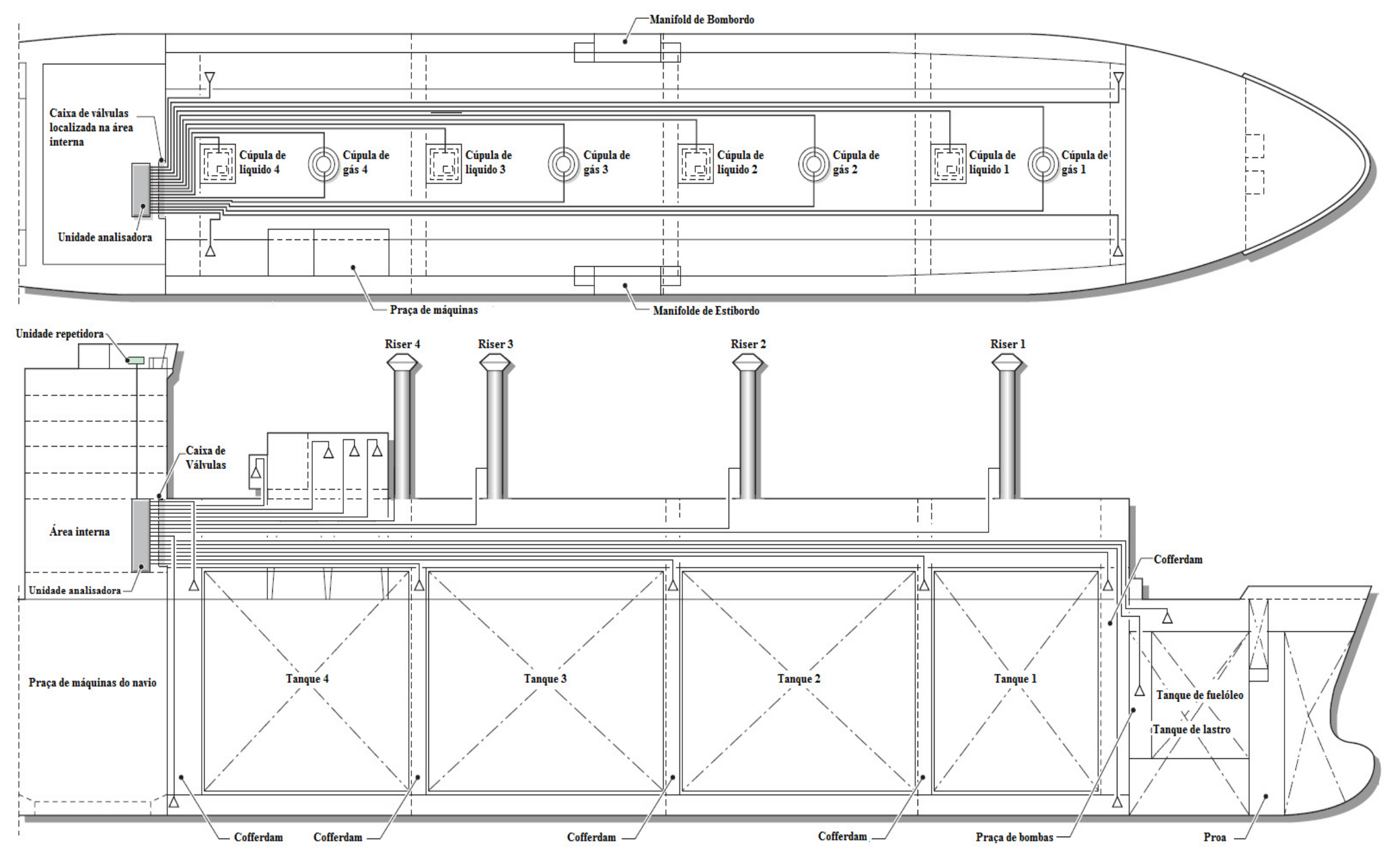

Figura 5.28 - Pontos de amostragem espalhados no navio para detectar a presença de gás metano 
Como mencionado anteriormente, o navio também conta com um sistema de detecção de gás que consiste de 40 pontos de detecção fixos, que estão localizados em áreas que não tem contato direto com o gás, por exemplo, o alojamento da tripulação, a sala de máquinas do próprio navio, a sala do gerador e do motor, entre outros. Os sinais destes 40 detectores vão para uma unidade de detecção apresentada na Figura 5.29.

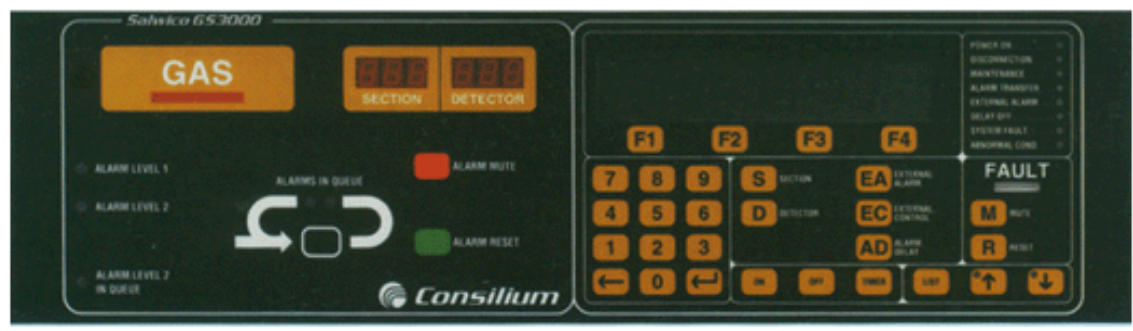

Figura 5.29 - Unidade de detecção GS3000 (CONSILIUM, 2012b)

A função do sistema de detecção é detectar a presença de gás (metano, $\mathrm{CO}_{2}$ e $\mathrm{CO}$ ). Os sensores do sistema de detecção que estão instalados no navio são de três tipos: catalítico, infravermelho e eletroquímico.

São 33 detectores catalíticos utilizados para detectar a presença do gás metano. Segundo Honeywell (2012), quase todos os sensores de detecção de gás combustível modernos, de baixo custo, são do tipo catalítico. O outro tipo de detector é o tipo infravermelho que serve para detectar o gás metano e o $\mathrm{CO}_{2}$. Existem cinco detectores deste tipo que detectam o gás metano e existe um detector que detecta o $\mathrm{CO}_{2}$. Tradicionalmente, o método convencional de detecção de vazamentos de gás se fazia através da detecção de ponto, utilizando vários sensores individuais para cobrir uma área ou perímetro. Mais recentemente, foram disponibilizados instrumentos que empregam tecnologia infravermelha e laser na forma de um feixe amplo (ou caminho aberto) que pode cobrir uma distância de centenas de metros. As aplicações comuns incluem FPSO, terminais de carga e descarga, tubulações, monitoramento de perímetro, plataformas em alto-mar e áreas de armazenamento de GNL (HONEYWELL, 2012). O último dos tipos de detectores é o eletroquímico que serve para detectar o CO. Existe um detector deste tipo. Os sensores eletroquímicos podem ser usados para detectar a maioria dos gases tóxicos comuns, inclusive $\mathrm{CO}, \mathrm{H}_{2} \mathrm{~S}, \mathrm{Cl}_{2}, \mathrm{SO}_{2}$, entre outros. $\mathrm{O}$ sensor eletroquímico normalmente apresenta uma garantia de dois anos. Na Figura 5.30 é apresentado o sistema de amostragem junto com o sistema de detecção de gás. 


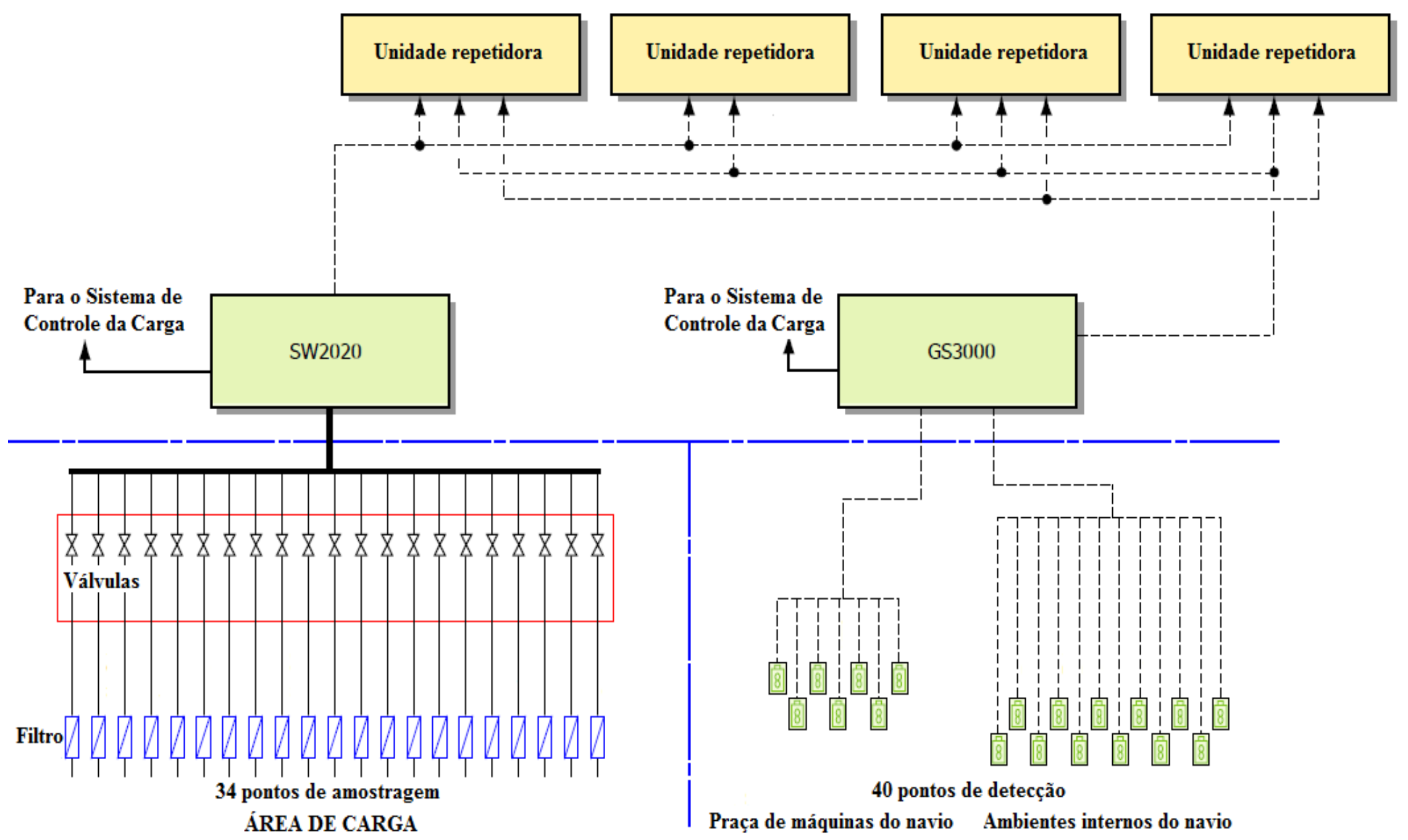

Figura 5.30 - Sistema de amostragem SW2020 junto com o sistema de detecção GS3000 
O navio também conta com aparelhos detectores portáteis os quais devem ser testados mensalmente para garantir um bom resultado no momento de fazer as amostras. Estes detectores de gás podem detectar a presença de diferentes gases como $\mathrm{CH}_{4}, \mathrm{O}_{2}$ e $\mathrm{CO}_{2}$. Estes aparelhos são utilizados pelo pessoal encarregado durante as operações de carga e descarga do GNL. Na Figura 5.31 são apresentados os detectores de gás portáteis que equipam o navio.

\begin{tabular}{|l|c|c|c|c|}
\hline & & & \\
\hline
\end{tabular}

Figura 5.31 - Diversos detectores portáteis

Dado que o sistema de detecção de gás não está em contato direto com o sistema de carga e descarga do GNL, o cálculo da confiabilidade é feito considerando o sistema de amostragem de gás somente para fazer o cálculo da confiabilidade da segunda barreira de proteção. Dados do OREDA (2002) mostram que a taxa de falha para uma unidade com o mesmo principio de funcionamento da unidade de amostragem é de $\lambda=8,44 * 10^{-6}$ falhas/hora sendo este valor da taxa de falha o mais elevado. Com esse valor é possível calcular a confiabilidade da unidade de amostragem de gás. Na Tabela 5.20 é apresentada a taxa de falha considerada para fazer o cálculo da confiabilidade deste sistema.

Tabela 5.20 - Taxa de falha do sistema de amostragem de gás

\begin{tabular}{|c|c|c|}
\hline Componente & Taxa de falha (falha/hora) & Referência \\
\hline Unidade de amostragem SW2020 & $8,44 \mathrm{E}-6\left(\lambda_{\text {unidade }}\right)$ & OREDA $(2002)$ \\
\hline
\end{tabular}

Para fazer o cálculo da confiabilidade da unidade analisadora considera-se que se tem uma distribuição exponencial e utiliza-se a Equação 5.7.

$$
R=e^{-\lambda_{\text {unidade }}^{* t}}
$$

Nesse valor da taxa de falha estão inclusos a própria analisadora de gás, as válvulas, os componentes eletrônicos. 
Na Figura 5.32 é apresentada a curva da confiabilidade do sistema de amostragem de gás para cinco anos de operação.

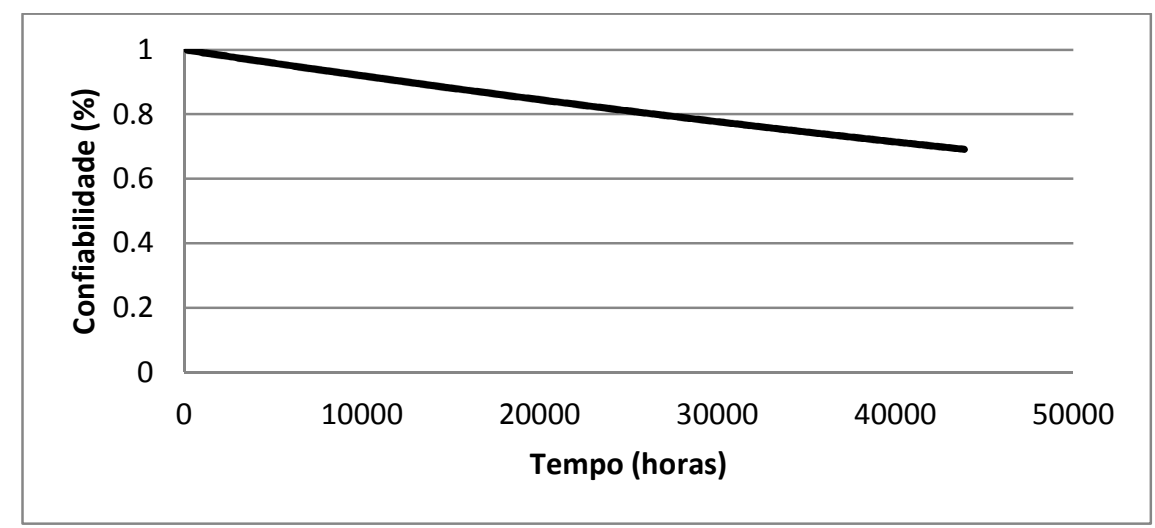

Figura 5.32 - Curva da confiabilidade do sistema de amostragem de gás

Na Tabela 5.21 são apresentados os valores da confiabilidade e da probabilidade de falha do sistema de amostragem de gás, calculados para cinco anos de operação.

Tabela 5.21 - Valores da confiabilidade e da probabilidade de falha ao longo de cinco anos de operação

\begin{tabular}{|l|c|c|}
\cline { 2 - 3 } \multicolumn{1}{c|}{} & Confiabilidade $(R)$ & Probabilidade de falha $(p f)$ \\
\hline Primeiro ano (8760 horas) & 0,9287 & 0,0712 \\
\hline Segundo ano (17520 horas) & 0,8625 & 0,1374 \\
\hline Terceiro ano (26280 horas) & 0,8010 & 0,1989 \\
\hline Quarto ano (35040 horas) & 0,7439 & 0,2560 \\
\hline Quinto ano (43800 horas) & 0,6909 & 0,3090 \\
\hline
\end{tabular}

Em componentes eletrônicos não é recomendável realizar tarefas de manutenção preventiva, mas sim esperar que o equipamento falhe para realizar tarefas de manutenção corretiva. Não obstante, deve-se ter peças sobressalentes disponíveis para eventualmente realizar a manutenção corretiva.

\subsubsection{Sistema de paralisação de emergência (ESD - Emergency Shut Down)}

O sistema de paralisação de emergência ESD é um requisito exigido pela IMO para navios carregadores de gases liquefeitos. De acordo com a BS (2007), a função do ESD é de minimizar o vazamento do hidrocarboneto e minimizar a propagação de qualquer evento de perigo em áreas adjacentes.

O sistema de paralisação de emergência é ativado nas seguintes circunstâncias: 
$\checkmark$ Ativação dos botões manuais de emergência localizados em vários lugares do navio, por exemplo, a sala de controle de carga, a ponte, o convés, a praça de máquinas, nos manifolds.

$\checkmark$ Detecção de algum parâmetro que não está de acordo com os valores habituais da carga ou descarga, expresso no SCC (níveis dos tanques, pressão do sistema, entre outros).

$\checkmark$ Detecção de vazamento tanto do sistema de amostragem quanto pelo sistema de detecção.

$\checkmark$ Falta de energia elétrica por causa de um blackout.

$\checkmark$ Também pode ser ativado pelo próprio terminal de liquefação ou de regaseificação.

A ativação do sistema de paralisação de emergência implicará na execução das seguintes ações:

$\checkmark$ Paralisar o funcionamento de todos os compressores de alta vazão e de baixa vazão.

$\checkmark$ Paralisar o funcionamento de todas as bombas criogênicas.

$\checkmark$ Fechar as válvulas que estão ligadas ao ESD.

$\checkmark$ Informar ao terminal da paralisação das operações de carga ou descarga do GNL.

$\checkmark$ Ativação dos alarmes próprios da situação de emergência.

Para conseguir fechar as válvulas que estão ligadas ao ESD, o navio conta com um sistema hidráulico de controle das válvulas e que constitui a terceira barreira do DCC.

Todas as válvulas necessárias para as operações da carga e descarga são operadas hidraulicamente, tanto as do circuito de GNL quanto as do circuito de boil-off. O controle do sistema hidráulico é feito por meio da SCC.

O sistema hidráulico de controle das válvulas tem um tanque principal de 1250 litros, um tanque secundário de 650 litros e um tanque de recepção do fluido hidráulico de 2500 litros de capacidade como apresentados na Figura 5.35. O tanque principal, o secundário e de recepção têm sensores de nível fixados em 1000, 400 e 2000 litros respectivamente.

O sistema de bombeio é composto por duas bombas hidráulicas de $22 \mathrm{~kW}$ e uma bomba topping up de $7,5 \mathrm{~kW}$ localizadas na parte superior dos tanques. As duas bombas principais 
tem uma vazão de 67,9 litros/min e operam a uma pressão na saída de 127 bares e a bomba topping up tem uma vazão de 19 litros/min com a mesma pressão na saída. Em uma operação normal, uma das bombas principais é necessária para o funcionamento do sistema hidráulico, entretanto a outra ficará em stand-by, e atuará quando a pressão na outra linha seja menor que 98 bar. O sistema de pressão está protegido por válvulas de alívio fixadas em 137 bar. Pressostatos localizados na linha de descarga do fluido hidráulico ativam ou desativam as bombas hidráulicas, sendo que desligam a bomba por baixa pressão na linha. Também tem um alarme da falha na própria bomba. Ambos alarmes são transmitidos à SCC, mandando ativar a bomba que está em stand-by.

O filtro deve impedir a passagem de partículas, removendo-as do fluido hidráulico, já que elas causarão o desgaste abrasivo, reduzindo a vida dos equipamentos do sistema hidráulico. $\mathrm{Na}$ linha de sucção das bombas estão instalados filtros de 150 mícrons.

Os acumuladores são reservatórios especiais onde está armazenado fluido sob pressão, pronto para executar algum trabalho. Um acumulador pode oferecer fluxo sob pressão, podendo somar-se ao fluxo da bomba em caso de emergência, para estabilizar o circuito, ou operar independentemente, fechando as válvulas governadas pelo sistema hidráulico no caso da falha do sistema de bombeio (DRAPINSKI, 1975). Existe um banco de nove acumuladores de pressão (óleo/nitrogênio) de 60 litros de capacidade cada, pressurizados a 88 bar que é a pressão que fornece o nitrogênio aos acumuladores. Os acumuladores utilizam nitrogênio e não ar comprimido, já que este último provoca condensação da água, que causará corrosão e, também oxidação do óleo, contaminando-o. Os acumuladores foram projetados para fechar as válvulas num tempo não maior que 1 minuto.

As válvulas estão equipadas com atuadores hidráulicos alimentados por uma unidade de potência hidráulica e controlada por um sistema solenoide eletro-hidráulico. O solenoide é um dispositivo que converte a energia elétrica em mecânica permitindo a movimentação do atuador. Quase todas as válvulas hidráulicas têm atuadores tipo pistão. O óleo hidráulico pressurizado é distribuído para cada um dos sete gabinetes de válvulas solenoides $(1 \mathrm{C}, 2 \mathrm{C}$, 3C, 4C, 5C, 6C, 7C), e desse gabinete é direcionado para a sua respectiva válvula. Segundo SCANA (2012), o gabinete de válvulas solenoides tem uma parte elétrica e uma parte hidráulica que servirá para fazer o comando das válvulas. Na Figura 5.33 é apresentado o gabinete de válvulas solenoides. 


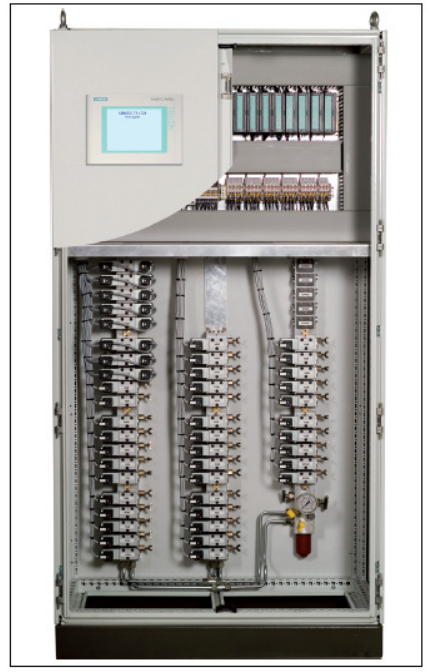

Figura 5.33 - Gabinete das válvulas solenoides das unidades atuadoras (SCANA, 2012)

Em caso de uma falta de energia elétrica entre a zona de controle das válvulas e a válvula solenoide, a válvula hidráulica pode ser operada manualmente. Todas as válvulas do sistema hidráulico tem uma conexão para a bomba manual de emergência. Existem três bombas manuais de emergência portáteis, como apresentada na Figura 5.34.

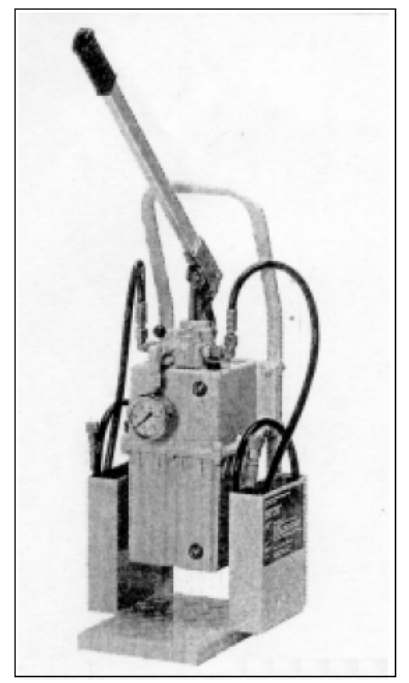

Figura 5.34 - Bomba manual de emergência

As válvulas que são ativadas pelo sistema de paralisação de emergência estão localizadas nos manifolds (gabinete 3C e 4C) e na praça de máquinas (gabinete 6C).

Na Figura 5.35 observa-se o esquema do circuito hidráulico de comando das válvulas de carga e descarga de GNL e boil-off. 


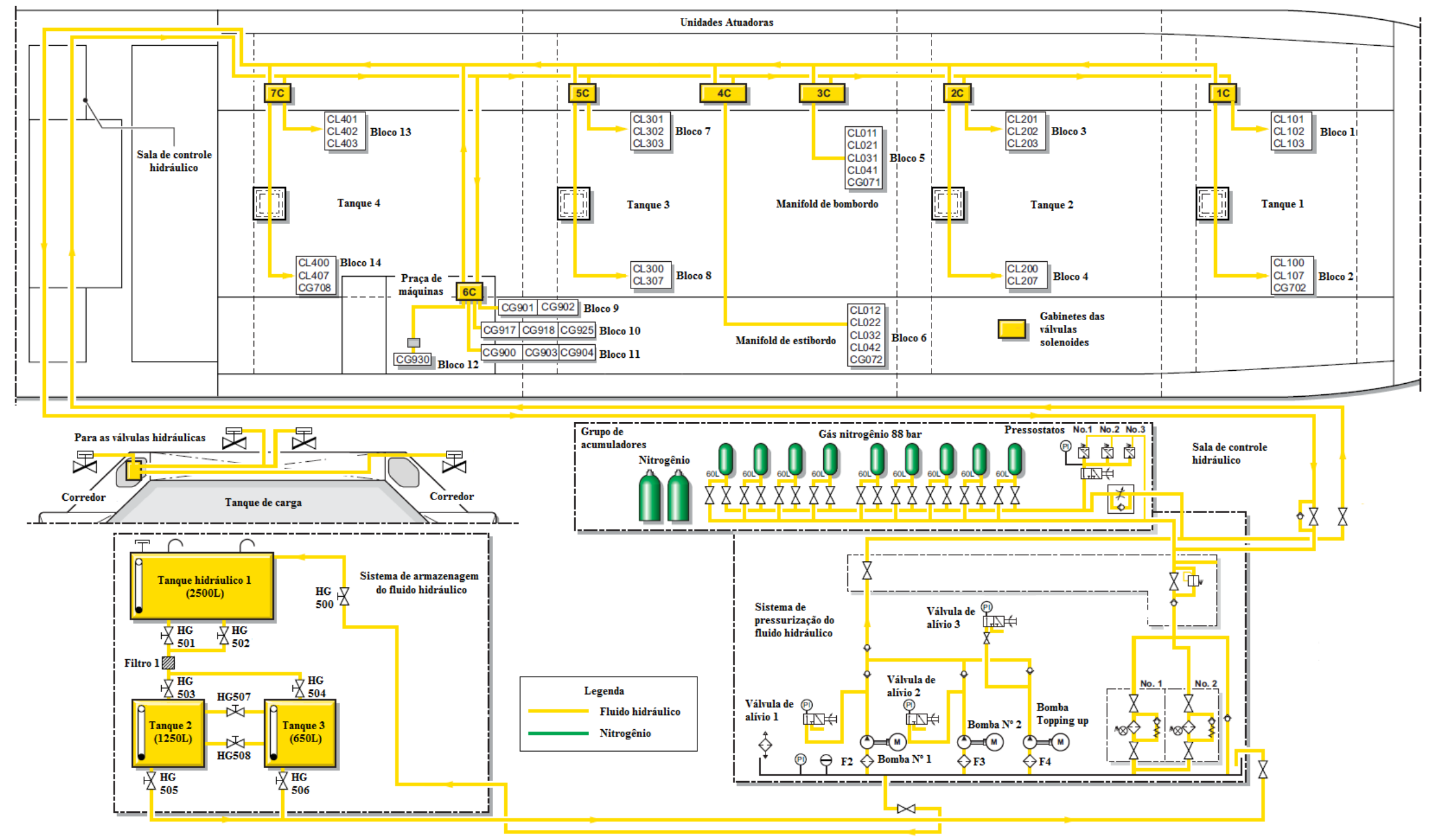

Figura 5.35 - Sistema hidráulico de controle das válvulas 
Para o sistema hidráulico que governa as válvulas de emergência é calculada a confiabilidade utilizando a ferramenta FTA e considerando o evento topo "Falha no fechamento das válvulas hidráulicas pela atuação do ESD (Paralisação de Emergência)". A Figura 5.36 ilustra a árvore de falhas elaborada para esse evento. 


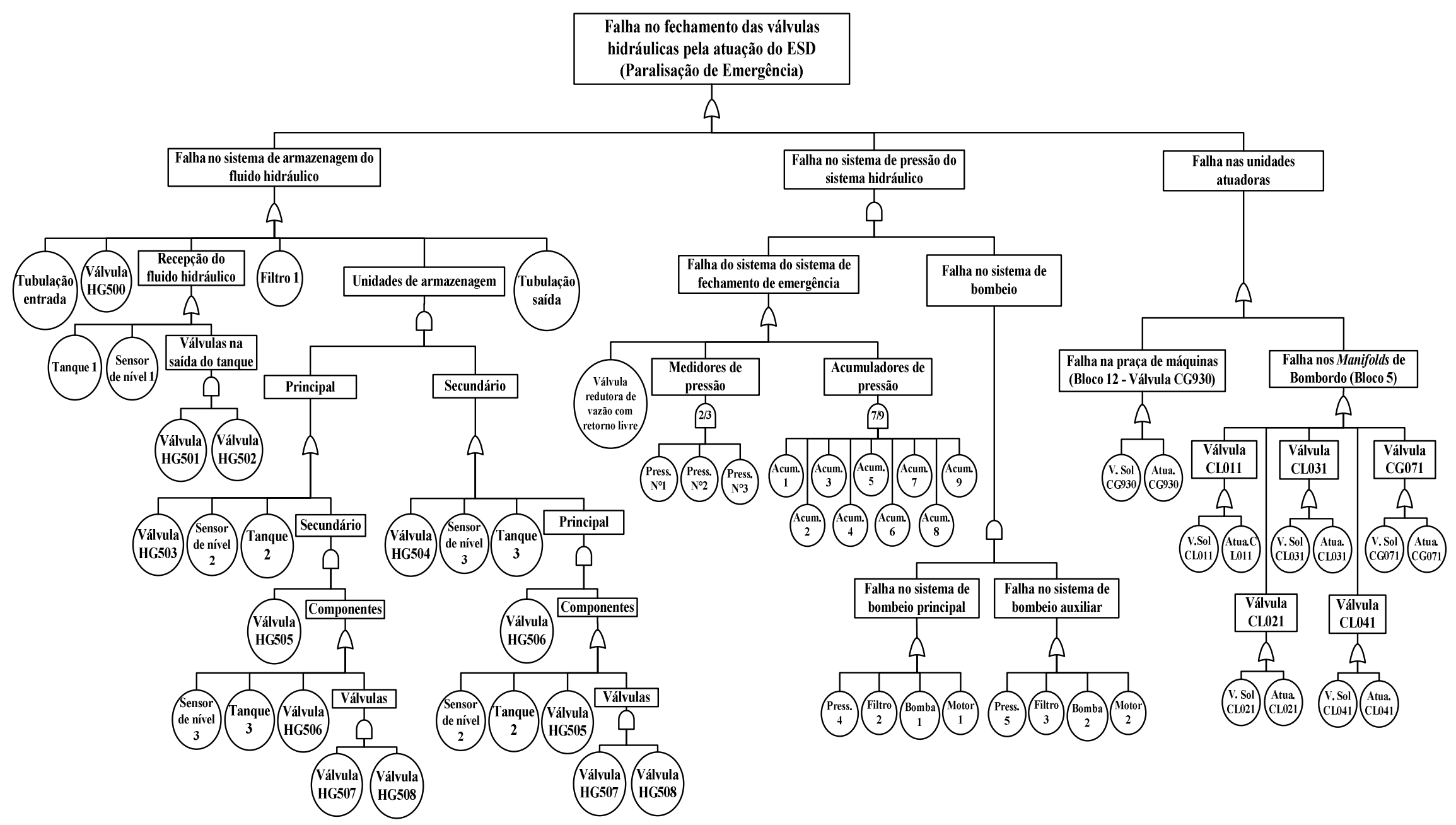

Figura 5.36 - Árvore de falhas para o evento topo "Falha no fechamento das válvulas hidráulicas pela atuação do ESD (Paralisação de Emergência)" 
Conforme a Figura 5.36, a ocorrência do evento topo é causada pela falha no sistema de armazenamento do fluido hidráulico, ou falha do sistema de pressurização do fluido ou pela falha nas unidades atuadoras.

Por meio da análise de árvore de falhas, procedeu-se à avaliação qualitativa das combinações dos eventos básicos que causam a ocorrência do evento topo. A árvore de falhas é renomeada na Figura 5.37 para que seja feita a análise qualitativa.

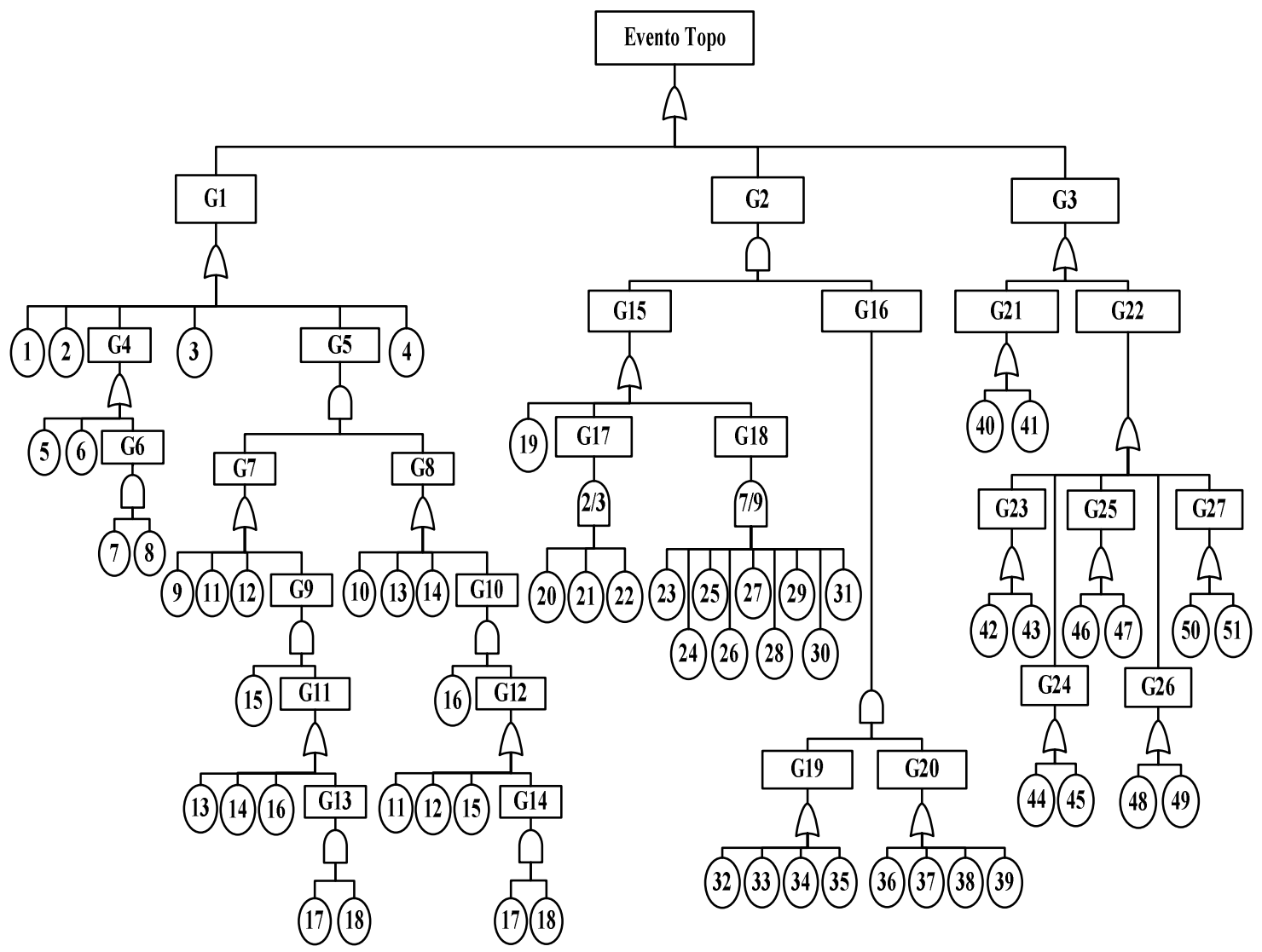

Figura 5.37 - Árvore de falhas renomeada para o evento topo "Falha no fechamento das válvulas hidráulicas pela atuação do ESD (Paralisação de Emergência)"

A ocorrência do evento topo é expressa pela Equação 5.8, conforme a Figura 5.37.

Evento Topo $=\mathrm{G} 1+\mathrm{G} 2+\mathrm{G} 3$

O evento topo está expresso em termos de G1,G2,G3. A seguir são listadas as expressões correspondentes a cada um desses eventos. Para maior entendimento será adicionada a letra "X" diante do número de cada evento base. 
O evento G1 é expresso pela Equação 5.9:

$\mathrm{G} 1=\mathrm{X} 1+\mathrm{X} 2+\mathrm{X} 5+\mathrm{X} 6+(\mathrm{X} 7 * \mathrm{X} 8)+\mathrm{X} 3+(\mathrm{X} 9 * \mathrm{X} 10)+(\mathrm{X} 9 * \mathrm{X} 13)+(\mathrm{X} 9 * \mathrm{X} 14)+(\mathrm{X} 9 * \mathrm{X} 16 * \mathrm{X} 11)$

$+(\mathrm{X} 9 * \mathrm{X} 16 * \mathrm{X} 12)+(\mathrm{X} 9 * \mathrm{X} 16 * \mathrm{X} 15)+(\mathrm{X} 9 * \mathrm{X} 16 * \mathrm{X} 17 * \mathrm{X} 18)+(\mathrm{X} 11 * \mathrm{X} 10)+(\mathrm{X} 11 * \mathrm{X} 13)+(\mathrm{X} 11$

$* \mathrm{X} 14)+(\mathrm{X} 11 * \mathrm{X} 16 * \mathrm{X} 11)+(\mathrm{X} 11 * \mathrm{X} 16 * \mathrm{X} 12)+(\mathrm{X} 11 * \mathrm{X} 16 * \mathrm{X} 15)+(\mathrm{X} 11 * \mathrm{X} 16 * \mathrm{X} 17 \mathrm{X} * 18)+(\mathrm{X} 12$

$* \mathrm{X} 10)+(\mathrm{X} 12 * \mathrm{X} 13)+(\mathrm{X} 12 * \mathrm{X} 14)+(\mathrm{X} 12 * \mathrm{X} 16 * \mathrm{X} 11)+(\mathrm{X} 12 * \mathrm{X} 16 * \mathrm{X} 12)+(\mathrm{X} 12 * \mathrm{X} 16 * \mathrm{X} 15)+$

$(\mathrm{X} 12 * \mathrm{X} 16 * \mathrm{X} 17 * \mathrm{X} 18)+(\mathrm{X} 15 * \mathrm{X} 13 * \mathrm{X} 10)+(\mathrm{X} 15 * \mathrm{X} 14 * \mathrm{X} 10)+(\mathrm{X} 15 * \mathrm{X} 16 * \mathrm{X} 10)+(\mathrm{X} 15 * \mathrm{X} 17$

$* \mathrm{X} 18 * \mathrm{X} 10)+(\mathrm{X} 15 * \mathrm{X} 13 * \mathrm{X} 13)+(\mathrm{X} 15 * \mathrm{X} 14 * \mathrm{X} 13)+(\mathrm{X} 15 * \mathrm{X} 16 * \mathrm{X} 13)+(\mathrm{X} 15 * \mathrm{X} 17 * \mathrm{X} 18 * \mathrm{X} 13)$

$+\left(\mathrm{X} 15^{*} \mathrm{X} 13 * \mathrm{X} 14\right)+(\mathrm{X} 15 * \mathrm{X} 14 * \mathrm{X} 14)+\left(\mathrm{X} 15^{*} \mathrm{X} 16^{*} \mathrm{X} 14\right)+\left(\mathrm{X} 15^{*} \mathrm{X} 17^{*} \mathrm{X} 18^{*} \mathrm{X} 14\right)+\left(\mathrm{X} 15^{*} \mathrm{X} 13\right.$

$* \mathrm{X} 16 * \mathrm{X} 11)+(\mathrm{X} 15 * \mathrm{X} 13 * \mathrm{X} 16 * \mathrm{X} 12)+(\mathrm{X} 15 * \mathrm{X} 13 * \mathrm{X} 16 * \mathrm{X} 15)+(\mathrm{X} 15 * \mathrm{X} 13 * \mathrm{X} 16 * \mathrm{X} 17 * \mathrm{X} 18)$

$+\left(\mathrm{X} 15^{*} \mathrm{X} 14 * \mathrm{X} 16^{*} \mathrm{X} 11\right)+\left(\mathrm{X} 15^{*} \mathrm{X} 14 * \mathrm{X} 16 * \mathrm{X} 12\right)+(\mathrm{X} 15 * \mathrm{X} 14 * \mathrm{X} 16 * \mathrm{X} 15)+(\mathrm{X} 15 * \mathrm{X} 14 * \mathrm{X} 16$

$* \mathrm{X} 17 * \mathrm{X} 18)+(\mathrm{X} 15 * \mathrm{X} 16 * \mathrm{X} 16 * \mathrm{X} 11)+(\mathrm{X} 15 * \mathrm{X} 16 * \mathrm{X} 16 * \mathrm{X} 12)+(\mathrm{X} 15 * \mathrm{X} 16 * \mathrm{X} 16 * \mathrm{X} 15)+(\mathrm{X} 15$

$\left.* \mathrm{X} 16 * \mathrm{X} 16^{*} \mathrm{X} 17 * \mathrm{X} 18\right)+\left(\mathrm{X} 15^{*} \mathrm{X} 17 * \mathrm{X} 18^{*} \mathrm{X} 16^{*} \mathrm{X} 11\right)+\left(\mathrm{X} 15^{*} \mathrm{X} 17 * \mathrm{X} 18^{*} \mathrm{X} 16 * \mathrm{X} 12\right)+(\mathrm{X} 15$

$* \mathrm{X} 17 * \mathrm{X} 18 * \mathrm{X} 16 * \mathrm{X} 15)+(\mathrm{X} 15 * \mathrm{X} 17 * \mathrm{X} 18 * \mathrm{X} 16 * \mathrm{X} 17 * \mathrm{X} 18)+\mathrm{X} 4$

O portão G2 é expresso pela Equação 5.10:

$\mathrm{G} 2=(\mathrm{G} 15) *(\mathrm{G} 16)$

$\mathrm{G} 2=(\mathrm{X} 19+\mathrm{G} 17+\mathrm{G} 18) *(\mathrm{G} 16)$

Para o cálculo dos portões G17 e G18 da expressão anterior são utilizadas as seguintes formulações para o cálculo da probabilidade de falha:

$$
\begin{aligned}
& \mathrm{G} 17=\left(1-\left[3 *\left(R_{\text {press }}\right)^{2}-2 *\left(\left(R_{\text {press }}\right)^{3}\right]\right)\right. \\
& \mathrm{G} 18=\left(1-\left[36 * R_{\text {acum }}{ }^{7} *\left(1-R_{\text {acum }}\right)^{2}+9 * R_{\text {acum }}{ }^{8} *\left(1-R_{\text {acum }}\right)+R_{\text {acum }}{ }^{9} *\left(1-R_{\text {acum }}\right)^{0}\right]\right)
\end{aligned}
$$

Os termos $R_{\text {press }}$ e $R_{\text {acum }}$ representam a confiabilidade do pressostato e do acumulador respectivamente.

O portão G17 trata-se da probabilidade de falha de um sistema de pressostatos onde para a ocorrência da falha tem que falhar dois dos três pressostatos. O portão G18 trata da probabilidade de falha do grupo de acumuladores onde a falha ocorrerá quando falham sete dos nove acumuladores.

Para o cálculo da probabilidade de falha do portão G16 é utilizada a seguinte expressão: 
$\mathrm{G} 16=(\mathrm{X} 32 * \mathrm{X} 36)+(\mathrm{X} 32 * \mathrm{X} 37)+(\mathrm{X} 32 * \mathrm{X} 38)+(\mathrm{X} 32 * \mathrm{X} 39)+(\mathrm{X} 33 * \mathrm{X} 36)+(\mathrm{X} 33 * \mathrm{X} 37)+(\mathrm{X} 33$

$* \mathrm{X} 38)+(\mathrm{X} 33 * \mathrm{X} 39)+(\mathrm{X} 34 * \mathrm{X} 36)+(\mathrm{X} 34 * \mathrm{X} 37)+(\mathrm{X} 34 * \mathrm{X} 38)+(\mathrm{X} 34 * \mathrm{X} 39)+(\mathrm{X} 35 * \mathrm{X} 36)+(\mathrm{X} 35$

$* \mathrm{X} 37)+\left(\mathrm{X} 35^{*} \mathrm{X} 38\right)+(\mathrm{X} 35 * \mathrm{X} 39)$.

E por último o portão G3 é expresso pela Equação 5.11 a seguir.

$\mathrm{G} 3=\mathrm{G} 21+\mathrm{G} 22$

Sendo:

$\mathrm{G} 21=\mathrm{X} 40+\mathrm{X} 41$

$\mathrm{G} 22=\mathrm{X} 42+\mathrm{X} 43+\mathrm{X} 44+\mathrm{X} 45+\mathrm{X} 46+\mathrm{X} 47+\mathrm{X} 48+\mathrm{X} 49+\mathrm{X} 50+\mathrm{X} 51$

Colocando as expressões dos três eventos na Equação 5.8 e aplicando os conceitos da álgebra Booleana, obtém-se a expressão da Equação 5.12 que representa o resultado da análise qualitativa que indica as combinações dos eventos básicos que levam à ocorrência do evento topo.

EventoTopo $=[\mathrm{X} 1+\mathrm{X} 2+\mathrm{X} 3+\mathrm{X} 4+\mathrm{X} 5+\mathrm{X} 6+(\mathrm{X} 7 * \mathrm{X} 8)+(\mathrm{X} 9 * \mathrm{X} 10)+(\mathrm{X} 9 * \mathrm{X} 13)+(\mathrm{X} 9 * \mathrm{X} 14)$ $+(\mathrm{X} 10 * \mathrm{X} 11)+(\mathrm{X} 11 * \mathrm{X} 13)+(\mathrm{X} 11 * \mathrm{X} 14)+(\mathrm{X} 10 * \mathrm{X} 12)+(\mathrm{X} 12 * \mathrm{X} 13)+(\mathrm{X} 12 * \mathrm{X} 14)+(\mathrm{X} 11 * \mathrm{X} 16)$ $+(\mathrm{X} 12 * \mathrm{X} 16+\mathrm{X} 13 * \mathrm{X} 15)+(\mathrm{X} 14 * \mathrm{X} 15+\mathrm{X} 15 * \mathrm{X} 16)+(\mathrm{X} 9 * \mathrm{X} 16 * \mathrm{X} 17 * \mathrm{X} 18)+(\mathrm{X} 11 * \mathrm{X} 16 * \mathrm{X} 17$ $* \mathrm{X} 18)+(\mathrm{X} 12 * \mathrm{X} 16 * \mathrm{X} 17 * \mathrm{X} 18)+(\mathrm{X} 10 * \mathrm{X} 15 * \mathrm{X} 17 * \mathrm{X} 18)+(\mathrm{X} 13 * \mathrm{X} 15 * \mathrm{X} 17 * \mathrm{X} 18)+(\mathrm{X} 14 * \mathrm{X} 15$ $* \mathrm{X} 17 * \mathrm{X} 18)+(\mathrm{X} 12 * \mathrm{X} 13 * \mathrm{X} 15 * \mathrm{X} 18)+(\mathrm{X} 15 * \mathrm{X} 16 * \mathrm{X} 17 * \mathrm{X} 18)]+[(\mathrm{X} 19+\mathrm{G} 17+\mathrm{G} 18) *\{(\mathrm{X} 32 * \mathrm{X} 36)$ $+(\mathrm{X} 32 * \mathrm{X} 37)+(\mathrm{X} 32 * \mathrm{X} 38)+(\mathrm{X} 32 * \mathrm{X} 39)+(\mathrm{X} 33 * \mathrm{X} 36)+(\mathrm{X} 33 * \mathrm{X} 37)+(\mathrm{X} 33 * \mathrm{X} 38)+(\mathrm{X} 33 * \mathrm{X} 39)$ $+(\mathrm{X} 34 * \mathrm{X} 36)+(\mathrm{X} 34 * \mathrm{X} 37)+(\mathrm{X} 34 * \mathrm{X} 38)+(\mathrm{X} 34 * \mathrm{X} 39)+(\mathrm{X} 35 * \mathrm{X} 36)+(\mathrm{X} 35 * \mathrm{X} 37)+(\mathrm{X} 35 * \mathrm{X} 38)$ $+(\mathrm{X} 35 * \mathrm{X} 39)\}]+[\mathrm{X} 40+\mathrm{X} 41+\mathrm{X} 42+\mathrm{X} 43+\mathrm{X} 44+\mathrm{X} 45+\mathrm{X} 46+\mathrm{X} 47+\mathrm{X} 48+\mathrm{X} 49+\mathrm{X} 50+\mathrm{X} 51]$

Com a Equação 5.12 monta-se a Figura 5.38 que representa a Árvore de falhas reduzida onde podem ser visualizados os cortes mínimos. 


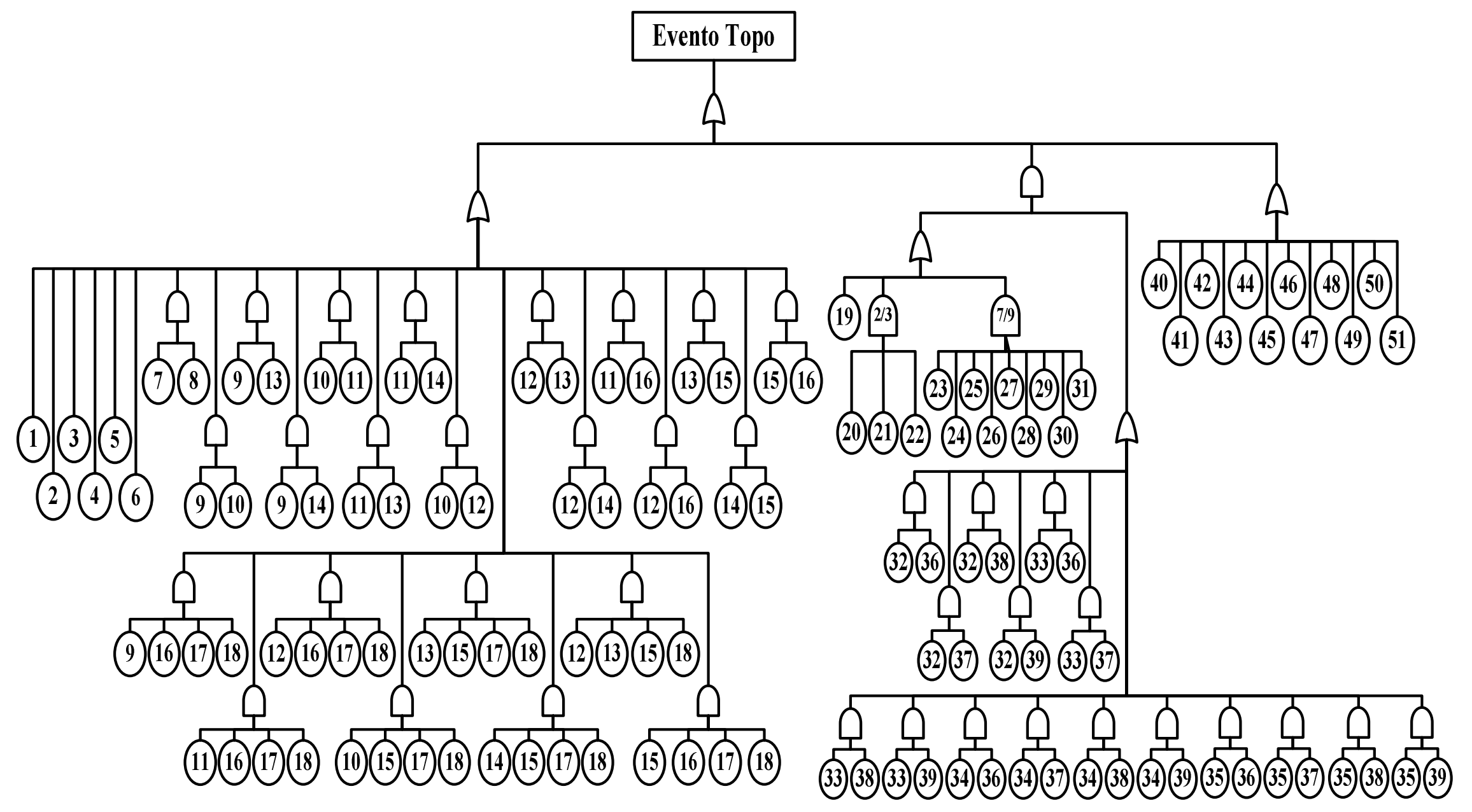

Figura 5.38 - Árvore de falhas reduzida para a obtenção dos cortes mínimos 
Na Tabela 5.22 são apresentadas as taxas de falha para os componentes que pertencem ao sistema hidráulico de controle das válvulas e que serão utilizados para a análise quantitativa. As probabilidades de falha dos eventos básicos são substituídas na Equação 5.12. Para determinar o valor da confiabilidade de cada um dos componentes foi utilizada a distribuição exponencial.

Tabela 5.22 - Taxa de falha para os componentes do sistema hidráulico de controle das válvulas

\begin{tabular}{|l|c|c|}
\hline \multicolumn{1}{|c|}{ Componente } & Taxa de falha (falha/hora) & Referência \\
\hline Tanque hidráulico & $7,56 \mathrm{E}-06\left(\lambda_{5}, \lambda_{12}, \lambda_{14}\right)$ & NPRD $(1995)$ \\
\hline Sensor de nível de óleo & $2,60 \mathrm{E}-06\left(\lambda_{6}, \lambda_{11}, \lambda_{13}\right)$ & NPRD $(1995)$ \\
\hline Válvula globo & $2,00 \mathrm{E}-06\left(\lambda_{2}, \lambda_{7}, \lambda_{8}, \lambda_{9}, \lambda_{10}, \lambda_{15}, \lambda_{16}, \lambda_{17}, \lambda_{18}\right)$ & $\mathrm{NPRD}(1995)$ \\
\hline Filtro & $1,06 \mathrm{E}-07\left(\lambda_{3}, \lambda_{33}, \lambda_{37}\right)$ & $\mathrm{NPRD}(1995)$ \\
\hline Tubulação hidráulica & $4,78 \mathrm{E}-07\left(\lambda_{1}, \lambda_{4}\right)$ & $\mathrm{NPRD}(1995)$ \\
\hline Bomba centrifuga & $8,63 \mathrm{E}-05\left(\lambda_{34}, \lambda_{38}\right)$ & $\mathrm{NPRD}(1995)$ \\
\hline Motor elétrico & $2,99 \mathrm{E}-05\left(\lambda_{35}, \lambda_{39}\right)$ & $\mathrm{NPRD}(1995)$ \\
\hline Válvula redutora de vazão com retorno livre & $6,06 \mathrm{E}-06\left(\lambda_{19}\right)$ & $\mathrm{NPRD}(1995)$ \\
\hline Pressostato & $4,71 \mathrm{E}-06\left(\lambda_{20}, \lambda_{21}, \lambda_{22}, \lambda_{32}, \lambda_{36}\right)$ & Hidalgo $(2010)$ \\
\hline Acumulador de pressão & $1,42 \mathrm{E}-05\left(\lambda_{23}, \ldots, \lambda_{31}\right)$ & $\mathrm{NPRD}(1995)$ \\
\hline Atuador tipo pistão da válvula & $2,58 \mathrm{E}-05\left(\lambda_{41}, \lambda_{43}, \lambda_{45}, \lambda_{47}, \lambda_{49}, \lambda_{51}\right)$ & $\mathrm{NPRD}(1995)$ \\
\hline Válvula solenoide & $2,24 \mathrm{E}-05\left(\lambda_{40}, \lambda_{42}, \lambda_{44}, \lambda_{46}, \lambda_{48}, \lambda_{50}\right)$ & $\mathrm{NPRD}(1995)$ \\
\hline
\end{tabular}

O sistema de paralisação de emergência somente será utilizado durante o processo de carga e descarga do navio, diferente do sistema de fornecimento de energia da SCC e do sistema de amostragem de gás que funcionam durante toda a vida operacional do navio.

Em um ano o sistema de controle das válvulas opera 24 vezes aproximadamente, já que estas válvulas são chamadas a operar durante a operação de carga e descarga do GNL no terminal de carga ou descarga. De acordo com Marine Traffic (2012) a carga e a descarga do GNL demoram aproximadamente 24 horas, isso significa que durante um ano este sistema hidráulico operaria 576 horas. Ao final dos cinco anos o sistema operou aproximadamente 2880 horas, considerando que opera duas vezes durante um mês, que corresponde ao período em que o navio faz a carga, navega durante um período de 15 dias, faz a descarga e navega até chegar ao ponto inicial de carga.

Na Figura 5.39 é apresentada a curva da confiabilidade do sistema hidráulico de controle das válvulas considerando unicamente as válvulas que são ativadas pelo sistema de paralisação de emergência. 


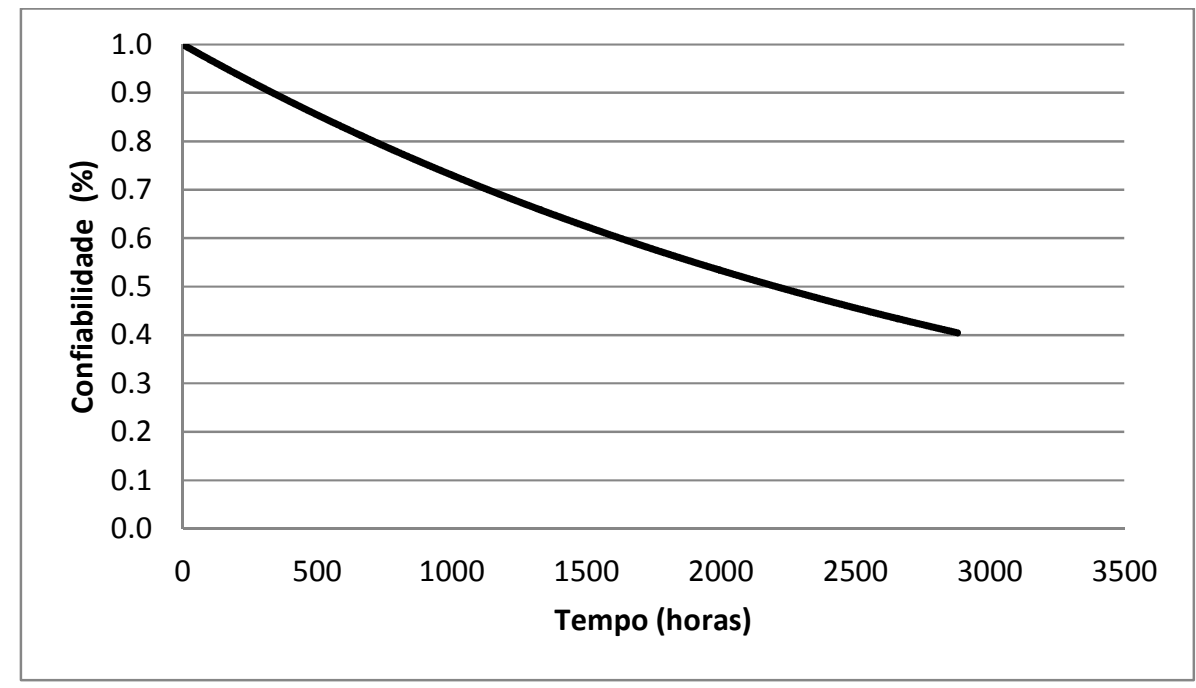

Figura 5.39 - Curva da confiabilidade do sistema hidráulico de controle das válvulas do ESD

Na Tabela 5.23 são apresentados os valores da confiabilidade e da probabilidade de falha do sistema hidráulico de controle das válvulas do ESD, calculados para cinco anos de operação.

Tabela 5.23 - Valores da confiabilidade e da probabilidade de falha para o sistema hidráulico de controle das válvulas do ESD ao longo de cinco anos de operação

\begin{tabular}{|l|c|c|}
\cline { 2 - 3 } \multicolumn{1}{c|}{} & Confiabilidade $(R)$ & Probabilidade de falha $(p f)$ \\
\hline Primeiro ano (576 horas) & 0,8344 & 0,1655 \\
\hline Segundo ano (1152 horas) & 0,6962 & 0,3037 \\
\hline Terceiro ano (1728 horas) & 0,5809 & 0,4190 \\
\hline Quarto ano (2304 horas) & 0,4847 & 0,5152 \\
\hline Quinto ano (2880 horas) & 0,4044 & 0,5955 \\
\hline
\end{tabular}

As três barreiras de contenção que correspondem às três primeiras caixas do DCC pertencem ao navio e são foco principal deste trabalho. No DCC também são apresentados os eventos que se relacionam com as condições ambientais, quantidade de GNL derramado, condições de inflamabilidade do gás, presença ou não de fontes de ignição, que não são discutidos nesta dissertação. Para todos esses eventos, que não estão relacionados com falhas dos equipamentos do navio é colocada uma probabilidade de ocorrência do evento de 0,5.

Para efetuar o cálculo da probabilidade de ocorrência do Cenário 1 na Figura 5.40, por exemplo, tem duas possibilidades: A primeira possibilidade, que seja monitorado e detectado algum parâmetro incorreto da operação na SCC (funcione A) e que o sistema de paralisação de emergência seja ativado (funcione C); ou a segunda possibilidade, que não seja detectado 
algum parâmetro incorreto da operação na SCC (não funcione A) e que o vazamento seja detectado pelo sistema de amostragem de gás (funcione B) e que o sistema de paralisação de emergência seja ativado (funcione $\mathrm{C}$ ). $\mathrm{O}$ anteriormente sinalado está representado na Equação 5.13 .

$$
\text { Cenário } 1=\mathrm{A}^{*} \mathrm{C}+\mathrm{A}^{*} * \mathrm{~B} * \mathrm{C}
$$

A' significa a negação da função da barreira de proteção A ou a falha da mesma.

As mesmas considerações foram realizadas para o cálculo dos demais cenários de falha no Diagrama Causa-Consequência.

Na Figura 5.40 observa-se os resultados da análise quantitativa do Diagrama CausaConsequência, onde foram obtidos os valores da probabilidade de ocorrência dos cenários de falha considerando cinco anos de operação dos sistemas do navio transportador de GNL. O DCC inicia-se com um vazamento nos componentes do sistema de carga e descarga do GNL do navio transportador. 


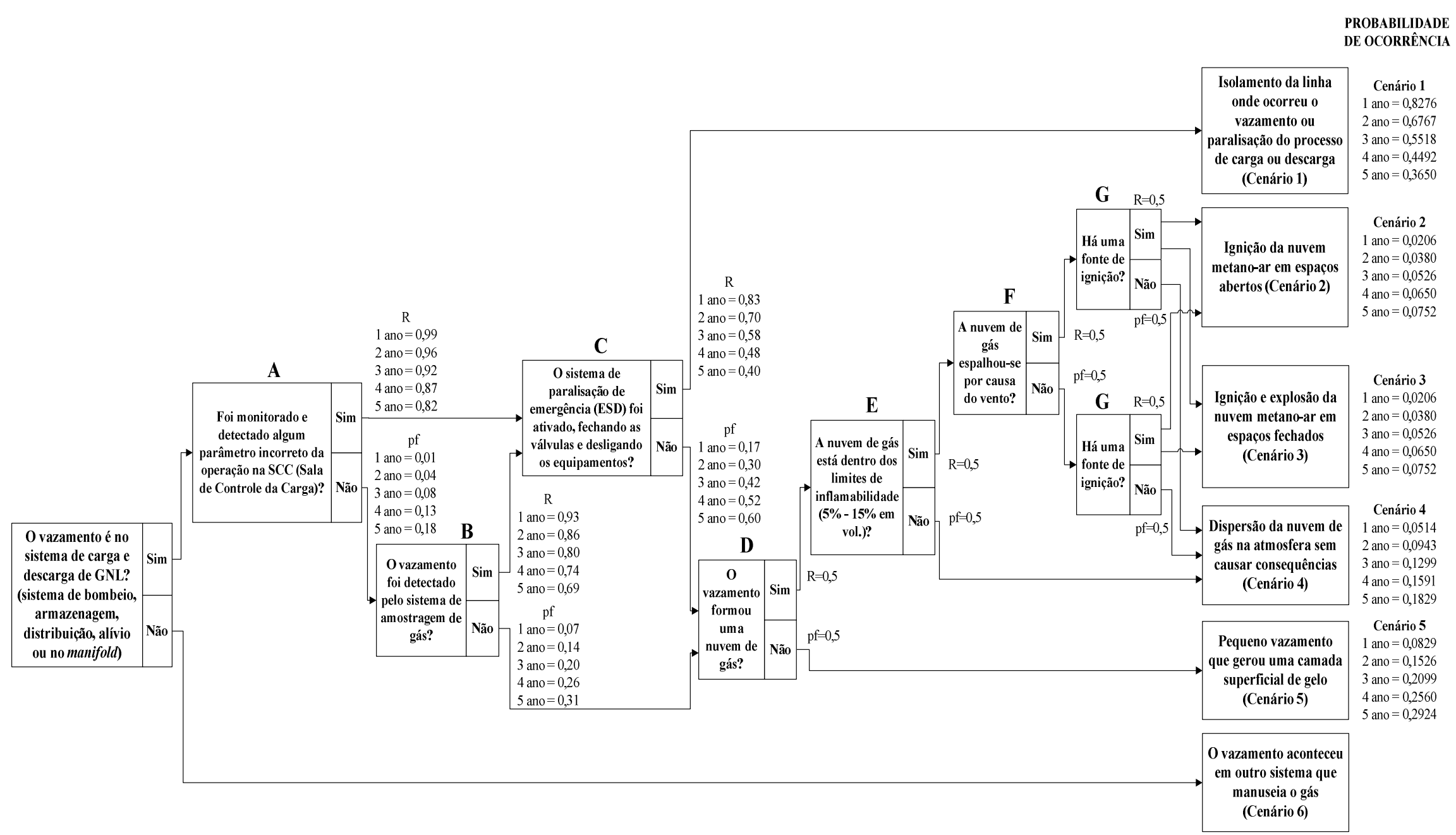

Figura 5.40 - Diagrama Causa-Consequência com os valores da probabilidade de ocorrência para a avaliação quantitativa dos cenários de falha 
Como resultado da análise quantitativa do diagrama Causa-Consequência pode-se observar que os piores cenários seriam o Cenário 2 e 3, mas estes cenários tem a menor probabilidade de ocorrência. Estes cenários consideram a não detecção de nenhum parâmetro incorreto nos painéis da SCC, seguido da não detecção do vazamento de gás por meio do sistema de amostragem de gás, o não funcionamento do sistema de paralisação de emergência, permitindo que se forme uma nuvem de gás que se movimentará, por causa do vento, até as instalações portuárias onde uma fonte de ignição ativaria a mistura de 5-15\% de gás-ar que causará um incêndio sem explosão em espaços abertos e um incêndio com explosão no caso de ambientes fechados como casas ou edifícios. Em ambos casos esses incêndios transmitirão radiação térmica provocando maiores danos nas áreas circunvizinhas.

O cenário ideal seria o Cenário 1, onde considera-se que as três barreiras de proteção cumpriram a sua função que é impedir que o evento iniciador se desenvolva e cause maiores consequências. A probabilidade de cair neste cenário é das maiores dentre os demais cenários levados em consideração, isso quer dizer que a probabilidade do acontecimento de um acidente no navio transportador de GNL durante as operações de carga e descarga do GNL é pequena.

O Cenário 4 leva em consideração que as barreiras de proteção não funcionaram corretamente, mas por causas das condições ambientais ou da mistura de gás-ar não estar dentro dos limites de inflamabilidade, a nuvem de gás se dispersará na atmosfera sem causar consequências.

No caso do Cenário 5 se considera que o vazamento não formou uma nuvem de gás e que esse pequeno vazamento congelaria a superfície externa do local onde se produz a falha.

De acordo com os valores obtidos, existe uma maior chance do acontecimento do Cenário 1, seguido do Cenário 5 e do Cenário 4 sendo os de menor chance da ocorrência os Cenários 2 ou 3.

\subsection{Passo 3 - Análise de Risco}

De acordo com as pesquisas feitas para a realização deste trabalho, não se registraram acidentes graves que causaram a liberação descontrolada da carga transportada (IMO, 2002). Entretanto ocorreram vazamentos de GNL devido ao enchimento excessivo dos tanques e da não ativação das barreiras de proteção do navio. Também ocorreram vazamentos produzidos 
de forma segura e controlada pelo sistema de alívio, especificamente pelos risers. Falhas dos componentes do sistema de carga/descarga como, válvulas criogênicas ou bombas de descarga, também foram registradas neste tipo de navios. Os modos de falha estudados nesta dissertação estão ligados aos modos pelos quais a falha envolve a ocorrência de um vazamento. A ocorrência dos modos de falha estudados deve-se em grande parte ao não funcionamento ou ativação das barreiras de proteção, é assim que considerando a não operação das barreiras de proteção foi feita a análise de risco apresentada na sequência.

Os componentes mecânicos que compõem os circuitos tanto de GNL quanto de boil-off podem falhar, e por causa destas falhas o sistema pode deixar de cumprir a sua função, mas o pior não é a perda da função, mas as falhas dos componentes do sistema de carga e descarga de GNL que podem também causar vazamentos aumentando o nível de risco.

\subsubsection{Determinação da probabilidade de ocorrência}

Neste método de estudo utilizar-se principalmente as bases de dados OREDA (2002), HSE (2010) e a NPRD (1995), que fornecem os valores da taxa de falha em termos de falha/unidade de tempo para os diferentes componentes dos sistemas analisados, e com a qual se poderá calcular a probabilidade de um evento iniciador acontecer (inicio do vazamento que é o evento iniciador do DCC). A taxa de falha nessas bases de dados é associada a uma distribuição exponencial, que significa que a taxa de falha é constante ao longo do tempo, mesmo que o componente seja reparado ou substituído.

Para cada componente do sistema de carga e descarga do GNL, obteve-se o valor de probabilidade de ocorrência utilizando a Equação 4.1, levando em consideração o valor de $n=1$ (ocorrência de esse modo de falha durante o tempo de análise), considerando um tempo de análise de 8760 horas ou um ano para componentes que trabalham o tempo todo e de 576 horas para componentes que trabalham somente durante a carga e descarga do GNL. Com o valor da probabilidade da ocorrência obtido utiliza-se a Tabela 4.2, e classifica-se essa probabilidade dentro dos cinco níveis de frequência de ocorrência.

Para efeitos de comparação também foi calculada a confiabilidade de cada item na coluna $R=e^{-\lambda t}$ na Tabela 5.24 e Tabela 5.25. Este valor é muito próximo do valor da probabilidade de não ocorrência de falha, calculado com a distribuição de Poisson $\operatorname{com} n=0$. 
O valor da probabilidade de ocorrência de uma falha, $n=1$ (uma ocorrência durante o tempo de análise), praticamente corresponde ao valor de $1-R$. Dessa forma o cálculo da probabilidade de falha pode ser executado considerando a ocorrência de uma falha ao longo do tempo operacional analisado.

Finalmente, na medida em que o valor de $n$ aumenta, o valor da probabilidade de ocorrência diminui. Isto pode ser visto com os valores obtidos para valores de $n=1$ e $n=2$.

\subsubsection{Determinação das consequências ou severidades}

Neste estudo são avaliadas as consequências que envolvem a segurança pessoal e a segurança das instalações. No que se refere às consequências no meio ambiente não são parte do escopo deste trabalho, como já indicado no desenvolvimento do Diagrama CausaConsequência.

As consequências produto do vazamento de GNL e do boil-off foram analisadas qualitativamente utilizando-se referências bibliográficas como Ramos et al. (2011), Martins et al. (2010), IMO (2007), ABS (2004), entre outras, sempre levando em consideração quais podem ser os efeitos produto do vazamento do GNL, e dado o hipotético caso que as barreiras de proteção não foram ativadas.

As consequências do vazamento de GNL foram analisadas com maior profundidade na Análise Preliminar de Perigos e na elaboração do diagrama Causa-Consequência, mas nos seguintes parágrafos são fornecidas algumas informações complementares.

De acordo com Ramos et al. (2011), o incêndio em poça e o incêndio em nuvem são os que representam o maior perigo. Os autores apresentaram o cálculo da distância percorrida pela nuvem de vapor que está acima do limite inferior de inflamabilidade, bem como a radiação térmica emitida pelo incêndio em poça (pool fire). Para determinar as consequências das simulações efetuadas foi importante definir o tamanho do furo que causará o vazamento e a capacidade do tanque de armazenamento onde está armazenado o GNL, além de estabelecer as condições climáticas. A radiação térmica é gerada apenas pela poça e o flash fire terá efeitos apenas na região interna da nuvem, mas o efeito do flash fire não provoca fatalidade para a pessoa que está abrigada. 
Outra consequência pode ser exposição direta da tripulação do navio à substância criogênica. De acordo com IMO (2007), as consequências dos incidentes ocorridos durante a carga e descarga do GNL nos terminais são geralmente de menor escala, onde possíveis ferimentos ou mortes serão devido à exposição ou contato direto com a substância vazada.

De acordo com a ABS (2004), podem apresentar-se efeitos sobre as estruturas metálicas ou não metálicas, cujas consequências dependerão do tipo de material que entrou em contato com o fluido criogênico.

Na Tabela 5.24 e Tabela 5.25 serão apresentados os valores da frequência de ocorrência e da consequência, tanto para o sistema de carga e descarga do GNL, quanto para o sistema de descarga do boil-off respectivamente, e para cada um dos modos de falha dos componentes desses sistemas. A consequência é baseada no estudo do Diagrama Causa-Consequência apresentado no item 5.2.2. 
Tabela 5.24 - Probabilidade de ocorrência e a sua consequência nos componentes do sistema de carga e descarga do GNL

\begin{tabular}{|c|c|c|c|c|c|c|c|c|c|c|c|c|c|}
\hline Componente & Referência & $\mathbf{N}^{0}$ & Modos de Falha & $\begin{array}{l}\text { Taxa de falha } \\
\text { [falha/hora] }\end{array}$ & {$\left[\begin{array}{c}\text { Tempo } \\
{[\text { Horas }]}\end{array}\right]$} & $\mathbf{R}=\mathrm{e}^{-\lambda t}$ & $\begin{array}{c}\text { Poisson } \\
\mathrm{n}=0\end{array}$ & $\begin{array}{c}1-\mathrm{R} \\
\text { Probabilidade }\end{array}$ & $\begin{array}{c}\mathbf{P}(\mathbf{n}=1) \\
\text { Probabilidade }\end{array}$ & $\begin{array}{c}P(n=2) \\
\text { Probabilidade }\end{array}$ & $\begin{array}{c}\text { Categoria da } \\
\text { Frequência }\end{array}$ & $\begin{array}{r}\text { Categoria da } \\
\text { Consequência }\end{array}$ & RISCO \\
\hline Bomba centrifuga & OREDA & 1 & Não parar quando requisitado & $1.55 \mathrm{E}-06$ & 576 & 0.99911 & 0.99911 & 0.0008924 & 0.0008920 & 0.00000039819026 & $\mathrm{C}$ & IV & $\mathrm{C}$ \\
\hline Válvula de retenção & OREDA & 2 & Todos os modos de falha & $1.46 \mathrm{E}-06$ & 8760 & 0.98729 & 0.98729 & 0.0127082 & 0.0126271 & 0.00008074757258 & $\mathrm{D}$ & II & $\mathbf{M}$ \\
\hline Válvula antiretorno & OREDA & 3 & Todos os modos de falha & $1.46 \mathrm{E}-06$ & 8760 & 0.98729 & 0.98729 & 0.0127082 & 0.0126271 & 0.00008074757258 & $\mathrm{D}$ & II & M \\
\hline \multirow{3}{*}{ Válvula de globo } & OREDA & 4 & Pequeno vazamento & $1.94 \mathrm{E}-06$ & 8760 & 0.98315 & 0.98315 & 0.0168508 & 0.0167080 & 0.00014197147760 & $\mathrm{D}$ & II & $\mathbf{M}$ \\
\hline & OREDA & 5 & Perda da integridade estrutural & $3.90 \mathrm{E}-07$ & 8760 & 0.99659 & 0.99659 & 0.0034106 & 0.0034047 & 0.00000581599075 & $\mathrm{C}$ & II & $\mathbf{M}$ \\
\hline & OREDA & 6 & Vazamento na posição fechada & $9.70 \mathrm{E}-07$ & 8760 & 0.99154 & 0.99154 & 0.0084612 & 0.0084253 & 0.00003579574438 & $\mathrm{C}$ & II & M \\
\hline \multirow{3}{*}{ Válvula borboleta } & OREDA & 7 & Perda da integridade estrutural & $3.90 \mathrm{E}-07$ & 8760 & 0.99659 & 0.99659 & 0.0034106 & 0.0034047 & 0.00000581599075 & $\mathrm{C}$ & II & $\mathbf{M}$ \\
\hline & OREDA & 8 & Pequeno vazamento & $4.31 \mathrm{E}-06$ & 8760 & 0.96295 & 0.96295 & 0.0370517 & 0.0363567 & 0.00068633430738 & $\mathrm{D}$ & II & M \\
\hline & OREDA & 9 & Vazamento na posição fechada & $7.40 \mathrm{E}-07$ & 8760 & 0.99354 & 0.99354 & 0.0064614 & 0.0064405 & 0.00002087499526 & $\mathrm{C}$ & II & $\mathbf{M}$ \\
\hline \multirow{2}{*}{ Tanque primário } & HSE & 10 & Catastrófica (ruptura) & $5.70 \mathrm{E}-12$ & 8760 & 1.00000 & 1.00000 & 0.0000000 & 0.0000000 & 0.00000000000000 & A & II & $\mathrm{NC}$ \\
\hline & HSE & 11 & Falha menor (trinca) & $1.14 \mathrm{E}-10$ & 8760 & 1.00000 & 1.00000 & 0.0000010 & 0.0000010 & 0.00000000000050 & $\mathrm{~A}$ & II & $\mathrm{NC}$ \\
\hline \multirow{3}{*}{$\begin{array}{c}\text { Tubulações } \\
\text { secundárias e de } \\
\text { alívio (400 mm) }\end{array}$} & HSE & 12 & $\begin{array}{l}\text { Trinca na tubulação de } 4 \text { mm em } \\
\text { tubulações entre } 300 \text { e } 499 \mathrm{~mm}\end{array}$ & $9.13 \mathrm{E}-09$ & 8760 & 0.99992 & 0.99992 & 0.0000800 & 0.0000799 & 0.00000000319609 & B & II & $\mathrm{NC}$ \\
\hline & HSE & 13 & \begin{tabular}{|l|} 
Ruptura de $1 / 3$ de dia. da tubulação \\
em tubulações entre 300 e 499 mm \\
\end{tabular} & $2.28 \mathrm{E}-09$ & 8760 & 0.99998 & 0.99998 & 0.0000200 & 0.0000200 & 0.00000000019977 & B & IV & $\mathbf{M}$ \\
\hline & HSE & 14 & $\begin{array}{l}\text { Guilhotina em tubulações entre } 300 \\
\text { e } 499 \mathrm{~mm}\end{array}$ & 7.99E-10 & 8760 & 0.99999 & 0.99999 & 0.0000070 & 0.0000070 & 0.00000000002447 & A & IV & $\mathbf{M}$ \\
\hline \multirow{3}{*}{$\begin{array}{l}\text { Tubulação primária } \\
\text { (600 mm) }\end{array}$} & HSE & 15 & $\begin{array}{l}\text { Trinca na tubulação de } 4 \mathrm{~mm} \text { em } \\
\text { tubulações entre } 500 \text { e } 1000 \mathrm{~mm}\end{array}$ & 7.99E-09 & 576 & 1.00000 & 1.00000 & 0.0000046 & 0.0000046 & 0.00000000001058 & A & II & $\mathrm{NC}$ \\
\hline & HSE & 16 & \begin{tabular}{|l|} 
Ruptura de $1 / 3$ de dia. da tubulação \\
em tubulações entre 500 e $1000 \mathrm{~mm}$ \\
\end{tabular} & $1.14 \mathrm{E}-09$ & 576 & 1.00000 & 1.00000 & 0.0000007 & 0.0000007 & 0.00000000000022 & A & IV & $\mathbf{M}$ \\
\hline & HSE & 17 & $\begin{array}{l}\text { Guilhotina em tubulações entre } 500 \\
\text { e } 1000 \mathrm{~mm}\end{array}$ & $4.56 \mathrm{E}-10$ & 576 & 1.00000 & 1.00000 & 0.0000003 & 0.0000003 & 0.00000000000003 & A & IV & M \\
\hline \multirow{3}{*}{$\begin{array}{l}\text { Válvula borboleta } \\
\text { ativada pelo ESD }\end{array}$} & OREDA & 18 & Não fechar quando requisitado & $5.42 \mathrm{E}-05$ & 576 & 0.96925 & 0.96925 & 0.0307537 & 0.0302758 & 0.00047285539578 & $\mathrm{D}$ & IV & $\mathbf{C}$ \\
\hline & OREDA & 19 & Perda da integridade estrutural & $5.16 \mathrm{E}-06$ & 576 & 0.99703 & 0.99703 & 0.0029677 & 0.0029633 & 0.00000440375939 & $\mathrm{C}$ & II & $\mathbf{M}$ \\
\hline & OREDA & 20 & Pequeno vazamento & $6.47 \mathrm{E}-05$ & 576 & 0.96344 & 0.96344 & 0.0365591 & 0.0358825 & 0.00066820764261 & $\mathrm{D}$ & II & $\mathbf{M}$ \\
\hline \multirow{3}{*}{ Válvula de alívio } & OREDA & 21 & Perda da integridade estrutural & $8.50 \mathrm{E}-07$ & 8760 & 0.99258 & 0.99258 & 0.0074183 & 0.0073908 & 0.00002751581060 & $\mathrm{C}$ & II & $\mathbf{M}$ \\
\hline & OREDA & 22 & Pequeno vazamento & $3.00 \mathrm{E}-06$ & 8760 & 0.97406 & 0.97406 & 0.0259377 & 0.0255984 & 0.00033636241901 & $\mathrm{D}$ & II & $\mathbf{M}$ \\
\hline & OREDA & 23 & Vazamento na posição fechada & $2.62 \mathrm{E}-06$ & 8760 & 0.97731 & 0.97731 & 0.0226898 & 0.0224304 & 0.00025740277214 & $\mathrm{D}$ & II & $\mathbf{M}$ \\
\hline Manifold & OREDA & 24 & Todos os modos de falha & $2.27 \mathrm{E}-05$ & 576 & 0.98703 & 0.98703 & 0.0129673 & 0.0128829 & 0.00008407488872 & $\mathrm{D}$ & II & M \\
\hline
\end{tabular}


Tabela 5.25 - Probabilidade de ocorrência e a sua consequência nos componentes do sistema de descarga do boil-off

\begin{tabular}{|c|c|c|c|c|c|c|c|c|c|c|c|c|c|}
\hline Componente & Referência & $\mathbf{N}^{0}$ & Modos de falha & $\begin{array}{c}\text { Taxa de falha } \\
\text { [falha/hora] }\end{array}$ & {$\left[\begin{array}{c}\text { Tempo } \\
{[\text { Horas }]}\end{array}\right]$} & $\mathbf{R}=\mathrm{e}^{-\lambda t}$ & $\begin{array}{c}\text { Poisson } \\
\mathrm{n}=\mathbf{0}\end{array}$ & \begin{tabular}{|c|}
$1-\mathrm{R}$ \\
Probabilidade
\end{tabular} & $\begin{array}{c}\mathbf{P}(\mathbf{n}=\mathbf{1}) \\
\text { Probabilidade }\end{array}$ & $\begin{array}{c}\mathbf{P}(\mathbf{n}=2) \\
\text { Probabilidade }\end{array}$ & $\begin{array}{c}\text { Categoria da } \\
\text { Frequência }\end{array}$ & $\begin{array}{c}\text { Categoria da } \\
\text { Consequência }\end{array}$ & RISCO \\
\hline \multirow{3}{*}{$\begin{array}{l}\text { Válvula borboleta } \\
\text { ativada pelo ESD }\end{array}$} & OREDA & 25 & Não fechar quando requisitado & $5.42 \mathrm{E}-05$ & 576 & 0.96925 & 0.96925 & 0.0307537 & 0.0302758 & 0.00047285539578 & $\mathrm{D}$ & IV & C \\
\hline & OREDA & 26 & Perda da integridade estrutural & $5.16 \mathrm{E}-06$ & 576 & 0.99703 & 0.99703 & 0.0029677 & 0.0029633 & 0.00000440375939 & $\mathrm{C}$ & II & M \\
\hline & OREDA & 27 & Pequeno vazamento & $6.47 \mathrm{E}-05$ & 576 & 0.96344 & 0.96344 & 0.0365591 & 0.0358825 & 0.00066820764261 & $\mathrm{D}$ & II & M \\
\hline \multirow{3}{*}{ Válvula borboleta } & OREDA & 28 & Perda da integridade estrutural & $3.90 \mathrm{E}-07$ & 8760 & 0.99659 & 0.99659 & 0.0034106 & 0.0034047 & 0.00000581599075 & $\mathrm{C}$ & II & $\mathbf{M}$ \\
\hline & OREDA & 29 & Pequeno vazamento & $4.31 \mathrm{E}-06$ & 8760 & 0.96295 & 0.96295 & 0.0370517 & 0.0363567 & 0.00068633430738 & $\mathrm{D}$ & II & $\mathbf{M}$ \\
\hline & OREDA & 30 & Vazamento na posição fechada & $7.40 \mathrm{E}-07$ & 8760 & 0.99354 & 0.99354 & 0.0064614 & 0.0064405 & 0.00002087499526 & $\mathrm{C}$ & II & $\mathbf{M}$ \\
\hline \multirow{3}{*}{ Válvula de globo } & OREDA & 31 & Pequeno vazamento & $1.94 \mathrm{E}-06$ & 8760 & 0.98315 & 0.98315 & 0.0168508 & 0.0167080 & 0.00014197147760 & $\mathrm{D}$ & II & $\mathbf{M}$ \\
\hline & OREDA & 32 & Perda da integridade estrutural & $3.90 \mathrm{E}-07$ & 8760 & 0.99659 & 0.99659 & 0.0034106 & 0.0034047 & 0.00000581599075 & $\mathrm{C}$ & II & $\mathbf{M}$ \\
\hline & OREDA & 33 & Vazamento na posição fechada & 9.70E-07 & 8760 & 0.99154 & 0.99154 & 0.0084612 & 0.0084253 & 0.00003579574438 & $\mathrm{C}$ & II & $\mathbf{M}$ \\
\hline \multirow{3}{*}{ Riser (400 mm) } & HSE & 34 & $\begin{array}{l}\text { Trinca na tubulação de } 4 \mathrm{~mm} \text { em } \\
\text { tubulações entre } 300 \text { e } 499 \mathrm{~mm}\end{array}$ & $9.13 \mathrm{E}-09$ & 8760 & 0.99992 & 0.99992 & 0.0000800 & 0.0000799 & 0.00000000319609 & B & II & NC \\
\hline & HSE & 35 & $\begin{array}{l}\text { Ruptura de } 1 / 3 \text { de dia. da tubulação } \\
\text { em tubulações entre } 300 \text { e } 499 \mathrm{~mm}\end{array}$ & $2.28 \mathrm{E}-09$ & 8760 & 0.99998 & 0.99998 & 0.0000200 & 0.0000200 & 0.00000000019977 & B & IV & M \\
\hline & HSE & 36 & $\begin{array}{l}\text { Guilhotina em tubulações entre } 300 \\
\text { e } 499 \mathrm{~mm}\end{array}$ & 7.99E-10 & 8760 & 0.99999 & 0.99999 & 0.0000070 & 0.0000070 & 0.00000000002447 & A & IV & M \\
\hline \multirow{2}{*}{ Separador } & OREDA & 37 & Perda da integridade estrutural & $1.83 \mathrm{E}-05$ & 576 & 0.98952 & 0.98952 & 0.0104797 & 0.0104246 & 0.00005491197605 & $\mathrm{D}$ & II & M \\
\hline & OREDA & 38 & Pequeno vazamento & $5.53 \mathrm{E}-05$ & 576 & 0.96867 & 0.96867 & 0.0313285 & 0.0308326 & 0.00049069681967 & $\mathrm{D}$ & II & $\mathbf{M}$ \\
\hline \multirow{3}{*}{$\begin{array}{c}\text { Tubulações } \\
\text { secundárias } \\
\text { (400 mm) }\end{array}$} & HSE & 39 & $\begin{array}{l}\text { Trinca na tubulação de } 4 \mathrm{~mm} \text { em } \\
\text { tubulações entre } 300 \text { e } 499 \mathrm{~mm}\end{array}$ & $9.13 \mathrm{E}-09$ & 8760 & 0.99992 & 0.99992 & 0.0000800 & 0.0000799 & 0.00000000319609 & B & II & $\mathrm{NC}$ \\
\hline & HSE & 40 & $\begin{array}{l}\text { Ruptura de } 1 / 3 \text { de dia. da tubulação } \\
\text { em tubulações entre } 300 \text { e } 499 \mathrm{~mm}\end{array}$ & $2.28 \mathrm{E}-09$ & 8760 & 0.99998 & 0.99998 & 0.0000200 & 0.0000200 & 0.00000000019977 & B & IV & M \\
\hline & HSE & 41 & $\begin{array}{l}\text { Guilhotina em tubulações entre } 300 \\
\text { e } 499 \mathrm{~mm}\end{array}$ & 7.99E-10 & 8760 & 0.99999 & 0.99999 & 0.0000070 & 0.0000070 & 0.00000000002447 & A & IV & M \\
\hline \multirow{3}{*}{$\begin{array}{c}\text { Tubulação primária } \\
(600 \mathrm{~mm})\end{array}$} & HSE & 42 & $\begin{array}{l}\text { Trinca na tubulação de } 4 \mathrm{~mm} \text { em } \\
\text { tubulações entre } 500 \text { e } 1000 \mathrm{~mm}\end{array}$ & 7.99E-09 & 576 & 1.00000 & 1.00000 & 0.0000046 & 0.0000046 & 0.00000000001058 & A & II & NC \\
\hline & HSE & 43 & $\begin{array}{l}\text { Ruptura de } 1 / 3 \text { de dia. da tubulação } \\
\text { em tubulações entre } 500 \text { e } 1000 \mathrm{~mm}\end{array}$ & $1.14 \mathrm{E}-09$ & 576 & 1.00000 & 1.00000 & 0.0000007 & 0.0000007 & 0.00000000000022 & A & IV & M \\
\hline & HSE & 44 & $\begin{array}{l}\text { Guilhotina em tubulações entre } 500 \\
\text { e } 1000 \mathrm{~mm}\end{array}$ & 4.56E-10 & 576 & 1.00000 & 1.00000 & 0.0000003 & 0.0000003 & 0.00000000000003 & A & IV & M \\
\hline \multirow{3}{*}{ Válvula de alívio } & OREDA & 45 & Perda da integridade estrutural & $8.50 \mathrm{E}-07$ & 8760 & 0.99258 & 0.99258 & 0.0074183 & 0.0073908 & 0.00002751581060 & $\mathrm{C}$ & II & M \\
\hline & OREDA & 46 & Pequeno vazamento & $3.00 \mathrm{E}-06$ & 8760 & 0.97406 & 0.97406 & 0.0259377 & 0.0255984 & 0.00033636241901 & $\mathrm{D}$ & II & $\mathbf{M}$ \\
\hline & OREDA & 47 & Vazamento na posição fechada & $2.62 \mathrm{E}-06$ & 8760 & 0.97731 & 0.97731 & 0.0226898 & 0.0224304 & 0.00025740277214 & $\mathrm{D}$ & II & M \\
\hline \multirow{3}{*}{ Compressor } & OREDA & 48 & Perda da integridade es trutural & $1.64 \mathrm{E}-05$ & 576 & 0.99059 & 0.99059 & 0.0094133 & 0.0093689 & 0.00004430510338 & $\mathrm{C}$ & II & M \\
\hline & OREDA & \begin{tabular}{|l|}
49 \\
\end{tabular} & Pequeno vazamento & $8.15 \mathrm{E}-06$ & 576 & 0.99532 & 0.99532 & 0.0046834 & 0.0046724 & 0.00001096709074 & $\mathrm{C}$ & II & $\mathbf{M}$ \\
\hline & OREDA & 50 & Não parar quando requisitado & $6.91 \mathrm{E}-06$ & 576 & 0.99603 & 0.99603 & 0.0039722 & 0.0039643 & 0.00000788937327 & $\mathrm{C}$ & IV & C \\
\hline Válvula antiretorno & OREDA & 51 & Todos os modos de falha & $1.46 \mathrm{E}-06$ & 8760 & 0.98729 & 0.98729 & 0.0127082 & 0.0126271 & 0.00008074757258 & $\mathrm{D}$ & II & $\mathbf{M}$ \\
\hline Manifold & OREDA & 52 & Todos os modos de falha & $2.27 \mathrm{E}-05$ & 576 & 0.98703 & 0.98703 & 0.0129673 & 0.0128829 & 0.00008407488872 & $\mathrm{D}$ & II & M \\
\hline
\end{tabular}




\subsubsection{Elaboração da Matriz de Risco}

Para a elaboração da Matriz de Risco foram consideradas duas variáveis, a frequência e a consequência de ocorrência de cada modo de falha dos componentes que pertencem ao sistema de carga e descarga do GNL. Na Tabela 5.26 é apresentada a matriz de risco para os componentes do sistema de carga e descarga do GNL, e na Tabela 5.27 é apresentada a matriz de risco para os componentes do sistema de descarga do boil-off.

Tabela 5.26 - Matriz de risco para os componentes do sistema de carga e descarga do GNL

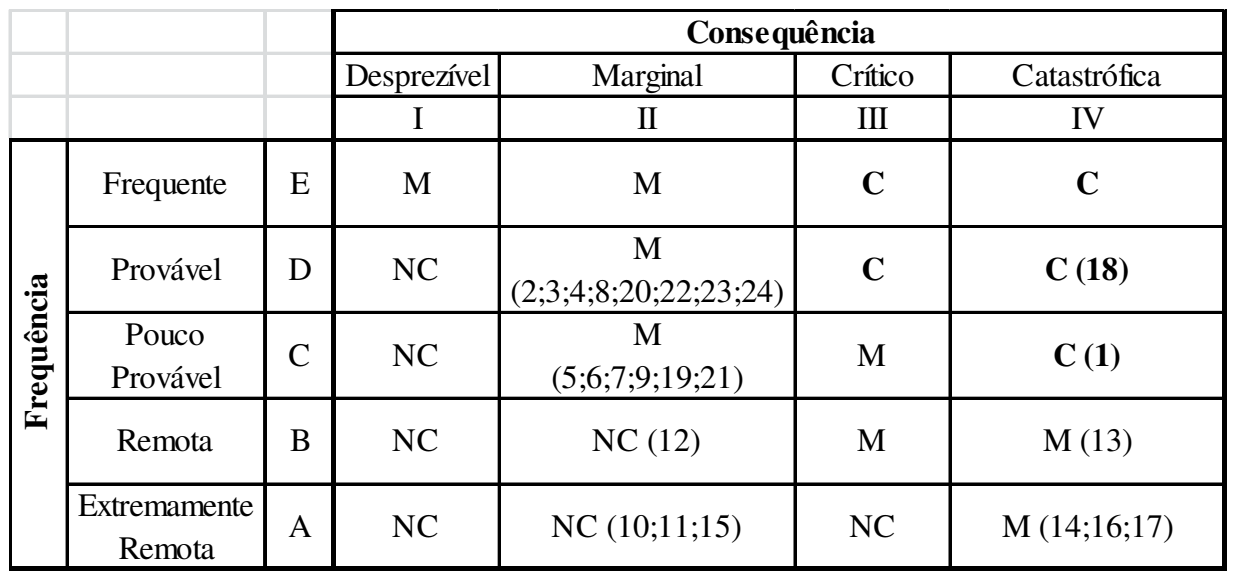

$\mathrm{Na}$ Tabela 5.26 foram encontrados quatro modos de falha considerados como Não Críticos, 18 modos de falha considerados como Moderado e dois modos de falha onde o risco foi considerado Crítico. Estes modos de falha críticos são o modo de falha 1 (não parar a bomba criogênica quando requisitado) na bomba e o modo de falha 18 (não fechar a válvula de emergência quando requisitado).

Tabela 5.27 - Matriz de risco para os componentes do sistema de descarga do boil-off

\begin{tabular}{|c|c|c|c|c|c|c|}
\hline & & & \multicolumn{4}{|c|}{ Consequência } \\
\hline & & & Desprezível & Marginal & Crítico & Catastrófica \\
\hline & & & $\mathrm{I}$ & II & III & IV \\
\hline \multirow{5}{*}{ 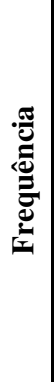 } & Frequente & $\mathrm{E}$ & M & M & $\mathbf{C}$ & C \\
\hline & Provável & $\mathrm{D}$ & $\mathrm{NC}$ & $\begin{array}{c}\mathrm{M} \\
(27 ; 29 ; 31 ; 37 ; 38 ; 46 ; 47 ; 51 ; 52)\end{array}$ & C & $\mathrm{C}(25)$ \\
\hline & $\begin{array}{c}\text { Pouco } \\
\text { Provável } \\
\end{array}$ & $\mathrm{C}$ & $\mathrm{NC}$ & $\begin{array}{c}\mathrm{M} \\
(26 ; 28 ; 30 ; 32 ; 33 ; 45 ; 48 ; 49) \\
\end{array}$ & M & $\mathrm{C}(\mathbf{5 0})$ \\
\hline & Remota & B & $\mathrm{NC}$ & NC $(34 ; 39)$ & M & M $(35 ; 40)$ \\
\hline & $\begin{array}{l}\text { Extremamente } \\
\text { Remota }\end{array}$ & A & $\mathrm{NC}$ & $\mathrm{NC}(42)$ & $\mathrm{NC}$ & M $(36 ; 41 ; 43 ; 44)$ \\
\hline
\end{tabular}


Na Tabela 5.27 foram encontrados três modos de falha considerados como Não Críticos, 23 modos de falha considerados com risco Moderado e dois modos de falha foram considerados como Críticos. Estes dois modos de falha pertencem ao modo de falha 25 (não fechar a válvula de emergência quando requisitado) e o modo de falha 50 (não parar o compressor quando requisitado).

Ressalta-se que para a elaboração da Matriz de Risco considerou-se o cenário de falha com consequências mais graves para o sistema em análise, de acordo com os resultados do Diagrama Causa-Consequência apresentado na Figura 5.40.

\subsection{Passo 4 - Recomendações e Conclusões Finais}

De acordo com CETESB (2012), os fluidos criogênicos podem solidificar ou condensar outros gases. Isso significa que a água poderá congelar no caso de ter contato com a substância criogênica, e se isso ocorrer próximo de, por exemplo, uma válvula de controle de fluxo, esta apresentará dificuldade para a realização de manobras de abertura ou fechamento. Sendo assim, não se deve jogar água diretamente sobre as válvulas porque elas podem ficar travadas.

Quando da ocorrência de uma falha grave nos tanques de armazenamento primários e secundários existe um procedimento de emergência que consiste no descarregamento do GNL para o mar pelo manifold do navio, já que isto se constitui no último recurso visando evitar a redução da temperatura do casco do navio, que poderia ocasionar grave falha estrutural. Este procedimento é feito utilizando uma das bombas de descarga, porque não se deve jogar o GNL com muita rapidez, devido a possibilidade de ocorrer uma transição rápida de fase. É recomendável que antes de realizar este procedimento a tripulação avalie todas as condições atmosféricas, como a direção do vento, para que dessa maneira o GNL se afaste do navio na direção do vento. Também todos os equipamentos de combate de fogo devem estar prontos para serem utilizados caso ocorra um incêndio.

Os navios em geral estão submetidos às condições climáticas da área do terminal de liquefação ou regaseificação. Preferencialmente as operações de carga ou descarga de GNL devem ser feitas somente quando as condições climatológicas sejam ótimas para evitar um cenário de perigo que possa causar a colisão do navio com o terminal ou a possibilidade de ocorrência de danos nos braços criogênicos do terminal. 
Deve-se prestar muita atenção nas atividades prévias às operações de carga e descarga do GNL já que elas cumprem um papel importante para evitar condições de perigo quando se trata do manuseio do GNL no interior do navio. A inertização é importante porque visa diminuir a quantidade de oxigênio dentro dos circuitos de carga e descarga fazendo com que a quantidade de oxigênio dentro do sistema seja de $2 \%$ em volume. Por outro lado, o processo de resfriamento evitará a formação de boil-off de maneira excessiva, evitando também a mudança brusca de temperatura dentro do circuito de GNL, que poderia causar trincas nas válvulas. Durante as atividades de inertização e de resfriamento não devem ocorrer vazamentos de GNL ou de boil-off.

Recomenda-se que uma quantidade de GNL permaneça no interior dos tanques para conseguir que a temperatura interna seja sempre baixa, visando manter uma temperatura inferior a do ambiente externo.

É recomendável que, no inicio do processo de carga/descarga de GNL a vazão da carga seja feita a uma taxa consideravelmente inferior à vazão de operação normal do processo. Isso permitirá inspecionar a existência de vazamentos de GNL ou de boil-off nos respectivos circuitos. Essa inspeção também deve ser feita durante todo o processo de inertização e resfriamento do sistema de carga e descarga do GNL. Sob nenhuma circunstância deverá ser realizado o processo da carga ou descarga se houver algum vazamento de GNL, mesmo que este seja de baixo volume. Deve se ativar o procedimento de emergência que provocará a paralisação da transferência de GNL.

As tarefas de inspeção em tanques integrados são mais complexas quando comparada com navios independentes devido à acessibilidade, porém um bom controle de qualidade nos processos de soldagem nas placas do tanque durante a fabricação é uma tarefa de prevenção recomendada.

Segundo Souza et al. (2012), mesmo que a probabilidade de ocorrência de uma trinca na tubulação principal de GNL seja muito baixa, devem ser consideradas tarefas periódicas de inspeção das mesmas, para identificar alguma trinca que possa causar o rompimento da tubulação. Ante qualquer vazamento as barreiras de proteção devem estar prontas para atuar, interrompendo a operação de carga/descarga. 
É recomendável que durante a operação de carga ou descarga do GNL sempre jogue-se água na parte do casco que está abaixo da conexão manifold, isto servirá como uma medida para proteger o próprio casco do navio das baixas temperaturas do GNL.

Antes de realizar a carga ou descarga do GNL deve-se comprovar a operacionalidade dos sistemas envolvidos na realização das operações mencionadas. Deve-se verificar o correto funcionamento das válvulas dos circuitos de GNL e de boil-off, principalmente as válvulas ativadas pelo ESD, ativando manualmente cada uma delas. Sugere-se também verificar a operabilidade das bombas manuais de emergência que serão utilizadas no caso da falha do acionamento automático das válvulas do circuito. $\mathrm{O}$ sistema de alarmes também deve ser testado antes de efetuar as atividades de carga e descarga do GNL.

Recomenda-se que as bombas de descarga do GNL nunca funcionem a seco, inclusive durante períodos curtos de tempo, pois isso pode provocar a falha do motor da bomba. Caso as duas bombas submersas em cada tanque falhem, dever-se-á instalar a bomba de emergência, seguindo o procedimento estabelecido pela tripulação do navio.

Os materiais utilizados nos componentes dos circuitos são projetados para suportar as baixas temperaturas próprias da substância transportada, mas variação de temperatura é um problema, já que ao longo da sua vida operacional o material sofre processos de contração e dilatação que provocarão trincas do material, mesmo que ele esteja projetado de acordo com os requisitos para suportar baixas temperaturas. Os materiais não projetados para suportar as baixas temperaturas, por exemplo, a estrutura do navio, podem tornar-se frágeis. Assim, um vazamento de grande porte poderia danificar a estrutura do navio e causar a perda da integridade estrutural.

Tanto os geradores de energia elétrica quanto os transformadores devem estar disponíveis quando requisitados. Recomenda-se implementar planos de manutenção que permitam realizar as tarefas que reduzam a degradação da confiabilidade dos mesmos. Sugere-se também realizar análise de óleo dos transformadores, permitindo determinar o estado desses componentes, e em caso de necessidade de manutenção haja tempo suficiente para tomar as medidas correspondentes. Também deve ser verificada a operabilidade do controlador automático que ligará os geradores elétricos.

Os conjuntos de baterias internos dos UPS's no sistema de alimentação de energia 230 VAC devem ser testados periodicamente, visando comprovar a operacionalidade dos mesmos. 
Para ter uma longa vida das baterias recomenda-se também que a descarga das mesmas não seja muito profunda, porque isso diminui o seu tempo de vida (NASIRI, 2007).

No sistema de amostragem de gás estão instalados 2 vacuostátos (do inglês - vacuum switch), um deles é usado para o teste de vazamento interno e o outro para detectar a falta de fluxo nas bombas de sucção. Sugere-se que o primeiro teste de vazamento interno seja desenvolvido cada 24 horas. Este teste consiste em fechar todas as válvulas solenoide e ativar as bombas de sucção. Se este vacuostáto é ativado se comprovará a integridade de todas as tubulações, válvulas, bombas, e também do próprio vacuostáto. Um alarme na sala de controle da carga se ativará caso o vacuostáto não seja ativado durante o teste. O segundo teste consiste na ativação do vacuostáto das bombas de sucção quando a tubulação que vem dos pontos de amostragem está bloqueada. Isso causará que as bombas parem e comece o processo de desbloqueio da linha bloqueada. Este processo de desbloqueio consiste em purgar a linha de amostragem bloqueada com ar seco pressurizado por 15 segundos a fim de eliminar o bloqueio da linha. A bomba de sucção é ativada novamente tentando obter uma nova amostragem. Se a falha persistir, o ponto de amostragem é desligado automaticamente, gerando-se um alarme de ponto bloqueado que precisa ser checado pelo pessoal correspondente, ativando-se nesse momento o alarme de falta de fluxo na bomba de sucção na sala de controle da carga. Este sistema deve operar corretamente o tempo todo, já que ele tem a função de detectar a presença de gás.

As baterias dos equipamentos portáteis, por exemplo, os detectores portáteis, nunca devem ser substituídas nas áreas de influência do gás, devido ao perigo potencial de acontecer uma descarga elétrica.

Drapinski (1975) e Hidalgo (2010), afirmam que uma vida prolongada do equipamento hidráulico é conseguida através de condições de limpeza e lubrificação adequadas e posteriormente com inspeções e ajustes periódicos, eliminando-se desalinhamento e folgas. Como uma recomendação destes autores o óleo hidráulico deve ser trocado cada 2000 horas (84 dias). Também o óleo hidráulico e os filtros devem ser trocados após o reparo de qualquer componente principal do sistema hidráulico. O nível do óleo deve ser conferido com frequência, não deixando faltar nem sobrar óleo, esta inspeção visual deve ser feita periodicamente. Os mesmos autores indicam para a manutenção preventiva de válvulas em geral, a providência principal é evitar a penetração de sujeira, o super-aquecimento e os vazamentos. 
Componentes tais como as tubulações ou a barreira primária do tanque podem ser analisados utilizando os conceitos de mecanismos de fratura linear elástica para calcular o número de ciclos que fariam com que uma fissura possa tornar-se trinca passante e causar vazamento de GNL. A propagação de trinca em tubulações está associada com as cargas cíclicas induzidas pela mudança de temperatura ao longo da vida operacional. Recomendamse tarefas de inspeção estrutural durante a vida toda do navio e testes de pressão no sistema de tubulações para determinar a sua integridade. Especial cuidado deve ser tomado durante o reparo por soldagem visando a não introdução de novos defeitos após a intervenção. 


\section{CONCLUSÕES}

\subsection{Conclusões}

Em primeiro lugar pode-se concluir que o método desenvolvido para a avaliação de risco das operações de carga e descarga de GNL nos seus respectivos circuitos mostra-se apropriado para a determinação de quais são os componentes cuja falha geram maior risco. Ressalta-se a importância de seguir o fluxograma proposto na Figura 4.1 mostrando a sequência das atividades que permitem fazer a análise detalhada, pois são utilizadas em ordem lógica e organizada, para que o método seja aplicado corretamente.

Vale ressaltar a importância do passo 1 do método proposto, que permite caracterizar o sistema sob análise. Este passo envolve a elaboração da Descrição Funcional e da Árvore Funcional dos equipamentos que fazem parte do sistema. Por meio da utilização da Árvore Funcional obtém-se o conhecimento da função de cada componente do sistema de carga e descarga de GNL, e a importância de cada um deles para o desempenho do sistema. Já a elaboração da Descrição Funcional complementa o desenvolvimento da Árvore Funcional.

Verificou-se a utilidade da aplicação da Análise Preliminar de Perigos para determinar quais são as causas que fazem com que o GNL ou o boil-off vazem dos seus respectivos circuitos e entrem em circuitos que não foram projetados para abrigar essas substâncias durante o processo de carga ou descarga. Também foi possível identificar as barreiras de proteção que estão destinadas a conter o evento iniciador de perigo. Com esses dados foi possível o desenvolvimento do Diagrama Causa-Consequência, elaborado de forma paralela no passo 2 do método proposto.

O diagrama Causa-Consequência possibilitou a definição dos cenários de falha associados com a ocorrência de um dado evento de perigo. Conclui-se que o Diagrama CausaConsequência permitiu identificar os possíveis cenários caso aconteça um vazamento de GNL e de boil-off. A análise quantitativa do DCC permitiu determinar que a probabilidade do Cenário 1 foi mais elevada, o que significa que existe uma grande chance de detectar algum comportamento anômalo que permita interromper o processo de carga e descarga do GNL, impedindo a ocorrência de algum tipo de acidente. Mesmo que falhem as barreiras de proteção devem ser considerados outros fenômenos que estão relacionados com as condições ambientais. Nesse sentido, se as barreiras de proteção falharem e não ocorrerem condições 
ambientais específicas, também não acontecerá nenhum acidente, representando o Cenário 4. O Cenário 5 considera também a falha das barreiras de proteção, mas pelo fato de ser um pequeno vazamento não se formaria a nuvem de gás, e sim se produziria a geração de uma capa de gelo superficial. Finalmente, os Cenário 2 e 3, são os piores cenários, mas estes cenários tem uma baixa probabilidade de ocorrência. Estes cenários consideram a falha de todas as barreiras de proteção e também consideram a ocorrência de certas condições que permitem existir um acidente como incêndio ou explosão.

Foram feitas as Árvores de Falhas das barreiras de proteção para poder determinar a confiabilidade das mesmas, considerando um tempo operação de cinco anos. Os dados da confiabilidade e da probabilidade de falha serviram para alimentar o Diagrama CausaConsequência e poder determinar quantitativamente a probabilidade de ocorrência dos cenários identificados.

Pela quantidade de GNL que está armazenado dentro dos tanques, caso ocorra alguma falha dos componentes dos circuitos que permita o vazamento do fluido, pode haver dano parcial ou total na estrutura do navio. Assim, é que cada um dos quatro tanques criogênicos de armazenamento conta com um tanque secundário que impedirá que o GNL entre em contato com a estrutura do navio, danificando-a. Outro componente que pode causar um grande vazamento em caso de falha é a tubulação principal, tanto de GNL quanto de boil-off, dado que nelas as tubulações secundárias descarregam os seus produtos. A falha das mesmas paralisa por completo o processo de carga/descarga.

Todo o processo de carga e descarga é monitorado e controlado pelo sistema de controle da carga SCC, sendo que este é a base de controle da operação de carga/descarga. Todas as válvulas, inclusive as que pertencem ao ESD, são operadas pelo Sistema de Controle da Carga. Portanto, este sistema não pode ficar sem alimentação elétrica durante a operação do navio, sendo por isso que a confiabilidade deste sistema é muito alta, devido à presença de elementos redundantes, e no último dos casos, da presença dos UPS's que são a última fonte de energia elétrica, caso falhem todas as fontes de energia utilizadas, as quais estão associadas com a geração de energia para o navio.

Existem um sistema de amostragem e um sistema de detecção de gases que trabalham de maneira independente, um deles monitora as zonas de armazenamento do GNL e o outro as áreas habitadas. No caso de detectar-se algum vazamento de gás natural um alarme é ativado 
na Sala de Controle da Carga e em diferentes lugares do navio. Ao longo do tempo a confiabilidade do sistema de amostragem cai é por essa razão que este sistema deve ser testado periodicamente para assegurar o seu correto funcionamento.

Conclui-se que o valor da confiabilidade do sistema hidráulico de fechamento das válvulas de paralisação de emergência e baixo e, se deve, por um lado aos valores elevados da taxa de falha do atuador hidráulico e da válvula solenoide e por outro lado à configuração em série que eles têm, já que não se poderá permitir que o navio fique com uma falha em qualquer uma das válvulas de paralisação de emergência, devendo, portanto estar em perfeitas condições todos os acionamentos e atuadores das válvulas do sistema de paralisação de emergência (ESD).

Na sequência foi realizada a Análise de Risco onde pode-se concluir que os modos de falha considerados como críticos no circuito de GNL são o modo de falha 1 (não parar a bomba criogênica quando requisitado) e o modo de falha 18 (não fechar a válvula de emergência quando requisitado). Os modos de falha considerados como críticos no circuito de boil-off foram o modo de falha 25 (não fechar a válvula de emergência quando requisitado) e o modo de falha 50 (não parar o compressor quando requisitado). Estes modos de falha acontecem dado o não funcionamento do sistema de paralisação de emergência, daí a importância das barreiras de proteção.

A matriz de risco apresentou-se útil para classificar cada um dos modos de falha e categorizá-los de acordo com o nível de risco.

Ante a ocorrência de um vazamento, a chance de ocorrência de um acidente é fortemente dependente do correto funcionamento das barreiras de proteção, já que elas quando detectam algum parâmetro incorreto enviam sinais para fechar as válvulas de emergência conseguindo paralisar o processo de carga e descarga do GNL.

Conclui-se que de todos os acidentes ocorridos na história do transporte do GNL por meio de navios (alguns deles apresentados no Anexo I), não houve perda total da carga transportada, relacionada aos vazamentos. Existiram sim, eventos que foram controlados pela ativação das barreiras de proteção após a ocorrência de um vazamento, evitando que os vazamentos tivessem consequências muito graves, demostrando que as barreiras de proteção são equipamentos de vital importância durante toda a vida operacional do navio transportador de GNL. As barreiras de proteção tem a função de detectar algum evento de perigo 
relacionado ao vazamento para poder efetuar ações de emergência visando interromper a sequência acidental do evento iniciador.

O método proposto neste estudo identificou uma série de eventos iniciadores de um vazamento de GNL. Muitos dos eventos identificados foram os causadores de acidentes com navios de GNL, como os indicados no Anexo I. Desta forma pode-se verificar a validade do método proposto para estudar os possíveis acidentes envolvendo operações de carga e descarga de GNL em terminais portuários.

A dificuldade da aplicação deste método foi estruturar numa sequência lógica todos os eventos intermediários desde a ocorrência do evento iniciador até o cenário final da falha. Estudar os eventos intermediários foi possível pelo conhecimento dos sistemas que operam no navio e a determinação dos valores quantitativos pela utilização de base de dados disponíveis na literatura, já que não se tem uma base de dados relacionada ao transporte e manuseio de GNL em particular.

\subsection{Considerações para Trabalhos Futuros}

O método proposto nesta dissertação pode ser utilizado para analisar o risco de qualquer outro sistema empregado em instalações industriais.

É preciso que seja feito o levantamento dos dados reais das taxas de falha dos componentes estudados nesta dissertação para calcular a probabilidade de falha do sistema, permitindo calcular as categorias de risco com os dados reais, já que para a análise quantitativa desta dissertação foi utilizada base de dados disponíveis na literatura. Para isso se deve ter um histórico de falhas para poder classificar, cada uma destas e fazer um seguimento da frequência com que elas ocorrem durante certo período de tempo.

Alguns componentes dos sistemas analisados nesta dissertação poderiam ser submetidos a testes de confiabilidade visando determinar um valor experimental da taxa de falha, mas a dificuldade é que nem todos poderiam passar por esse processo devido às condições reais de operação com que eles operam. Conhecendo o tipo de distribuição que rege o comportamento dos componentes será possível colocar a taxa de falha na distribuição de Poisson ou outra que considere valores de taxa de falha variáveis no tempo para calcular a probabilidade de ocorrência. Da mesma forma determinar-se as taxas de falha dos componentes que formam parte das barreiras de proteção para calcular a confiabilidade das mesmas. 
Propõe-se como trabalhos futuros, a implementação de uma estratégia de manutenção, que leve em consideração os custos de manutenção e o risco para obter o tempo ótimo de intervenção do equipamento. Esta determinação desse tempo deve ser analisada com muito cuidado, dado que trata-se de componentes que manuseiam produtos inflamáveis.

Poderia ser realizada a análise de confiabilidade do sistema de carga e descarga do GNL, para determinar qual é a probabilidade do sistema operar durante o período de carga e descarga do gás natural liquefeito, dado que o navio está pronto para realizar essas operações no terminal de liquefação e de regaseificação.

No Diagrama Causa-Consequência foi colocada uma probabilidade de ocorrência de 0,5 para os eventos que estão relacionados com as condições ambientais, quantidade de GNL derramado, condições de inflamabilidade do gás e presença ou não de fontes de ignição. Estes eventos poderiam ser estudados com maior detalhe com o intuito de fornecer estimativas de valores de probabilidade de ocorrência dos mesmos, os quais podem ser obtidos de simulações, ou do estudo de referências bibliográficas.

Adicionalmente pode-se realizar um estudo de confiabilidade visando à determinação da probabilidade de ocorrência de vazamento de GNL durante a operação de carga e/ou descarga. Dessa forma pode-se definir a probabilidade de ocorrência do evento inicial do Diagrama Causa-Consequência proposto neste estudo. 


\section{REFERÊNCIAS BIBLIOGRÁFICAS}

ABDELFATAH, M.; EL-SHIMY, M. ISMAIL, H.M. Reliability analysis of 220 kV power transformers in Egypt. Ain Shams Engineering Journal 2, p. 183-194, 2011.

ABS. American Bureau of Shipping. ABS Consulting. Consequence Assessment Methods for Incidents Involving Releases from Liquefied Natural Gas Carriers. GEMS 1288209 131-04, report for the Federal Energy Regulatory Commission under contract number FERC04C40196, 2004

ABS. American Bureau of Shipping. Guidance notes on Risk Assessment Applications for the Marine and Offshore Oil and Gas Industries. June 2000.

ABS. American Bureau of Shipping. Surveys during construction of membrane tank LNG carriers. June 2008.

ALENCAR, L. Metodologias de análise de riscos APP \& HAZOP 2005. Disponível em:<http://professor.ucg.br/SiteDocente/admin/arquivosUpload/13179/material/APP_e_HAZ OP.pdf>. Acesso em: 22 feb. 2011.

ALVAREZ, J.M.S. Sistema de medida y control de una estación de descarga y regasificacion de metaneiros. 2009. 172pp. Projecto de fin de Carrera de Ingeniería Técnica Naval, para la obtención del título de Ingeniero Técnico Naval, especialidad en Propulsión y Servicios del Buque, Universidad de Cádiz, España, 2009

ANDREWS, J.D.; RIDLEY, L.M. Application of the cause-consequence diagram method to static systems. Reliability Engineering and System Safety 75. p. 47 - 58, 2002.

ANP. Agência Nacional do Petróleo, Gás Natural e Bicombustíveis. O gás natural liquefeito no Brasil. Boletim Mensal do Gás Natural. Superintendência de Comercialização e Movimentação de Petróleo, seus Derivados e Gás Natural - SCM. Número 14. Rio de Janeiro 2010.

BAI, Y. et al. Risk Based Inspection (RBI) for subsea equipments. Proceedings of the ASME $201029^{\text {th }}$ International Conference on Ocean, Offshore and Arctic Engineering. OMAE 2010, Shanghai, China. 2010

BEZERRA, C.L. Avaliação de riscos em desenvolvimento de software. Dissertação de Mestrado apresentada à Escola de Administração da Universidade Federal do Rio Grande do Sul, Porto Alegre, 151p, 2004.

BP. British Petroleum. BP Statistical Review of World Energy 2010. Base de dados. Disponível em: <http://www.bp.com>. Acesso em: 05 mar. 2010.

BS. British Standard. Installation and equipment for liquefied natural gas - Design of onshore installations. BS EN 1473:2007, 2007.

CALIFORNIA SENATE OFFICE OF RESEARCH. Liquefied Natural Gas: What is LNG? And What is proposed for California? September 2008. Disponível em: $<$ http://www.sor.govoffice3.com/>. Acesso em 20 ago. 2011 
CARAZAS, F.J.G. Decisões baseadas em Risco-Método aplicado na indústria de geração de energia elétrica para a seleção de equipamentos críticos e políticas de manutenção. Dissertação de Doutorado apresentada à Escola Politécnica da Universidade de São Paulo, São Paulo, 2011.

CCPS-AIChE. CENTER FOR CHEMICAL PROCESS SAFETY OF THE AMERICAN INSTITUTE OF CHEMICAL ENGINEERS. Guidelines for Hazard Evaluation Procedures. $3^{\text {rd }}$ ed. New York, 2008.

CETESB. Companhia Ambiental do Estado de São Paulo. Emergências Químicas - Líquidos Criogênicos. Disponível em: < http://www.cetesb.sp.gov.br/gerenciamento-de-riscos/An?lisede-Risco-Tecnol?gico/27-L\%C3\%ADquidos-Criog\%C3\%AAnicos>. Acesso em: 09 feb. 2012.

CH IV International. Safety History of International LNG Operations. December 2006. Technical Document TD-02109. Disponível em: <http://www.ch-iv.com/>. Acesso em: 15 out. 2010.

CHANG, D.; RHEE, T.; NAM, K; CHANG, K.; LEE, D.;JEONG, S. A study on availability and safety of new propulsion systems for LNG carriers. Reliability Engineering and System Safety 93. p. 1877-1885, 2008.

CONSILIUM a. The Salwico GS3000 Fixed Gas Detection System. Disponível em: <http://www.consilium.se/products/>. Acesso em: 12 jun. 2012.

CONSILIUM b. The Salwico SW2020 Fixed Gas Sampling System. Disponível em: <http://www.consilium.se/products/>. Acesso em: 06 jun. 2012.

CSChE. Canadian Society for Chemical Engineering. ISBN $\mathrm{N}^{\circ}$ 0-920804-92-6. Risk Assessment-Recommended Practices for Municipalities and Industry. 2004.

DITALI, S.; FIORE, R. A realistic assessment of LNG hazard and consequences of release scenarios. Health, Safety \& Environment - Design, Snamprogetti SpA Viale de Gasperi, Italy, 2007.

DNV. Det Norske Veritas. Part 5 Chapter 5: Liquefied gas carriers. Rules for classification of ships. 2011.

DOE. Department of Energy. Liquefied Natural Gas: Understanding the Basic Facts. DOE/FE-0489. 2005.

DORIGONI, S.; GRAZIANO, C; PONTONI, F. Can LNG increase competitiveness in the natural gas market?. Energy Policy 38. p. 7653-7664, 2010.

DRAPINSKI, J. Hidráulica e Pneumática Industrial e móvel. $1^{\circ}$ ed. São Paulo: McGrawHill do Brasil, p 287, 1975.

EIA. Energy Administration Information. Use of natural gas. Disponível em: $<$ http://www.eia.gov/energyexplained/index.cfm?page=natural_gas_use $>$. Acesso em 11 out. 2011.

EIA. U.S. Energy Information Administration. DOE/EIA-0637 (2003). The Global Liquefied 
Natural Gas Market: Status \& Outlook. Disponível em: <http://www.eia.doe.gov/>. Acesso em: 06 abr. 2011.

ENAGAS. Empresa Nacional del Gás. Procedimiento de descarga segura de buques. Área: Dirección de Infraestructuras. PF-003-DI 07/2006, 15 pp., 2006

ERICSON, C.A. Hazard Analysis Techniques for System Safety. New Jersey: John Wiley \& Sons, 2005.

FERNANDES, E.; FONSECA, M.V. de A.; ALONSO, P.S.R. Natural gas in Brazil's energy matrix: demand for 1995-2010 and usage factors. Energy Policy, 33, 365-386, 2005.

FORTES, C. Mecânica da fratura 2003. Disponível em: <http://www.esab.com.br/br/por/Instrucao/biblioteca/upload/ApostilaMecanicaFratura.pdf>. Acesso em: 10 nov. 2011.

FUJIYAMA, K. et al.; Risk-based inspection and maintenance systems for steam turbine. International Journal of Pressure Vessels and Piping 81, p. 403-407.2009.

GAMA GASES. Propriedades dos gases. Disponível em: <http://www.gamagases.com.br/propriedades_metano.htm>. Acesso em: 11 out. 2011.

GARVEY, P.R.; LANDSDOWNE, A.F. Risk Matrix: An approach for identifying, assessing and ranking program risks. Air Force Journal of Logistics. V. XXII, N 1. p. 18$22,1998$.

GASNET. $O$ site do gás natural. Disponível em: <http://www.gasnet.com.br/novo_gasnatural/gas_completo.asp>. Acesso em: 13 out. 2011

GE. General Electric. Oil and Gas, Overhung Centrifugal Compressors D Series Single-Stage 2010. Disponível em: <http://www.geenergy.com/content/multimedia/_files/downloads/Overhung\%20Centrifugal\%20Compressors .pdf>. Acesso em: 15 ago. 2011.

GIIGNL. Groupe International des Imporateurs de Gaz Naturel Liquéfié - The International Group of Liquefied Natural Gas Importes.Baseic Properties of LNG. LNG Information Paper $\mathrm{N}^{\circ}$. 1 2008. Disponível em: <http://www.giignl.org/fileadmin/user_upload/pdf/LNG_Safety/1-

LNG_Basics_8.28.09_Final_HQ.pdf>. Acesso em: 12 jul. 2011.

GLOBAL LNG INFO. World's LNG Liquefaction Plants and Regasification Terminals as of March 2011. Disponível em <http://www.globallnginfo.com>. Acesso em: 10 feb. 2011.

GOLAR LNG. Delivering the World's first FSRUs 2009. Disponível em: $<$ http://www.golarlng.com>. Acesso em: 15 out. 2010.

HADDAD, E. Riscos associados aos produtos perigosos 2003. Disponível em: <http://www.bvsde.paho.org/cursode/p/modulos/modulo_1.6.pdf>. Acesso em: 2 set. 2011.

HAIMES, Y.Y. Risk Modeling Assessment and Management. New York: John Wiley and Sons, 1010 p, 1998. 
HARRIS, F.S. Safety feature on LNG ships. Cryogenics 33, p 772-777, 1993.

HIDALGO, E.M.P. Modelo para diagnose de falhas em reguladores de velocidade de turbinas hidráulicas. Dissertação de Mestrado apresentada à Escola Politécnica da Universidade de São Paulo, São Paulo, 177p, 2010.

HIDALGO, E.M.P.; SILVA, D.W.R.; SOUZA, G.F.M. FMEA and FTA analysis applied to the steering system of LNG carriers for the selection of maintenance policies. Proceeding of the $21^{\text {st }}$ Brazilian Congress of Mechanical Engineering. Natal, Brazil, 2011.

HONEYWELL. Detector infravermelho de gás inflamável de caminho aberto. Disponível em: $<$ http://www.honeywellanalytics.com/pt-

PT/gasdetection/principles/Paginas/gasprinciples.aspx>. Acesso em: 02 maio 2012.

HSE. Health and Safety Executive. Failure Rate and Event Data for use within Land Use Planning Risk Assessments 2010. Disponível em: <http://www.hse.gov.uk/landuseplanning/failure-rates.pdf>. Acesso em: 5 jul 2011.

ICS. The International Chamber of Shipping. Tanker Safety Guide Liquefied Gas $2^{\text {nd }}$ Edition. ISBN 0-906270-03-0. 1995.

IEC. International Electrotechnical Commission. Risk Management - Risk Assessment Techniques. IEC/FDIS 31010:2009(E), 2009.

IGC IMO. International Maritime Organization. International Code for the Construction and Equipment of ships Carrying Liquefied Gases in Bulk. 2005 Edition.

IKEDA, N.H; MARTINS, M.R; SOUZA, G.F.M. Análise Preliminar de Perigos aplicada a Navios Transportadores de Gás Natural Liquefeito (GNL). $23^{\circ}$ Congresso Nacional de Transporte Aquaviário, Construção Naval e Offshore. Rio de Janeiro. 2010.

IMO. International Maritime Organization. Formal Safety Assessment FSA - Liquefied Natural Gas (LNG) Carriers. Detail of the Formal Safety Assessment. MSC 83/INF. 3, IMO, 2007.

IMO. International Maritime Organization. Guidelines for Formal Safety Assessment (FSA) for use in the IMO Rule-Making Process. MSC/Circ. 1023-MEPC/Circ.392, IMO, 2002.

JONES, N; TVEITNES, T. The M-FLEX LNG Carrier Design - Creating Value in Three Parts of the LNG Chain 2003. Disponível em <http://www.Ingpedia.com/wpcontent/uploads/lng_floating_offshore_production/The $\% 20 \mathrm{M}$ -

FLEX\%20LNG\%20Carrier\%20Design\%20-\%20Nicholas\%20Jones\%20(FlexLNG).pdf>. Acesso em: 18 mar. 2011.

KARASSIK, I.J.; MESSINA, J.P.; COOPER, P.; HEALD, C.C. Pump Handbook. McGrawHill. 3th Edition, p 1765, 2001.

KECECIOGLU, D. Reliability Engineering Handbook. Prentice Hall, Volume 2, 1991.

KONTOVAS, C.A; PSARAFTIS, H.N. Formal Safety Assessment: A Critical Review. Marine technology 46. p. 45-59, 2009. 
KRISTIANSEN, S. Maritime Transportation - Safety Management and Risk Analysis. 1st Edition, Oxford, Butterworth Heinemann, 2005.

KUTZ, M. Mechanical Engineer's Handbook - Energy and Power. $3^{\text {rd }}$ Edition, John Wiley \& Son, 2006.

LAMB, T. Ship Design and Construction. Volumes 1-2. Society of naval Architects and Marine Engineers (SNAME). pp 2056, 2004.

LEES, F.P. Loss Prevention in the Process Industries. Hazard Identification, Assessment and control. 2nd Edition, London, Butterworth Co., 1996.

LEVESON, N.G. Safeware - System Safety and Computers. Addison Wesley, 1995.

LNG JOURNAL. World LNG Carrier Fleet - January 2010. Disponível em: <http://www.lngjournal.com>. Acesso em: 20 nov. 2010.

LUKETA, A.H. A review of large -scale LNG spills: Experiments and modeling. Journal of Hazardous Materials A132. p 119-140, 2006.

MAERSK. Manual de Operação de Carga.

MARINE TRAFFIC. Disponível em: <http://www.marinetraffic.com/ais/>. Acesso em: 12 mar. 2012.

MARTINS, M.R.; SOUZA, G.F.M.; IKEDA, N.H. Consequence Analysis of a Liquefied Natural Gas Floating Production Storage Offloading (LNG FPSO) Leakage. Proceeding of the ASME $201130^{\text {th }}$ International Conference on Ocean, Offshore and Artic Engineering. OMAE 2001-50268. Rotterdam, The Netherlands. 2011.

MAXWELL, D.; ZHU, Z. Natural gas prices, LNG transport costs, and the dynamics of LNG imports. Energy Economics 33. p. 217-226, 2011.

MELCHERS, R. E. Structural reliability analysis and Prediction. Wiley, 2 edition, 1999.

MICHOT, F.M. Sistemas de Seguridad y Protección de GNL. Center for Energy Economics. The University of Texas at Austin, Houston. USA, Oct, 2003.

MME. Balanço Energético Nacional 2010 ano base 2009. Ministério de Minas e Energia MME. Empresa de Pesquisa Energética - EPE. Disponível em $<$ https://ben.epe.gov.br/downloads/Relatorio_Final_BEN_2010.pdf>. Acesso em: 17 ago. 2011 .

MODARRES, M. What every engineer should know about reliability and risk analysis. Marcel Dekker, EUA, 1993.

MOKHATAB, S.; POE, W. A.; SPEIGHT, J. G. Handbook of Natural Gas Transmission and Processing. 1st Edition, Oxford UK, Gulf Professional Publising, 2006.

NASIRI, A. Chapter 21: Uninterruptible Power Supplies. Published by Elsevier Publishing, 2007. 
NATACCI, F.B.; MARTINS, M.R. Metodologia para análise preliminar de riscos de um navio de transporte de gás natural comprimido, 2009. Disponível em: <http://www.ipen.org.br/>. Acesso em: 5 out. 2011.

NATIONAL ACADEMY OF SCIENCE. Prudent Practices in the Laboratory Handling and Disposal of Chemicals. Washington D.C. 427 pp. 1995.

NATURALGAS. NaturalGas.org. $\quad$ Disponível em <http://www.naturalgas.org/naturalgas/naturalgas.asp>. Acesso em: 02 maio 2010.

NFPA59A. National Fire Protection Association. Standard for the Production, Storage, and Handling of Liquefied Natural Gas (LNG). 2001.

NILSON, F. Risk-based approach to plant life management. Nuclear Engineering and Design 221, p. 293-300. 2003.

NIST. NATIONAL INSTITUTE OF STANDARDS AND TECHNOLOGY. ISD's. Manufacturing Engineering Laboratory. 2008. Disponível em: $<$ http://www.isd.mel.nist.gov/projects/processcontrol/members/documents $>$. Acesso em: 19 de maio 2010.

NPRD. Nonelectric Parts Reliability Data. Reliability Analysis Center, 1995.

O' CONNOR, P.D.T. Practical Reliability Engineering. $2^{\text {nd }}$ Edition. New York: Wiley\&Sons, 500 pp. 1985.

OREDA. Offshore Reliability Data Handbook. 4th Edition - SINTEF Industrial Management, 2002.

PARKER, Hydraulic Rotary Actuators. Catalog HY03-1800/US. 2004. Disponível em: <http://www.parker.com/literature/Literature\%20Files/pneumatic/UPD_2010/HY03-

1800.pdf>. Acesso em: 28 set. 2011.

PETROBRAS NBR 2782. Critérios para Aplicação de Técnicas de Avaliação de Riscos. Rio de Janeiro, 2004.

PETROBRAS NBR 2784. Confiabilidade e Análise de Riscos. Rio de Janeiro, 2005.

PETROTECNIA. Revista del Instituto Argentino del Petróleo y del Gás. World Gas Conference 2009. Disponível em: < http://www.petrotecnia.com.ar/>. Acesso em: 15 out. 2010.

RAMOS, M.A.; MARTINS, M.R., DROGUETT, E.L.; SOUZA, H.P. Quantitative Risk Analysis and Comparison for Onshore and Offshore LNG Terminals: The port of Suape - Brasil Case. Procceding of the ASME $201130^{\text {th }}$ International Conference on Ocean, Offshore and Artic Engineering. OMAE 2001-50268. Rotterdam, The Netherlands. 2011.

RAUSAND, M. Risk Assessment: Theory, Methods, and Applications. New Jersey: John Wiley \& Sons, p 664, 2011.

RAUSAND, M. System Reliability Theory. Models, Statistical Methods, and Applications. 2th Edition, New Jersey: John Wiley \& Sons, p 664, 2004. 
RISKNOLOGY. Independent Risk Assessment of the Proposed Cabrillo Port Liquefied Natural Gas Deepwater Port Project. January 2006. Disponível em: <http://www.slc.ca.gov/>. Acesso em: 30 ago. 2011.

SANDIA. Guidance on Risk Analysis and Safety Implications of a Large Liquefied Natural Gas (LNG) Spill Over Water. SAND2004-6258, 2004.

SCANA. Solenoid Valve Cabinet. Disponível em: $<$ http://www.scana.no/sites/all/files/scana/companies/documents/solenoid-valvecabinet_0.pdf>. Acesso em: 14 maio 2012.

SHIGLEY, E. Mechanical Engineering Design. McGraw-Hill, New York, $8^{\text {th }}$ Edition, 2008

SHIPBUILDING HISTORY. The World Fleet of LNG Carriers, 2011. Disponível em: $<$ http://shipbuildinghistory.com/>. Acesso em: 21 abr. 2011.

SIGTTO. Society of International Gas Tanker and Terminal Operators. The Selection and Testing of Valves for LNG Applications 2002. Disponível em: <http://sigtto.reinvent.net/DNN/>. Acesso em: 24 jun. 2011.

SILVA, D.W.R.; SOUZA, G.F.M. Risk-based analysis of LNG carriers loading and unloading operations. Proceeding of the $22^{\text {nd }}$ International Ocean and Polar Engineering Conference. ISOPE-2012. Rhodes, Greece. 2012.

SKRAMSTAD, E.; MUSAEUS, S.U.; MELBO, S. Use of risk analysis for emergency planning of LNG carriers, 2000. Disponível em: <http://www.ivt.ntnu.no/ept/fag/tep4215/innhold/LNG\%20Conferences/2000/Data/Papers/>. Acesso em: 23 nov. 2010.

SMITH, D.J. Reliability, Maintainability and Risk. $6^{\circ}$ ed. Oxford: Butterwoth Heinemann, 2001.

SOARES, G.C.; TEIXEIRA, A.P. Risk assessment in maritime transportation. Reliability Engineering and System Safety 71. p. 299-309, 2001.

SOUZA, G.F.M. Análise de Confiabilidade Aplicada ao Projeto de Sistemas Mecânicos. São Paulo: EPUSP, 2010. Apostila para disciplina de pós-graduação, do Departamento de Engenharia Mecatrônica, PMR-5201. Análise de Confiabilidade Aplicada ao Projeto de Sistemas Mecânicos.

SOUZA, G.F.M; HIDALGO, E.M.P.; SILVA, D.W.R.; MARTINS, M.R. Probabilistic risk analysis of a LNG carrier loading pipeline. Proceeding of the ASME $201231^{\text {st }}$ International Conference on Ocean, Offshore and Artic Engineering. OMAE 2012-50268. Rio de Janeiro, Brazil. 2012.

SOVACOOL, B.K. The costs of failure: A preliminary assessment of major energy accidents, 1907 - 2007. Energy Policy 36. p. 1802-1829, 2008.

SPEIGHT, J.G. Handbook of Petroleum Product Analysis, Wiley, Hoboken, NJ, 2002.

THE ECONOMIST a. Japan's trading houses. Resourceful and energetic. Mitsubishi, Mitsui and their peers have bet boldly on a raw-materials boom. Disponível em: < 
http://www.economist.com/node/21554552>. Acesso em: 01 jul. 2012.

THE ECONOMIST b. Japan's energy security. Foot on the gas. The nuclear crisis helps reshape Japan's foreign-policy priorities. Disponível em: < http://www.economist.com/node/21563342>. Acesso em: 01 jul. 2012.

TIEN, S.W.; HWANG, W.T.; TSAI, C.H. Study of a risk-based piping inspection guideline system. ISA Transactions 46. p.119-126, 2007.

VANEM, E., ANTAO, P., OSTVIK, I., COMAS, F.C. Analyzing the risk of LNG carrier operations. Reliability Engineering \& System Safety 93. p.1328-1344, 2008.

WANG, K.S. Loss Prevention Through Risk Assessment Surveys of LNG Carriers in Operation, Under Construction, Conversion and Repair 2005. Disponível em: <http://www.bmtmarinerisk.com/>. Acesso em: 25 ago. 2010.

WAVESPEC. Wavespec Limited. A Braemar Seascope Plc. Group Company. August 2006. Ensuring Your New Gas Carrier Meets Expectations. Disponível em: < http://www.wavespec.com/profile.html>. Acesso em: 18 jul. 2011.

WILSON, J.J. An introduction to the marine transportation of bulk LNG and the design of LNG carriers. Cryogenics. p 115-120, 1974.

ZEUS VIRTUAL ENERGY LIBRARY a. Liquefaction Plants. Houston, Estados Unidos, 2009. Disponível em: <http://www.zeuslibrary.com/VEL/Export/>. Acesso em: 08 abr. 2011.

ZEUS VIRTUAL ENERGY LIBRARY b. Regaseification terminals. Houston, Estados Unidos, 2009. Disponível em: <http://www.zeuslibrary.com/VEL/Import/>. Acesso em: 11 abr. 2011.

ZUBAIR, M.; ZHIJIAN, Z. Reliability data update method for emergency diesel generator of Daya Bay Nuclear Power Plant. Annals of Nuclear Energy 38, p. 2575-2580, 2011. 


\section{APÊNDICE A. DESCRIÇÃO FUNCIONAL}

\section{CARGA DE GNL}

Função primária: Transferir o GNL desde a planta de liquefação até os tanques de armazenamento do navio transportador de GNL.

\section{I.1. Circuito de GNL}

Função primária: Permitir que o GNL percorra o trajeto entre o ponto de conexão do navio/porto até os tanques de armazenamento de GNL.

\section{I.1.1. Sistema de conexão Manifold}

Função primária: Conectar o navio com os braços criogênicos para realizar a carga de GNL.

\section{I.1.1.1. Manifold de bombordo}

Função primária: Conectar a parte esquerda do navio com o porto.

$$
\text { I.1.1.1.1. Válvulas }
$$

Função primária: Permitir ou impedir o fluxo do GNL.

\section{I.1.1.1.1.1. Válvulas controladoras de fluxo}

Função primária: Controlar a vazão de GNL no sistema manifold de bombordo.

\section{I.1.1.1.1.2. Válvulas de bloqueio}

Função primária: Manter isolado o circuito de spray, impedir a circulação do GNL para dentro do circuito spray.

\section{I.1.1.1.1.3. Válvulas de alívio}

Função primária: Limitar a pressão no manifold de bombordo.

\section{I.1.1.1.2. Tubulações}

Função primária: Encaminhar o GNL para o sistema de distribuição e servir como meio de conexão entre as válvulas no manifold de bombordo.

\section{I.1.1.2. Manifold de estibordo}

Função primária: Conectar a parte direita do navio com o porto.

\section{I.1.1.2.1. Válvulas de bloqueio}

Função primária: Manter isolado, impedir a circulação do GNL para dentro do circuito spray.

\section{I.1.1.2.2. Válvulas de alívio}

Função primária: Limitar a pressão no manifold de estibordo.

\section{I.1.1.2.3. Tubulações}

Função primária: Encaminhar o GNL para o sistema de distribuição e servir como meio de conexão entre as válvulas no manifold de estibordo.

\section{I.1.2. Sistema de distribuição}

Função primária: Encaminhar o GNL dos manifolds de bombordo e de estibordo até o sistema de armazenagem.

$$
\text { I.1.2.1. Tubulação principal }
$$


Função primária: Coletar o GNL antes de passar para as tubulações secundárias.

\section{I.1.2.2. Tubulações secundárias}

Função primária: Encaminhar o GNL para dentro dos seus respectivos tanques.

\section{I.1.2.2.1. Tubulações entre os manifolds até a tubulação principal}

Função primária: Encaminhar o GNL dos manifolds até a tubulação principal.

\section{I.1.2.2.2. Tubulações entre a tubulação principal e o sistema de armazenagem}

Função primária: Encaminhar o GNL da tubulação principal até o sistema de armazenamento.

\section{I.1.2.3. Válvulas de bloqueio}

Função primária: Manter isolado, impedir a circulação do GNL para dentro de outras linhas.

\section{I.1.2.4. Válvulas de alívio}

Função primária: Limitar a pressão na tubulação principal.

\section{I.1.3. Sistema de armazenagem}

Função primária: Armazenar o GNL durante o processo de carga e ao longo da "viagem” do navio.

\section{I.1.3.1. Válvulas}

Função primária: Permitir ou impedir o fluxo de GNL.

$$
\text { I.1.3.1.1. Válvulas de controle de fluxo }
$$

Função principal: Controlar a vazão de GNL no sistema de armazenagem.

$$
\text { I.1.3.1.2. Válvulas de bloqueio }
$$

Função principal: Manter isolado, impedir a circulação do GNL para dentro de outras linhas.

$$
\text { I.1.3.1.3. Válvulas de alívio }
$$

Função primária: Limitar a pressão nas tubulações de alimentação dos tanques.

\section{I.1.3.2. Tanques}

Função primária: Armazenar e conter o GNL durante a carga, descarga e transporte.

\section{I.1.3.3. Tubulações}

Função primária: Encaminhar o GNL para dentro dos reservatórios de GNL e servir como meio de conexão entre as válvulas.

\section{I.1.3.4. Isolamento}

Função primária: Isolar e impedir a troca de calor com o meio externo evitando a geração do boil-off.

\section{I.1.4. Sistema de controle da carga}

Função primária: Monitorar e controlar todos os componentes que pertencem aos circuitos de GNL e de boil-off, assim como monitor os parâmetros de funcionamento do processo.

I.1.5. Sistema de amostragem e detecção de gás

Função primária: Verificar a existência de gás nas áreas do navio, devido à ocorrência de algum vazamento de GNL.

I.1.6. Sistema hidráulico de controle das válvulas 
Função primária: Acionar hidraulicamente as válvulas que pertencem ao circuito de GNL e de boil-off.

\section{I.2. Circuito de boil-off}

Função primária: Deslocar o boil-off que é gerado no navio durante o processo de carga para que ele seja encaminhado até a planta de liquefação.

\section{I.2.1. Sistema de baixa pressão}

Função primária: Deslocar o boil-off gerado dentro dos tanques de armazenagem para dentro sistemas instalados na praça de máquinas.

\section{I.2.1.1. Válvulas}

Função primária: Permitir ou impedir o fluxo de boil-off.

$$
\text { I.2.1.1.1. Válvulas nos tanques }
$$

Função primária: Permitir ou impedir o fluxo de boil-off.

I.2.1.1.1.1. Válvulas de controle de fluxo

Função primária: Controlar a vazão do boil-off.

I.2.1.1.1.2. Válvulas de bloqueio

Função primária: Manter isolado, impedir a circulação do boil-off para dentro de outras linhas.

I.2.1.1.1.3. Válvulas de alívio

Função primária: Impedir o aumento da pressão dentro dos tanques criogênicos.

$$
\text { I.2.1.1.2 Válvulas na distribuição de baixa pressão }
$$

Função primária: Permitir ou impedir o fluxo de boil-off.

\section{I.2.1.1.2.1. Válvula de controle de fluxo}

Função primária: Controlar a vazão do boil-off.

\section{I.2.1.1.2.2. Válvulas de bloqueio}

Função primária: Manter isolado, impedir a circulação do boil-off dentro de outras linhas.

\section{I.2.1.1.2.3. Válvula de alívio}

Função primária: Impedir o aumento da pressão no circuito de boil-off.

$$
\text { I.2.1.1.3. Válvulas na praça de máquinas }
$$

Função primária: Permitir ou impedir o fluxo de boil-off.

I.2.1.1.3.1. Válvulas no circuito de alta vazão

Função primária: Controlar a vazão do boil-off.

\section{I.2.1.1.3.2. Válvulas no circuito de baixa vazão}

Função primária: Controlar a vazão do boil-off.

$$
\text { I.2.1.2. Misturador/Separador }
$$

Função primária: Separar o GNL do boil-off.

$$
\text { I.2.1.3. Tubulações }
$$


Função primária: Encaminhar o boil-off para equipamentos localizados na praça de máquinas e servir como meio de conexão entre as válvulas.

\section{I.2.1.3.1. Tubulação principal}

Função primária: Coletar o boil-off antes de passar para as tubulações secundárias.

\section{I.2.1.3.2. Tubulações secundárias}

Função primária: Encaminhar o boil-off dentro do sistema de baixa pressão.

\section{I.2.1.4. Risers}

Função primária: Servir como caminho seguro para a expulsão dos gases que provem de cada um dos tanques.

\section{I.2.2. Sistema de alta pressão}

Função primária: Elevar a pressão do boil-off para que seja transportado para a instalação portuária.

$$
\text { I.2.2.1. Compressores }
$$

Função primária: Elevar a pressão do boil-off.

$$
\text { I.2.2.1.1. Compressores de alta vazão }
$$

Função primária: Comprimir o boil-off para entregá-lo com uma alta vazão.

\section{I.2.2.1.2. Compressores de baixa vazão}

Função primária: Comprimir o boil-off para entregá-lo com uma baixa vazão.

\section{I.2.2.2. Válvulas}

Função primária: Permitir ou impedir o fluxo do boil-off no sistema de alta pressão.

\section{I.2.2.3. Tubulações}

Função primária: Transferir o boil-off pressurizado dos equipamentos localizados na praça de máquinas até a instalação de recepção, no terminal portuário e servir como meio de conexão dos equipamentos.

\section{I.2.3. Sistema de controle da carga}

Função primária: Monitorar e controlar todos os componentes que pertencem aos circuitos de GNL e de boil-off, assim como monitor os parâmetros de funcionamento do processo.

\section{I.2.4. Sistema de amostragem e detecção de gás}

Função primária: Verificar a existência de gás nas áreas do navio, devido à ocorrência de algum vazamento de GNL.

I.2.5. Sistema de hidráulico de controle das válvulas

Função primária: Acionar hidraulicamente as válvulas que pertencem ao circuito de GNL e de boil-off. 


\section{DESCARGA DE GNL}

Função primária: Fornecer o GNL desde os tanques de armazenamento do navio transportador até a instalação de descarga no porto.

\section{II.1.Circuito de GNL}

Função primária: Permitir que o GNL percorra o trajeto entre os tanques de armazenamento de GNL até o ponto de conexão do navio com a instalação de recepção.

\section{II.1.1. Sistema de Bombeio}

Função primária: Descarregar o GNL dos tanques de armazenamento do navio.

\section{II.1.1.1. Bombas criogênicas}

Função primária: Converter a energia mecânica em energia hidráulica fazendo os fluidos escoarem a uma pressão e vazão previamente especificadas.

\section{II.1.1.2. Válvulas}

Função primária: Permitir ou impedir o fluxo do GNL:

\section{II.1.2. Sistema de Armazenagem}

Função primária: Armazenar o GNL durante o processo de descarga.

\section{II.1.2.1. Tanques}

Função primária: Armazenar e conter o GNL durante a carga, descarga e transporte.

\section{II.1.2.2. Tubulações}

Função primária: Transferir o GNL dos reservatórios de GNL para o sistema de distribuição e servir como meio de conexão entre as válvulas.

\section{II.1.2.3. Isolamento}

Função primária: Isolar e impedir a troca de calor com o meio externo.

$$
\text { II.1.2.4. Válvulas }
$$

Função primária: Permitir ou impedir o fluxo do GNL.

$$
\text { II.1.2.4.1. Válvulas controladoras de fluxo }
$$

Função primária: Controlar a vazão de GNL no sistema de armazenagem.

$$
\text { II.1.2.4.2. Válvulas de bloqueio }
$$

Função primária: Manter isolado, impedir a circulação do GNL para dentro de outras linhas.

$$
\text { II.1.2.4.3. Válvulas de alívio }
$$

Função primária: Limitar a pressão nas linhas de ingresso aos tanques.

\section{II.1.3. Sistema de distribuição}

Função primária: Encaminhar o GNL do sistema de armazenagem até os manifolds de bombordo e de estibordo.

\section{II.1.3.1. Tubulação principal}

Função primária: Coletar o GNL antes de passar para as tubulações secundárias.

$$
\text { II.1.3.2. Tubulações secundárias }
$$

Função primária: Encaminhar o GNL dentro do sistema de distribuição. 
II.1.3.2.1. Tubulações entre o sistema de armazenamento até a tubulação principal

Função primária: Encaminhar o GNL do sistema de armazenamento até a tubulação principal.

II.1.3.2.2. Tubulações entre a tubulação principal até o sistema de conexão de manifold

Função primária: Encaminhar o GNL desde a tubulação principal até os manifolds

II.1.3.3. Válvulas de bloqueio

Função primária: Manter isolado, impedir a circulação do GNL para dentro de outras linhas.

II.1.3.4. Válvulas de alívio

Função primária: Limitar a pressão na tubulação principal

\section{II.1.4. Sistema de conexão Manifold}

Função primária: Conectar o navio com os braços criogênicos para realizar a descarga de GNL.

\section{II.1.4.1. Manifold de bombordo}

Função primária: Conectar a parte esquerda do navio com o porto.

\section{II.1.4.1.1. Válvulas}

Função primária: Permitir ou impedir o fluxo do GNL.

II.1.4.1.1.1. Válvulas controladoras de fluxo

Função primária: Controlar a vazão de GNL no sistema manifold de bombordo.

\section{II.1.4.1.1.2. Válvulas de bloqueio}

Função primária: Manter isolado o circuito de spray, impedir a circulação do GNL para dentro do circuito spray.

\section{II.1.4.1.1.3. Válvulas de alívio}

Função primária: Limitar a pressão no manifold de bombordo.

\section{II.1.4.1.2. Tubulações}

Função primária: Encaminhar o GNL para a conexão entre o navio e a instalação de descarga e servir como meio de conexão entre as válvulas no manifold de bombordo.

\section{II.1.4.2. Manifold de estibordo}

Função primária: Conectar a parte direita do navio com o porto.

\section{II.1.4.2.1. Válvulas de bloqueio}

Função primária: Manter isolado o circuito de spray, impedir a circulação do GNL para dentro do circuito spray.

\section{II.1.4.2.2. Válvulas de alívio}

Função primária: Limitar a pressão no manifold de estibordo.

\section{II.1.4.2.3. Tubulações}

Função primária: Encaminhar o GNL do sistema de distribuição para o terminal, e servir como meio de conexão entre as válvulas no manifold de estibordo.

\section{II.1.5. Sistema de controle de carga}

Função primária: Monitorar e controlar todos os componentes que pertencem aos circuitos de GNL e de boil-off, assim como monitor os parâmetros de funcionamento do processo. 
II.1.6. Sistema de amostragem e detecção de gás

Função primária: Verificar a existência de gás nas áreas úteis do navio, devido à ocorrência de algum vazamento de GNL.

II.1.7. Sistema hidráulico de controle das válvulas

Função primária: Acionar hidraulicamente as válvulas que pertencem ao circuito de GNL e de boil-off.

\section{II.2. Circuito de boil-off}

Função primária: Deslocar o boil-off que é gerado no navio durante o processo de descarga para que ele seja encaminhado até o terminal de regaseificação.

A descrição funcional do circuito de boil-off é a mesma apresentada no item I.2 deste Apêndice. 


\section{APÊNDICE B. TABELAS DA APLICAÇÃO DA ANÁLISE PRELIMINAR DE PERIGOS}

Tabela B.1 - Aplicação da técnica APP para um pequeno vazamento de GNL

\begin{tabular}{|c|c|c|c|c|c|}
\hline \multicolumn{4}{|c|}{ Sistema: Sistema de carga e descarga do navio transportador de GNL } & \multirow{2}{*}{$\begin{array}{l}\text { ANÁLISE PRELIMINAR DE } \\
\text { PERIGOS }\end{array}$} & Analista: \\
\hline \multicolumn{4}{|c|}{$\begin{array}{l}\text { Sub-sistemas: Sistema de conexão manifold, Sistema de distribuição, Sistema de Armazenagem, Sistema } \\
\text { de alívio, Sistema de baixa pressão, Sistema de alta pressão, Sistema de alívio do boil-off. }\end{array}$} & & Data: \\
\hline $\mathrm{N}^{\circ}$ & Perigo & Causas & Consequências & \multicolumn{2}{|c|}{ Barreiras de proteção } \\
\hline 1 & \multirow{4}{*}{$\begin{array}{l}\text { Pequeno } \\
\text { vazamento } \\
\text { de GNL }\end{array}$} & $\begin{array}{l}\text { Conexão indevida de pelo menos } 1 \text { dos } 3 \\
\text { braços criogênicos que transferem o GNL } \\
\text { por meio do manifold de bombordo. }\end{array}$ & $\begin{array}{l}\text { Possíveis danos à estrutura do navio. } \\
\text { Paralisação do processo de transferência do } \\
\text { GNL. Ativação dos sistemas de emergência. }\end{array}$ & \multicolumn{2}{|c|}{$\begin{array}{l}\text { Instalação de um reservatório na parte inferior do ponto de } \\
\text { conexão dos braços criogênicos que conterá o GNL após a } \\
\text { desconexão dos mesmos. Tem-se um sistema de } \\
\text { monitoração que monitora e indica quais são as condições } \\
\text { internas do circuito de GNL, um sistema de amostragem } \\
\text { que indica a ocorrência de algum vazamento de gás natural } \\
\text { e o ESD que paralisa a transferência da carga. }\end{array}$} \\
\hline 2 & & $\begin{array}{l}\text { Perda da integridade estrutural das } \\
\text { válvulas de controle de luxo no manifold } \\
\text { de bombordo CL011, CL021, CL031, } \\
\text { CL013, CL023, CL033. }\end{array}$ & $\begin{array}{l}\text { Possíveis danos à estrutura do navio. } \\
\text { Paralisação do processo de transferência do } \\
\text { GNL. }\end{array}$ & \multicolumn{2}{|c|}{$\begin{array}{l}\text { Tem-se um sistema de monitoração que monitora e indica } \\
\text { quais são as condições internas do circuito de GNL, um } \\
\text { sistema de amostragem que indica a ocorrência de algum } \\
\text { vazamento de gás natural e o ESD que paralisa a } \\
\text { transferência da carga. }\end{array}$} \\
\hline 3 & & $\begin{array}{l}\text { Perda da integridade estrutural das } \\
\text { válvulas de bloqueio do manifold de } \\
\text { bombordo CS011, CS021, CS031, CS013, } \\
\text { CS023, CS033, CL043. }\end{array}$ & $\begin{array}{l}\text { Possíveis danos à estrutura do navio. } \\
\text { Paralisação do processo de transferência do } \\
\text { GNL. }\end{array}$ & \multicolumn{2}{|c|}{$\begin{array}{l}\text { Tem-se um sistema de monitoração que monitora e indica } \\
\text { quais são as condições internas do circuito de GNL, um } \\
\text { sistema de amostragem que indica a ocorrência de algum } \\
\text { vazamento de gás natural e o ESD que paralisa a } \\
\text { transferência da carga. }\end{array}$} \\
\hline 4 & & $\begin{array}{l}\text { Abertura das válvulas de bloqueio do } \\
\text { manifold de bombordo CS011, CS021, } \\
\text { CS031, CS013, CS023, CS033, CL043. }\end{array}$ & $\begin{array}{l}\text { Ingresso do GNL no circuito de spray. } \\
\text { Ingresso de GNL para dentro do sistema de } \\
\text { alívio. }\end{array}$ & \multicolumn{2}{|c|}{$\begin{array}{l}\text { Têm-se outras válvulas de bloqueio que impedem que o } \\
\text { GNL entre numa linha onde não deveria fluir. Tem-se um } \\
\text { sistema de alívio para transferir o GNL nessas linhas. Tem- } \\
\text { se um sistema de monitoração que monitora e indica quais } \\
\text { são as condições internas do circuito de GNL, um sistema } \\
\text { de amostragem que indica a ocorrência de algum } \\
\text { vazamento de gás natural e o ESD que paralisa a } \\
\text { transferência da carga. }\end{array}$} \\
\hline
\end{tabular}




\begin{tabular}{|c|c|c|c|c|c|}
\hline \multicolumn{4}{|c|}{ Sistema: Sistema de carga e descarga do navio transportador de GNL } & \multirow[b]{2}{*}{$\begin{array}{l}\text { ANÁLISE PRELIMINAR DE } \\
\text { PERIGOS }\end{array}$} & Analista: \\
\hline \multicolumn{4}{|c|}{$\begin{array}{l}\text { Sub-sistemas: Sistema de conexão manifold, Sistema de distribuição, Sistema de Armazenagem, Sistema } \\
\text { de alívio, Sistema de baixa pressão, Sistema de alta pressão, Sistema de alívio do boil-off. }\end{array}$} & & Data: \\
\hline $\mathrm{N}^{\circ}$ & Perigo & Causas & Consequências & \multicolumn{2}{|c|}{ Barreiras de proteção } \\
\hline 5 & \multirow{4}{*}{$\begin{array}{l}\text { Pequeno } \\
\text { vazamento } \\
\text { de GNL }\end{array}$} & $\begin{array}{l}\text { Fissuras nas tubulações de conexão entre } \\
\text { as válvulas do manifold de bombordo. }\end{array}$ & $\begin{array}{l}\text { Possíveis danos à estrutura do navio. } \\
\text { Paralisação do processo de transferência do } \\
\text { GNL. }\end{array}$ & \multicolumn{2}{|c|}{$\begin{array}{l}\text { Tem-se um sistema de monitoração que monitora e indica } \\
\text { quais são as condições internas do circuito de GNL, um } \\
\text { sistema de amostragem que indica a ocorrência de algum } \\
\text { vazamento de gás natural e o ESD que paralisa a } \\
\text { transferência da carga. }\end{array}$} \\
\hline 6 & & $\begin{array}{l}\text { Perda da integridade estrutural das } \\
\text { válvulas de bloqueio no manifold de } \\
\text { estibordo CL014, CL024, CL034, CL044, } \\
\text { CS026, CS036. }\end{array}$ & $\begin{array}{l}\text { Possíveis danos à estrutura do navio. } \\
\text { Paralisação do processo de transferência do } \\
\text { GNL. }\end{array}$ & \multicolumn{2}{|c|}{$\begin{array}{l}\text { Tem-se um sistema de monitoração que monitora e indica } \\
\text { quais são as condições internas do circuito de GNL, um } \\
\text { sistema de amostragem que indica a ocorrência de algum } \\
\text { vazamento de gás natural e o ESD que paralisa a } \\
\text { transferência da carga. }\end{array}$} \\
\hline 7 & & $\begin{array}{l}\text { Abertura das válvulas de bloqueio no } \\
\text { manifold de estibordo CL014, CL024, } \\
\text { CL034, CL044, CS026, CS036. }\end{array}$ & $\begin{array}{l}\text { Ingresso do GNL no circuito de spray. } \\
\text { Ingresso de GNL para dentro do sistema de } \\
\text { alívio. }\end{array}$ & \multicolumn{2}{|c|}{$\begin{array}{l}\text { Têm-se outras válvulas de bloqueio que impedem que o } \\
\text { GNL entre numa linha onde não deveria fluir. Tem-se um } \\
\text { sistema de alívio para transferir o GNL nessas linhas. Tem- } \\
\text { se um sistema de monitoração que monitora e indica quais } \\
\text { são as condições internas do circuito de GNL, um sistema } \\
\text { de amostragem que indica a ocorrência de algum } \\
\text { vazamento de gás natural e o ESD que paralisa a } \\
\text { transferência da carga. }\end{array}$} \\
\hline 8 & & $\begin{array}{l}\text { Fissuras nas tubulações no manifold de } \\
\text { estibordo. }\end{array}$ & $\begin{array}{l}\text { Possíveis danos à estrutura do navio. } \\
\text { Congelamento da instalação circunvizinha. } \\
\text { Paralisação do processo de transferência do } \\
\text { GNL. }\end{array}$ & \multicolumn{2}{|c|}{$\begin{array}{l}\text { Tem-se um sistema de monitoração que monitora e indica } \\
\text { quais são as condições internas do circuito de GNL, um } \\
\text { sistema de amostragem que indica a ocorrência de algum } \\
\text { vazamento de gás natural e o ESD que paralisa a } \\
\text { transferência da carga. }\end{array}$} \\
\hline
\end{tabular}




\begin{tabular}{|c|c|c|c|c|c|}
\hline \multicolumn{4}{|c|}{ Sistema: Sistema de carga e descarga do navio transportador de GNL } & \multirow{2}{*}{$\begin{array}{l}\text { ANÁLISE PRELIMINAR DE } \\
\text { PERIGOS }\end{array}$} & Analista: \\
\hline \multicolumn{4}{|c|}{$\begin{array}{l}\text { Sub-sistemas: Sistema de conexão manifold, Sistema de distribuição, Sistema de Armazenagem, Sistema } \\
\text { de alívio, Sistema de baixa pressão, Sistema de alta pressão, Sistema de alívio do boil-off. }\end{array}$} & & \\
\hline $\mathrm{N}^{\circ}$ & Perigo & Causas & Consequências & \multicolumn{2}{|c|}{ Barreiras de proteção } \\
\hline 9 & \multirow{4}{*}{$\begin{array}{l}\text { Pequeno } \\
\text { vazamento } \\
\text { de GNL }\end{array}$} & Fissura na tubulação principal de GNL. & $\begin{array}{l}\text { Possíveis danos à estrutura do navio. } \\
\text { Congelamento da instalação circunvizinha. } \\
\text { Paralisação do processo de transferência do } \\
\text { GNL. }\end{array}$ & \multicolumn{2}{|c|}{$\begin{array}{l}\text { Tem-se um sistema de monitoração que monitora e indica } \\
\text { quais são as condições internas do circuito de GNL, um } \\
\text { sistema de amostragem que indica a ocorrência de algum } \\
\text { vazamento de gás natural e o ESD que paralisa a } \\
\text { transferência da carga. }\end{array}$} \\
\hline 10 & & $\begin{array}{l}\text { Fissura nas tubulações secundárias ligando } \\
\text { os manifolds até a tubulação principal. }\end{array}$ & $\begin{array}{l}\text { Possíveis danos à estrutura do navio. } \\
\text { Congelamento da instalação circunvizinha. } \\
\text { Paralisação do processo de transferência do } \\
\text { GNL. }\end{array}$ & \multicolumn{2}{|c|}{$\begin{array}{l}\text { Tem-se um sistema de monitoração que monitora e indica } \\
\text { quais são as condições internas do circuito de GNL, um } \\
\text { sistema de amostragem que indica a ocorrência de algum } \\
\text { vazamento de gás natural e o ESD que paralisa a } \\
\text { transferência da carga. }\end{array}$} \\
\hline 11 & & $\begin{array}{l}\text { Fissura nas tubulações secundárias ligando } \\
\text { a tubulação principal até o sistema de } \\
\text { armazenagem. }\end{array}$ & $\begin{array}{l}\text { Possíveis danos à estrutura do navio. } \\
\text { Congelamento da instalação circunvizinha. } \\
\text { Paralisação do processo de transferência do } \\
\text { GNL. }\end{array}$ & \multicolumn{2}{|c|}{$\begin{array}{l}\text { Tem-se um sistema de monitoração que monitora e indica } \\
\text { quais são as condições internas do circuito de GNL, um } \\
\text { sistema de amostragem que indica a ocorrência de algum } \\
\text { vazamento de gás natural e o ESD que paralisa a } \\
\text { transferência da carga. }\end{array}$} \\
\hline 12 & & $\begin{array}{l}\text { Perda da integridade estrutural das } \\
\text { válvulas de bloqueio no sistema de } \\
\text { distribuição CL700, CL701, CS703. }\end{array}$ & $\begin{array}{l}\text { Possíveis danos à estrutura do navio. } \\
\text { Paralisação do processo de transferência do } \\
\text { GNL. }\end{array}$ & \multicolumn{2}{|c|}{$\begin{array}{l}\text { Tem-se um sistema de monitoração que monitora e indica } \\
\text { quais são as condições internas do circuito de GNL, um } \\
\text { sistema de amostragem que indica a ocorrência de algum } \\
\text { vazamento de gás natural e o ESD que paralisa a } \\
\text { transferência da carga. }\end{array}$} \\
\hline
\end{tabular}




\begin{tabular}{|c|c|c|c|c|c|}
\hline \multicolumn{4}{|c|}{ Sistema: Sistema de carga e descarga do navio transportador de GNL } & \multirow{2}{*}{$\begin{array}{l}\text { ANÁLISE PRELIMINAR DE } \\
\text { PERIGOS }\end{array}$} & Analista: \\
\hline \multicolumn{4}{|c|}{$\begin{array}{l}\text { Sub-sistemas: Sistema de conexão manifold, Sistema de distribuição, Sistema de Armazenagem, Sistema } \\
\text { de alívio, Sistema de baixa pressão, Sistema de alta pressão, Sistema de alívio do boil-off. }\end{array}$} & & Data: \\
\hline $\mathrm{N}^{\circ}$ & Perigo & Causas & Consequências & \multicolumn{2}{|c|}{ Barreiras de proteção } \\
\hline 13 & \multirow{4}{*}{$\begin{array}{l}\text { Pequeno } \\
\text { vazamento } \\
\text { de GNL }\end{array}$} & $\begin{array}{l}\text { Abertura das válvulas de bloqueio CL700, } \\
\text { CL701, CS703. }\end{array}$ & $\begin{array}{l}\text { Ingresso do GNL no circuito de boil-off de } \\
\text { baixa pressão (CL700). Ingresso do GNL } \\
\text { para o circuito de inertização (CL701). } \\
\text { Ingresso do GNL no circuito de spray } \\
\text { (CS703). }\end{array}$ & \multicolumn{2}{|c|}{$\begin{array}{l}\text { Têm-se outras válvulas de bloqueio que impedem que o } \\
\text { GNL entre numa linha onde não deveria fluir. Tem-se um } \\
\text { sistema de alívio para transferir o GNL nessas linhas. Tem- } \\
\text { se um sistema de monitoração que monitora e indica quais } \\
\text { são as condições internas do circuito de GNL, um sistema } \\
\text { de amostragem que indica a ocorrência de algum } \\
\text { vazamento de gás natural e o ESD que paralisa a } \\
\text { transferência da carga. }\end{array}$} \\
\hline 14 & & $\begin{array}{l}\text { Perda da integridade estrutural das } \\
\text { válvulas de controle de fluxo que permitem } \\
\text { o ingresso do GNL nos tanques de } \\
\text { armazenamento CL107, CL100, CL207, } \\
\text { CL200, CL307, CL300, CL407, CL400. }\end{array}$ & $\begin{array}{l}\text { Possíveis danos à estrutura do navio. } \\
\text { Paralisação do processo de transferência do } \\
\text { GNL. }\end{array}$ & \multicolumn{2}{|c|}{$\begin{array}{l}\text { Tem-se um sistema de monitoração que monitora e indica } \\
\text { quais são as condições internas do circuito de GNL, um } \\
\text { sistema de amostragem que indica a ocorrência de algum } \\
\text { vazamento de gás natural e o ESD que paralisa a } \\
\text { transferência da carga. }\end{array}$} \\
\hline 15 & & $\begin{array}{l}\text { Perda da integridade estrutural das } \\
\text { válvulas de bloqueio nos tanques de } \\
\text { armazenamento CL107, CL100, CL207, } \\
\text { CL200, CL307, CL300, CL407, CL400. }\end{array}$ & $\begin{array}{l}\text { Possíveis danos à estrutura do navio. } \\
\text { Paralisação do processo de transferência do } \\
\text { GNL. }\end{array}$ & \multicolumn{2}{|c|}{$\begin{array}{l}\text { Tem-se um sistema de monitoração que monitora e indica } \\
\text { quais são as condições internas do circuito de GNL, um } \\
\text { sistema de amostragem que indica a ocorrência de algum } \\
\text { vazamento de gás natural e o ESD que paralisa a } \\
\text { transferência da carga. }\end{array}$} \\
\hline 16 & & $\begin{array}{l}\text { Abertura das válvulas de bloqueio que } \\
\text { permite o ingresso de GNL nos tanques de } \\
\text { armazenamento CL104, CL106, CL105, } \\
\text { CS104, CL204, CL202, CL201, CS204, } \\
\text { CL304, CL302, CL301, CS304, CL404, } \\
\text { CL402, CL401, CS404. }\end{array}$ & $\begin{array}{l}\text { Ingresso do GNL no circuito de spray } \\
\text { (CS104, CS204, CS304, CS404). Ingresso } \\
\text { do GNL para dentro das tubulações que } \\
\text { servem para a descarga de GNL (CL104, } \\
\text { CL106, CL105, CL204, CL202, CL201, } \\
\text { CL304, CL302, CL301, CL404, CL402, } \\
\text { CL401). }\end{array}$ & \multicolumn{2}{|c|}{$\begin{array}{l}\text { Têm-se outras válvulas de bloqueio que impedem que o } \\
\text { GNL entre numa linha onde não deveria fluir. Tem-se um } \\
\text { sistema de alívio para transferir o GNL nessas linhas. Tem- } \\
\text { se um sistema de monitoração que monitora e indica quais } \\
\text { são as condições internas do circuito de GNL, um sistema } \\
\text { de amostragem que indica a ocorrência de algum } \\
\text { vazamento de gás natural e o ESD que paralisa a } \\
\text { transferência da carga. }\end{array}$} \\
\hline
\end{tabular}




\begin{tabular}{|c|c|c|c|c|c|}
\hline \multicolumn{4}{|c|}{ Sistema: Sistema de carga e descarga do navio transportador de GNL } & \multirow[b]{2}{*}{$\begin{array}{l}\text { ANÁLISE PRELIMINAR DE } \\
\text { PERIGOS }\end{array}$} & Analista: \\
\hline \multicolumn{4}{|c|}{$\begin{array}{l}\text { Sub-sistemas: Sistema de conexão manifold, Sistema de distribuição, Sistema de Armazenagem, Sistema } \\
\text { de alívio, Sistema de baixa pressão, Sistema de alta pressão, Sistema de alívio do boil-off. }\end{array}$} & & Data: \\
\hline $\mathrm{N}^{\circ}$ & Perigo & Causas & Consequências & \multicolumn{2}{|c|}{ Barreiras de proteção } \\
\hline 17 & \multirow{3}{*}{$\begin{array}{l}\text { Pequeno } \\
\text { vazamento } \\
\text { de GNL }\end{array}$} & Fissura nos tanques de armazenamento. & $\begin{array}{l}\text { Produzirá um vazamento de GNL que será } \\
\text { contido no tanque secundário do navio. } \\
\text { Paralisação do processo de transferência do } \\
\text { GNL. }\end{array}$ & \multicolumn{2}{|c|}{$\begin{array}{l}\text { Tem-se um sistema de monitoração que monitora e indica } \\
\text { quais são as condições internas do circuito de GNL, um } \\
\text { sistema de amostragem que indica a ocorrência de algum } \\
\text { vazamento de gás natural e o ESD que paralisa a } \\
\text { transferência da carga. Tem-se um tanque secundário que } \\
\text { executa a função de contenção caso de qualquer vazamento } \\
\text { de GNL do tanque primário. }\end{array}$} \\
\hline 18 & & $\begin{array}{l}\text { Fissura nas tubulações que estão no } \\
\text { sistema de armazenagem. }\end{array}$ & $\begin{array}{l}\text { Possíveis danos à estrutura do navio. } \\
\text { Congelamento da instalação circunvizinha. } \\
\text { Paralisação do processo de transferência do } \\
\text { GNL. }\end{array}$ & \multicolumn{2}{|c|}{$\begin{array}{l}\text { Tem-se um sistema de monitoração que monitora e indica } \\
\text { quais são as condições internas do circuito de GNL, um } \\
\text { sistema de amostragem que indica a ocorrência de algum } \\
\text { vazamento de gás natural e o ESD que paralisa a } \\
\text { transferência da carga. }\end{array}$} \\
\hline 19 & & $\begin{array}{l}\text { Perda da integridade das válvulas de alívio } \\
\text { CR701, CR702, CR704, CR102, CR202, } \\
\text { CR302, CR402; CR011, CR012, CR013, } \\
\text { CR014, CR021, CR022, CR023, CR024, } \\
\text { CR031, CR032, CR033, CR034, CR103, } \\
\text { CR105, CR104, CR203, CR205, CR204, } \\
\text { CR303, CR305, CR304, CR403, CR405, } \\
\text { CR404, CR700, CR703; CR905, CR903, } \\
\text { CR904. }\end{array}$ & $\begin{array}{l}\text { Possíveis danos à estrutura do navio. } \\
\text { Paralisação do processo de transferência do } \\
\text { GNL. }\end{array}$ & \multicolumn{2}{|c|}{$\begin{array}{l}\text { Tem-se um sistema de monitoração que monitora e indica } \\
\text { quais são as condições internas do circuito de GNL, um } \\
\text { sistema de amostragem que indica a ocorrência de algum } \\
\text { vazamento de gás natural e o ESD que paralisa a } \\
\text { transferência da carga. }\end{array}$} \\
\hline
\end{tabular}




\begin{tabular}{|c|c|c|c|c|c|}
\hline \multicolumn{4}{|c|}{ Sistema: Sistema de carga e descarga do navio transportador de GNL } & \multirow[b]{2}{*}{$\begin{array}{l}\text { ANÁLISE PRELIMINAR DE } \\
\text { PERIGOS }\end{array}$} & Analista: \\
\hline \multicolumn{4}{|c|}{$\begin{array}{l}\text { Sub-sistemas: Sistema de conexão manifold, Sistema de distribuição, Sistema de Armazenagem, Sistema } \\
\text { de alívio, Sistema de baixa pressão, Sistema de alta pressão, Sistema de alívio do boil-off. }\end{array}$} & & Data: \\
\hline $\mathrm{N}^{\circ}$ & Perigo & Causas & Consequências & \multicolumn{2}{|c|}{ Barreiras de proteção } \\
\hline 20 & \multirow{4}{*}{$\begin{array}{l}\text { Pequeno } \\
\text { vazamento } \\
\text { de GNL }\end{array}$} & $\begin{array}{l}\text { Abertura das válvulas de alívio CR701, } \\
\text { CR702, CR704, CR102, CR202, CR302, } \\
\text { CR402; CR905, CR903, CR904. }\end{array}$ & $\begin{array}{l}\text { Ingresso do GNL no circuito de spray } \\
\text { (CR701, CR702, CR704, CR102, CR202, } \\
\text { CR302, CR402). Ingresso do GNL para as } \\
\text { tubulações de descarga de GNL (CR011, } \\
\text { CR012, CR013, CR014, CR021, CR022, } \\
\text { CR023, CR024, CR031, CR032, CR033, } \\
\text { CR034, CR103, CR105, CR104, CR203, } \\
\text { CR205, CR204, CR303, CR305, CR304, } \\
\text { CR403, CR405, CR404, CR700, CR703). } \\
\text { Ingresso do GNL no sistema de vaporização } \\
\text { na praça de máquinas (CR905, CR903, } \\
\text { CR904). }\end{array}$ & \multicolumn{2}{|c|}{$\begin{array}{l}\text { Têm-se outras válvulas de bloqueio que impedem que o } \\
\text { GNL entre numa linha onde não deveria fluir. Tem-se um } \\
\text { sistema de alívio para transferir o GNL nessas linhas. Tem- } \\
\text { se um sistema de monitoração que monitora e indica quais } \\
\text { são as condições internas do circuito de GNL, um sistema } \\
\text { de amostragem que indica a ocorrência de algum } \\
\text { vazamento de gás natural e o ESD que paralisa a } \\
\text { transferência da carga. }\end{array}$} \\
\hline 21 & & $\begin{array}{l}\text { Fissura nas tubulações que servem para } \\
\text { transferir o GNL aliviado para dentro dos } \\
\text { tanques } 2 \text { e } 3 \text {. }\end{array}$ & $\begin{array}{l}\text { Possíveis danos à estrutura do navio. } \\
\text { Congelamento da instalação circunvizinha. } \\
\text { Paralisação do processo de transferência do } \\
\text { GNL. }\end{array}$ & \multicolumn{2}{|c|}{$\begin{array}{l}\text { Tem-se um sistema de monitoração que monitora e indica } \\
\text { quais são as condições internas do circuito de GNL, um } \\
\text { sistema de amostragem que indica a ocorrência de algum } \\
\text { vazamento de gás natural e o ESD que paralisa a } \\
\text { transferência da carga. }\end{array}$} \\
\hline 22 & & $\begin{array}{l}\text { Falha do sistema de alarmes de nível de } \\
\text { GNL no interior dos tanques de } \\
\text { armazenamento que provocará o sobre } \\
\text { enchimento de um ou vários tanques de } \\
\text { armazenamento. }\end{array}$ & $\begin{array}{l}\text { Paralisação do processo de transferência do } \\
\text { GNL. Possíveis danos à estrutura do navio. } \\
\text { Congelamento da instalação circunvizinha. } \\
\text { Formação de gases produto do vazamento } \\
\text { de GNL. }\end{array}$ & \multicolumn{2}{|c|}{$\begin{array}{l}\text { Têm-se três níveis de alarmes que paralisam o processo de } \\
\text { transferência do GNL para o navio. Tem-se um sistema de } \\
\text { monitoração que monitora e indica quais são as condições } \\
\text { internas do circuito de GNL, um sistema de amostragem } \\
\text { que indica a ocorrência de algum vazamento de gás natural } \\
\text { e o ESD que paralisa a transferência da carga. }\end{array}$} \\
\hline 23 & & $\begin{array}{l}\text { Aumento da pressão no interior do circuito } \\
\text { de GNL devido à elevada pressão de } \\
\text { descarga do GNL na saída das bombas } \\
\text { criogênicas. }\end{array}$ & $\begin{array}{l}\text { Fissuras dos componentes no circuito de } \\
\text { GNL devido à elevada pressão no interior } \\
\text { do mesmo. Paralisação do processo de } \\
\text { transferência do GNL. Formação de gases } \\
\text { produto do vazamento de GNL. }\end{array}$ & \multicolumn{2}{|c|}{$\begin{array}{l}\text { Tem-se um sistema de monitoração que monitora e indica } \\
\text { quais são as condições internas do circuito de GNL, um } \\
\text { sistema de amostragem que indica a ocorrência de algum } \\
\text { vazamento de gás natural e o ESD que paralisa a } \\
\text { transferência da carga. }\end{array}$} \\
\hline
\end{tabular}


Tabela B.2 - Aplicação da técnica APP para um grande vazamento de GNL

\begin{tabular}{|c|c|c|c|c|c|}
\hline \multicolumn{4}{|c|}{ Sistema: Sistema de carga e descarga do navio transportador de GNL } & \multirow{2}{*}{$\begin{array}{l}\text { ANÁLISE PRELIMINAR } \\
\text { DE PERIGOS }\end{array}$} & Analista: \\
\hline \multicolumn{4}{|c|}{$\begin{array}{l}\text { Sub-sistemas: Sistema de conexão manifold, Sistema de distribuição, Sistema de Armazenagem, Sistema de } \\
\text { alívio, Sistema de baixa pressão, Sistema de alta pressão, Sistema de alívio do boil-off. }\end{array}$} & & Data: \\
\hline $\mathrm{N}^{\circ}$ & Perigo & Causas & Consequências & \multicolumn{2}{|c|}{ Barreiras de proteção } \\
\hline 1 & \multirow{4}{*}{$\begin{array}{c}\text { Grande } \\
\text { vazamento } \\
\text { de GNL }\end{array}$} & $\begin{array}{l}\text { Conexão indevida de pelo menos } 1 \text { dos } 3 \\
\text { braços criogênicos que transferem o GNL } \\
\text { por meio do manifold de bombordo. }\end{array}$ & $\begin{array}{l}\text { Danos à estrutura do navio. Possibilidade de } \\
\text { geração de uma nuvem de gás. Paralisação } \\
\text { do processo de transferência do GNL. }\end{array}$ & \multicolumn{2}{|c|}{$\begin{array}{l}\text { Instalação de um reservatório na parte inferior do ponto } \\
\text { de conexão dos braços criogênicos que conterá o GNL } \\
\text { após a desconexão dos mesmos. Tem-se um sistema de } \\
\text { monitoração que monitora e indica quais são as condições } \\
\text { internas do circuito de GNL, um sistema de amostragem } \\
\text { que indica a ocorrência de algum vazamento de gás } \\
\text { natural e o ESD que paralisa a transferência da carga. }\end{array}$} \\
\hline 2 & & $\begin{array}{l}\text { Perda da integridade estrutural das válvulas } \\
\text { de controle de fluxo no manifold de } \\
\text { bombordo CL011, CL021, CL031, CL013, } \\
\text { CL023, CL033. }\end{array}$ & $\begin{array}{l}\text { Danos à estrutura do navio. Possibilidade de } \\
\text { geração de uma nuvem de gás. Paralisação } \\
\text { do processo de transferência do GNL. }\end{array}$ & \multicolumn{2}{|c|}{$\begin{array}{l}\text { Tem-se um sistema de monitoração que monitora e indica } \\
\text { quais são as condições internas do circuito de GNL, um } \\
\text { sistema de amostragem que indica a ocorrência de algum } \\
\text { vazamento de gás natural e o ESD que paralisa a } \\
\text { transferência da carga. }\end{array}$} \\
\hline 3 & & $\begin{array}{l}\text { Perda da integridade estrutural das válvulas } \\
\text { de bloqueio do manifold de bombordo } \\
\text { CS011, CS021, CS031, CS013, CS023, } \\
\text { CS033, CL043. }\end{array}$ & $\begin{array}{l}\text { Danos à estrutura do navio. Possibilidade de } \\
\text { geração de uma nuvem de gás. Paralisação } \\
\text { do processo de transferência do GNL. }\end{array}$ & \multicolumn{2}{|c|}{$\begin{array}{l}\text { Tem-se um sistema de monitoração que monitora e indica } \\
\text { quais são as condições internas do circuito de GNL, um } \\
\text { sistema de amostragem que indica a ocorrência de algum } \\
\text { vazamento de gás natural e o ESD que paralisa a } \\
\text { transferência da carga. }\end{array}$} \\
\hline 4 & & $\begin{array}{l}\text { Abertura das válvulas de bloqueio do } \\
\text { manifold de bombordo CS011, CS021, } \\
\text { CS031, CS013, CS023, CS033, CL043. }\end{array}$ & $\begin{array}{l}\text { Ingresso do GNL no circuito de spray. } \\
\text { Ingresso de GNL para dentro do sistema de } \\
\text { alívio. Paralisação do processo de } \\
\text { transferência do GNL. }\end{array}$ & \multicolumn{2}{|c|}{$\begin{array}{l}\text { Têm-se outras válvulas de bloqueio que impedem que o } \\
\text { GNL entre numa linha onde não deveria fluir. Tem-se um } \\
\text { sistema de alívio para transferir o GNL nessas linhas. } \\
\text { Tem-se um sistema de monitoração que monitora e indica } \\
\text { quais são as condições internas do circuito de GNL, um } \\
\text { sistema de amostragem que indica a ocorrência de algum } \\
\text { vazamento de gás natural e o ESD que paralisa a } \\
\text { transferência da carga. }\end{array}$} \\
\hline
\end{tabular}




\begin{tabular}{|c|c|c|c|c|c|}
\hline \multicolumn{4}{|c|}{ Sistema: Sistema de carga e descarga do navio transportador de GNL } & \multirow[b]{2}{*}{$\begin{array}{l}\text { ANÁLISE PRELIMINAR } \\
\text { DE PERIGOS }\end{array}$} & Analista: \\
\hline \multicolumn{4}{|c|}{$\begin{array}{l}\text { Sub-sistemas: Sistema de conexão manifold, Sistema de distribuição, Sistema de Armazenagem, Sistema de } \\
\text { alívio, Sistema de baixa pressão, Sistema de alta pressão, Sistema de alívio do boil-off. }\end{array}$} & & Data: \\
\hline $\mathrm{N}^{\circ}$ & Perigo & Causas & Consequências & \multicolumn{2}{|c|}{ Barreiras de proteção } \\
\hline 5 & \multirow{3}{*}{$\begin{array}{c}\text { Grande } \\
\text { vazamento } \\
\text { de GNL }\end{array}$} & $\begin{array}{l}\text { Ruptura nas tubulações de conexão entre as } \\
\text { válvulas do manifold de bombordo. Ruptura } \\
\text { total da secção transversal. }\end{array}$ & $\begin{array}{l}\text { Danos à estrutura do navio. Possibilidade de } \\
\text { geração de uma nuvem de gás. } \\
\text { Congelamento da instalação circunvizinha. } \\
\text { Possibilidade de ingresso de ar atmosférico } \\
\text { para dentro do sistema quebrando o } \\
\text { ambiente de inertização. Paralisação do } \\
\text { processo de transferência do GNL. }\end{array}$ & \multicolumn{2}{|c|}{$\begin{array}{l}\text { Tem-se um sistema de emergência que paralisa o processo } \\
\text { de carga/descarga no caso de haver um grande vazamento. } \\
\text { Tem-se um sistema de monitoração que monitora e indica } \\
\text { quais são as condições internas do circuito de GNL, um } \\
\text { sistema de amostragem que indica a ocorrência de algum } \\
\text { vazamento de gás natural e o ESD que paralisa a } \\
\text { transferência da carga. }\end{array}$} \\
\hline 6 & & $\begin{array}{l}\text { Perda da integridade estrutural das válvulas } \\
\text { de bloqueio no manifold de estibordo } \\
\text { CL014, CL024, CL034, CL044, CS026, } \\
\text { CS036. }\end{array}$ & $\begin{array}{l}\text { Danos à estrutura do navio. Possibilidade de } \\
\text { geração de uma nuvem de gás. Paralisação } \\
\text { do processo de transferência do GNL. }\end{array}$ & \multicolumn{2}{|c|}{$\begin{array}{l}\text { Tem-se um sistema de monitoração que monitora e indica } \\
\text { quais são as condições internas do circuito de GNL, um } \\
\text { sistema de amostragem que indica a ocorrência de algum } \\
\text { vazamento de gás natural e o ESD que paralisa a } \\
\text { transferência da carga. }\end{array}$} \\
\hline 7 & & $\begin{array}{l}\text { Abertura das válvulas de bloqueio no } \\
\text { manifold de estibordo CL014, CL024, } \\
\text { CL034, CL044, CS026, CS036. }\end{array}$ & $\begin{array}{l}\text { Danos à estrutura do navio. Possibilidade de } \\
\text { geração de uma nuvem de gás. Paralisação } \\
\text { do processo de transferência do GNL. }\end{array}$ & \multicolumn{2}{|c|}{$\begin{array}{l}\text { Têm-se outras válvulas de bloqueio que impedem que o } \\
\text { GNL entre numa linha onde não deveria fluir. Tem-se um } \\
\text { sistema de alívio para transferir o GNL nessas linhas. } \\
\text { Tem-se um sistema de monitoração que monitora e indica } \\
\text { quais são as condições internas do circuito de GNL, um } \\
\text { sistema de amostragem que indica a ocorrência de algum } \\
\text { vazamento de gás natural e o ESD que paralisa a } \\
\text { transferência da carga. }\end{array}$} \\
\hline
\end{tabular}




\begin{tabular}{|c|c|c|c|c|c|}
\hline \multicolumn{4}{|c|}{ Sistema: Sistema de carga e descarga do navio transportador de GNL } & \multirow[b]{2}{*}{$\begin{array}{l}\text { ANÁLISE PRELIMINAR } \\
\text { DE PERIGOS }\end{array}$} & Analista: \\
\hline \multicolumn{4}{|c|}{$\begin{array}{l}\text { Sub-sistemas: Sistema de conexão manifold, Sistema de distribuição, Sistema de Armazenagem, Sistema de } \\
\text { alívio, Sistema de baixa pressão, Sistema de alta pressão, Sistema de alívio do boil-off. }\end{array}$} & & Data: \\
\hline $\mathrm{N}^{\circ}$ & Perigo & Causas & Consequências & \multicolumn{2}{|c|}{ Barreiras de proteção } \\
\hline 8 & \multirow{3}{*}{$\begin{array}{c}\text { Grande } \\
\text { vazamento } \\
\text { de GNL }\end{array}$} & $\begin{array}{l}\text { Ruptura nas tubulações de conexão entre as } \\
\text { válvulas do manifold de estibordo. }\end{array}$ & $\begin{array}{l}\text { Danos à estrutura do navio. Possibilidade de } \\
\text { geração de uma nuvem de gás. } \\
\text { Congelamento da instalação circunvizinha. } \\
\text { Possibilidade de ingresso de ar atmosférico } \\
\text { para dentro do sistema quebrando o } \\
\text { ambiente de inertização. Paralisação do } \\
\text { processo de transferência do GNL. }\end{array}$ & \multicolumn{2}{|c|}{$\begin{array}{l}\text { Tem-se um sistema de emergência que paralisa o processo } \\
\text { de carga/descarga no caso de haver um grande vazamento. } \\
\text { Tem-se um sistema de monitoração que monitora e indica } \\
\text { quais são as condições internas do circuito de GNL, um } \\
\text { sistema de amostragem que indica a ocorrência de algum } \\
\text { vazamento de gás natural e o ESD que paralisa a } \\
\text { transferência da carga. }\end{array}$} \\
\hline 9 & & $\begin{array}{l}\text { Ruptura na tubulação principal de GNL. } \\
\text { Ruptura total da secção transversal. }\end{array}$ & $\begin{array}{l}\text { Danos à estrutura do navio. Possibilidade de } \\
\text { geração de uma nuvem de gás. } \\
\text { Congelamento da instalação circunvizinha. } \\
\text { Possibilidade de ingresso de ar atmosférico } \\
\text { para dentro do sistema quebrando o } \\
\text { ambiente de inertização. Paralisação do } \\
\text { processo de transferência do GNL. }\end{array}$ & \multicolumn{2}{|c|}{$\begin{array}{l}\text { Tem-se um sistema de emergência que paralisa o processo } \\
\text { de carga/descarga no caso de haver um grande vazamento. } \\
\text { Tem-se um sistema de monitoração que monitora e indica } \\
\text { quais são as condições internas do circuito de GNL, um } \\
\text { sistema de amostragem que indica a ocorrência de algum } \\
\text { vazamento de gás natural e o ESD que paralisa a } \\
\text { transferência da carga. }\end{array}$} \\
\hline 10 & & $\begin{array}{l}\text { Ruptura nas tubulações secundárias entre os } \\
\text { manifolds até a tubulação principal. }\end{array}$ & $\begin{array}{l}\text { Danos à estrutura do navio. Possibilidade de } \\
\text { geração de uma nuvem de gás. } \\
\text { Congelamento da instalação circunvizinha. } \\
\text { Possibilidade de ingresso de ar atmosférico } \\
\text { para dentro do sistema quebrando o } \\
\text { ambiente de inertização. Paralisação do } \\
\text { processo de transferência do GNL. }\end{array}$ & \multicolumn{2}{|c|}{$\begin{array}{l}\text { Tem-se um sistema de emergência que paralisa o processo } \\
\text { de carga/descarga no caso de haver um grande vazamento. } \\
\text { Tem-se um sistema de monitoração que monitora e indica } \\
\text { quais são as condições internas do circuito de GNL, um } \\
\text { sistema de amostragem que indica a ocorrência de algum } \\
\text { vazamento de gás natural e o ESD que paralisa a } \\
\text { transferência da carga. }\end{array}$} \\
\hline
\end{tabular}




\begin{tabular}{|c|c|c|c|c|c|}
\hline \multicolumn{4}{|c|}{ Sistema: Sistema de carga e descarga do navio transportador de GNL } & \multirow[b]{2}{*}{$\begin{array}{l}\text { ANÁLISE PRELIMINAR } \\
\text { DE PERIGOS }\end{array}$} & Analista: \\
\hline \multicolumn{4}{|c|}{$\begin{array}{l}\text { Sub-sistemas: Sistema de conexão manifold, Sistema de distribuição, Sistema de Armazenagem, Sistema de } \\
\text { alívio, Sistema de baixa pressão, Sistema de alta pressão, Sistema de alívio do boil-off. }\end{array}$} & & Data: \\
\hline $\mathrm{N}^{\circ}$ & Perigo & Causas & Consequências & \multicolumn{2}{|c|}{ Barreiras de proteção } \\
\hline 11 & \multirow{4}{*}{$\begin{array}{c}\text { Grande } \\
\text { vazamento } \\
\text { de GNL }\end{array}$} & $\begin{array}{l}\text { Ruptura nas tubulações secundárias entre a } \\
\text { tubulação principal e o sistema de } \\
\text { armazenagem. }\end{array}$ & $\begin{array}{l}\text { Danos à estrutura do navio. Possibilidade de } \\
\text { geração de uma nuvem de gás. } \\
\text { Congelamento da instalação circunvizinha. } \\
\text { Possibilidade de ingresso de ar atmosférico } \\
\text { para dentro do sistema quebrando o } \\
\text { ambiente de inertização. Paralisação do } \\
\text { processo de transferência do GNL. }\end{array}$ & \multicolumn{2}{|c|}{$\begin{array}{l}\text { Tem-se um sistema de emergência que paralisa o processo } \\
\text { de carga/descarga no caso de haver um grande } \\
\text { vazamento. Tem-se um sistema de monitoração que } \\
\text { monitora e indica quais são as condições internas do } \\
\text { circuito de GNL, um sistema de amostragem que indica a } \\
\text { ocorrência de algum vazamento de gás natural e o ESD } \\
\text { que paralisa a transferência da carga. }\end{array}$} \\
\hline 12 & & $\begin{array}{l}\text { Perda da integridade estrutural das válvulas } \\
\text { de bloqueio no sistema de distribuição } \\
\text { CL700, CL701, CS703. }\end{array}$ & $\begin{array}{l}\text { Danos à estrutura do navio. Possibilidade de } \\
\text { geração de uma nuvem de gás. Paralisação } \\
\text { do processo de transferência do GNL. }\end{array}$ & \multicolumn{2}{|c|}{$\begin{array}{l}\text { Tem-se um sistema de monitoração que monitora e indica } \\
\text { quais são as condições internas do circuito de GNL, um } \\
\text { sistema de amostragem que indica a ocorrência de algum } \\
\text { vazamento de gás natural e o ESD que paralisa a } \\
\text { transferência da carga. }\end{array}$} \\
\hline 13 & & $\begin{array}{l}\text { Abertura das válvulas de bloqueio CL700, } \\
\text { CL701, CS703. }\end{array}$ & $\begin{array}{l}\text { Ingresso do GNL no circuito de boil-off de } \\
\text { baixa pressão (CL700). Ingresso do GNL no } \\
\text { circuito de inertização (CL701). Ingresso do } \\
\text { GNL no circuito de spray (CS703). } \\
\text { Paralisação do processo de transferência do } \\
\text { GNL. }\end{array}$ & \multicolumn{2}{|c|}{$\begin{array}{l}\text { Têm-se outras válvulas de bloqueio que impedem que o } \\
\text { GNL entre numa linha onde não deveria fluir. Tem-se um } \\
\text { sistema de alívio para transferir o GNL nessas linhas. } \\
\text { Tem-se um sistema de monitoração que monitora e indica } \\
\text { quais são as condições internas do circuito de GNL, um } \\
\text { sistema de amostragem que indica a ocorrência de algum } \\
\text { vazamento de gás natural e o ESD que paralisa a } \\
\text { transferência da carga. }\end{array}$} \\
\hline 14 & & $\begin{array}{l}\text { Perda da integridade estrutural das válvulas } \\
\text { de controle de fluxo que estão ao ingresso } \\
\text { dos tanques de armazenamento CL107, } \\
\text { CL100, CL207, CL200, CL307, CL300, } \\
\text { CL407, CL400. }\end{array}$ & $\begin{array}{l}\text { Danos à estrutura do navio. Possibilidade de } \\
\text { geração de uma nuvem de gás. Paralisação } \\
\text { do processo de transferência do GNL. }\end{array}$ & \multicolumn{2}{|c|}{$\begin{array}{l}\text { Tem-se um sistema de monitoração que monitora e indica } \\
\text { quais são as condições internas do circuito de GNL, um } \\
\text { sistema de amostragem que indica a ocorrência de algum } \\
\text { vazamento de gás natural e o ESD que paralisa a } \\
\text { transferência da carga. }\end{array}$} \\
\hline
\end{tabular}




\begin{tabular}{|c|c|c|c|c|c|}
\hline \multicolumn{4}{|c|}{ Sistema: Sistema de carga e descarga do navio transportador de GNL } & \multirow[b]{2}{*}{$\begin{array}{l}\text { ANÁLISE PRELIMINAR } \\
\text { DE PERIGOS }\end{array}$} & Analista: \\
\hline \multicolumn{4}{|c|}{$\begin{array}{l}\text { Sub-sistemas: Sistema de conexão manifold, Sistema de distribuição, Sistema de Armazenagem, Sistema de } \\
\text { alívio, Sistema de baixa pressão, Sistema de alta pressão, Sistema de alívio do boil-off. }\end{array}$} & & Data: \\
\hline $\mathrm{N}^{\circ}$ & Perigo & Causas & Consequências & \multicolumn{2}{|c|}{ Barreiras de proteção } \\
\hline 15 & \multirow{4}{*}{$\begin{array}{l}\text { Grande } \\
\text { vazamento } \\
\text { de GNL }\end{array}$} & $\begin{array}{l}\text { Perda da integridade estrutural das válvulas } \\
\text { de bloqueio que estão ao ingresso dos } \\
\text { tanques de armazenamento CL107, CL100, } \\
\text { CL207, CL200, CL307, CL300, CL407, } \\
\text { CL400. }\end{array}$ & $\begin{array}{l}\text { Danos à estrutura do navio. Possibilidade de } \\
\text { geração de uma nuvem de gás. Paralisação } \\
\text { do processo de transferência do GNL. }\end{array}$ & \multicolumn{2}{|c|}{$\begin{array}{l}\text { Tem-se um sistema de monitoração que monitora e indica } \\
\text { quais são as condições internas do circuito de GNL, um } \\
\text { sistema de amostragem que indica a ocorrência de algum } \\
\text { vazamento de gás natural e o ESD que paralisa a } \\
\text { transferência da carga. }\end{array}$} \\
\hline 16 & & $\begin{array}{l}\text { Abertura das válvulas de bloqueio que estão } \\
\text { ao ingresso dos tanques de armazenamento } \\
\text { CL104, CL106, CL105, CS104, CL204, } \\
\text { CL202, CL201, CS204, CL304, CL302, } \\
\text { CL301, CS304, CL404, CL402, CL401, } \\
\text { CS404. }\end{array}$ & $\begin{array}{l}\text { Ingresso do GNL no circuito de spray } \\
\text { (CS104, CS204, CS304, CS404). Ingresso } \\
\text { do GNL para dentro das tubulações que } \\
\text { servem para a descarga de GNL (CL104, } \\
\text { CL106, CL105, CL204, CL202, CL201, } \\
\text { CL304, CL302, CL301, CL404, CL402, } \\
\text { CL401). Paralisação do processo de } \\
\text { transferência de GNL. }\end{array}$ & \multicolumn{2}{|c|}{$\begin{array}{l}\text { Têm-se outras válvulas de bloqueio que impedem que o } \\
\text { GNL entre numa linha onde não deveria fluir. Tem-se um } \\
\text { sistema de alívio para transferir o GNL nessas linhas. } \\
\text { Tem-se um sistema de monitoração que monitora e indica } \\
\text { quais são as condições internas do circuito de GNL, um } \\
\text { sistema de amostragem que indica a ocorrência de algum } \\
\text { vazamento de gás natural e o ESD que paralisa a } \\
\text { transferência da carga. }\end{array}$} \\
\hline 17 & & Ruptura nos tanques de armazenamento. & $\begin{array}{l}\text { Danos à estrutura do navio. Possibilidade de } \\
\text { geração de uma nuvem de gás. } \\
\text { Congelamento da instalação circunvizinha. } \\
\text { Possibilidade de ingresso de ar atmosférico } \\
\text { para dentro do sistema quebrando o } \\
\text { ambiente de inertização. Paralisação do } \\
\text { processo de transferência do GNL. }\end{array}$ & \multicolumn{2}{|c|}{$\begin{array}{l}\text { Tem-se um sistema de monitoração que monitora e indica } \\
\text { quais são as condições internas do circuito de GNL, um } \\
\text { sistema de amostragem que indica a ocorrência de algum } \\
\text { vazamento de gás natural e o ESD que paralisa a } \\
\text { transferência da carga. Tem-se um tanque secundário que } \\
\text { cumpre a função de contenção em caso de qualquer } \\
\text { vazamento de GNL desde o tanque primário. Tem-se um } \\
\text { sistema de emergência que paralisa o processo de } \\
\text { carga/descarga. }\end{array}$} \\
\hline 18 & & $\begin{array}{l}\text { Ruptura nas tubulações que estão no } \\
\text { sistema de armazenagem. }\end{array}$ & $\begin{array}{l}\text { Danos à estrutura do navio. Possibilidade de } \\
\text { geração de uma nuvem de gás. } \\
\text { Congelamento da instalação circunvizinha. } \\
\text { Possibilidade de ingresso de ar atmosférico } \\
\text { para dentro do sistema quebrando o } \\
\text { ambiente de inertização. Paralisação do } \\
\text { processo de transferência do GNL. }\end{array}$ & \multicolumn{2}{|c|}{$\begin{array}{l}\text { Tem-se um sistema de emergência que paralisa o processo } \\
\text { de carga/descarga no caso de haver um grande } \\
\text { vazamento. Tem-se um sistema de monitoração que } \\
\text { monitora e indica quais são as condições internas do } \\
\text { circuito de GNL, um sistema de amostragem que indica a } \\
\text { ocorrência de algum vazamento de gás natural e o ESD } \\
\text { que paralisa a transferência da carga. }\end{array}$} \\
\hline
\end{tabular}




\begin{tabular}{|c|c|c|c|c|c|}
\hline \multicolumn{4}{|c|}{ Sistema: Sistema de carga e descarga do navio transportador de GNL } & \multirow{2}{*}{$\begin{array}{l}\text { ANÁLISE PRELIMINAR } \\
\text { DE PERIGOS }\end{array}$} & Analista: \\
\hline \multicolumn{4}{|c|}{$\begin{array}{l}\text { Sub-sistemas: Sistema de conexão manifold, Sistema de distribuição, Sistema de Armazenagem, Sistema de } \\
\text { alívio, Sistema de baixa pressão, Sistema de alta pressão, Sistema de alívio do boil-off. }\end{array}$} & & Data: \\
\hline $\mathrm{N}^{\circ}$ & Perigo & Causas & Consequências & \multicolumn{2}{|c|}{ Barreiras de proteção } \\
\hline 19 & \multirow[b]{2}{*}{$\begin{array}{c}\text { Grande } \\
\text { vazamento } \\
\text { de GNL }\end{array}$} & $\begin{array}{l}\text { Perda da integridade das válvulas de alívio } \\
\text { CR701, CR702, CR704, CR102, CR202, } \\
\text { CR302, CR402; CR011, CR012, CR013, } \\
\text { CR014, CR021, CR022, CR023, CR024, } \\
\text { CR031, CR032, CR033, CR034, CR103, } \\
\text { CR105, CR104, CR203, CR205, CR204, } \\
\text { CR303, CR305, CR304, CR403, CR405, } \\
\text { CR404, CR700, CR703; CR905, CR903, } \\
\text { CR904. }\end{array}$ & $\begin{array}{l}\text { Danos à estrutura do navio. Possibilidade de } \\
\text { geração de uma nuvem de gás. Paralisação } \\
\text { do processo de transferência do GNL. }\end{array}$ & \multicolumn{2}{|c|}{$\begin{array}{l}\text { Tem-se um sistema de monitoração que monitora e indica } \\
\text { quais são as condições internas do circuito de GNL, um } \\
\text { sistema de amostragem que indica a ocorrência de algum } \\
\text { vazamento de gás natural e o ESD que paralisa a } \\
\text { transferência da carga. }\end{array}$} \\
\hline 20 & & $\begin{array}{l}\text { Abertura das válvulas de alívio CR701, } \\
\text { CR702, CR704, CR102, CR202, CR302, } \\
\text { CR402; CR905, CR903, CR904. }\end{array}$ & $\begin{array}{l}\text { Ingresso do GNL no circuito de spray } \\
\text { (CR701, CR702, CR704, CR102, CR202, } \\
\text { CR302, CR402). Ingresso do GNL nas } \\
\text { tubulações de descarga de GNL (CR011, } \\
\text { CR012, CR013, CR014, CR021, CR022, } \\
\text { CR023, CR024, CR031, CR032, CR033, } \\
\text { CR034, CR103, CR105, CR104, CR203, } \\
\text { CR205, CR204, CR303, CR305, CR304, } \\
\text { CR403, CR405, CR404, CR700, CR703). } \\
\text { Ingresso do GNL no sistema de vaporização } \\
\text { na praça de máquinas (CR905, CR903, } \\
\text { CR904). Paralisação do processo de } \\
\text { transferência do GNL. }\end{array}$ & \multicolumn{2}{|c|}{$\begin{array}{l}\text { Têm-se outras válvulas de bloqueio que impedem que o } \\
\text { GNL entre numa linha onde não deveria fluir. Tem-se um } \\
\text { sistema de alívio para transferir o GNL nessas linhas. } \\
\text { Tem-se um sistema de monitoração que monitora e indica } \\
\text { quais são as condições internas do circuito de GNL, um } \\
\text { sistema de amostragem que indica a ocorrência de algum } \\
\text { vazamento de gás natural e o ESD que paralisa a } \\
\text { transferência da carga. }\end{array}$} \\
\hline
\end{tabular}




\begin{tabular}{|c|c|c|c|c|c|}
\hline \multicolumn{4}{|c|}{ Sistema: Sistema de carga e descarga do navio transportador de GNL } & \multirow[b]{2}{*}{$\begin{array}{l}\text { ANÁLISE PRELIMINAR } \\
\text { DE PERIGOS }\end{array}$} & Analista: \\
\hline \multicolumn{4}{|c|}{$\begin{array}{l}\text { Sub-sistemas: Sistema de conexão manifold, Sistema de distribuição, Sistema de Armazenagem, Sistema de } \\
\text { alívio, Sistema de baixa pressão, Sistema de alta pressão, Sistema de alívio do boil-off. }\end{array}$} & & Data: \\
\hline $\mathrm{N}^{\circ}$ & Perigo & Causas & Consequências & \multicolumn{2}{|c|}{ Barreiras de proteção } \\
\hline 21 & \multirow{3}{*}{$\begin{array}{l}\text { Grande } \\
\text { vazamento } \\
\text { de GNL }\end{array}$} & $\begin{array}{l}\text { Ruptura nas tubulações que servem para } \\
\text { deslocar o GNL aliviado para dentro dos } \\
\text { tanques } 2 \text { e } 3 \text {. }\end{array}$ & $\begin{array}{l}\text { Danos à estrutura do navio. Possibilidade de } \\
\text { geração de uma nuvem de gás. } \\
\text { Congelamento da instalação circunvizinha. } \\
\text { Possibilidade de ingresso de ar atmosférico } \\
\text { para dentro do sistema quebrando o } \\
\text { ambiente de inertização. Paralisação do } \\
\text { processo de transferência do GNL. }\end{array}$ & \multicolumn{2}{|c|}{$\begin{array}{l}\text { Tem-se um sistema de emergência que paralisa o processo } \\
\text { de carga/descarga no caso de haver um grande } \\
\text { vazamento. Tem-se um sistema de monitoração que } \\
\text { monitora e indica quais são as condições internas do } \\
\text { circuito de GNL, um sistema de amostragem que indica a } \\
\text { ocorrência de algum vazamento de gás natural e o ESD } \\
\text { que paralisa a transferência da carga. }\end{array}$} \\
\hline 22 & & $\begin{array}{l}\text { Falha do sistema de alarmes de nível de } \\
\text { GNL no interior dos tanques de } \\
\text { armazenamento que provocará o sobre } \\
\text { enchimento de um ou vários tanques de } \\
\text { armazenamento. }\end{array}$ & $\begin{array}{l}\text { Paralisação do processo de transferência do } \\
\text { GNL. Danos à estrutura do navio. } \\
\text { Congelamento da instalação circunvizinha. } \\
\text { Formação de gases produto do vazamento } \\
\text { de GNL. }\end{array}$ & \multicolumn{2}{|c|}{$\begin{array}{l}\text { Têm-se três níveis de alarmes que paralisa o processo de } \\
\text { transferência do GNL para o navio. Tem-se um sistema de } \\
\text { monitoração que monitora e indica quais são as condições } \\
\text { internas do circuito de GNL, um sistema de amostragem } \\
\text { que indica a ocorrência de algum vazamento de gás } \\
\text { natural e o ESD que paralisa a transferência da carga. }\end{array}$} \\
\hline 23 & & $\begin{array}{l}\text { Aumento da pressão no interior do circuito } \\
\text { de GNL devido à elevada pressão de } \\
\text { descarga do GNL à saída das bombas } \\
\text { criogênicas. }\end{array}$ & $\begin{array}{l}\text { Ruptura nos componentes no circuito de } \\
\text { GNL devido à elevada pressão no interior } \\
\text { do mesmo. Paralisação do processo de } \\
\text { transferência do GNL. Formação de poça } \\
\text { produto do vazamento de GNL. }\end{array}$ & \multicolumn{2}{|c|}{$\begin{array}{l}\text { Tem-se um sistema de monitoração que monitora e indica } \\
\text { quais são as condições internas do circuito de GNL, um } \\
\text { sistema de amostragem que indica a ocorrência de algum } \\
\text { vazamento de gás natural e o ESD que paralisa a } \\
\text { transferência da carga. }\end{array}$} \\
\hline
\end{tabular}


Tabela B.3 - Aplicação da técnica APP para um pequeno vazamento de boil-off

\begin{tabular}{|c|c|c|c|c|c|}
\hline \multicolumn{4}{|c|}{ Sistema: Sistema de carga e descarga do navio transportador de GNL } & \multirow{2}{*}{$\begin{array}{l}\text { ANÁLISE PRELIMINAR DE } \\
\text { PERIGOS }\end{array}$} & Analista: \\
\hline \multicolumn{4}{|c|}{$\begin{array}{l}\text { Sub-sistemas: Sistema de conexão manifold, Sistema de distribuição, Sistema de Armazenagem, Sistema } \\
\text { de alívio, Sistema de baixa pressão, Sistema de alta pressão, Sistema de alívio do boil-off. }\end{array}$} & & Data: \\
\hline $\mathrm{N}^{\circ}$ & Perigo & Causas & Consequências & \multicolumn{2}{|c|}{ Barreiras de proteção } \\
\hline 1 & \multirow{5}{*}{$\begin{array}{l}\text { Pequeno } \\
\text { vazamento } \\
\text { de boil-off }\end{array}$} & $\begin{array}{l}\text { Conexão indevida do braço criogênico que } \\
\text { descarrega o boil-off por meio do manifold } \\
\text { de bombordo. }\end{array}$ & $\begin{array}{l}\text { Liberação do boil-off para o ambiente } \\
\text { externo. Paralisação do processo de } \\
\text { transferência do GNL. Ativação dos } \\
\text { sistemas de emergência. }\end{array}$ & \multicolumn{2}{|c|}{$\begin{array}{l}\text { Tem-se um sistema de monitoração que monitora e indica } \\
\text { quais são as condições internas do circuito de boil-off, um } \\
\text { sistema de amostragem que indica a ocorrência de algum } \\
\text { vazamento de gás natural e o ESD que paralisa a } \\
\text { transferência da carga. }\end{array}$} \\
\hline 2 & & $\begin{array}{l}\text { Perda da integridade estrutural das válvulas } \\
\text { de controle de fluxo nos tanques CG100, } \\
\text { CG200, CG300, CG400. }\end{array}$ & $\begin{array}{l}\text { Liberação do boil-off para o ambiente } \\
\text { externo. Paralisação do processo de } \\
\text { transferência do GNL. }\end{array}$ & \multicolumn{2}{|c|}{$\begin{array}{l}\text { Tem-se um sistema de monitoração que monitora e indica } \\
\text { quais são as condições internas do circuito de boil-off, um } \\
\text { sistema de amostragem que indica a ocorrência de algum } \\
\text { vazamento de gás natural e o ESD que paralisa a } \\
\text { transferência da carga. }\end{array}$} \\
\hline 3 & & $\begin{array}{l}\text { Perda da integridade estrutural das válvulas } \\
\text { de bloqueio na saída dos tanques de } \\
\text { armazenamento de GNL CG101, CG201, } \\
\text { CG301, CG401. }\end{array}$ & $\begin{array}{l}\text { Liberação do boil-off para o ambiente } \\
\text { externo. Paralisação do processo de } \\
\text { transferência do GNL. }\end{array}$ & \multicolumn{2}{|c|}{$\begin{array}{l}\text { Tem-se um sistema de monitoração que monitora e indica } \\
\text { quais são as condições internas do circuito de boil-off, um } \\
\text { sistema de amostragem que indica a ocorrência de algum } \\
\text { vazamento de gás natural e o ESD que paralisa a } \\
\text { transferência da carga. }\end{array}$} \\
\hline 4 & & $\begin{array}{l}\text { Abertura das válvulas de bloqueio na saída } \\
\text { dos tanques de armazenamento de GNL } \\
\text { CG101, CG201, CG301, CG } 401 \text {. }\end{array}$ & $\begin{array}{l}\text { Ingresso do boil-off para dentro do circuito } \\
\text { de inertização. Paralisação do processo de } \\
\text { transferência do GNL. }\end{array}$ & \multicolumn{2}{|c|}{$\begin{array}{l}\text { Tem-se um sistema de monitoração que monitora e indica } \\
\text { quais são as condições internas do circuito de boil-off, um } \\
\text { sistema de amostragem que indica a ocorrência de algum } \\
\text { vazamento de gás natural e o ESD que paralisa a } \\
\text { transferência da carga. }\end{array}$} \\
\hline 5 & & $\begin{array}{l}\text { Perda da integridade estrutural da válvula } \\
\text { de controle de fluxo na distribuição no } \\
\text { sistema de baixa pressão CG704. }\end{array}$ & $\begin{array}{l}\text { Liberação do boil-off para o ambiente } \\
\text { externo. Paralisação do processo de } \\
\text { transferência do GNL. }\end{array}$ & \multicolumn{2}{|c|}{$\begin{array}{l}\text { Tem-se um sistema de monitoração que monitora e indica } \\
\text { quais são as condições internas do circuito de boil-off, um } \\
\text { sistema de amostragem que indica a ocorrência de algum } \\
\text { vazamento de gás natural e o ESD que paralisa a } \\
\text { transferência da carga. }\end{array}$} \\
\hline
\end{tabular}




\begin{tabular}{|c|c|c|c|c|c|}
\hline \multicolumn{4}{|c|}{ Sistema: Sistema de carga e descarga do navio transportador de GNL } & \multirow{2}{*}{$\begin{array}{l}\text { ANÁLISE PRELIMINAR DE } \\
\text { PERIGOS }\end{array}$} & Analista: \\
\hline \multicolumn{4}{|c|}{$\begin{array}{l}\text { Sub-sistemas: Sistema de conexão manifold, Sistema de distribuição, Sistema de Armazenagem, Sistema } \\
\text { de alívio, Sistema de baixa pressão, Sistema de alta pressão, Sistema de alívio do boil-off. }\end{array}$} & & \\
\hline $\mathrm{N}^{\circ}$ & Perigo & Causas & Consequências & \multicolumn{2}{|c|}{ Barreiras de proteção } \\
\hline 6 & \multirow{4}{*}{$\begin{array}{l}\text { Pequeno } \\
\text { vazamento } \\
\text { de boil-off }\end{array}$} & $\begin{array}{l}\text { Perda da integridade estrutural das válvulas } \\
\text { de bloqueio na distribuição no sistema de } \\
\text { baixa pressão CG701, CG700, CG707, } \\
\text { CG705, CG075, CS912, CG928. }\end{array}$ & $\begin{array}{l}\text { Liberação de boil-off para o ambiente } \\
\text { externo. Paralisação do processo de } \\
\text { transferência do GNL. }\end{array}$ & $\begin{array}{l}\text { Tem-se um sistema de monitoraç } \\
\text { quais são as condições internas d } \\
\text { sistema de amostragem que indic } \\
\text { vazamento de gás natural e o ES } \\
\text { transferência da carga. }\end{array}$ & $\begin{array}{l}\text { ão que monitora e indica } \\
\text { o circuito de boil-off, um } \\
\text { a a ocorrência de algum } \\
\text { que paralisa a }\end{array}$ \\
\hline 7 & & $\begin{array}{l}\text { Abertura das válvulas de bloqueio na } \\
\text { distribuição no sistema de baixa pressão } \\
\text { CG701, CG700, CG707, CG705, CG075, } \\
\text { CS912, CG928. }\end{array}$ & $\begin{array}{l}\text { Ingresso do boil-off nas tubulações do alívio } \\
\text { da tubulação principal (CG701). Ingresso do } \\
\text { boil-off no sistema de inertização (CG700). } \\
\text { Ingresso do boil-off para a praça de } \\
\text { máquinas chegando até a válvula CG927 na } \\
\text { praça (CG707). Liberação de boil-off pela } \\
\text { parte inferior do Misturador/Separador } \\
\text { (CS912). Ingresso do boil-off pressurizado } \\
\text { do sistema de alta pressão (CG075). } \\
\text { Ingresso do boil-off que provem do } \\
\text { Misturador/Separador e que vai para os } \\
\text { vaporizadores (CG928). }\end{array}$ & \multicolumn{2}{|c|}{$\begin{array}{l}\text { Têm-se outras válvulas de bloqueio que impedem que o } \\
\text { boil-off entre numa linha onde não deveria fluir. Tem-se } \\
\text { um sistema de monitoração que monitora e indica quais } \\
\text { são as condições internas do circuito de boil-off, um } \\
\text { sistema de amostragem que indica a ocorrência de algum } \\
\text { vazamento de gás natural e o ESD que paralisa a } \\
\text { transferência da carga. }\end{array}$} \\
\hline 8 & & $\begin{array}{l}\text { Perda da integridade estrutural das válvulas } \\
\text { de controle de fluxo na praça de máquinas } \\
\text { no circuito de alta vazão CG903, CG904, } \\
\text { CG907, CG908. }\end{array}$ & $\begin{array}{l}\text { Liberação de boil-off para dentro da praça de } \\
\text { máquinas. Paralisação do processo de } \\
\text { transferência do GNL. }\end{array}$ & \multicolumn{2}{|c|}{$\begin{array}{l}\text { Tem-se um sistema de monitoração que monitora e indica } \\
\text { quais são as condições internas do circuito de boil-off, um } \\
\text { sistema de amostragem que indica a ocorrência de algum } \\
\text { vazamento de gás natural e o ESD que paralisa a } \\
\text { transferência da carga. }\end{array}$} \\
\hline 9 & & $\begin{array}{l}\text { Abertura das válvulas de controle de fluxo } \\
\text { na praça de máquinas no circuito de alta } \\
\text { vazão CG903, CG904, CG907, CG908. }\end{array}$ & $\begin{array}{l}\text { Ingresso do boil-off pressurizado para o } \\
\text { sistema de baixa pressão. Paralisação do } \\
\text { processo de transferência do GNL. }\end{array}$ & \multicolumn{2}{|c|}{$\begin{array}{l}\text { Têm-se outras válvulas de bloqueio que impedem que o } \\
\text { boil-off entre numa linha onde não deveria fluir. Tem-se } \\
\text { um sistema de monitoração que monitora e indica quais } \\
\text { são as condições internas do circuito de boil-off, um } \\
\text { sistema de amostragem que indica a ocorrência de algum } \\
\text { vazamento de gás natural e o ESD que paralisa a } \\
\text { transferência da carga. }\end{array}$} \\
\hline
\end{tabular}




\begin{tabular}{|c|c|c|c|c|c|}
\hline \multicolumn{4}{|c|}{ Sistema: Sistema de carga e descarga do navio transportador de GNL } & \multirow{2}{*}{$\begin{array}{l}\text { ANÁLISE PRELIMINAR DE } \\
\text { PERIGOS }\end{array}$} & Analista: \\
\hline \multicolumn{4}{|c|}{$\begin{array}{l}\text { Sub-sistemas: Sistema de conexão manifold, Sistema de distribuição, Sistema de Armazenagem, Sistema } \\
\text { de alívio, Sistema de baixa pressão, Sistema de alta pressão, Sistema de alívio do boil-off. }\end{array}$} & & Data: \\
\hline $\mathrm{N}^{\circ}$ & Perigo & Causas & Consequências & \multicolumn{2}{|c|}{ Barreiras de proteção } \\
\hline 10 & \multirow{5}{*}{$\begin{array}{l}\text { Pequeno } \\
\text { vazamento } \\
\text { de boil-off }\end{array}$} & $\begin{array}{l}\text { Perda da integridade estrutural das válvulas } \\
\text { de bloqueio na praça de máquinas no } \\
\text { circuito de baixa vazão CG901, CG902. }\end{array}$ & $\begin{array}{l}\text { Liberação de boil-off para dentro da praça de } \\
\text { máquinas. Paralisação do processo de } \\
\text { transferência do GNL. }\end{array}$ & \multicolumn{2}{|c|}{$\begin{array}{l}\text { Tem-se um sistema de monitoração que monitora e indica } \\
\text { quais são as condições internas do circuito de boil-off, um } \\
\text { sistema de amostragem que indica a ocorrência de algum } \\
\text { vazamento de gás natural e o ESD que paralisa a } \\
\text { transferência da carga. }\end{array}$} \\
\hline 11 & & $\begin{array}{l}\text { Abertura das válvulas de bloqueio na praça } \\
\text { de máquinas no circuito de baixa vazão } \\
\text { CG901, CG902. }\end{array}$ & $\begin{array}{l}\text { Ingresso do boil-off de baixa pressão para } \\
\text { dentro do sistema de compressão de baixa } \\
\text { vazão. }\end{array}$ & \multicolumn{2}{|c|}{$\begin{array}{l}\text { Têm-se outras válvulas de bloqueio que impedem que o } \\
\text { boil-off entre numa linha onde não deveria fluir. Tem-se } \\
\text { um sistema de monitoração que monitora e indica quais } \\
\text { são as condições internas do circuito de boil-off, um } \\
\text { sistema de amostragem que indica a ocorrência de algum } \\
\text { vazamento de gás natural e o ESD que paralisa a } \\
\text { transferência da carga. }\end{array}$} \\
\hline 12 & & $\begin{array}{l}\text { Perda da integridade estrutural do } \\
\text { Misturador/Separador. }\end{array}$ & $\begin{array}{l}\text { Liberação de boil-off para dentro da praça de } \\
\text { máquinas. Paralisação do processo de } \\
\text { transferência do GNL. }\end{array}$ & \multicolumn{2}{|c|}{$\begin{array}{l}\text { Tem-se um sistema de monitoração que monitora e indica } \\
\text { quais são as condições internas do circuito de boil-off, um } \\
\text { sistema de amostragem que indica a ocorrência de algum } \\
\text { vazamento de gás natural e o ESD que paralisa a } \\
\text { transferência da carga. }\end{array}$} \\
\hline 13 & & Fissura na tubulação principal. & $\begin{array}{l}\text { Liberação de boil-off para o ambiente } \\
\text { externo. Paralisação do processo de } \\
\text { transferência do GNL. }\end{array}$ & \multicolumn{2}{|c|}{$\begin{array}{l}\text { Tem-se um sistema de monitoração que monitora e indica } \\
\text { quais são as condições internas do circuito de boil-off, um } \\
\text { sistema de amostragem que indica a ocorrência de algum } \\
\text { vazamento de gás natural e o ESD que paralisa a } \\
\text { transferência da carga. }\end{array}$} \\
\hline 14 & & $\begin{array}{l}\text { Fissura nas tubulações secundárias entre as } \\
\text { cúpulas dos tanques até a tubulação } \\
\text { principal. }\end{array}$ & $\begin{array}{l}\text { Liberação de boil-off para o ambiente } \\
\text { externo. Paralisação do processo de } \\
\text { transferência do GNL. }\end{array}$ & \multicolumn{2}{|c|}{$\begin{array}{l}\text { Tem-se um sistema de monitoração que monitora e indica } \\
\text { quais são as condições internas do circuito de boil-off, um } \\
\text { sistema de amostragem que indica a ocorrência de algum } \\
\text { vazamento de gás natural e o ESD que paralisa a } \\
\text { transferência da carga. }\end{array}$} \\
\hline
\end{tabular}




\begin{tabular}{|c|c|c|c|c|c|}
\hline \multicolumn{4}{|c|}{ Sistema: Sistema de carga e descarga do navio transportador de GNL } & \multirow{2}{*}{$\begin{array}{l}\text { ANÁLISE PRELIMINAR DE } \\
\text { PERIGOS }\end{array}$} & Analista: \\
\hline \multicolumn{4}{|c|}{$\begin{array}{l}\text { Sub-sistemas: Sistema de conexão manifold, Sistema de distribuição, Sistema de Armazenagem, Sistema } \\
\text { de alívio, Sistema de baixa pressão, Sistema de alta pressão, Sistema de alívio do boil-off. }\end{array}$} & & Data: \\
\hline $\mathrm{N}^{\circ}$ & Perigo & Causas & Consequências & \multicolumn{2}{|c|}{ Barreiras de proteção } \\
\hline 15 & \multirow{4}{*}{$\begin{array}{l}\text { Pequeno } \\
\text { vazamento } \\
\text { de boil-off }\end{array}$} & $\begin{array}{l}\text { Fissura nas tubulações secundárias entre a } \\
\text { tubulação principal até a praça de } \\
\text { máquinas. }\end{array}$ & $\begin{array}{l}\text { Liberação de boil-off para o ambiente } \\
\text { externo. Liberação de boil-off para a praça } \\
\text { de máquinas. Paralisação do processo de } \\
\text { transferência do GNL }\end{array}$ & \multicolumn{2}{|c|}{$\begin{array}{l}\text { Tem-se um sistema de monitoração que monitora e indica } \\
\text { quais são as condições internas do circuito de boil-off, um } \\
\text { sistema de amostragem que indica a ocorrência de algum } \\
\text { vazamento de gás natural e o ESD que paralisa a } \\
\text { transferência da carga. }\end{array}$} \\
\hline 16 & & $\begin{array}{l}\text { Perda da integridade estrutural dos } \\
\text { compressores de alta vazão. }\end{array}$ & $\begin{array}{l}\text { Liberação de boil-off para dentro da praça de } \\
\text { máquinas. Paralisação do processo de } \\
\text { transferência do GNL. }\end{array}$ & \multicolumn{2}{|c|}{$\begin{array}{l}\text { Tem-se um sistema de monitoração que monitora e indica } \\
\text { quais são as condições internas do circuito de boil-off, um } \\
\text { sistema de amostragem que indica a ocorrência de algum } \\
\text { vazamento de gás natural e o ESD que paralisa a } \\
\text { transferência da carga. }\end{array}$} \\
\hline 17 & & $\begin{array}{l}\text { Perda da integridade estrutural das válvulas } \\
\text { de controle de fluxo no sistema de alta } \\
\text { pressão CG911, CG912, CG915, CG916, } \\
\text { CG900, CG071, CG073. }\end{array}$ & $\begin{array}{l}\text { Liberação de boil-off para dentro da praça de } \\
\text { máquinas (CG911, CG912, CG915, CG916, } \\
\text { CG900). Liberação do boil-off para o } \\
\text { ambiente externo (CG071, CG073). } \\
\text { Paralisação do processo de transferência do } \\
\text { GNL. }\end{array}$ & \multicolumn{2}{|c|}{$\begin{array}{l}\text { Tem-se um sistema de monitoração que monitora e indica } \\
\text { quais são as condições internas do circuito de boil-off, um } \\
\text { sistema de amostragem que indica a ocorrência de algum } \\
\text { vazamento de gás natural e o ESD que paralisa a } \\
\text { transferência da carga. }\end{array}$} \\
\hline 18 & & $\begin{array}{l}\text { Perda da integridade estrutural das válvulas } \\
\text { de bloqueio no sistema de alta pressão } \\
\text { CG925, CG917, CG703, CG072, CG074. }\end{array}$ & $\begin{array}{l}\text { Liberação de boil-off para dentro da praça de } \\
\text { máquinas. Paralisação do processo de } \\
\text { transferência do GNL. }\end{array}$ & \multicolumn{2}{|c|}{$\begin{array}{l}\text { Tem-se um sistema de monitoração que monitora e indica } \\
\text { quais são as condições internas do circuito de boil-off, um } \\
\text { sistema de amostragem que indica a ocorrência de algum } \\
\text { vazamento de gás natural e o ESD que paralisa a } \\
\text { transferência da carga. }\end{array}$} \\
\hline
\end{tabular}




\begin{tabular}{|c|c|c|c|c|c|}
\hline \multicolumn{4}{|c|}{ Sistema: Sistema de carga e descarga do navio transportador de GNL } & \multirow{2}{*}{$\begin{array}{l}\text { ANÁLISE PRELIMINAR DE } \\
\text { PERIGOS }\end{array}$} & Analista: \\
\hline \multicolumn{4}{|c|}{$\begin{array}{l}\text { Sub-sistemas: Sistema de conexão manifold, Sistema de distribuição, Sistema de Armazenagem, Sistema } \\
\text { de alívio, Sistema de baixa pressão, Sistema de alta pressão, Sistema de alívio do boil-off. }\end{array}$} & & \\
\hline $\mathrm{N}^{\circ}$ & Perigo & Causas & Consequências & \multicolumn{2}{|c|}{ Barreiras de proteção } \\
\hline 19 & \multirow{4}{*}{$\begin{array}{l}\text { Pequeno } \\
\text { vazamento } \\
\text { de boil-off }\end{array}$} & $\begin{array}{l}\text { Abertura das válvulas de bloqueio no } \\
\text { sistema de alta pressão CG925, CG917, } \\
\text { CG703, CG072, CG074. }\end{array}$ & $\begin{array}{l}\text { Ingresso do boil-off no circuito de baixa } \\
\text { vazão e para o sistema de boil-off/warm up } \\
\text { Heater } \mathrm{N}^{\circ} 2 \text { (CG925). Ingresso do boil-off } \\
\text { para o sistema de boil-off/warm up Heater } \\
\mathrm{N}^{\circ} 1 \text { (CG917). Ingresso do boil-off para o } \\
\text { circuito de inertização (CG703). Liberação } \\
\text { de boil-off para o meio ambiente pelo lado } \\
\text { do manifold de estibordo (CG072 e CG074). } \\
\text { Paralisação do processo de transferência do } \\
\text { GNL. }\end{array}$ & \multicolumn{2}{|c|}{$\begin{array}{l}\text { Têm-se outras válvulas de bloqueio que impedem que o } \\
\text { boil-off entre numa linha onde não deveria fluir. Tem-se } \\
\text { um sistema de monitoração que monitora e indica quais } \\
\text { são as condições internas do circuito de boil-off, um } \\
\text { sistema de amostragem que indica a ocorrência de algum } \\
\text { vazamento de gás natural e o ESD que paralisa a } \\
\text { transferência da carga. }\end{array}$} \\
\hline 20 & & $\begin{array}{l}\text { Fissura nas tubulações de saída da praça de } \\
\text { máquinas até a conexão do navio com o } \\
\text { porto. }\end{array}$ & $\begin{array}{l}\text { Liberação de boil-off para dentro da praça de } \\
\text { máquinas. Liberação do boil-off para o } \\
\text { ambiente externo. Paralisação do processo } \\
\text { de transferência do GNL. . }\end{array}$ & \multicolumn{2}{|c|}{$\begin{array}{l}\text { Tem-se um sistema de monitoração que monitora e indica } \\
\text { quais são as condições internas do circuito de boil-off, um } \\
\text { sistema de amostragem que indica a ocorrência de algum } \\
\text { vazamento de gás natural e o ESD que paralisa a } \\
\text { transferência da carga. }\end{array}$} \\
\hline 21 & & $\begin{array}{l}\text { Perda da integridade estrutural das válvulas } \\
\text { de alívio nos próprios tanques CR100, } \\
\text { CR101, CR200, CR201, CR300, CR301, } \\
\text { CR400, CR401. }\end{array}$ & $\begin{array}{l}\text { Liberação de boil-off para o ambiente } \\
\text { externo. Paralisação do processo de } \\
\text { transferência do GNL. }\end{array}$ & \multicolumn{2}{|c|}{$\begin{array}{l}\text { Tem-se um sistema de monitoração que monitora e indica } \\
\text { quais são as condições internas do circuito de boil-off, um } \\
\text { sistema de amostragem que indica a ocorrência de algum } \\
\text { vazamento de gás natural e o ESD que paralisa a } \\
\text { transferência da carga. }\end{array}$} \\
\hline 22 & & $\begin{array}{l}\text { Fissura nas tubulações que saem das } \\
\text { válvulas de alívio dos tanques e chegam até } \\
\text { o riser. }\end{array}$ & $\begin{array}{l}\text { Liberação de boil-off para o ambiente } \\
\text { externo. Paralisação do processo de } \\
\text { transferência do GNL. }\end{array}$ & \multicolumn{2}{|c|}{$\begin{array}{l}\text { Tem-se um sistema de monitoração que monitora e indica } \\
\text { quais são as condições internas do circuito de boil-off, um } \\
\text { sistema de amostragem que indica a ocorrência de algum } \\
\text { vazamento de gás natural e o ESD que paralisa a } \\
\text { transferência da carga. }\end{array}$} \\
\hline
\end{tabular}




\begin{tabular}{|c|c|c|c|c|c|}
\hline \multicolumn{4}{|c|}{ Sistema: Sistema de carga e descarga do navio transportador de GNL } & \multirow{2}{*}{$\begin{array}{l}\text { ANÁLISE PRELIMINAR DE } \\
\text { PERIGOS }\end{array}$} & Analista: \\
\hline \multicolumn{4}{|c|}{$\begin{array}{l}\text { Sub-sistemas: Sistema de conexão manifold, Sistema de distribuição, Sistema de Armazenagem, Sistema } \\
\text { de alívio, Sistema de baixa pressão, Sistema de alta pressão, Sistema de alívio do boil-off. }\end{array}$} & & Data: \\
\hline $\mathrm{N}^{\circ}$ & Perigo & Causas & Consequências & \multicolumn{2}{|c|}{ Barreiras de proteção } \\
\hline 23 & \multirow{3}{*}{$\begin{array}{c}\text { Pequeno } \\
\text { vazamento } \\
\text { de boil-off }\end{array}$} & $\begin{array}{l}\text { Fissura nos risers dos tanques Riser } 1 \text {, } \\
\text { Riser } 2 \text {, Riser } 3 \text {, Riser } 4 .\end{array}$ & $\begin{array}{l}\text { Liberação de boil-off para o ambiente } \\
\text { externo. Paralisação do processo de } \\
\text { transferência do GNL. }\end{array}$ & \multicolumn{2}{|c|}{$\begin{array}{l}\text { Tem-se um sistema de monitoração que monitora e indica } \\
\text { quais são as condições internas do circuito de boil-off, um } \\
\text { sistema de amostragem que indica a ocorrência de algum } \\
\text { vazamento de gás natural e o ESD que paralisa a } \\
\text { transferência da carga. }\end{array}$} \\
\hline 24 & & $\begin{array}{l}\text { Perda da integridade estrutural da válvula } \\
\text { de alívio CG702. }\end{array}$ & $\begin{array}{l}\text { Liberação de boil-off para o ambiente } \\
\text { externo. Paralisação do processo de } \\
\text { transferência do GNL. }\end{array}$ & \multicolumn{2}{|c|}{$\begin{array}{l}\text { Tem-se um sistema de monitoração que monitora e indica } \\
\text { quais são as condições internas do circuito de boil-off, um } \\
\text { sistema de amostragem que indica a ocorrência de algum } \\
\text { vazamento de gás natural e o ESD que paralisa a } \\
\text { transferência da carga. }\end{array}$} \\
\hline 25 & & $\begin{array}{l}\text { Fissura da tubulação que sai da válvula } \\
\text { CG702 e chega até o riser do tanque } 1 .\end{array}$ & $\begin{array}{l}\text { Liberação de boil-off para o ambiente } \\
\text { externo. Paralisação do processo de } \\
\text { transferência do GNL. }\end{array}$ & \multicolumn{2}{|c|}{$\begin{array}{l}\text { Tem-se um sistema de monitoração que monitora e indica } \\
\text { quais são as condições internas do circuito de boil-off, um } \\
\text { sistema de amostragem que indica a ocorrência de algum } \\
\text { vazamento de gás natural e o ESD que paralisa a } \\
\text { transferência da carga. }\end{array}$} \\
\hline
\end{tabular}


Tabela B.4 - Aplicação da técnica APP para um grande vazamento de boil-off

\begin{tabular}{|c|c|c|c|c|c|}
\hline \multicolumn{4}{|c|}{ Sistema: Sistema de carga e descarga do navio transportador de GNL } & \multirow{2}{*}{$\begin{array}{l}\text { ANÁLISE PRELIMINAR DE } \\
\text { PERIGOS }\end{array}$} & Analista: \\
\hline \multicolumn{4}{|c|}{$\begin{array}{l}\text { Sub-sistemas: Sistema de conexão manifold, Sistema de distribuição, Sistema de Armazenagem, } \\
\text { Sistema de alívio, Sistema de baixa pressão, Sistema de alta pressão, Sistema de alívio do boil-off. }\end{array}$} & & Data: \\
\hline $\mathrm{N}^{\circ}$ & Perigo & Causas & Consequências & \multicolumn{2}{|c|}{ Barreiras de proteção } \\
\hline 1 & \multirow{5}{*}{$\begin{array}{c}\text { Grande } \\
\text { vazamento } \\
\text { de boil-off }\end{array}$} & $\begin{array}{l}\text { Conexão indevida do braço criogênico } \\
\text { que descarrega o boil-off por meio do } \\
\text { manifold de bombordo. }\end{array}$ & $\begin{array}{l}\text { Liberação do boil-off para o ambiente } \\
\text { externo. Possibilidade de geração de uma } \\
\text { nuvem de gás. Paralisação do processo de } \\
\text { transferência do GNL. Ativação dos } \\
\text { sistemas de emergência. }\end{array}$ & \multicolumn{2}{|c|}{$\begin{array}{l}\text { Tem-se um sistema de monitoração que monitora e indica } \\
\text { quais são as condições internas do circuito de boil-off, um } \\
\text { sistema de amostragem que indica a ocorrência de algum } \\
\text { vazamento de gás natural e o ESD que paralisa a transferência } \\
\text { da carga. }\end{array}$} \\
\hline 2 & & $\begin{array}{l}\text { Perda da integridade estrutural das } \\
\text { válvulas de controle de fluxo nos tanques } \\
\text { CG100, CG200, CG300, CG400. }\end{array}$ & $\begin{array}{l}\text { Liberação de boil-off para o ambiente } \\
\text { externo. Possibilidade de geração de uma } \\
\text { nuvem de gás. Paralisação do processo de } \\
\text { transferência do GNL. }\end{array}$ & \multicolumn{2}{|c|}{$\begin{array}{l}\text { Tem-se um sistema de monitoração que monitora e indica } \\
\text { quais são as condições internas do circuito de boil-off, um } \\
\text { sistema de amostragem que indica a ocorrência de algum } \\
\text { vazamento de gás natural e o ESD que paralisa a transferência } \\
\text { da carga. }\end{array}$} \\
\hline 3 & & $\begin{array}{l}\text { Perda da integridade estrutural das } \\
\text { válvulas de bloqueio na saída dos } \\
\text { tanques de armazenamento do GNL } \\
\text { CG101, CG201, CG301, CG401. }\end{array}$ & $\begin{array}{l}\text { Liberação de boil-off para o ambiente } \\
\text { externo. Possibilidade de geração de uma } \\
\text { nuvem de gás. Paralisação do processo de } \\
\text { transferência do GNL. }\end{array}$ & \multicolumn{2}{|c|}{$\begin{array}{l}\text { Tem-se um sistema de monitoração que monitora e indica } \\
\text { quais são as condições internas do circuito de boil-off, um } \\
\text { sistema de amostragem que indica a ocorrência de algum } \\
\text { vazamento de gás natural e o ESD que paralisa a transferência } \\
\text { da carga. }\end{array}$} \\
\hline 4 & & $\begin{array}{l}\text { Abertura das válvulas de bloqueio na } \\
\text { saída dos tanques de armazenamento do } \\
\text { GNL CG101, CG201, CG301, CG401. }\end{array}$ & $\begin{array}{l}\text { Ingresso do boil-off para dentro do circuito } \\
\text { de inertização. Paralisação do processo de } \\
\text { transferência do GNL. }\end{array}$ & \multicolumn{2}{|c|}{$\begin{array}{l}\text { Tem-se um sistema de monitoração que monitora e indica } \\
\text { quais são as condições internas do circuito de boil-off, um } \\
\text { sistema de amostragem que indica a ocorrência de algum } \\
\text { vazamento de gás natural e o ESD que paralisa a transferência } \\
\text { da carga. }\end{array}$} \\
\hline 5 & & $\begin{array}{l}\text { Perda da integridade estrutural da } \\
\text { válvula de controle de fluxo na } \\
\text { distribuição no sistema de baixa pressão } \\
\text { CG704. }\end{array}$ & $\begin{array}{l}\text { Liberação de boil-off para o ambiente } \\
\text { externo. Possibilidade de geração de uma } \\
\text { nuvem de gás. Paralisação do processo de } \\
\text { transferência do GNL. }\end{array}$ & \multicolumn{2}{|c|}{$\begin{array}{l}\text { Tem-se um sistema de monitoração que monitora e indica } \\
\text { quais são as condições internas do circuito de boil-off, um } \\
\text { sistema de amostragem que indica a ocorrência de algum } \\
\text { vazamento de gás natural e o ESD que paralisa a transferência } \\
\text { da carga. }\end{array}$} \\
\hline
\end{tabular}




\begin{tabular}{|c|c|c|c|c|c|}
\hline \multicolumn{4}{|c|}{ Sistema: Sistema de carga e descarga do navio transportador de GNL } & \multirow{2}{*}{$\begin{array}{l}\text { ANÁLISE PRELIMINAR DE } \\
\text { PERIGOS }\end{array}$} & Analista: \\
\hline \multicolumn{4}{|c|}{$\begin{array}{l}\text { Sub-sistemas: Sistema de conexão manifold, Sistema de distribuição, Sistema de Armazenagem, } \\
\text { Sistema de alívio, Sistema de baixa pressão, Sistema de alta pressão, Sistema de alívio do boil-off. }\end{array}$} & & Data. \\
\hline $\mathrm{N}^{\circ}$ & Perigo & Causas & Consequências & \multicolumn{2}{|c|}{ Barreiras de proteção } \\
\hline 6 & \multirow{3}{*}{$\begin{array}{c}\text { Grande } \\
\text { vazamento } \\
\text { de boil-off }\end{array}$} & $\begin{array}{l}\text { Perda da integridade estrutural das } \\
\text { válvulas de bloqueio na distribuição do } \\
\text { sistema de baixa pressão CG701, } \\
\text { CG700, CG707, CG705, CG075, CS912, } \\
\text { CG928. }\end{array}$ & $\begin{array}{l}\text { Liberação de boil-off para o ambiente } \\
\text { externo. Possibilidade de geração de uma } \\
\text { nuvem de gás. Paralisação do processo de } \\
\text { transferência do GNL. }\end{array}$ & \multicolumn{2}{|c|}{$\begin{array}{l}\text { Tem-se um sistema de monitoração que monitora e indica } \\
\text { quais são as condições internas do circuito de boil-off, um } \\
\text { sistema de amostragem que indica a ocorrência de algum } \\
\text { vazamento de gás natural e o ESD que paralisa a transferência } \\
\text { da carga. }\end{array}$} \\
\hline 7 & & $\begin{array}{l}\text { Abertura das válvulas de bloqueio na } \\
\text { distribuição do sistema de baixa pressão } \\
\text { CG701, CG700, CG707, CG705, } \\
\text { CG075, CS912, CG928. }\end{array}$ & $\begin{array}{l}\text { Ingresso do boil-off para as tubulações do } \\
\text { alívio da tubulação principal (CG701). } \\
\text { Ingresso do boil-off para a circuito de } \\
\text { inertização (CG700). Ingresso do boil-off } \\
\text { para a praça de máquinas chegando até a } \\
\text { válvula CG927 na praça (CG707). } \\
\text { Liberação de boil-off pela parte inferior do } \\
\text { Misturador/Separador (CS912). Ingresso do } \\
\text { boil-off pressurizado do sistema de alta } \\
\text { pressão (CG075). Ingresso do boil-off que } \\
\text { provem do lado direito do } \\
\text { Misturador/Separador e que vai para os } \\
\text { vaporizadores(CG928). Paralisação do } \\
\text { processo de transferência do GNL. }\end{array}$ & \multicolumn{2}{|c|}{$\begin{array}{l}\text { Tem-se outras válvulas de bloqueio que impedem que o boil- } \\
\text { off entre numa linha onde não deveria fluir. Tem-se um } \\
\text { sistema de monitoração que monitora e indica quais são as } \\
\text { condições internas do circuito de boil-off, um sistema de } \\
\text { amostragem que indica a ocorrência de algum vazamento de } \\
\text { gás natural e o ESD que paralisa a transferência da carga. }\end{array}$} \\
\hline 8 & & $\begin{array}{l}\text { Perda da integridade estrutural das } \\
\text { válvulas de controle de fluxo na praça de } \\
\text { máquinas no circuito de alta vazão } \\
\text { CG903, CG904, CG907, CG908. }\end{array}$ & $\begin{array}{l}\text { Liberação de boil-off para o ambiente } \\
\text { externo. Possibilidade de geração de uma } \\
\text { nuvem de gás. Paralisação do processo de } \\
\text { transferência do GNL. }\end{array}$ & \multicolumn{2}{|c|}{$\begin{array}{l}\text { Tem-se um sistema de monitoração que monitora e indica } \\
\text { quais são as condições internas do circuito de boil-off, um } \\
\text { sistema de amostragem que indica a ocorrência de algum } \\
\text { vazamento de gás natural e o ESD que paralisa a transferência } \\
\text { da carga. }\end{array}$} \\
\hline
\end{tabular}




\begin{tabular}{|c|c|c|c|c|c|}
\hline \multicolumn{4}{|c|}{ Sistema: Sistema de carga e descarga do navio transportador de GNL } & \multirow{2}{*}{$\begin{array}{l}\text { ANÁLISE PRELIMINAR DE } \\
\text { PERIGOS }\end{array}$} & Analista: \\
\hline \multicolumn{4}{|c|}{$\begin{array}{l}\text { Sub-sistemas: Sistema de conexão manifold, Sistema de distribuição, Sistema de Armazenagem, } \\
\text { Sistema de alívio, Sistema de baixa pressão, Sistema de alta pressão, Sistema de alívio do boil-off. }\end{array}$} & & \\
\hline $\mathrm{N}^{\circ}$ & Perigo & Causas & Consequências & \multicolumn{2}{|c|}{ Barreiras de proteção } \\
\hline 9 & \multirow{5}{*}{$\begin{array}{c}\text { Grande } \\
\text { vazamento } \\
\text { de boil-off }\end{array}$} & $\begin{array}{l}\text { Abertura das válvulas de controle de } \\
\text { fluxo na praça de máquinas no circuito } \\
\text { de alta vazão CG903, CG904, CG907, } \\
\text { CG908. }\end{array}$ & $\begin{array}{l}\text { Ingresso do boil-off pressurizado para o } \\
\text { sistema de baixa pressão. Paralisação do } \\
\text { processo de transferência do GNL. }\end{array}$ & \multicolumn{2}{|c|}{$\begin{array}{l}\text { Tem-se outras válvulas de bloqueio que impedem que o boil- } \\
\text { off entre numa linha onde não deveria fluir. Tem-se um } \\
\text { sistema de monitoração que monitora e indica quais são as } \\
\text { condições internas do circuito de boil-off, um sistema de } \\
\text { amostragem que indica a ocorrência de algum vazamento de } \\
\text { gás natural e o ESD que paralisa a transferência da carga. }\end{array}$} \\
\hline 10 & & $\begin{array}{l}\text { Perda da integridade estrutural das } \\
\text { válvulas de bloqueio na praça de } \\
\text { máquinas no circuito de baixa vazão } \\
\text { CG901, CG902. }\end{array}$ & $\begin{array}{l}\text { Liberação de boil-off para o ambiente } \\
\text { externo. Possibilidade de geração de uma } \\
\text { nuvem de gás. Paralisação do processo de } \\
\text { transferência do GNL. }\end{array}$ & \multicolumn{2}{|c|}{$\begin{array}{l}\text { Tem-se um sistema de monitoração que monitora e indica } \\
\text { quais são as condições internas do circuito de boil-off, um } \\
\text { sistema de amostragem que indica a ocorrência de algum } \\
\text { vazamento de gás natural e o ESD que paralisa a transferência } \\
\text { da carga. }\end{array}$} \\
\hline 11 & & $\begin{array}{l}\text { Abertura das válvulas de bloqueio na } \\
\text { praça de máquinas no circuito de baixa } \\
\text { vazão CG901, CG902. }\end{array}$ & $\begin{array}{l}\text { Ingresso do boil-off de baixa pressão para } \\
\text { dentro do sistema de compressão de baixa } \\
\text { vazão. Paralisação do processo de } \\
\text { transferência do GNL. }\end{array}$ & \multicolumn{2}{|c|}{$\begin{array}{l}\text { Tem-se outras válvulas de bloqueio que impedem que o boil- } \\
\text { off entre numa linha onde não deveria fluir. Tem-se um } \\
\text { sistema de monitoração que monitora e indica quais são as } \\
\text { condições internas do circuito de boil-off, um sistema de } \\
\text { amostragem que indica a ocorrência de algum vazamento de } \\
\text { gás natural e o ESD que paralisa a transferência da carga. }\end{array}$} \\
\hline 12 & & $\begin{array}{l}\text { Perda da integridade estrutural do } \\
\text { Misturador/Separador. }\end{array}$ & $\begin{array}{l}\text { Liberação de boil-off para o ambiente } \\
\text { externo. Possibilidade de geração de uma } \\
\text { nuvem de gás. Paralisação do processo de } \\
\text { transferência do GNL. }\end{array}$ & \multicolumn{2}{|c|}{$\begin{array}{l}\text { Tem-se um sistema de monitoração que monitora e indica } \\
\text { quais são as condições internas do circuito de boil-off, um } \\
\text { sistema de amostragem que indica a ocorrência de algum } \\
\text { vazamento de gás natural e o ESD que paralisa a transferência } \\
\text { da carga. }\end{array}$} \\
\hline 13 & & Ruptura na tubulação principal. & $\begin{array}{l}\text { Liberação de boil-off para o ambiente } \\
\text { externo. Possibilidade de geração de uma } \\
\text { nuvem de gás. Possibilidade de ingresso de } \\
\text { ar atmosférico para dentro do sistema } \\
\text { quebrando o ambiente de inertização. } \\
\text { Paralisação do processo de transferência do } \\
\text { GNL. }\end{array}$ & \multicolumn{2}{|c|}{$\begin{array}{l}\text { Tem-se um sistema de emergência que paralisa o processo de } \\
\text { carga/descarga no caso de haver um grande vazamento. Tem- } \\
\text { se um sistema de monitoração que monitora e indica quais são } \\
\text { as condições internas do circuito de boil-off, um sistema de } \\
\text { amostragem que indica a ocorrência de algum vazamento de } \\
\text { gás natural e o ESD que paralisa a transferência da carga. }\end{array}$} \\
\hline
\end{tabular}




\begin{tabular}{|c|c|c|c|c|c|}
\hline \multicolumn{4}{|c|}{ Sistema: Sistema de carga e descarga do navio transportador de GNL } & \multirow{2}{*}{$\begin{array}{l}\text { ANÁLISE PRELIMINAR DE } \\
\text { PERIGOS }\end{array}$} & Analista: \\
\hline \multicolumn{4}{|c|}{$\begin{array}{l}\text { Sub-sistemas: Sistema de conexão manifold, Sistema de distribuição, Sistema de Armazenagem, } \\
\text { Sistema de alívio, Sistema de baixa pressão, Sistema de alta pressão, Sistema de alívio do boil-off. }\end{array}$} & & \\
\hline $\mathrm{N}^{\circ}$ & Perigo & Causas & Consequências & \multicolumn{2}{|c|}{ Barreiras de proteção } \\
\hline 14 & \multirow{4}{*}{\begin{tabular}{|c|} 
Grande \\
vazamento \\
de boil-off
\end{tabular}} & $\begin{array}{l}\text { Ruptura nas tubulações secundárias entre } \\
\text { as cúpulas dos tanques até a tubulação } \\
\text { principal. }\end{array}$ & $\begin{array}{l}\text { Liberação de boil-off para o ambiente } \\
\text { externo. Possibilidade de geração de uma } \\
\text { nuvem de gás. Possibilidade de ingresso de } \\
\text { ar atmosférico para dentro do sistema } \\
\text { quebrando o ambiente de inertização. } \\
\text { Paralisação do processo de transferência do } \\
\text { GNL. }\end{array}$ & \multicolumn{2}{|c|}{$\begin{array}{l}\text { Tem-se um sistema de emergência que paralisa o processo de } \\
\text { carga/descarga no caso de haver um grande vazamento. Tem- } \\
\text { se um sistema de monitoração que monitora e indica quais são } \\
\text { as condições internas do circuito de boil-off, um sistema de } \\
\text { amostragem que indica a ocorrência de algum vazamento de } \\
\text { gás natural e o ESD que paralisa a transferência da carga. }\end{array}$} \\
\hline 15 & & $\begin{array}{l}\text { Ruptura nas tubulações secundárias entre } \\
\text { a tubulação principal até o quarto de } \\
\text { máquinas. }\end{array}$ & $\begin{array}{l}\text { Liberação de boil-off para o ambiente } \\
\text { externo. Possibilidade de geração de uma } \\
\text { nuvem de gás. Possibilidade de ingresso de } \\
\text { ar atmosférico para dentro do sistema } \\
\text { quebrando o ambiente de inertização. } \\
\text { Paralisação do processo de transferência do } \\
\text { GNL. }\end{array}$ & \multicolumn{2}{|c|}{$\begin{array}{l}\text { Tem-se um sistema de emergência que paralisa o processo de } \\
\text { carga/descarga no caso de haver um grande vazamento. Tem- } \\
\text { se um sistema de monitoração que monitora e indica quais são } \\
\text { as condições internas do circuito de boil-off, um sistema de } \\
\text { amostragem que indica a ocorrência de algum vazamento de } \\
\text { gás natural e o ESD que paralisa a transferência da carga. }\end{array}$} \\
\hline 16 & & $\begin{array}{l}\text { Perda da integridade estrutural dos } \\
\text { compressores de alta vazão. }\end{array}$ & $\begin{array}{l}\text { Liberação de boil-off para o ambiente } \\
\text { externo. Possibilidade de geração de uma } \\
\text { nuvem de gás. Paralisação do processo de } \\
\text { transferência do GNL. }\end{array}$ & \multicolumn{2}{|c|}{$\begin{array}{l}\text { Tem-se um sistema de monitoração que monitora e indica } \\
\text { quais são as condições internas do circuito de boil-off, um } \\
\text { sistema de amostragem que indica a ocorrência de algum } \\
\text { vazamento de gás natural e o ESD que paralisa a transferência } \\
\text { da carga. }\end{array}$} \\
\hline 17 & & $\begin{array}{l}\text { Perda da integridade estrutural das } \\
\text { válvulas de controle de fluxo no sistema } \\
\text { de alta pressão CG911, CG912, CG915, } \\
\text { CG916, CG900, CG071, CG073. }\end{array}$ & $\begin{array}{l}\text { Liberação de boil-off para dentro da praça } \\
\text { de máquinas (CG911, CG912, CG915, } \\
\text { CG916, CG900). Liberação do boil-off para } \\
\text { o ambiente externo (CG071, CG073). } \\
\text { Possibilidade de geração de uma nuvem de } \\
\text { gás. Paralisação do processo de } \\
\text { transferência do GNL. }\end{array}$ & \multicolumn{2}{|c|}{$\begin{array}{l}\text { Tem-se um sistema de monitoração que monitora e indica } \\
\text { quais são as condições internas do circuito de boil-off, um } \\
\text { sistema de amostragem que indica a ocorrência de algum } \\
\text { vazamento de gás natural e o ESD que paralisa a transferência } \\
\text { da carga. }\end{array}$} \\
\hline
\end{tabular}




\begin{tabular}{|c|c|c|c|c|c|}
\hline \multicolumn{4}{|c|}{ Sistema: Sistema de carga e descarga do navio transportador de GNL } & \multirow{2}{*}{$\begin{array}{l}\text { ANÁLISE PRELIMINAR DE } \\
\text { PERIGOS }\end{array}$} & Analista: \\
\hline \multicolumn{4}{|c|}{$\begin{array}{l}\text { Sub-sistemas: Sistema de conexão manifold, Sistema de distribuição, Sistema de Armazenagem, } \\
\text { Sistema de alívio, Sistema de baixa pressão, Sistema de alta pressão, Sistema de alívio do boil-off. }\end{array}$} & & Data. \\
\hline $\mathrm{N}^{\circ}$ & Perigo & Causas & Consequências & \multicolumn{2}{|c|}{ Barreiras de proteção } \\
\hline 18 & \multirow{4}{*}{$\begin{array}{c}\text { Grande } \\
\text { vazamento } \\
\text { de boil-off }\end{array}$} & $\begin{array}{l}\text { Perda da integridade estrutural das } \\
\text { válvulas de bloqueio do sistema de alta } \\
\text { pressão CG925, CG917, CG703, CG072, } \\
\text { CG074. }\end{array}$ & $\begin{array}{l}\text { Liberação de boil-off para dentro da praça } \\
\text { de máquinas. Possibilidade de geração de } \\
\text { uma nuvem de gás. Paralisação do processo } \\
\text { de transferência do GNL. }\end{array}$ & \multicolumn{2}{|c|}{$\begin{array}{l}\text { Tem-se um sistema de monitoração que monitora e indica } \\
\text { quais são as condições internas do circuito de boil-off, um } \\
\text { sistema de amostragem que indica a ocorrência de algum } \\
\text { vazamento de gás natural e o ESD que paralisa a transferência } \\
\text { da carga. }\end{array}$} \\
\hline 19 & & $\begin{array}{l}\text { Abertura das válvulas de bloqueio do } \\
\text { sistema de alta pressão CG925, CG917, } \\
\text { CG703, CG072, CG074. }\end{array}$ & $\begin{array}{l}\text { Ingresso do boil-off para o circuito de baixa } \\
\text { vazão e para o sistema de boil-off/warm up } \\
\text { Heater } \mathrm{N}^{\circ} 2 \text { (CG925). Ingresso do boil-off } \\
\text { no sistema de boil-off/warm up Heater } \mathrm{N}^{\circ} 1 \\
\text { (CG917). Ingresso do boil-off no circuito } \\
\text { de inertização (CG703). Liberação de boil- } \\
\text { off para o meio ambiente pelo lado do } \\
\text { manifold de estibordo (CG072 e CG074). } \\
\text { Paralisação do processo de transferência do } \\
\text { GNL. }\end{array}$ & \multicolumn{2}{|c|}{$\begin{array}{l}\text { Tem-se outras válvulas de bloqueio que impedem que o boil- } \\
\text { off entre numa linha onde não deveria fluir. Tem-se um } \\
\text { sistema de monitoração que monitora e indica quais são as } \\
\text { condições internas do circuito de boil-off, um sistema de } \\
\text { amostragem que indica a ocorrência de algum vazamento de } \\
\text { gás natural e o ESD que paralisa a transferência da carga. }\end{array}$} \\
\hline 20 & & $\begin{array}{l}\text { Ruptura nas tubulações de saída da praça } \\
\text { de máquinas até a conexão do navio com } \\
\text { o porto. }\end{array}$ & $\begin{array}{l}\text { Liberação de boil-off para dentro da praça } \\
\text { de máquinas. Liberação do boil-off para o } \\
\text { ambiente externo. Possibilidade de geração } \\
\text { de uma nuvem de gás. Possibilidade de } \\
\text { ingresso de ar atmosférico para dentro do } \\
\text { sistema quebrando o ambiente de } \\
\text { inertização. Paralisação do processo de } \\
\text { transferência do GNL. }\end{array}$ & \multicolumn{2}{|c|}{$\begin{array}{l}\text { Tem-se um sistema de emergência que paralisa o processo de } \\
\text { carga/descarga no caso de haver um grande vazamento. Tem- } \\
\text { se um sistema de monitoração que monitora e indica quais são } \\
\text { as condições internas do circuito de boil-off, um sistema de } \\
\text { amostragem que indica a ocorrência de algum vazamento de } \\
\text { gás natural e o ESD que paralisa a transferência da carga. }\end{array}$} \\
\hline 21 & & $\begin{array}{l}\text { Perda da integridade estrutural das } \\
\text { válvulas de alívio nos próprios tanques } \\
\text { CR100, CR101, CR200, CR201, CR300, } \\
\text { CR301, CR400, CR401. }\end{array}$ & $\begin{array}{l}\text { Liberação de boil-off para o ambiente } \\
\text { externo. Possibilidade de geração de uma } \\
\text { nuvem de gás. Paralisação do processo de } \\
\text { transferência do GNL. }\end{array}$ & \multicolumn{2}{|c|}{$\begin{array}{l}\text { Tem-se um sistema de monitoração que monitora e indica } \\
\text { quais são as condições internas do circuito de boil-off, um } \\
\text { sistema de amostragem que indica a ocorrência de algum } \\
\text { vazamento de gás natural e o ESD que paralisa a transferência } \\
\text { da carga. }\end{array}$} \\
\hline
\end{tabular}




\begin{tabular}{|c|c|c|c|c|c|}
\hline \multicolumn{4}{|c|}{ Sistema: Sistema de carga e descarga do navio transportador de GNL } & \multirow{2}{*}{$\begin{array}{l}\text { ANÁLISE PRELIMINAR DE } \\
\text { PERIGOS }\end{array}$} & Analista: \\
\hline \multicolumn{4}{|c|}{$\begin{array}{l}\text { Sub-sistemas: Sistema de conexão manifold, Sistema de distribuição, Sistema de Armazenagem, } \\
\text { Sistema de alívio, Sistema de baixa pressão, Sistema de alta pressão, Sistema de alívio do boil-off. }\end{array}$} & & \\
\hline $\mathrm{N}^{\circ}$ & Perigo & Causas & Consequências & \multicolumn{2}{|c|}{ Barreiras de proteção } \\
\hline 22 & \multirow{4}{*}{$\begin{array}{c}\text { Grande } \\
\text { vazamento } \\
\text { de boil-off }\end{array}$} & $\begin{array}{l}\text { Ruptura nas tubulações que saem das } \\
\text { válvulas de alívio dos tanques e chegam } \\
\text { até o riser. }\end{array}$ & $\begin{array}{l}\text { Liberação de boil-off para o ambiente } \\
\text { externo. Possibilidade de geração de uma } \\
\text { nuvem de gás. Paralisação do processo de } \\
\text { transferência do GNL. }\end{array}$ & \multicolumn{2}{|c|}{$\begin{array}{l}\text { Tem-se um sistema de emergência que paralisa o processo de } \\
\text { carga/descarga no caso de haver um grande vazamento. Tem- } \\
\text { se um sistema de monitoração que monitora e indica quais são } \\
\text { as condições internas do circuito de boil-off, um sistema de } \\
\text { amostragem que indica a ocorrência de algum vazamento de } \\
\text { gás natural e o ESD que paralisa a transferência da carga. }\end{array}$} \\
\hline 23 & & $\begin{array}{l}\text { Ruptura nos risers dos tanques Riser } 1 \text {, } \\
\text { Riser } 2 \text {, Riser } 3 \text {, Riser } 4 .\end{array}$ & $\begin{array}{l}\text { Liberação de boil-off para o ambiente } \\
\text { externo. Possibilidade de geração de uma } \\
\text { nuvem de gás. Paralisação do processo de } \\
\text { transferência do GNL. }\end{array}$ & \multicolumn{2}{|c|}{$\begin{array}{l}\text { Tem-se um sistema de emergência que paralisa o processo de } \\
\text { carga/descarga no caso de haver um grande vazamento. Tem- } \\
\text { se um sistema de monitoração que monitora e indica quais são } \\
\text { as condições internas do circuito de boil-off, um sistema de } \\
\text { amostragem que indica a ocorrência de algum vazamento de } \\
\text { gás natural e o ESD que paralisa a transferência da carga. }\end{array}$} \\
\hline 24 & & $\begin{array}{l}\text { Perda da integridade estrutural da } \\
\text { válvula de alívio CG702. }\end{array}$ & $\begin{array}{l}\text { Liberação de boil-off para o ambiente } \\
\text { externo. Possibilidade de geração de uma } \\
\text { nuvem de gás. Paralisação do processo de } \\
\text { transferência do GNL. }\end{array}$ & \multicolumn{2}{|c|}{$\begin{array}{l}\text { Tem-se um sistema de monitoração que monitora e indica } \\
\text { quais são as condições internas do circuito de boil-off, um } \\
\text { sistema de amostragem que indica a ocorrência de algum } \\
\text { vazamento de gás natural e o ESD que paralisa a transferência } \\
\text { da carga. }\end{array}$} \\
\hline 25 & & $\begin{array}{l}\text { Ruptura da tubulação que sai da válvula } \\
\text { CG702 e chega até o riser do tanque } 1 .\end{array}$ & $\begin{array}{l}\text { Liberação de boil-off para o ambiente } \\
\text { externo. Possibilidade de geração de uma } \\
\text { nuvem de gás. Paralisação do processo de } \\
\text { transferência do GNL. }\end{array}$ & \multicolumn{2}{|c|}{$\begin{array}{l}\text { Tem-se um sistema de monitoração que monitora e indica } \\
\text { quais são as condições internas do circuito de boil-off, um } \\
\text { sistema de amostragem que indica a ocorrência de algum } \\
\text { vazamento de gás natural e o ESD que paralisa a transferência } \\
\text { da carga. }\end{array}$} \\
\hline
\end{tabular}




\section{ANEXO I. ACIDENTES ACONTECIDOS EM NAVIOS DE TRANSPORTE DE GNL NOS TERMINAIS DE CARGA E}

\section{DESCARGA}

De acordo com Vanem et al. (2008) e IMO (2007), analisando os cenários que se apresentaram em diversos acidentes envolvendo navios transportadores de GNL, estes podem ser classificados de acordo com as consequências enumeradas e identificadas abaixo:

$\checkmark$ Colisão

$\checkmark$ Encalhe

$\checkmark$ Contato

$\checkmark \quad$ Fogo e Explosão

$\checkmark$ Equipamentos e Máquinas

$\checkmark \quad$ Mau Tempo

$\checkmark$ Carregamento/Descarregamento

$\checkmark$ Sistemas de Contenção de Carga
Col

Enc

Con

FE

EM

MT

$\mathrm{C} / \mathrm{D}$

SCC

\begin{tabular}{|c|c|c|c|c|c|c|c|}
\hline $\mathbf{N}^{\circ}$ & Ano & $\begin{array}{c}\text { Nome do } \\
\text { Navio }\end{array}$ & $\begin{array}{c}\text { Tipo de } \\
\text { Navio }\end{array}$ & Ferimentos/Fatalidades & $\begin{array}{c}\text { Vazamento } \\
\text { do GNL }\end{array}$ & $\begin{array}{c}\text { Categoria do } \\
\text { Acidente }\end{array}$ & Descrição do Acidente \\
\hline 1 & 1964 & $\begin{array}{c}\text { Methane } \\
\text { Progress }\end{array}$ & Outro & Não & Fão & $\begin{array}{l}\text { Durante as operações de carga do GNL em um terminal na Argélia um raio } \\
\text { atingiu um dos risers deste navio, utilizado para expulsar boil-off, atuando } \\
\text { como um sistema de alívio, o qual causou a ignição do gás natural. A chama } \\
\text { foi controlada rapidamente injetando nitrogênio dentro dessa tubulação. }\end{array}$ \\
\hline 2 & 1965 & $\begin{array}{c}\text { Cinderella } \\
\text { ou Jules } \\
\text { Verne }\end{array}$ & Outro & Não & Sim & C/D & $\begin{array}{l}\text { Vazamento do GNL por causa de um sobrecarregamento do tanque do navio } \\
\text { no terminal na Argélia. Houve uma pequena liberação do GNL que causou } \\
\text { fraturas na coberta do navio e do tanque devido à baixa temperatura da } \\
\text { sustância transportada. }\end{array}$ \\
\hline
\end{tabular}




\begin{tabular}{|c|c|c|c|c|c|c|c|}
\hline $\mathbf{N}^{\circ}$ & Ano & $\begin{array}{l}\text { Nome do } \\
\text { Navio }\end{array}$ & $\begin{array}{l}\text { Tipo de } \\
\text { Navio }\end{array}$ & Ferimentos/Fatalidades & $\begin{array}{c}\text { Vazamento } \\
\text { do GNL }\end{array}$ & $\begin{array}{c}\text { Categoria do } \\
\text { Acidente }\end{array}$ & Descrição do Acidente \\
\hline 3 & 1965 & $\begin{array}{l}\text { Methane } \\
\text { Princess }\end{array}$ & Outro & Não & Sim & $\mathrm{C} / \mathrm{D}$ & $\begin{array}{l}\text { Uma pequena quantidade de GNL vazou após a desconexão dos braços de } \\
\text { transferência. O líquido saiu pelo manifold do navio. Esse vazamento causou } \\
\text { a fratura da chapa do navio que ficava embaixo do manifold por causa das } \\
\text { baixas temperaturas. }\end{array}$ \\
\hline 4 & 1971 & $\begin{array}{l}\text { Esso Brega } \\
\text { ou LNG } \\
\text { Palmaria }\end{array}$ & Outro & Não & Sim & $\mathrm{C} / \mathrm{D}$ & $\begin{array}{l}\text { Ocorreu um aumento repentino da pressão no interior do tanque de } \\
\text { armazenamento durante o descarregamento do GNL. O vapor gerado foi } \\
\text { descarregado pelo sistema de alívio por várias horas. A parte superior do } \\
\text { tanque foi ligeiramente danificada. }\end{array}$ \\
\hline 5 & 1974 & $\begin{array}{l}\text { Methane } \\
\text { Progress }\end{array}$ & Outro & Não & Não & Col & $\begin{array}{l}\text { Este navio foi abalroado pelo navio cargueiro Tower Princess quando o } \\
\text { navio transportador de GNL estava atracando no terminal de GNL Canvey } \\
\text { Island no Reino Unido, provocando um corte no casco exterior de } 1 \text { metro } \\
\text { comprimento. }\end{array}$ \\
\hline 6 & 1976 & $\begin{array}{c}\text { Em } \\
\text { Equador }\end{array}$ & - & $\begin{array}{c}\text { Mais de } 50 \text { pessoas com } \\
\text { lesões }\end{array}$ & Sim & $\mathrm{C} / \mathrm{D}$ & $\begin{array}{l}\text { Um curto-circuito ocorreu durante o descarregamento do GNL, ignitando o } \\
\text { gás natural. Logo após ocorreu uma série de explosões, danificando cinco } \\
\text { tanques de gás natural e também a plataforma de descarregamento. O fogo } \\
\text { foi controlado após várias horas. }\end{array}$ \\
\hline 7 & 1977 & LNG Delta & Membrana & Não & Sim & $\mathrm{C} / \mathrm{D}$ & $\begin{array}{l}\text { Ocorreu uma falha em uma válvula de alumínio que estava em contato com } \\
\text { baixas temperaturas do GNL. A causa da falha foi uma falha na composição } \\
\text { química do material com que foi fabricada essa válvula, a qual era uma } \\
\text { válvula de reposição. }\end{array}$ \\
\hline 8 & 1977 & $\begin{array}{l}\text { LNG } \\
\text { Aquarius }\end{array}$ & $\begin{array}{l}\text { Navio tipo } \\
\text { Moss }\end{array}$ & Não & Não & $\mathrm{FE}$ & $\begin{array}{l}\text { Um raio atingiu simultaneamente duas tubulações do sistema de alívio que, } \\
\text { nesse momento, estavam liberando gás por meio dos risers dos tanques de } \\
\text { armazenamento. O navio estava sendo descarregado em Tobata no Japão. O } \\
\text { fogo foi rapidamente extinto. }\end{array}$ \\
\hline 9 & 1977 & $\begin{array}{l}\text { LNG } \\
\text { Aquarius }\end{array}$ & Moss & Não & Sim & $\mathrm{C} / \mathrm{D}$ & $\begin{array}{l}\text { O GNL foi liberado pelo sistema de alívio dos taques do navio quando este } \\
\text { estava atracado na planta de liquefação de Badak na Indonésia. Não ocorreu } \\
\text { fratura na coberta como consequência desse acidente. }\end{array}$ \\
\hline 10 & 1978 & LNG Aries & Moss & Não & Não & MT & $\begin{array}{l}\text { Este navio foi removido do ponto de atracação por causa das péssimas } \\
\text { condições climáticas, incluindo ventos fortes. O local de ancoragem não era } \\
\text { a área de descarregamento do GNL. }\end{array}$ \\
\hline
\end{tabular}




\begin{tabular}{|c|c|c|c|c|c|c|c|}
\hline $\mathbf{N}^{\circ}$ & Ano & $\begin{array}{l}\text { Nome do } \\
\text { Navio }\end{array}$ & $\begin{array}{l}\text { Tipo de } \\
\text { Navio }\end{array}$ & Ferimentos/Fatalidades & $\begin{array}{l}\text { Vazamento } \\
\text { do GNL }\end{array}$ & $\begin{array}{l}\text { Categoria do } \\
\text { Acidente }\end{array}$ & Descrição do Acidente \\
\hline 11 & 1978 & $\begin{array}{l}\text { Polar } \\
\text { Alaska }\end{array}$ & Membrana & Não & Não & Con & $\begin{array}{l}\text { O navio bateu contra a plataforma de carregamento no terminal no Alaska, e } \\
\text { nenhum detalhamento do acidente foi registrado, mas os danos foram } \\
\text { pequenos. }\end{array}$ \\
\hline 12 & 1978 & $\begin{array}{l}\text { LNG } \\
\text { Gemini }\end{array}$ & Moss & Não & Não & $\mathrm{SCC}$ & $\begin{array}{l}\text { Ocorreu a contaminação dos tanques de armazenamento, tubulações e } \\
\text { bombas quando estava no terminal de Nagoya no Japão. }\end{array}$ \\
\hline 13 & 1979 & $\begin{array}{l}\text { Mostefa } \\
\text { Ben } \\
\text { Boulaid }\end{array}$ & Membrana & Não & Sim & $\mathrm{C} / \mathrm{D}$ & $\begin{array}{l}\text { Ocorreu um pequeno vazamento de GNL por uma válvula de bloqueio } \\
\text { quando estava descarregando no terminal de Cove Point em Maryland nos } \\
\text { EEUU. Como consequências deste vazamento ocorreram fraturas na chapa } \\
\text { da coberta do navio por causa das temperaturas criogênicas do fluido. }\end{array}$ \\
\hline 14 & 1979 & $\begin{array}{c}\text { Polleger ou } \\
\text { LNG } \\
\text { Challenger } \\
\text { ou Hoegh } \\
\text { Galleon }\end{array}$ & Moss & Não & Sim & $\mathrm{C} / \mathrm{D}$ & $\begin{array}{l}\text { Houve um pequeno vazamento de GNL por uma válvula quando estava } \\
\text { descarregando o GNL no terminal de regaseificação em Everett nos EEUU. } \\
\text { Como consequência deste vazamento a chapa do tanque e a coberta do navio } \\
\text { apresentaram fratura. }\end{array}$ \\
\hline 15 & 1979 & $\begin{array}{l}\text { Pollenger } \\
\text { ou LNG } \\
\text { Challenger }\end{array}$ & Moss & Não & Não & EM & $\begin{array}{l}\text { Houve uma queda no mar da âncora e da corrente quando se alterava a } \\
\text { posição do navio no Estreito de Gibraltar. }\end{array}$ \\
\hline 16 & 1980 & $\begin{array}{l}\text { LNG } \\
\text { Taurus }\end{array}$ & Moss & Não & Não & Enc & $\begin{array}{l}\text { Este navio encalhou no Japão por causa das péssimas condições climáticas. } \\
\text { Como consequência deste acidente houve uma extensa avaria da parte } \\
\text { inferior do casco do navio. O navio foi levado por rebocadores para o } \\
\text { terminal de Kitakyushu e a carga foi descarregada. }\end{array}$ \\
\hline 17 & 1980 & $\begin{array}{l}\text { El Paso } \\
\text { Howard } \\
\text { Boyd ou } \\
\text { Matthew } \\
\end{array}$ & Membrana & Não & Não & Enc & $\begin{array}{l}\text { Este navio encalhou em Hampton Roads nos EEUU, após o navio ter ficado } \\
\text { fora de controle. }\end{array}$ \\
\hline 18 & 1980 & LNG Leo & Moss & Não & Não & $\mathrm{C} / \mathrm{D}$ & $\begin{array}{l}\text { Quando o navio estava atracado na plataforma de descarregamento as } \\
\text { amarras de fixação do navio à plataforma se romperam provocando o } \\
\text { movimento violento do navio, causando um contato do navio com essa } \\
\text { plataforma. A causa do acidente foi a ocorrência de vento forte no local. }\end{array}$ \\
\hline
\end{tabular}




\begin{tabular}{|c|c|c|c|c|c|c|c|}
\hline $\mathbf{N}^{\circ}$ & Ano & $\begin{array}{l}\text { Nome do } \\
\text { Navio }\end{array}$ & $\begin{array}{l}\text { Tipo de } \\
\text { Navio }\end{array}$ & Ferimentos/Fatalidades & $\begin{array}{l}\text { Vazamento } \\
\text { do GNL }\end{array}$ & $\begin{array}{l}\text { Categoria do } \\
\text { Acidente }\end{array}$ & Descrição do Acidente \\
\hline 19 & 1981 & $\begin{array}{l}\text { LNG } \\
\text { Gemini }\end{array}$ & Moss & Não & Não & $\mathrm{C} / \mathrm{D}$ & $\begin{array}{l}\text { O motor da bomba que descarregava o GNL em Bontang na Indonésia } \\
\text { queimou. }\end{array}$ \\
\hline 20 & 1981 & $\begin{array}{c}\mathrm{LNG} \\
\text { Capricorn }\end{array}$ & Moss & Não & Não & $\mathrm{FE}$ & $\begin{array}{l}\text { Ocorreu uma explosão no duto de admissão de ar da caldeira principal do } \\
\text { navio quando este se encontrava perto no terminal de Arun na Indonésia }\end{array}$ \\
\hline 21 & 1982 & $\begin{array}{l}\text { Larbi Ben } \\
\text { M'Hidi }\end{array}$ & Membrana & Não & Sim & $\mathrm{C} / \mathrm{D}$ & $\begin{array}{l}\text { Houve uma liberação do vapor de gás natural liquefeito durante a } \\
\text { desconexão do braço de transferência do GNL. }\end{array}$ \\
\hline 22 & 1983 & $\begin{array}{l}\text { LNG } \\
\text { Taurus }\end{array}$ & Moss & Não & Não & $\mathrm{C} / \mathrm{D}$ & Ocorreu uma falha na bomba principal de descarga de GNL. \\
\hline 23 & 1983 & LNG Libra & Moss & Não & Não & $\mathrm{C} / \mathrm{D}$ & Ocorreu uma falha na bomba que serve para descarregar o GNL. \\
\hline 24 & 1984 & $\begin{array}{l}\text { Tenaga } \\
\text { Satu }\end{array}$ & Membrana & Não & Não & Col & O navio sofreu alguns danos devido à colisão com o rebocador Kapit. \\
\hline 25 & 1984 & LNG Aries & Moss & Não & Não & $\mathrm{C} / \mathrm{D}$ & $\begin{array}{l}\text { Ocorreu uma falha na bomba número 4, que é utilizada para o } \\
\text { descarregamento do GNL. }\end{array}$ \\
\hline 26 & 1984 & LNG Libra & Moss & Não & Não & $\mathrm{C} / \mathrm{D}$ & Ocorreram falhas nas bombas utilizadas para descarregar o GNL. \\
\hline 27 & 1984 & $\begin{array}{c}\text { LNG } \\
\text { Aquarius }\end{array}$ & Moss & Não & Não & $\mathrm{C} / \mathrm{D}$ & Ocorreu uma falha na bomba principal de carregamento do GNL. \\
\hline 28 & 1985 & $\begin{array}{l}\text { Gadinia ou } \\
\text { Bebatik }\end{array}$ & Membrana & Não & Não & EM & Ocorreu uma falha no sistema de direção do navio. \\
\hline 29 & 1985 & Isabella & Membrana & Não & Sim & $\mathrm{C} / \mathrm{D}$ & $\begin{array}{l}\text { Ocorreu um vazamento do GNL dentro do navio como consequência do } \\
\text { excessivo enchimento do tanque. Ocorreram fraturas na coberta do navio. }\end{array}$ \\
\hline 30 & 1985 & $\begin{array}{l}\text { Tenaga } \\
\text { Satu }\end{array}$ & Membrana & Não & Não & $\mathrm{C} / \mathrm{D}$ & Ocorreu uma falha na bomba utilizada para descarregar o GNL do navio. \\
\hline 31 & 1989 & Tellier & Membrana & Não & Sim & MT & $\begin{array}{l}\text { Ocorreram danos na tubulação do navio quando este estava atracado para o } \\
\text { carregamento do GNL. As amarras que seguravam o navio foram rompidas } \\
\text { também. Ocorrido em Skikda na Argélia. A causa foi o vento forte no local } \\
\text { do terminal. }\end{array}$ \\
\hline 32 & 1990 & $\begin{array}{l}\text { Louisiana } \\
\text { ou LNG } \\
\text { Abuja }\end{array}$ & Moss & Não & Não & $\mathrm{C} / \mathrm{D}$ & $\begin{array}{l}\text { Ocorreu uma falha na bomba utilizada para descarregar o GNL no terminal } \\
\text { em Lake Charles nos EEUU. }\end{array}$ \\
\hline
\end{tabular}




\begin{tabular}{|c|c|c|c|c|c|c|c|}
\hline $\mathbf{N}^{\circ}$ & Ano & $\begin{array}{l}\text { Nome do } \\
\text { Navio }\end{array}$ & $\begin{array}{l}\text { Tipo de } \\
\text { Navio }\end{array}$ & Ferimentos/Fatalidades & $\begin{array}{l}\text { Vazamento } \\
\text { do GNL }\end{array}$ & $\begin{array}{l}\text { Categoria do } \\
\text { Acidente }\end{array}$ & Descrição do Acidente \\
\hline 33 & 1993 & $\begin{array}{l}\text { Hoegh } \\
\text { Gandria }\end{array}$ & Moss & Não & Não & Col & Ocorreu uma colisão com o navio Ever Oasis em Singapura. \\
\hline 34 & 1996 & $\begin{array}{l}\text { Bachir } \\
\text { Chihani }\end{array}$ & Membrana & Não & Não & EM & $\begin{array}{l}\text { Efetuaram-se reparos nos motores e em dois tanques do navio em Marselha, } \\
\text { devido à ocorrência de falhas nesses equipamentos. }\end{array}$ \\
\hline 35 & 1996 & $\begin{array}{l}\text { Mostefa } \\
\text { Ben } \\
\text { Boulaid }\end{array}$ & Membrana & Não & Não & $\mathrm{FE}$ & $\begin{array}{l}\text { Houve um incêndio na praça de máquinas quando o navio estava atracado no } \\
\text { terminal de Everett nos EEUU. A carga foi transferida normalmente, mas a } \\
\text { uma vazão inferior à normal. A causa foi uma falha elétrica. }\end{array}$ \\
\hline 36 & 1998 & $\begin{array}{l}\text { Mostefa } \\
\text { Ben } \\
\text { Boulaid }\end{array}$ & Membrana & Não & Não & EM & Ocorreu uma falha no gerador do navio. \\
\hline 37 & 1999 & $\begin{array}{l}\text { Methane } \\
\text { Polar }\end{array}$ & Membrana & Não & Não & Con & $\begin{array}{l}\text { Ocorreu uma falha no motor do navio. Este atingiu a plataforma de } \\
\text { transferência em Point Fortin em Trindade e Tobago. O navio estava vazio e } \\
\text { estava no local para ser carregado com GNL. }\end{array}$ \\
\hline 38 & 2001 & Khannur & Moss & Não & Sim & $\mathrm{C} / \mathrm{D}$ & $\begin{array}{l}\text { Houve um vazamento do GNL pelo sistema de alívio dos tanques. Como } \\
\text { consequência ocorreram trincas na cúpula do tanque. A causa deste acidente } \\
\text { foi uma sobrepressão nesse tanque. }\end{array}$ \\
\hline 39 & 2002 & $\begin{array}{l}\text { Mostefa } \\
\text { Ben } \\
\text { Boulaid }\end{array}$ & Membrana & Não & Sim & $\mathrm{C} / \mathrm{D}$ & $\begin{array}{l}\text { Ocorreu um derramamento de GNL que trouxe como consequência uma } \\
\text { fratura nas chapas do navio. }\end{array}$ \\
\hline 40 & 2003 & Hilli & Moss & Não & Não & EM & Ocorreu uma falha nos dutos da caldeira do navio. \\
\hline 41 & 2004 & $\begin{array}{l}\text { Methane } \\
\text { Arctic }\end{array}$ & Membrana & Não & Não & FE & $\begin{array}{l}\text { Houve um incêndio após o navio sair de Barcelona na Espanha. O incêndio } \\
\text { foi extinto após uma hora. A causa deste acidente foi um raio que atingiu o } \\
\text { navio. }\end{array}$ \\
\hline 42 & 2005 & Laieta & Outro & Não & Não & EM & Ocorreu uma falha no motor do navio. \\
\hline
\end{tabular}


